\title{
The role of electronic cigarettes and heated tobacco products in tobacco control in Italy and Europe
}

Citation for published version (APA):

Gallus, S. (2022). The role of electronic cigarettes and heated tobacco products in tobacco control in Italy and Europe. [Doctoral Thesis, Maastricht University]. Maastricht University. https://doi.org/10.26481/dis.20220214sg

Document status and date:

Published: 01/01/2022

DOI:

10.26481/dis.20220214sg

Document Version:

Publisher's PDF, also known as Version of record

\section{Please check the document version of this publication:}

- A submitted manuscript is the version of the article upon submission and before peer-review. There can be important differences between the submitted version and the official published version of record.

People interested in the research are advised to contact the author for the final version of the publication, or visit the DOI to the publisher's website.

- The final author version and the galley proof are versions of the publication after peer review.

- The final published version features the final layout of the paper including the volume, issue and page numbers.

Link to publication

\footnotetext{
General rights rights.

- You may freely distribute the URL identifying the publication in the public portal. please follow below link for the End User Agreement:

www.umlib.nl/taverne-license

Take down policy

If you believe that this document breaches copyright please contact us at:

repository@maastrichtuniversity.nl

providing details and we will investigate your claim.
}

Copyright and moral rights for the publications made accessible in the public portal are retained by the authors and/or other copyright owners and it is a condition of accessing publications that users recognise and abide by the legal requirements associated with these

- Users may download and print one copy of any publication from the public portal for the purpose of private study or research.

- You may not further distribute the material or use it for any profit-making activity or commercial gain

If the publication is distributed under the terms of Article $25 \mathrm{fa}$ of the Dutch Copyright Act, indicated by the "Taverne" license above, 


\section{The role of electronic cigarettes and heated tobacco products in tobacco control in Italy and Europe}

Silvano Gallus 
The role of electronic cigarettes and heated tobacco products in tobacco control in Italy and Europe

Silvano Gallus

Lay-out: Silvano Gallus

Printed by: Centro Stampa Lima, Milan, Italy

(c) Copyright Silvano Gallus, 2022

All rights reserved. No part of this dissertation may be reproduced or transmitted in any form or by any means, electronic or mechanical, including photocopying, recording or any information storage or retrieval system, without permission in writing from the author, or, when appropriate, from the publishers of the publications. 


\title{
The role of electronic cigarettes and heated tobacco products in tobacco control in Italy and Europe
}

\author{
DISSERTATION \\ To obtain the degree of Doctor at Maastricht University, \\ on the authority of the Rector Magnificus, Prof.dr. Pamela Habibović, \\ in accordance with the decision of the Board of Deans, \\ to be defended in public on
}

Monday, 14th of February, 2022 at 13:00

by

Silvano Gallus 


\section{Supervisors:}

Prof.dr.ir. P. A. van den Brandt

Prof.dr. A. Odone, University of Pavia, Italy

\section{Assessment Committee}

Prof.dr. M.C. Willemsen (chair)

Prof.dr. S. Galea, Boston University School of Public Health, USA

Dr. T. Effertz, Universität Hamburg, Germany

Prof.dr. H. de Vries

Prof.dr. M.P. Zeegers

The studies conducted within this dissertation were preformed at the Department of Environmental Health Sciences, Istituto di Ricerche Farmacologiche Mario Negri IRCCS, Milan, Italy, in collaboration with the Care and Public Health Research Institute (CAPHRI). Faculty of Health, Medicine and Life Sciences, Maastricht, the Netherlands. 


\section{Table of Contents}

$\begin{array}{lll}\text { Chapter } 1 & \text { General introduction } & 7\end{array}$

Chapter 2 The role of novel (tobacco) products on tobacco

control in Italy 29

Chapter 3 The impact of electronic cigarettes and heated tobacco products on smoking habit: a prospective cohort study form Italy

Chapter 4 Use of electronic cigarettes and heated tobacco products during the Covid-19 pandemic

Chapter 5 Electronic cigarette use among Italian smokers: patterns, settings, and adverse events

Chapter 6 Electronic cigarette use in 12 European countries. Results from the TackSHS survey

Chapter 7 Use and awareness of heated tobacco products in Europe 105

Chapter 8: Exposure to secondhand aerosol of electronic cigarettes in indoor settings in 12 European countries: data from the TackSHS survey

Chapter 9 Conflict of interest in research on heated tobacco products: a systematic review

Chapter 10 General discussion

Summary

Riassunto

Impact Statement

Acknowledgements

About the Author

List of publications 



\section{Chapter 1}

General introduction 


\section{$1.1 \quad$ Tobacco smoking}

\subsubsection{What is tobacco?}

Tobacco is a plant grown for its leaves that contain nicotine, a highly addictive stimulant alkaloid [1, 2]. People can smoke, chew, or sniff tobacco. The most common smoked tobacco products are cigarettes. Other smoked tobacco products include cigars and bidis. Loose tobacco might also be smoked in pipes or waterpipes (hookah or shisha). Chewed tobacco products include chewing tobacco, snuff, and Swedish snus. Snuff can either be chewed or sniffed [1, 2].

\subsubsection{Historical notes}

The tobacco plant is indigenous to the Americas. Archeological studies show that tobacco was already used by Maya people more than 2000 years ago. Native Americans used tobacco for religious rites or for its alleged potential to cure certain illnesses [2]. After the arrival of the Spanish conquerors in the $15^{\text {th }}$ century, tobacco was imported into Europe as a trade item to be used for smoking. It was then since the production of cigarettes, during the $19^{\text {th }}$ century, that tobacco became increasingly popular worldwide [2].

Today, the tobacco plant is grown in most countries worldwide. The top 5 producers of unmanufactured tobacco are China (around $40 \%$ of global production), India (12\%), Brazil (12\%), Zimbabwe (4\%) and the USA (3\%). Italy, with more than 40,000 tonnes of tobacco per year (almost $1 \%$ of global production), ranked $19^{\text {th }}$ globally and first in Europe.

\subsubsection{Epidemiology of smoking}

The Global Burden of Disease (GBD) recently provided the prevalence of tobacco smoking for 204 countries and territories from 1990 to 2019 [3]. In 2019, 1.14 billion individuals were current smokers, annually consuming 7.4 trillion cigarettes. The age-adjusted prevalence of current smokers was $32.7 \%$ among males and $6.6 \%$ among females aged 15 years and older. Globally, although the prevalence of smoking had significantly decreased since 1990 among both sexes (27.5\% reduction for men and $37.7 \%$ reduction for women), population growth has led to a significant increase in the total number of smokers. Smoking prevalence in Western Europe was 28.8\% in men and $22.7 \%$ in women [3]. These findings are in broad agreement with the Special Eurobarometer conducted in 2020 [4], and with a cross-sectional study conducted in 2017-2018 within the TackSHS project [5], based on representative samples of 12 European countries which represented around $80 \%$ of the European Union (EU-28) population. The TackSHS study showed an overall smoking prevalence of $25.9 \%$ (31.0\% in men and $21.2 \%$ in women) [6]. According to GBD data, also in Italy, a $30 \%$ decrease 
in age-adjusted smoking prevalence has been observed in adults of both sexes from 1990 to 2019. In 2019, smoking prevalence was $27.3 \%$ among Italian men and $18.9 \%$ among women [3].

With reference to adolescents, the European School Survey Project on Alcohol and Other Drugs (ESPAD) study, conducted in 2019 on representative samples of 15-16-year-old school adolescents from 35 European countries, showed in Italy the highest prevalence of 30-day use of cigarettes (32\%) compared with the average European estimate (20\%). Also, the proportion of students reporting daily use of cigarette smoking was relatively high in Italy (19\%), compared to the European average (10\%) [7].

\subsubsection{Health consequences of tobacco smoking}

It was the year 1950 when Ernst Wynder and Evards Graham [8] and Richard Doll and Bradford Hill [9] first published the evidence of a direct association between tobacco smoking and lung cancer risk. Over the subsequent 70 years, thousands of epidemiological studies systematically confirmed this association, and found that tobacco smoking was also responsible of several other chronic conditions $[10,11]$. This is due to the many harmful or potentially harmful chemicals that are present in tobacco or are created by its combustion.

Today we know that cigarette smoking causes about $85 \%$ of all cases of lung cancer, which is a disease with a very poor prognosis (5-year survival from diagnosis is less than 10\%) [10]. Moreover, the International Agency for Research on Cancer (IARC) monograph on tobacco concluded that smoking contributes to the onset of 15 different types of cancer, mainly of the respiratory tract and digestive system. The increased risk of cancer in heavy smokers is between 2 and 10 times higher for these cancer sites [10,12]. Additionally, recent studies are further increasing the number of cancer sites associated with smoking [13, 14]. Cigarette smoking is also the most important risk factor for chronic obstructive pulmonary disease (COPD), a condition characterized by reduced respiratory flow with a significant social and economic impact (prolonged disability and treatment costs, repeated hospitalizations, absenteeism from work) [11]. Moreover, ischemic heart diseases and stroke - conditions that contribute to make cardiovascular disease the leading cause of death in most high income countries, including Italy - are much more frequent in smokers than in nonsmokers [11, 14].

The main health consequence of tobacco smoking is premature death. The wellknown cohort of British doctors, a prospective study of nearly 35,000 males followed for 50 years, showed that a smoker lived about ten years less than a never smoker. In this study, out of 10035 -year-olds who had never smoked, 81 will reach 70,59 will reach 80 , and 24 will reach 90 years of age. On the other 
hand, out of 100 smokers who continue to smoke, only 58 will reach the age of 70,26 reach 80 and only 4 will reach 90 years of age (Figure 1) [15].

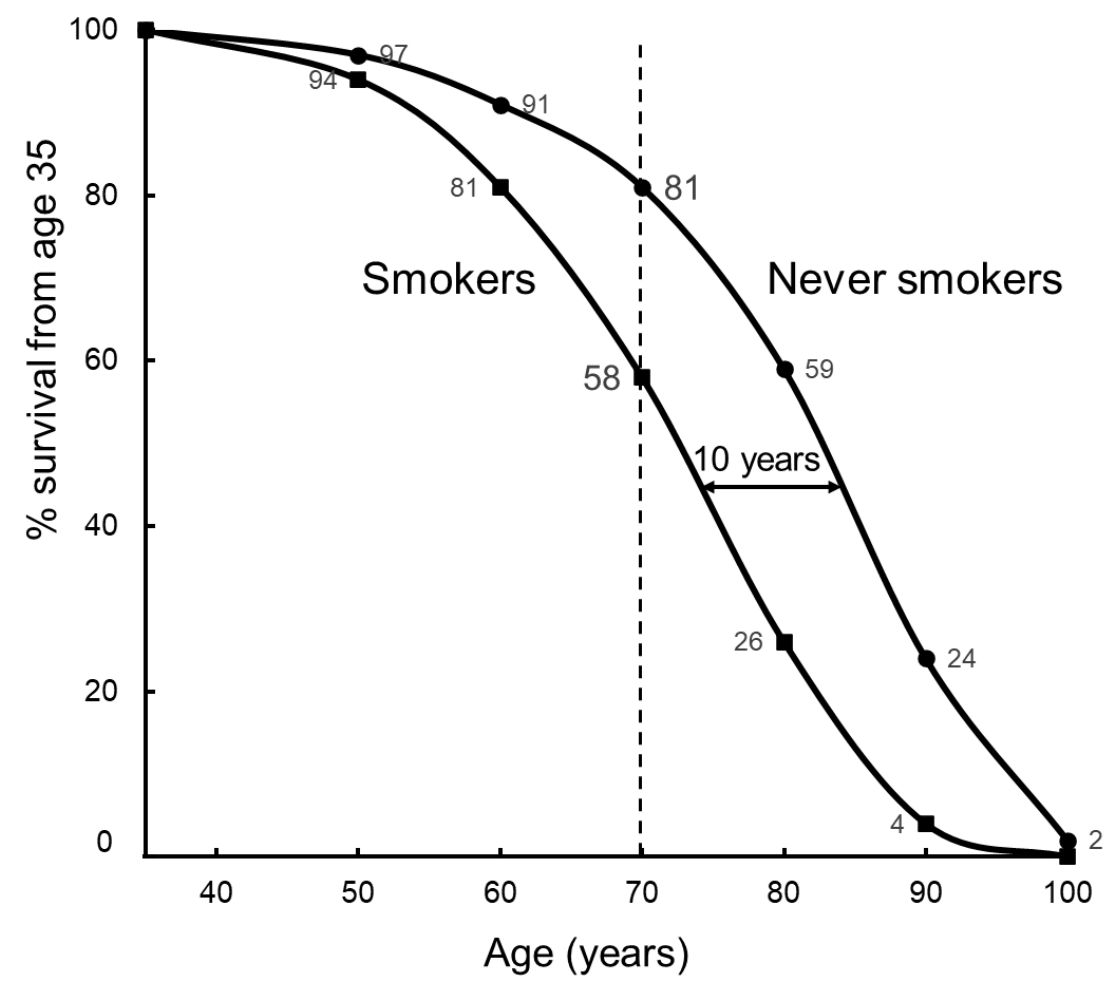

Figure 1: Survival from age 35 for continuing cigarette smokers and never smokers among UK male doctors born in 1900-1930, with percentages alive at each decade of age. Figure adapted from Doll et al., 2004 [15].

In 2008 the World Health Organization (WHO) declared that tobacco smoking was the single greatest preventable cause of death in the world [16]. Globally in 2019 it is estimated that tobacco smoking was annually responsible for approximately 7.69 million deaths worldwide, being the leading risk factor for death among males (more than $20 \%$ of all male deaths) [3]. Smoking tobacco accounted for 200 million disability-adjusted life-years (DALYs) [3]. In Italy, in 2010, our research group estimated that every year more than 70 thousand deaths (12.5\% of total mortality) were attributable to smoking [17].

\subsubsection{Second-hand smoke}

Exposure to second-hand tobacco smoke (SHS) has been classified as a "Group 1" carcinogen (known human carcinogen) by the IARC [12], and has been shown to have adverse health effects on adults and children, including heart disease 
and respiratory disorders [18]. To the huge number of deaths attributable to smoking among ever smokers, we also have to add 0.88 million deaths among non-smokers who annually die due to SHS exposure [18].

\subsubsection{Health consequences of smoking cessation}

The beneficial health effects of smoking cessation are impressive. The cohort of British doctors also showed that those who quit when aged 40 years avoid practically all the excess risk of mortality of smokers, quitting when 50 years old allows to avoid much of the risk of dying from smoking, and those who quit when aged 60 years also avoid nearly half of their excess risk [15]. Therefore, quitting at any age has favourable health consequences.

\subsection{Tobacco control}

\subsubsection{Tobacco control globally}

Tobacco control is a field of public health science devoted to the regulation of tobacco use in order to reduce tobacco-related morbidity and mortality. Tobacco control aims therefore to identify and promote interventions able to reduce smoking prevalence $[19,20]$.

Once it appears that a commercial product causes adverse effects threatening the health of the population, that product is usually withdrawn from the market by the manufacturer itself or by the government that immediately bans its production, sale and consumption. This happens every day for harmful food products, defective cars, or unsafe drugs. This did not happen for tobacco products. Tobacco companies rather preferred to deny, or even hide, the evidence of the harms of smoking.

The strategy used by the tobacco industry was to try to influence part of the scientific community in order to generate doubt about tobacco harms and to create mixed evidence counterbalancing overwhelming evidence from researchers without conflicts of interest (COI) [21]. Consequently, during the second half of the $20^{\text {th }}$ century, the tobacco industry has secretly engaged a large number of conniving researchers providing financial support to receive research conclusions favourable to the survival of their products [22, 23]. At the end of the $20^{\text {th }}$ century, the verdicts of important US legal processes forced "Big Tobacco" to reveal their secrets: millions of pages of confidential reports and internal documents were made publicly available online. This made it possible to put in evidence how the industry had succeeded, until then, in influencing the scientific community, and to unmask the name of those researchers who agreed to collaborate with the tobacco industry [24-26]. 
Of relevance, at the beginning of the new millennium, the WHO in 2003 established the Framework Convention on Tobacco Control (FCTC), a treaty recommending to 182 signatory countries (i.e., Parties) the strategies to be adopted to protect the present and future generations from the harmful effects of smoking [20,27]. Tobacco control strategies included those introduced by WHO itself and known by the acronym MPOWER: Monitor tobacco use and prevention policies; Protect from tobacco smoke; Offer help to quit tobacco use; Warn about the dangers of tobacco; Enforce bans on tobacco advertising, promotion and sponsorship; and Raise taxes on tobacco [20]. One of the FCTC articles (article 5.3) recommended avoiding any influence from the tobacco industry on the debate on the tobacco control policies to be implemented in each country [27]. Thus, around 2010 awareness was raised within the scientific community, and in particular of the WHO, towards the possible $\mathrm{COI}$ in tobacco research. It seemed therefore that the risk of interference of tobacco companies in the scientific debate could decrease thereafter. Unfortunately, this did not happen.

The 2021 WHO report on the global tobacco epidemic has just been released. It clearly shows the steady progress made by countries on tobacco control. As of 2020 , three quarters of countries and more than 5.3 billion people $-69 \%$ of the world's population - are covered by at least one MPOWER measure at the highest level [20].

At the end of the $20^{\text {th }}$ century and during the first decade of the $21^{\text {st }}$ century, a substantial decrease in the trend of tobacco sales has been observed in most high-income countries. Protagonists of this success were i) the scientific community, which was able to effectively divulgate the harmful effects of smoking and SHS on human health, ii) the growing tobacco control movement, which was able to recommend the implementation of effective tobacco control strategies, and iii) the firm viewpoint of the WHO.

This achievement encouraged policymakers to follow the articles outlined in the WHO-FCTC [27] and adopt strict tobacco control regulations, that resulted in a fall in smoking prevalence and a substantial decline in social acceptability of tobacco use in high income countries $[3,17]$. Also in Italy, smoking prevalence has been consistently decreasing since late 1950's and for the subsequent five decades [28].

\subsubsection{Tobacco control in Europe and Italy}

Europe is highly covered by MPOWER measures [20]. Within the European Union, at least part of the reason is that tobacco and tobacco related products are regulated at the EU level through selected directives. These include the Tobacco Taxation Directive (TTD; 2011/64/EU), regulating the structure and rates of excise duty applied to manufactured tobacco [29], and the Tobacco Products Directive (TPD; 2014/40/EU), regulating sale and merchandising with 
the aim to improve the functioning of the internal market for tobacco, ensuring a high level of health protection for European citizens [30, 31].

Also within EU Member States, major differences by country are available in the adoption of the main tobacco control strategies at a government level. The Tobacco Control Scale (TCS) systematically quantifies the implementation of tobacco control policies at country-level across Europe. The TCS provides a score for each of the policies described by the World Bank, which should be prioritized in comprehensive tobacco control programmes [19]. The TCS scale allocates points to each policy, with a maximum score of 100: price increase (30 points), smoke free public places (22 points), spending on public information campaigns (10 points), comprehensive advertising bans (13 points), large health warnings (10 points), cessation support (treatment; 10 points), combatting illicit trade (3 points) and tobacco industry interference (article 3.5 of the FCTC; 2 points). Countries that have not ratified the WHO-FCTC lose one point. Considering 36 European countries, the 2019 version of the TCS ranged from 40 out of 100 (Germany had the lowest implementation of policies) to 80 out of 100 (UK had the highest implementation of effective tobacco control policies) [19].

In 2019, Italy obtained 52 points out of 100 , ranking $15^{\text {th }}$ out of 36 European countries. In particular, Italy obtained $15 / 30$ points for price, $16 / 22$ for public place bans, $0 / 10$ for budget for information campaigns, 9/13 for advertising bans, 5/10 for health warnings, $6 / 10$ for treatment, $1 / 10$ for illicit trade and $0 / 2$ for article 3.5 of the FCTC [19]. This highlights the large room of improvement of Italy in the implementation of selected effective tobacco control intervention, including in particular tobacco price increase (a pack of cigarettes in ltaly still costs less than $€ 6$, in contrast with $€ 10$ or more for France and the UK), information campaigns expenditure on tobacco, and measures to restrict tobacco industry interference [19].

\subsubsection{The "Endgame Strategy"}

In 2010, Dr Ruth E. Malone, the Editor-in-chief of Tobacco Control, first went through a 1994 provocative article by Drs Benowitz and Henningfield [32], and published a paper proposing a novel approach to tackle tobacco: the Tobacco Endgame Strategy, explicitly aiming to create a smoke-free society [33]. That publication obtained widespread attention, at least among the tobacco control community [34-37]. The debate on this "new approach" brought a few countries, including New Zealand, Finland, Singapore and the Australian state of Tasmania, to immediately develop plans to completely ban the sale and/or use of cigarettes within the subsequent couple of decades [38-40]. Later on, also the European Union set the goal to create a tobacco-free generation in Europe, where less than $5 \%$ of people use tobacco by 2040 [41]. Although, in practice, the barriers against 
the adoption of a tobacco endgame strategy were impressive [34-36, 40, 42], for the first time, it was licit to imagine a world without tobacco.

What happened that permitted what seemed completely unrealistic only a few years before, to appear feasible in 2010? The answer relies for sure in the success of anti-smoking campaigns, resulting in a fall of smoking prevalence and a substantial decline in social acceptability of tobacco use in high income countries [17, 34]. Moreover, the example given by the implementation of a comprehensive smoking ban in workplaces and in indoor public places might have played a role. The comprehensive smoking ban adopted by many countries, starting from California state (in 1994), Ireland and Scotland (in 2004), and Italy (in 2005) [43, 44], proved to the tobacco control community and the general population that it is possible to change things in the tobacco world. It was in fact inconceivable, in 2000, to imagine that, in just a few years, tobacco would have been banned, for example, from restaurants and pubs.

The spread of electronic cigarettes might also have had a role. At that time, ten years ago, the dream of a safe (or safer) alternative to tobacco (not necessarily represented by electronic cigarette), having the possibility to substitute in full conventional cigarettes appeared possible. Probably this was the original idea of those countries having set the tobacco endgame too early, or those organizations, as the government agency Public Health England, having espoused the tobacco harm reduction strategy [45], particularly in those countries, as the UK, where the adoption of effective tobacco control policies was still extremely high [19]. As we will see, things did not go as planned.

\subsection{Electronic cigarettes}

\subsubsection{Historical notes}

At the beginning of the present century, an electronic nicotine delivery system (ENDS) named electronic cigarette (e-cigarette) was first introduced in 2005 into the Chinese market by the Beijing company Ruyan [46-50]. E-cigarettes are electronic devices containing a liquid - a chemical mixture including propylene glycol and flavours - heated to generate an inhalable vapor, which usually contains nicotine $[48,51]$. Given the shape, the method of inhalation, the taste and the possible content of nicotine, e-cigarette users (known as "vapers") when consuming the product receive a sensation which is similar to that experienced by inhaling the tobacco smoke of a conventional cigarette [49].

There are many different types of e-cigarettes in use with varying amounts of nicotine and harmful emissions. E-cigarette types might be classified according to the generation. We are currently at the $4^{\text {th }}$ generation of e-cigarettes. Table 1 
shows the evolution of e-cigarettes, describing various types of this ENDS, classified by generation $[52,53]$.

Table 1: Description of different types of e-cigarettes.

\begin{tabular}{|c|c|c|}
\hline \multirow[t]{5}{*}{ Example } & $\begin{array}{l}\text { Generation / } \\
\text { Product }\end{array}$ & Description of the device \\
\hline & $\begin{array}{l}\text { 1'st generation: } \\
\text { cig-a-like; } \\
\text { disposable e- } \\
\text { cigarette; closed } \\
\text { system }\end{array}$ & $\begin{array}{l}\text { The size and the shape are similar to a } \\
\text { conventional cigarette. It includes a } \\
\text { battery and a cartridge containing an } \\
\text { atomizer used to heat a solution (with } \\
\text { or without nicotine) to obtain an } \\
\text { aerosol. It is not rechargeable or } \\
\text { refillable and is discarded when the } \\
\text { solution ends. }\end{array}$ \\
\hline & $\begin{array}{l}2^{\text {nd }} \text { generation: } \\
\text { vape-pen; } \\
\text { rechargeable e- } \\
\text { cigarette }\end{array}$ & $\begin{array}{l}\text { The size is similar to - or a bit larger } \\
\text { than - a conventional cigarettes. The e- } \\
\text { liquid usually includes nicotine. This } \\
\text { type of e-cigarette often contains a } \\
\text { switch allowing to regulate length and } \\
\text { frequency of puffs. The e-liquid is } \\
\text { rechargeable. }\end{array}$ \\
\hline & $\begin{array}{l}3^{\text {rd }} \text { generation: } \\
\text { Box-mod; vape } \\
\text { tanks; open } \\
\text { systems; } \\
\text { refillable e- } \\
\text { cigarette }\end{array}$ & $\begin{array}{l}\text { The size is much larger than a } \\
\text { conventional cigarette with a higher- } \\
\text { capacity battery. It can be easily } \\
\text { modified to customize the battery or } \\
\text { the cartridge capacity or other } \\
\text { parameters. The e-liquid is refillable. }\end{array}$ \\
\hline & $\begin{array}{l}4^{\text {th }} \text { generation: } \\
\text { vape pod with } \\
\text { nicotine salts } \\
\text { (as Juul) }\end{array}$ & $\begin{array}{l}\text { The size is relatively small. Instead of } \\
\text { e-liquids it includes nicotine salts (i.e., } \\
\text { readily available nicotine, which makes } \\
\text { it highly addictive) that should be pre- } \\
\text { heated before inhalation. This is a } \\
\text { rechargeable e-cigarette. }\end{array}$ \\
\hline
\end{tabular}

Besides the device, also the liquids used are heterogeneous, having different ingredients, including a vast variety of flavours. It has been estimated that more than 15,000 different flavours are used in e-cigarettes [52]. 


\subsubsection{Descriptive epidemiology of e-cigarettes}

In Europe, after an initial rapid spread since 2010 [54], the proportion of adult regular e-cigarette users did not substantially rise from 2014 (1.5\%) to 2017 (1.8\%), with large differences among countries [55]. A Eurobarometer survey conducted in summer 2020 showed that more than 1 in 10 have at least tried ecigarette, $9 \%$ having tried this product only once or twice, $3 \%$ having used it in the past and $2 \%$ using it currently [4].

E-cigarettes are available in Italy since 2010, and their regular use increased from $0.4 \%$ in $2014-2015$ to $1.8 \%$ in $2016-2017$ [49, 50].

\subsubsection{Safety of e-cigarettes}

Public Health England, a governmental agency of the Department of Health and Social Care in the UK, and e-cigarette advocates promote the substitution of combustible cigarettes with e-cigarettes among all smokers, hinting on a possible consequent harm reduction [56]. On the other hand, the WHO warned against ecigarette use even as a smoking cessation tool, stating that it is "undoubtedly harmful" [57]. Actually, some of the common components of e-liquids are known to have harmful health effects. For example, among the thousands flavours used in e-cigarettes, many have been shown to increase the toxicity of the aerosol generated by the e-liquid [20,52].

As a consequence, although still no information is available on the long-term effects on incidence and mortality of cancer and other chronic conditions, in the scientific literature there is evidence that e-cigarette use has harmful short- to intermediate-term health effects. In particular, e-cigarettes have been shown to increase the risk of cardiovascular diseases, including heart rate and blood pressure [58]. Daily e-cigarette use has also been associated with increased risk of myocardial infarction [59].

In addition, studies on the impact of e-cigarette use on respiratory health show measurable effects on organ and cellular health in humans, in animals, and in vitro [60, 61]. E-cigarette use might also be associated with asthma and chronic obstructive pulmonary disease [61,62].

Many e-cigarette users are dual users (also consuming conventional cigarettes). Dual use might have a more deleterious effect rather than the use of e-cigarette or conventional cigarettes alone [63-65]. Nicotine, besides being highly addictive, also poses health risks to pregnant women [20, 52], and children and adolescents, having this substance deleterious impacts on brain development, potentially leading to learning and anxiety disorders [66, 67].

Finally, since April 2019, a new pulmonary disease, associated specifically to ecigarettes, has been observed and described in the USA. This has been termed e-cigarette or vaping product use associated lung injury (EVALI). In 2019-2020 EVALI resulted in more than 2700 hospitalizations and 60 deaths in the USA. 
EVALI was prevalently observed in healthy adolescents who had vaped within 90 days of symptom onset. EVALI patients had abnormal lung imaging in the absence of any pulmonary infection. The leading etiology of EVALI is the contamination with vitamin $\mathrm{E}$ acetate, a substance used in the dilution of cannabis, of delta-9-tetrahydrocannabinoid (THC) e-liquids [52, 68].

\subsection{Heated tobacco products}

\subsubsection{Launch of HTPs}

As already mentioned, approximately ten years ago, tobacco sales in highincome countries were falling, mainly due to an increased awareness of the harmful effects of tobacco smoking and the measures taken to reduce smoking incidence. This encouraged even the most resistant policymakers to follow the articles outlined in the WHO-FCTC [27] and adopt strict tobacco regulations. As described in chapter 1.2.3, for the first time many countries glimpsed the possibility of ending the tobacco epidemic and the prospect of a smoke-free future $[37,40]$.

In reaction to this dramatic impact on their business, tobacco companies succeeded in introducing the HTP, a new device designed allegedly to be relatively safe. HTPs are hybrids between e-cigarettes and combusted cigarettes: as e-cigarettes, they are equipped with an electronic device heating a product to generate an aerosol containing nicotine; as combusted cigarettes, the heated product is "real" tobacco $[57,69]$. HTPs therefore pose potential dangers to public health and the nicotine ensures that consumers remain enslaved, guaranteeing future customers for tobacco companies among the youngest generations.

Philip Morris International (PMI) launched IQOS, the first HTP, for the first time in December 2014, selecting Milan, Italy and Nagoya, Japan as pilot cities for the European and Asian markets, respectively. Today IQOS is available in a large majority of high-income countries, together with other HTPs such as Glo of British American Tobacco (BAT) and Pax of Japan Tobacco International (JTI) [69-71].

\subsubsection{Descriptive epidemiology of HTPs}

Only a few studies, mostly from Japan where HTPs are substantially prevalent [71-73] and the US [74], have investigated the diffusion and/or the public health consequences of HTPs. To our knowledge, data from Europe are limited to three representative national-based surveys from Italy and the UK, showing a strong interest in use by non-smokers [70] and adolescents [75] and a limited but increasing prevalence of use $[70,76]$. An analysis of tobacco sales confirmed the increasing trend in use of this product until 2018 in Italy [69]. One recent study, 
based on smokers only, has identified factors related to product use from six European countries [77]. In general, in Europe e-cigarette is still more frequently used compared to HTP. However, whereas the increasing trend of e-cigarette use was recently attenuated in many European countries [55], the popularity of HTP is substantially increasing in the same countries [69].

\subsubsection{Safety of HTPs}

Are these products safer than conventional tobacco? Given the destructive health consequences of combusted cigarettes, HTPs are likely less harmful than conventional cigarettes. However, we do not know this with any degree of certainty [57]. In fact, whereas it is true that selected toxicants and carcinogens known to be released by combusted cigarettes are emitted by HTPs at substantially lower concentrations (around 10\%), other toxicants and potential carcinogens emitted by HTPs are not even present in traditional cigarettes [78], thus we are not able to draw conclusions about their effects on human health. Moreover, HTPs release relatively high nicotine levels (similar to those released by conventional cigarettes) $[79,80]$ and non-negligible amounts of harmful substances, including various carcinogens [80, 81]. Finally, also for HTPs still no information is available on the long-term effects on incidence and mortality of cancer and other chronic conditions.

In January 2019, PMI made a formal request to the Italian authorities to evaluate the relative harmfulness of their novel tobacco product. For the reasons cited above, the Italian Ministry of Health and the National Health Institute (Istituto Superiore di Sanità; ISS) declared that it was impossible to acknowledge both the reduction of HTP's toxic substances and the potential risk reduction of HTPS compared to combusted products, under the same conditions of use. The results of this evaluation were sealed for more than one year, but were made publicly known through an investigation broadcast on the TV programme "Report" of RAI 3, a public national TV channel [82].

In July 2020, the Food and Drug Administration (FDA) in the US revised the status of IQOS, declaring that this product has a lower "exposure modification" (but not a lower harm or risk for human health) compared with conventional cigarettes. Yet FDA officers still need to explain how and why they made this decision, which amounts to endorsing HTPs. Indeed, the confusion resulting from this decision has been highly criticized by independent tobacco control experts [83, 84] but acclaimed by PMI as a "milestone for public health" [83]. 


\subsubsection{Fiscal and regulatory benefits of novel (tobacco) products}

Due to the alleged belief that e-cigarette and HTPs are effective harm reduction strategies, in most countries these products are exempted from the fiscal regimes of tobacco products. In many countries, including most European ones, an excise tax is not applied to e-cigarettes [52]. Also HTPs, although being tobacco products, benefit of major fiscal privileges. Moreover, e-cigarettes and HTPs are not always covered by smoking/vaping bans in public places. In a review of the legislation in 48 WHO European Region countries, 58\% of countries had legislation on e-cigarette use at the national level. Education facilities were the most regulated places (58.3\% of countries). Only a third of countries regulated ecigarette use indoors [85].

In Italy, HTPs benefit from the same tax reduction as e-cigarettes. Compared to the excise tax of conventional cigarettes, HTPs and e-cigarettes with nicotine are currently subject to $20 \%$ of such excise tax. Moreover, the enforcement of various tobacco control regulations is only minimally adopted for HTPs in Italy. Thus, health warnings are required to cover only $30 \%$ of the HTP packaging (instead of $65 \%$ for conventional cigarettes), without pictorial images. Moreover, comprehensive smoke-free regulations prohibiting smoking in all public places and workplaces do not apply to HTPs. Finally, advertising and promotions are not banned for these new products [69]. E-cigarettes enjoy more or less the same benefits of HTPs.

\subsection{Aims of the dissertation}

\subsubsection{Rationale}

The introduction of e-cigarettes has led to a debate about their impact on human health and tobacco control. Knowledge about e-cigarettes is currently incomplete, small-scale and not always free of COls.

The scientific community is divided over the significance of e-cigarettes in tobacco control. E-cigarettes are seen by some as a harm reduction tool, which may convince heavy smokers to switch from conventional cigarettes to a safer product. On the other hand, a larger part of the independent scientific community considers the e-cigarette a dangerous threat to tobacco control for a number of reasons, including: i) e-cigarette is likely safer than conventional cigarettes, but is far from being safe; ii) given the heterogeneity of e-cigarettes available in the market, it is impossible to verify the contents and the emissions of these constantly evolving products; iii) e-cigarette may be used by smokers in those places where conventional cigarettes are forbidden; iv) it may be a gateway to conventional tobacco smoking among younger generations; v) it may favour 
smoking relapse; vi) it may inhibit smoking cessation; and, more in general, vii) it may increase nicotine spread at the population level.

Things are even more complex today, with the launch in the market of HTPs. Recently, the tobacco industry joined the e-cigarette companies in investing huge amounts of money to fund research on tobacco towards the harm reduction strategy, driving the scientific community towards the sale of their allegedly safer products. Consequently, current evidence on the issue is already contaminated by a number of studies whose independence from the industry is questionable. For example, some preliminary systematic reviews already showed that authors having a COI with tobacco and/or e-cigarette manufacturers are more likely to consider favourably e-cigarettes [86, 87]. To our knowledge, no review addressed the issue focusing on HTPs. It is of crucial importance that independent research quantifies the role of the tobacco industry on current literature evidence, particularly now that tobacco companies, in particular PMI, allocated significant funds to financially support research on HTPs.

All the above mentioned aspects advocate the need for extensive research on these new-generation nicotine containing products that should be independent from the interest of all industries, be it a tobacco or an e-cigarette (or even a pharmaceutical) industry.

\subsubsection{Objectives of the dissertation}

The present project aimed at providing new and fully independent epidemiological data on prevalence, determinants and patterns of use of ecigarettes and HTPs in Italy and Europe. Particular focus has been given to elucidate the consequences of the use of these products on tobacco smoking habits and to quantify the role of the tobacco industry on current scientific knowledge.

Specific objectives of the present dissertation include the following:

1) Evaluation of the prevalence and trends of e-cigarette and HTP use in Italy (Chapter 2; [88]);

2) Evaluation of the impact of e-cigarette and HTP use on smoking habit (Chapter 3; [89]);

3) Evaluation of the effect of the Covid-19 pandemic on the use of e-cigarettes and HTPs in Italy (Chapter 4; [90]);

4) Evaluation of the patterns and settings of use and adverse events of ecigarette users among Italian smokers attempting to quit (Chapter 5; [91]);

5) Evaluation of the prevalence, patterns and determinants of e-cigarette use in Europe (Chapter 6; [92]);

6) Evaluation of the prevalence, patterns and determinants of HTP use in Europe (Chapter 7; (Chapter 7; [93]); 
7) Evaluation of the exposure to second-hand aerosol (SHA) from e-cigarette in European non-smokers (Chapter 8; [94]);

8) Evaluation of the impact of COls with the tobacco industry on the support for HTPs (Chapter 9; [95]).

\subsection{References}

1. Anonymous. Cigarettes and Other Tobacco Products DrugFacts. National Institute on Drug Abuse; National Institutes of Health; U.S. Department of Health and Human Services 2021.

2. Mishra S, Mishra MB. Tobacco: Its historical, cultural, oral, and periodontal health association. J Int Soc Prev Community Dent 2013; 3: 12-18.

3. GBD Tobacco Collaborators. Spatial, temporal, and demographic patterns in prevalence of smoking tobacco use and attributable disease burden in 204 countries and territories, 1990-2019: a systematic analysis from the Global Burden of Disease Study 2019. Lancet 2021; 397: 2337-2360.

4. Eurobarometer. Special Eurobarometer 506: Attitudes of Europeans towards tobacco and electronic cigarettes. European Commission. Available online at: https://europa.eu/eurobarometer/surveys/detail/2240. 2021.

5. Fernandez E, Lopez MJ, Gallus S et al. Tackling second-hand exposure to tobacco smoke and aerosols of electronic cigarettes: the TackSHS project protocol. Gac Sanit 2020; 34: 77-82.

6. Gallus S, Lugo A, Liu $X$ et al. Who smokes in Europe? Data from 12 European countries in the TackSHS survey (2017-2018). In press. J Epidemiol 2021; 31: 145-151.

7. ESPAD. ESPAD Report 2019 - Results from the European School Survey Project on Alcohol and Other Drugs. Available online at: https://www.emcdda.europa.eu/publications/joint-publications/espadreport-2019_en. 2020.

8. Wynder EL, Graham EA. Tobacco smoking as a possible etiologic factor in bronchiogenic carcinoma; a study of 684 proved cases. J Am Med Assoc 1950; 143: 329-336.

9. Doll R, Hill $A B$. Smoking and carcinoma of the lung; preliminary report. $\mathrm{Br}$ Med J 1950; 2: 739-748.

10. IARC. IARC Monograph on the Evaluation of Carcinogenic Risks to Humans. Volume 100E. A review of human carcinogens - Personal habits and indoor combustions. Lyon, France,2012.

11. U.S. Department of Health and Human Services. The Health Consequences of Smoking: A Report of the Surgeon General. Atlanta, GA: Centers for Disease Control and Prevention, National Center for Chronic Disease Prevention and Health Promotion, Office on Smoking and Health,2004. 
12. IARC. IARC Monograph on the Evaluation of Carcinogenic Risks to Humans. Volume 83. Tobacco Smoke and Involuntary Smoking. Lyon, France,2004.

13. Lugo A, Peveri G, Gallus S. Should we consider gallbladder cancer a new smoking-related cancer? A comprehensive meta-analysis focused on doseresponse relationships. Int J Cancer 2020; 146: 3304-3311.

14. Carter BD, Abnet CC, Feskanich D et al. Smoking and mortality--beyond established causes. N Engl J Med 2015; 372: 631-640.

15. Doll R, Peto R, Boreham J, Sutherland I. Mortality in relation to smoking: 50 years' observations on male British doctors. BMJ 2004; 328: 1519.

16. World Health Organization. WHO Report on the Global Tobacco Epidemic, 2008: the MPOWER package. World Health Organization. Available online at: https://apps.who.int/iris/handle/10665/43818. In. Geneva: World Health Organization 2008.

17. Gallus S, Tramacere I, Boffetta $P$ et al. Temporal changes of under-reporting of cigarette consumption in population-based studies. Tob Control 2011; 20: 34-39.

18. Oberg M, Jaakkola MS, Woodward A et al. Worldwide burden of disease from exposure to second-hand smoke: a retrospective analysis of data from 192 countries. Lancet 2011; 377: 139-146.

19. Joossens L, Feliu A, Fernandez E. The Tobacco Control Scale 2019 in Europe. Brussels: Association of European Cancer Leagues, Catalan Institute of Oncology; 2020. Available online at: http://www.tobaccocontrolscale.org/TCS2019.pdf. 2020.

20. World Health Organization. WHO Report on the Global Tobacco Epidemic, 2021. Addressing new and emerging products. Available online at: https://www.who.int/teams/health-promotion/tobacco-control/globaltobacco-report-2021. 2021.

21. Legg $T$, Legendre $M$, Gilmore $A B$. Paying lip service to publication ethics: scientific publishing practices and the Foundation for a Smoke-Free World. Tob Control 2021.

22. Fields N, Chapman S. Chasing Ernst L Wynder: 40 years of Philip Morris' efforts to influence a leading scientist. J Epidemiol Community Health 2003; 57: 571-578.

23. Daube M, Moodie R, McKee M. Towards a smoke-free world? Philip Morris International's new Foundation is not credible. Lancet 2017; 390: 1722 1724.

24. Dyer C. Confidential tobacco documents enter public domain. BMJ 1998; 316: 1186.

25. Ong EK, Glantz SA. Tobacco industry efforts subverting International Agency for Research on Cancer's second-hand smoke study. Lancet 2000; 355: 1253-1259. 
26. Malone RE, Balbach ED. Tobacco industry documents: treasure trove or quagmire? Tob Control 2000; 9: 334-338.

27. World Health Organization. World Health Organization Framework Convention on Tobacco Control (WHO FCTC). Available online: http://www.who.int/fctc/en/. In. Geneva: World Health Organization 2003.

28. Colombo $P$, Scarpino V, Zuccaro $P$ et al. Smoking in Italian women and men, 2001. Tumori 2002; 88: 10-12.

29. Lopez-Nicolas A, Stoklosa M. Tax harmonisation and tobacco product prices in the European Union, 2004-2015. Tob Control 2019; 28: 434-439.

30. Kyriakos CN, Driezen P, Girvalaki $C$ et al. Awareness and correlates of noticing changes to cigarette packaging design after implementation of the European Tobacco Products Directive: findings from the EUREST-PLUS ITC Europe Surveys. Eur J Public Health 2020; 30: iii98-iii107.

31. Lugo A, Zuccaro P, Pacifici R et al. Smoking in Italy in 2015-2016: prevalence, trends, roll-your-own cigarettes, and attitudes towards incoming regulations. Tumori 2017; 103: 353-359.

32. Benowitz NL, Henningfield JE. Establishing a nicotine threshold for addiction. The implications for tobacco regulation. N Engl J Med 1994; 331: 123-125.

33. Malone RE. Imagining things otherwise: new endgame ideas for tobacco control. Tob Control 2010; 19: 349-350.

34. Warner KE. An endgame for tobacco? Tob Control 2013; 22 Suppl 1: i3-5.

35. Jenks S. Shaking Tobacco's Residual Grip: Endgame Strategies Emerge. J Natl Cancer Inst 2013; 105: 1336-1338.

36. Smith EA. Questions for a tobacco-free future. Tob Control 2013; 22 Suppl 1: i1-2.

37. Gallus S, Lugo A, Fernandez E et al. Support for a tobacco endgame strategy in 18 European countries. Prev Med 2014; 67: 255-258.

38. Levy DT, Blackman K, Currie LM et al. SimSmokeFinn: how far can tobacco control policies move Finland toward tobacco-free 2040 goals? Scand $\mathrm{J}$ Public Health 2012; 40: 544-552.

39. Maubach N, Hoek JA, Edwards $R$ et al. 'The times are changing': New Zealand smokers' perceptions of the tobacco endgame. Tob Control 2012.

40. Malone RE. Tobacco endgames: what they are and are not, issues for tobacco control strategic planning and a possible US scenario. Tob Control 2013; 22 Suppl 1: i42-44.

41. European Commission. Public Health: EU Tobacco Products Directive is delivering but stronger action is needed. Brussels. Available online at: https://ec.europa.eu/commission/presscorner/detail/en/ip_21_2563. 2021.

42. Gallus S, Cattaruzza MS, Gorini $G$ et al. Vatican beats Italy 1-0 in the tobacco endgame. Tob Control 2018. 
43. IARC. IARC handbooks of cancer prevention: Evaluating the effectiveness of smoke-free policies; available online at: http://w2.iarc.fr/en/publications/pdfs-

online/prev/handbook13/handbook13.pdf. In. Lyon, France: IARC press 2009.

44. Gallus $\mathrm{S}$, Zuccaro $\mathrm{P}$, Colombo $\mathrm{P}$ et al. Effects of new smoking regulations in Italy. Ann Oncol 2006; 17: 346-347.

45. Torjesen I. Stop smoking services must become "e-cigarette" friendly, says Public Health England. BMJ 2015; 351: h4518.

46. Dawkins L, Turner J, Roberts A, Soar K. 'Vaping' profiles and preferences: an online survey of electronic cigarette users. Addiction 2013; 108: 11151125.

47. Dockrell M, Morison R, Bauld L, McNeill A. E-Cigarettes: Prevalence and Attitudes in Great Britain. Nicotine Tob Res 2013.

48. Pauly J, Li Q, Barry MB. Tobacco-free electronic cigarettes and cigars deliver nicotine and generate concern. Tob Control 2007; 16: 357.

49. Gallus S, Lugo A, Pacifici R et al. E-cigarette awareness, use, and harm perceptions in Italy: a national representative survey. Nicotine Tob Res 2014; 16: 1541-1548.

50. Liu X, Lugo A, Davoli $E$ et al. Electronic cigarettes in Italy: a tool for harm reduction or a gateway to smoking tobacco? Tob Control 2020; 29: 148-152.

51. Kuehn BM. FDA: Electronic cigarettes may be risky. JAMA 2009; 302: 937.

52. Baena García A, Córdoba García R, Regina Dalmau González-Galarza RD et al. CNPT Consensus Document On Nicotine Delivery Devices. Comité Nacional para la Prevención del Tabaquismo. Madrid, Spain. 2020.

53. Glantz SA, Bareham DW. E-Cigarettes: Use, Effects on Smoking, Risks, and Policy Implications. Annu Rev Public Health 2018; 39: 215-235.

54. Filippidis FT, Laverty AA, Gerovasili V, Vardavas Cl. Two-year trends and predictors of e-cigarette use in 27 European Union member states. Tob Control 2017; 26: 98-104.

55. Laverty AA, Filippidis FT, Vardavas Cl. Patterns, trends and determinants of e-cigarette use in 28 European Union Member States 2014-2017. Prev Med 2018; 116: 13-18.

56. McNeill A, Brose LS, Calder $R$ et al. Evidence review of e-cigarettes and heated tobacco products 2018. Available online at: https://www.gov.uk/government/publications/e-cigarettes-and-heatedtobacco-products-evidence-review/evidence-review-of-e-cigarettes-andheated-tobacco-products-2018-executive-summary\#use-of-e-cigarettes-inadults (last access: 30 July 2019). 2018.

57. World Health Organization. WHO Report on the Global Tobacco Epidemic, 2019. Offer help to quit tobacco use. Available at: https://www.who.int/tobacco/global_report/en/. 2019. 
58. Kennedy CD, van Schalkwyk MCl, McKee M, Pisinger C. The cardiovascular effects of electronic cigarettes: A systematic review of experimental studies. Prev Med 2019; 127: 105770.

59. Tsai M, Byun MK, Shin J, Crotty Alexander LE. Effects of e-cigarettes and vaping devices on cardiac and pulmonary physiology. J Physiol 2020; 598: 5039-5062.

60. Bhatta DN, Glantz SA. Association of E-Cigarette Use With Respiratory Disease Among Adults: A Longitudinal Analysis. Am J Prev Med 2020; 58: 182-190.

61. Wills TA, Soneji SS, Choi K et al. E-cigarette use and respiratory disorders: an integrative review of converging evidence from epidemiological and laboratory studies. Eur Respir J 2021; 57.

62. Gotts JE, Jordt SE, McConnell R, Tarran R. What are the respiratory effects of e-cigarettes? BMJ 2019; 366: 15275.

63. Reddy KP, Schwamm E, Kalkhoran S et al. Respiratory Symptom Incidence among People Using Electronic Cigarettes, Combustible Tobacco, or Both. Am J Respir Crit Care Med 2021; 204: 231-234.

64. Kim CY, Paek YJ, Seo HG et al. Dual use of electronic and conventional cigarettes is associated with higher cardiovascular risk factors in Korean men. Sci Rep 2020; 10: 5612.

65. Wang JB, Olgin JE, Nah G et al. Cigarette and e-cigarette dual use and risk of cardiopulmonary symptoms in the Health eHeart Study. PLoS One 2018; 13: e0198681.

66. Hall FS, Der-Avakian A, Gould TJ et al. Negative affective states and cognitive impairments in nicotine dependence. Neurosci Biobehav Rev 2015; 58: 168-185.

67. Yuan M, Cross SJ, Loughlin SE, Leslie FM. Nicotine and the adolescent brain. J Physiol 2015; 593: 3397-3412.

68. Aldy $\mathrm{K}$, Cao DJ, Weaver MM et al. E-cigarette or vaping product useassociated lung injury (EVALI) features and recognition in the emergency department. J Am Coll Emerg Physicians Open 2020; 1: 1090-1096.

69. Liu X, Lugo A, Spizzichino L et al. Heat-Not-Burn Tobacco Products Are Getting Hot in Italy. J Epidemiol 2018; 28: 274-275.

70. Liu X, Lugo A, Spizzichino L et al. Heat-not-burn tobacco products: concerns from the Italian experience. Tob Control 2019; 28: 113-114.

71. Tabuchi T, Gallus S, Shinozaki T et al. Heat-not-burn tobacco product use in Japan: its prevalence, predictors and perceived symptoms from exposure to secondhand heat-not-burn tobacco aerosol. Tob Control 2018; 27: e25e33.

72. Jankowski M, Brozek GM, Lawson J et al. New ideas, old problems? Heated tobacco products - a systematic review. Int J Occup Med Environ Health 2019; 32: 595-634. 
73. Tabuchi T, Kiyohara K, Hoshino $\mathrm{T}$ et al. Awareness and use of electronic cigarettes and heat-not-burn tobacco products in Japan. Addiction 2016; 111: 706-713.

74. Nyman AL, Weaver SR, Popova L et al. Awareness and use of heated tobacco products among US adults, 2016-2017. Tob Control 2018; 27: s55s61.

75. Czoli CD, White CM, Reid JL et al. Awareness and interest in IQOS heated tobacco products among youth in Canada, England and the USA. Tob Control 2020; 29: 89-95.

76. Brose L, Simonavicius E, Cheeseman H. Awareness and use of 'heat-notburn' tobacco products in Great Britain. Tob Regul Sci 2018; 4:: 44-50.

77. Maria Lotrean L, Trofor A, Radu-Loghin C et al. Awareness and use of heated tobacco products among adult smokers in six European countries: findings from the EUREST-PLUS ITC Europe Surveys. Eur J Public Health 2020; 30: iii78-iii83.

78. St Helen G, Jacob lii P, Nardone N, Benowitz NL. IQOS: examination of Philip Morris International's claim of reduced exposure. Tob Control 2018; 27: s30-s36.

79. Farsalinos KE, Yannovits N, Sarri T et al. Nicotine Delivery to the Aerosol of a Heat-Not-Burn Tobacco Product: Comparison With a Tobacco Cigarette and E-Cigarettes. Nicotine Tob Res 2018; 20: 1004-1009.

80. Auer R, Concha-Lozano N, Jacot-Sadowski I et al. Heat-Not-Burn Tobacco Cigarettes: Smoke by Any Other Name. JAMA Intern Med 2017; 177: 10501052.

81. Ruprecht AA, De Marco C, Saffari A et al. Environmental pollution and emission factors of electronic cigarettes, heat-not-burn tobacco products, and conventional cigarettes. Aerosol Science and Technology 2017; 51: 674-684.

82. Moskowitz E. OCCRP - Italy Releases Confidential Study on Philip Morris' IQOS. Available online at: https://www.occrp.org/en/daily/12452-italyreleases-secret-study-on-philip-morris-iqos. 2020.

83. Gilmore $A B$, Braznell $S$. US regulator adds to confusion around heated tobacco products. BMJ 2020; 370: m3528.

84. World Health Organization. WHO statement on heated tobacco products and the US FDA decision regarding IQOS. Available online at: https://www.who.int/news/item/27-07-2020-who-statement-on-heatedtobacco-products-and-the-us-fda-decision-regarding-iqos. 2020.

85. Amalia B, Fu M, Feliu A et al. Regulation of electronic cigarette use in public and private areas in 48 countries within the WHO European Region: a survey to in-country informants. J Epidemiol 2020. 
86. Pisinger C, Godtfredsen N, Bender AM. A conflict of interest is strongly associated with tobacco industry-favourable results, indicating no harm of ecigarettes. Prev Med 2019; 119: 124-131.

87. Martinez C, Fu M, Galan I et al. Conflicts of interest in research on electronic cigarettes. Tob Induc Dis 2018; 16: 28.

88. Gallus S, Borroni E, Odone A et al. The Role of Novel (Tobacco) Products on Tobacco Control in Italy. Int J Environ Res Public Health 2021; 18: 1896.

89. Gallus S, Stival C, McKee M et al. The impact of electronic cigarette and heated tobacco product on smoking habit: a prospective cohort study form Italy. Tob Control 2021; Submitted.

90. Gallus S, Stival C, Carreras $\mathrm{G}$ et al. Use of electronic cigarettes and heated tobacco products during the Covid-19 pandemic. Sci Rep 2022; In press.

91. Gallus S, Borroni E, Liu X et al. Electronic cigarette use among Italian smokers: patterns, settings, and adverse events. Tumori 2020; 300891620915784.

92. Gallus S, Lugo A, Stival $C$ et al. Electronic cigarette use in 12 European countries. Results from the TackSHS survey. J Epidemiol 2021; In press.

93. Gallus S, Lugo A, Liu X et al. Use and Awareness of Heated Tobacco Products in Europe. J Epidemiol 2021; In press.

94. Amalia B, Liu X, Lugo A et al. Exposure to secondhand aerosol of electronic cigarettes in indoor settings in 12 European countries: data from the TackSHS survey. Tob Control 2021; 30: 49-56.

95. Gallus S, Odone A, van den Brandt PA et al. Conflict of interest research in heated tobacco products: a systematic review. BMJ 2022; Under review. 

Chapter 2

The role of novel (tobacco) products on tobacco control in Italy 


\subsection{Abstract}

In Italy, electronic cigarettes have spread since 2010 and heated tobacco products (HTP) since 2016. We investigated their public health consequences on conventional cigarette smoking, taking advantage of a series of cross-sectional studies annually conducted between 2001 and 2019 in Italy. Every year, the sample, including around 3000 individuals, was representative of the general Italian population aged $\geq 15$ years. In Italy, smoking prevalence steadily declined from $29.1 \%$ in 2001 to $20.6 \%$ in 2013 , then increased to $22.0 \%$ in 2019 . In $2017-$ 2019, current electronic cigarette users were $2.1 \%$ and in 2019 current HTP users were $1.1 \%$. Among 498 ever electronic cigarette users, $23.2 \%$ started or restarted smoking and $15.7 \%$ quit smoking after electronic cigarette use; of 49 ever HTP users, $19.1 \%$ started or re-started smoking combusted cigarettes and $14.6 \%$ quit smoking after HTP use. The availability of novel products in Italy resulted in a halt of the decreasing trend in smoking prevalence. For the first time, we observed an increase of Italians inhaling nicotine, concurrently with the spread of novel (tobacco) products. More importantly, the use of novel products appears to increase-rather than decrease-the likelihood of smoking conventional cigarettes. Considering this evidence, we see no argument to justify the huge fiscal and regulatory benefits these products continue to have, at least in Italy.

Keywords: smoking prevalence; e-cigarette; heated tobacco products; heat-notburn tobacco products; harm reduction; Italy 


\section{$2.2 \quad$ Introduction}

Tobacco smoking is the main cause of preventable mortality worldwide: every year more than 8 million deaths are globally attributed to tobacco smoking [1]. In high-income countries, the increased awareness of the harmful effects of tobacco smoking encouraged policymakers to follow the articles outlined in the World Health Organization Framework Convention on Tobacco Control (WHO-FCTC) [2] and adopt stricter and stricter tobacco regulations [3-5]. This resulted in a dramatic fall in tobacco sales and consumption over the last few decades [6]. Also in Italy, smoking prevalence was consistently decreasing from 1957 and over the subsequent five decades $[7,8]$.

More recently, some novel products, which generate an aerosol containing nicotine or no nicotine, have been introduced into the market. These include electronic cigarettes (since 2010 in Italy) and heated tobacco products (HTP). IQOS, the first HTP by Philip Morris, was launched first in Milan in December 2014, then sold in the whole country from December 2015 and practically spread from 2016 [9]. Electronic cigarettes' liquids without nicotine (electronic nonnicotine delivery systems, ENNDS [10]) were also commercialized, although their use is limited [11]. All these new products were aggressively promoted by the (tobacco) industry, with the claim that they were less harmful than conventional cigarettes [1,12]. HTPs also circumvented the WHO-FCTC by claiming to be smoke-free and at reduced risk products compared to conventional cigarettes. However, decision n. 22 of the eighth session of the Conference of the Parties (COP8) stated that HTPs meet the definition of tobacco products under FCTC, thus the full range of policy and regulatory measures contained in the WHOFCTC apply to HTPs [13]. Due to the alleged-but never confirmed-reduced harm, these new products obtained fiscal and regulatory benefits compared to combusted cigarettes in most high-income countries [9,14]. Consequently, these products have gained rapid popularity worldwide [15]. Moreover, likeable flavors and non-regulated appealing advertisements, also on social media, contributed to the spread of electronic cigarettes, attracting in particular the youngest generations [16,17]. Electronic cigarettes and HTPs substantially spread also in Italy -awareness of electronic cigarettes rapidly increased in just a few years from the launch of this novel product [18] and regular electronic cigarette users increased from $0.4 \%$ in $2014-2015$ to $1.8 \%$ in 2016-2017 [19]. Among tobacco products, the market share of IQOS, the first HTP by Philip Morris, increased from $0.01 \%$ in 2015 to $0.11 \%$ in 2016 up to $0.67 \%$ in 2017 [9]. Whereas the safety consequences of these products are still largely unknown [1], more and more concerns have been raised by independent research on public health consequences [1,19-21]. In particular: (i) electronic cigarette use has been found to increase-rather than decrease-tobacco smoking in the general adult population [19] and has been associated with tobacco smoking initiation among 
adolescents [1,22-25]; (ii) also never smokers or ex-smokers having quit since several years are attracted to these new products [21]; (iii) novel product users are more frequently dual users consuming the novel product where smoking is forbidden [26]; (iv) the role of electronic cigarette on smoking cessation is unclear and uncertain [1] and, as HTPs are tobacco products, the conversion from conventional cigarettes to HTPs should not be considered cessation [1]; and (v) electronic cigarettes increase the risk of renormalization of smoking in society [1,27-29]. Moreover, a survey conducted in 12 European countries recently showed how a large proportion of ex-smokers using HTPs did not quit smoking switching to HTPs but they firstly quit and then relapsed to the use of tobacco [30]. In this landscape, it is clear that novel (tobacco) products may have an unfavorable public health effect rather than being harm reduction tools $[31,32]$. The aim of the present study is to provide updated data on the trends of the prevalence of nicotine consumers in Italy before and after the spread of novel products and to compare the demographic and socio-economic characteristics of conventional cigarette smokers with those of novel product users.

\subsection{Materials and Methods}

Since 1957 and annually since 2001, the Mario Negri Institute, in collaboration with the Italian National Institute of Health, conducts cross-sectional studies on smoking. Every year, DOXA, the Italian branch of the Worldwide Independent Network/Gallup International Association (WIN/GIA), interviews a sample of around 3000 subjects, representative of the general Italian population aged 15 years and over, in terms of sex, age, geographic area and socio-economic characteristics [8]. For the present study, we considered data from all the surveys conducted by DOXA from 1957 to 2019 , with a focus on the surveys conducted in 2017-2019, including a total sample of 9428 individuals (4533 men and 4895 women).

Survey participants were selected through a representative multistage sampling. The first stage involved the selection of municipalities (110 municipalities in 2017, 119 in 2018 and 114 in 2019) in all the 20 Italian regions, based on the region and municipality size. In the second stage, for each municipality, an adequate number of electoral wards was randomly extracted, so that the more or less affluent areas of the municipality were represented in the right proportions. In the third stage, individuals were randomly sampled from electoral rolls, within strata defined by sex and age group. Adolescents aged 15-17 years, who were not included in the electoral lists, were randomly selected by a 'quota' method based on the sex and age proportions among them. A statistical weight was generated 
for each subject to ensure the representativeness of the Italian population aged 15 years or more.

Ad hoc trained interviewers conducted face-to-face surveys using a structured questionnaire in the context of a computer-assisted personal in-house interview (CAPI). Besides general information on socio-demographic characteristics, detailed information was collected on smoking status (never, ex- and current smokers) and other smoking variables. Ever smokers (current and ex-smokers) were participants who had smoked 100 or more cigarettes in their lifetime. Exsmokers were participants who had quit smoking since at least one year and current smokers were individuals continuing smoking or having stopped since less than one year.

Since 2014, data was also collected on electronic cigarette use. Participants were asked to answer the following question: "Do you use electronic cigarettes or other electronic devices for vaping (disposable or pre-filled or refillable cartridges with liquid), even only occasionally?" (1) Yes, occasionally; (2) Yes, regularly; (3) I used it in the past; (4) No. In 2019, participants were also asked to report their use of HTPs, answering the following question: "Do you use heated tobacco products, like glo or IQOS?" (1) Yes, occasionally; (2) Yes, regularly; (3) I used it in the past; (4) No. Current users of either electronic cigarette or HTPs were defined as those who answered the first or the second items, past users as those answering the third item and never users as those answering the fourth item. Ever users of either electronic cigarette or HTPs were defined as those who were either current or past users (i.e., answering the first, the second or the third item). In 2014-2015 and 2017-2019 electronic cigarette users were asked to report the type of liquid used (with nicotine or without nicotine). We defined participants as "currently using nicotine-containing products," whether they were either current smokers or current electronic cigarette users consuming nicotine liquids (i.e., excluding users of exclusively non-nicotine liquids) or HTPs users.

We defined dual users as current cigarette smokers also using novel (tobacco) products (i.e., either electronic cigarette or HTPs, or both).

Level of education was categorized on the basis of participants' degree into low (up to middle school diploma), intermediate (high school) and high (university). Geographic area was categorized as northern (8 Italian regions), central (4 regions) and southern Italy (8 regions, including islands).

We used official three-month legal sales data on the amount of HTPs and other tobacco products sold in Italy between 2016 (first quarter) and 2019 (last quarter) to compute the market share of HTP tobacco over that period. These data were obtained by the Italian Ministry of Finance [9]. Official legal sales data do not include electronic cigarettes since in Italy they are not classified as tobacco product. 


\subsubsection{Statistical Analyses}

We carried out a joinpoint regression analysis on the prevalence of current smokers in the overall population and among the young (15-24 years), using the "Joinpoint Trend Analysis Software" developed by the "Surveillance, Epidemiology and End Results Program" of the National Cancer Institute (Bethesda, MD, USA) [33]. "Joinpoints" were identified as time point(s) when a change in the linear slope (on a log scale) of the temporal trend occurred, by testing from zero up to a maximum of four joinpoints for the overall population (23 data points between 1957 and 2019) and of three joinpoints for the young (19 data points between 2001 and 2019). As a summary measure, we also estimated the annual percent change (APC) for each identified linear segment. We derived odds ratios (OR) and corresponding 95\% confidence intervals (Cl), for current cigarette smokers vs. non-smokers, current electronic cigarette users vs. nonusers and current HTP users vs. non-users, through unconditional multiple logistic regression models after adjustment for sex, age, level of education, geographic area and survey year. Statistical analyses were conducted with SAS version 9.4 statistical package (SAS Institute, Cary, NC, USA). All the analyses considered statistical weights to reassure the representativeness of our sample in terms of age, sex, area of residence and socio-economic characteristics. The level of statistical significance was set to a 2 -sided $p$-value $<0.05$.

\section{$2.4 \quad$ Results}

The prevalence of current smokers from 1957 to 2019 among the population aged $\geq 15$ years is shown in Figure 1. In both sexes combined, smoking prevalence steadily decreased from $35.4 \%$ in 1957 to $29.1 \%$ in 2001 (APC 1957-2001: $-0.5 \%$; $p<0.05$ ), to $20.6 \%$ in 2013 (APC 2001-2013: $-2.8 \%$; $p<0.05$ ), then restarted increasing and was $22.3 \%$ in $2017,23.3 \%$ in 2018 and $22.0 \%$ in 2019 (APC 2013-2019: $+1.7 \%$; $p=0.1$ ). 


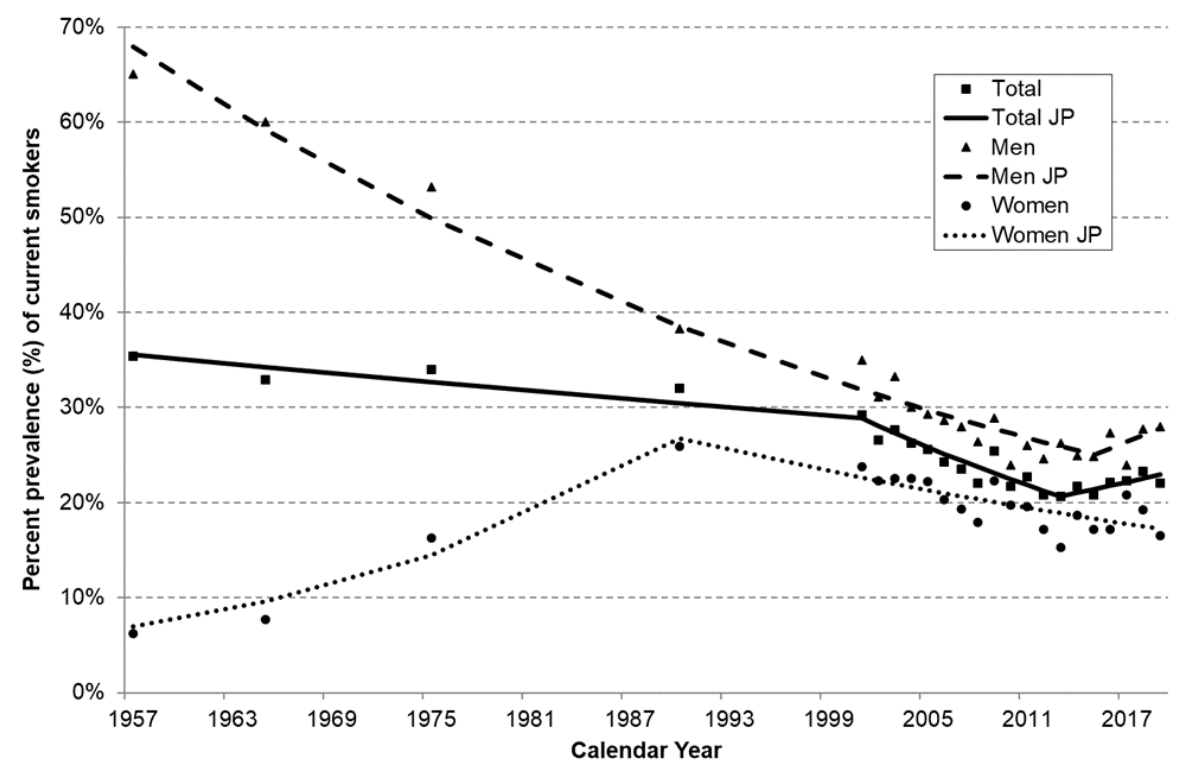

Figure 1: Trends in the prevalence of current smokers among Italian adults aged $\geq 15$ years, overall and by sex. Italy, 1957-2019. APC: Annual Percent Change; Cl: confidence interval; JP: Joinpoint.Squares, triangles and dots represent observed prevalence of current smokers overall and among men and women, respectively. Solid, dashed and dotted lines represent the predicted values obtained from the joinpoint regression models overall and among men and women, respectively. Total: $1957-2001: \mathrm{APC}=-0.5 \%(95 \% \mathrm{Cl}:-0.7$; $-0.2) ; 2001-2013:$ APC $=-2.8 \%(95 \% \mathrm{Cl}:-3.6 ;-1.9) ; 2013-2019: \mathrm{APC}=$ $+1.7 \%(95 \% \mathrm{Cl}:-0.5$; 4). Men: $1957-2015: \mathrm{APC}=-1.7 \%(95 \% \mathrm{Cl}:-1.8 ;-1.6)$; 2015-2019: $\mathrm{APC}=+2.6 \%$ (95\% Cl: $-4.1 ; 9.8)$. Women: $1957-1990:$ APC $=$ $+4.2 \%(95 \% \mathrm{Cl}: 1.1 ; 7.4) ; 1990-2019: \mathrm{APC}=-1.5 \%(95 \% \mathrm{Cl}:-2.2 ;-0.8)$.

Figure 2 shows the trends in current smoking prevalence, overall and by sex, in population aged 15-24 years. This prevalence decreased from $34.1 \%$ in 2001 to $20.8 \%$ in 2019 (APC 2001-2019: -3.2\%; $p<0.05$ ). 


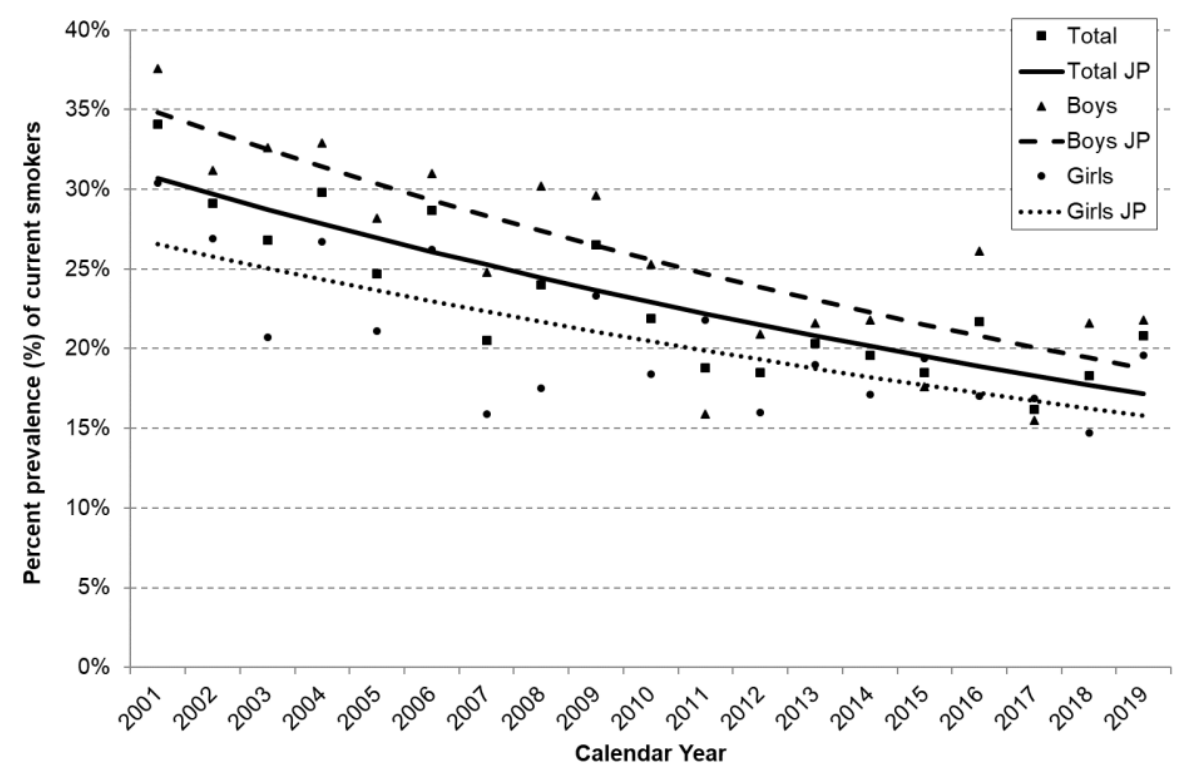

Figure 2: Trends in the prevalence of current smokers among Italian young adults aged 15-24 years, overall and by sex. Italy, 2001-2019. APC: Annual Percent Change; Cl: confidence interval; JP: Joinpoint Squares, triangles and dots represent observed prevalence of current smokers overall and among boys and girls, respectively. Solid, dashed and dotted lines represent the predicted values obtained from the joinpoint regression models overall and among boys and girls, respectively. Total: $2001-2019$ : APC $=-3.2 \%(95 \% \mathrm{Cl}$ : $-4.1 ;-2.2)$. Boys: $2001-2019$ : APC $=-3.4 \%(95 \% \mathrm{Cl}:-4.5 ;-2.2)$. Girls: 2001-2019: $\mathrm{APC}=-2.9 \%(95 \% \mathrm{Cl}:-4.1 ;-1.6)$.

Among Italian adults, the prevalence of current users of nicotine-containing products (i.e., users of any product, including nicotine-containing electronic cigarette - $64.1 \%$ of all electronic cigarette users - and excluding users of exclusively non-nicotine liquids $-35.9 \%$ of all users) was $22.2 \%$ in $2010-2011$, decreased to $20.7 \%$ in $2012-2013$ and increased subsequently to $21.0 \%$ in 2014-2015, to $21.5 \%$ in 2016-2017 and to $22.7 \%$ in 2018-2019 (Table 1). In $2019,75 \%$ of current electronic cigarette users and $81 \%$ of HTP users were dual users (also consuming conventional cigarettes). 
Table 1: Trends in the prevalence of Italian adults aged $\geq 15$ years currently using nicotine-containing products, overall and by selected tobacco or nicotine product. Italy, 2010-2019.

\begin{tabular}{|c|c|c|c|c|c|}
\hline \multicolumn{6}{|c|}{ Current use (\%) } \\
\hline & $2010-2011$ & $2012-2013$ & $2014-2015$ & $52016-2017$ & * 2018-2019 \\
\hline Cigarettes only & 22.2 & 20.7 & 20.2 & 20.7 & 21.1 \\
\hline Electronic cigarettes only & & & 0.1 & 0.2 & 0.3 \\
\hline $\begin{array}{l}\text { Cigarettes AND electronic } \\
\text { cigarettes }\end{array}$ & & & 0.7 & 0.6 & 0.8 \\
\hline HTPs only & & & & & 0.1 \\
\hline Cigarettes AND HTPs & & & & & 0.2 \\
\hline $\begin{array}{l}\text { Electronic cigarettes AND } \\
\text { HTPs }\end{array}$ & & & & & 0.0 \\
\hline $\begin{array}{l}\text { Cigarettes AND electronic } \\
\text { cigarettes AND HTPs }\end{array}$ & & & & & 0.2 \\
\hline $\begin{array}{l}\text { Total (users of nicotine- } \\
\text { containing products) }\end{array}$ & 22.2 & 20.7 & 21.0 & 21.5 & 22.7 \\
\hline
\end{tabular}

Abbreviation: HTP: heated tobacco product

* In 2016 no information on type of liquid used (nicotine vs. non-nicotine liquid) for electronic cigarette users was available. Thus, for 2016 all the electronic cigarette users have been considered.

In $2017-2019,22.5 \%$ of survey participants were current smokers $(26.5 \%$ among men and $18.8 \%$ among women), $12.5 \%$ were ex-smokers and $65.0 \%$ were never smokers. In the same period, $2.1 \%$ were current, $3.2 \%$ past and $94.7 \%$ never electronic cigarette users. In 2019, $1.1 \%$ were current, $0.5 \%$ past and $98.4 \%$ never HTP users.

The HTP sold increased from 82 tons in 2016, to 519 tons in $2017,1,522$ tons in 2018 up to 3,296 tons in 2019 . Of all the tobacco products, the corresponding market share was $0.11 \%$ in $2016,0.67 \%$ in $2017,1.99 \%$ in 2018 and $4.33 \%$ in 2019 (Figure 3).

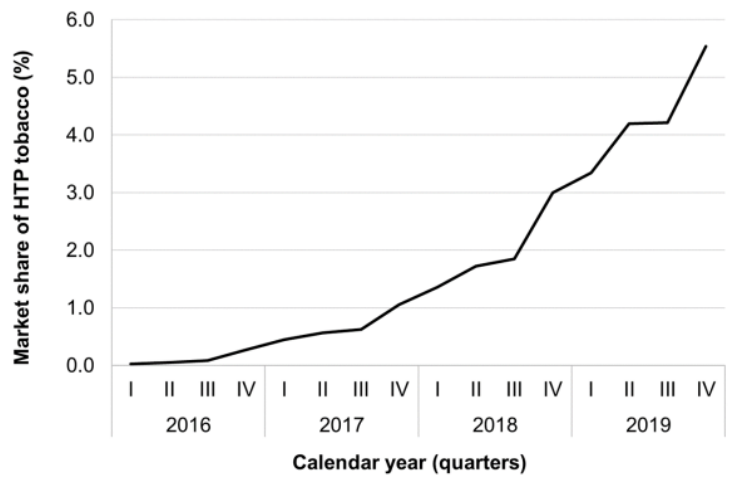

Figure 3: Quarter market share of heated tobacco products (HTP) tobacco (\%), Italy, 2016-2019. 
Among 498 ever electronic cigarette users, $23.2 \%$ reported to have started or restarted smoking as a consequence of their electronic cigarette use, $32.3 \%$ did not change their habits, $22.7 \%$ decreased their number of cigarettes smoked, $1.4 \%$ increased their number of cigarettes smoked, $15.7 \%$ quit smoking and $2.9 \%$ did not smoke cigarettes before their electronic cigarette use and continued avoiding smoking. Among 49 ever HTP users, 19.1\% started or re-started smoking combusted cigarettes, $35.6 \%$ did not change their habits, $23.8 \%$ decreased their number of cigarettes smoked, $2.1 \%$ increased their number of cigarettes smoked, $14.6 \%$ quit smoking and $3.3 \%$ did not smoke cigarettes before their HTP use and continued avoiding smoking (data not shown).

Table 2 shows the ORs for current cigarette smoking, electronic cigarette use and HTP use according to selected demographic and socio-economic characteristics. Women were less frequently cigarette smokers than men (OR was $0.66 ; 95 \% \mathrm{Cl}: 0.60-0.73)$. Smoking prevalence was highest among the young and middle-aged participants (compared with $\geq 65$ years, OR for $<25$ was 1.75 ; 95\% Cl: $1.42-2.16$, OR for $25-44$ was 3.23 ; 95\% Cl: $2.75-3.80$, OR for $45-$ 64 was $2.78,95 \% \mathrm{Cl}: 2.38-3.24)$ and decreased with increasing level of education ( $p$ for trend $<0.001$ ). Smoking was less frequent in central compared to northern Italian regions (OR was $0.81 ; 95 \% \mathrm{Cl}$ : $0.70-0.92$ ). No significant relationship has been observed between smoking prevalence and survey year. Current use of electronic cigarettes was less frequent among women (OR was $0.69 ; 95 \% \mathrm{Cl}: 0.52-0.93$ ). Electronic cigarette use increased with decreasing age ( $p$ for trend $<0.001$ ) and with increasing level of education ( $p$ for trend $<0.001$ ). Electronic cigarette use was more frequent in southern compared with northern Italian regions (OR was $1.51 ; 95 \% \mathrm{Cl}: 1.10-2.06)$ and was less frequent in 2019 compared with 2017 (OR was 0.68; 95\% Cl: 0.48-0.97). HTP use increased with decreasing age ( $p$ for trend $=0.029$ ). No significant relationship has been observed with sex, level of education and geographic area. 
Table 2. Prevalence of current smokers among 9428 Italian participants aged $\geq 15$ years, overall and by selected demographic and socio-economic characteristics. Corresponding odds ratios* and $95 \%$ confidence intervals. Italy, 2017-2019.

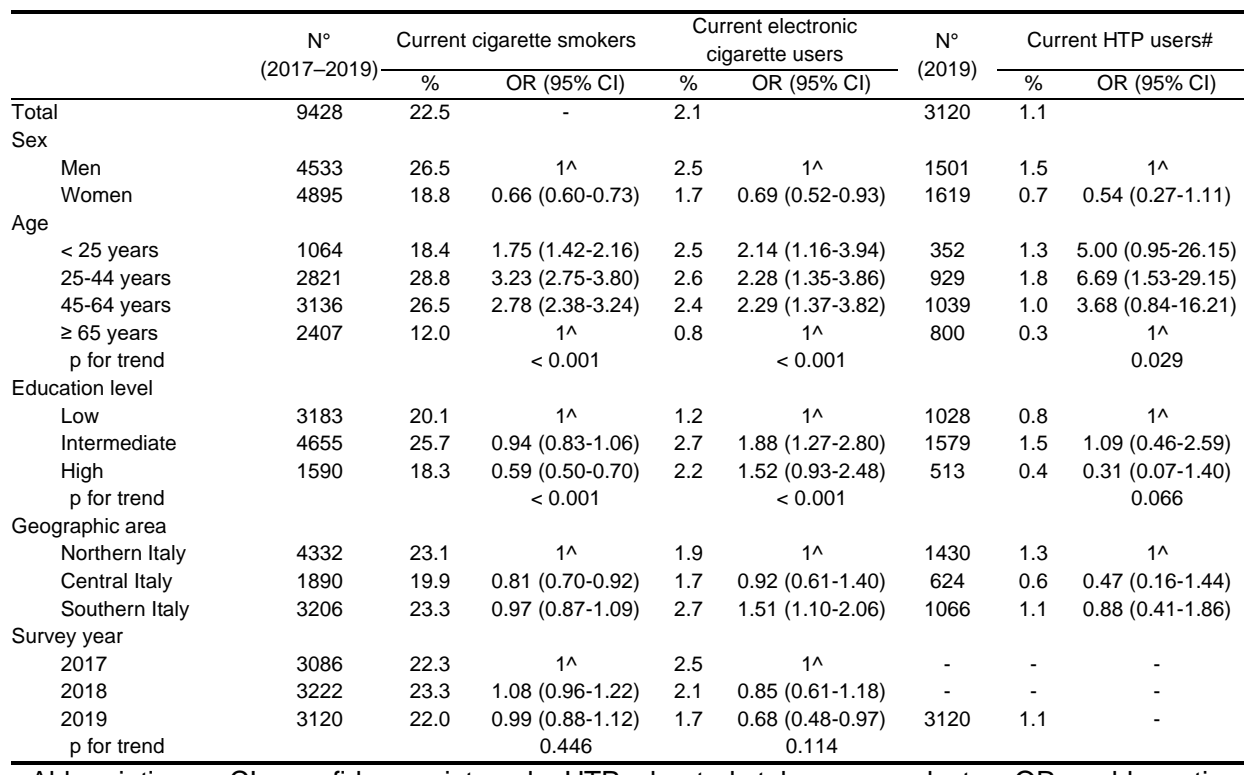

Abbreviations: $\mathrm{Cl}$ : confidence interval; HTP: heated tobacco products; OR: odds ratio * ORs were estimated using unconditional multiple logistic regression models after adjustment for sex, age, level of education, geographic area and survey year. Estimates in bold are statistically significant at 0.05 level. \# Analyses limited to $2019 .{ }^{\circ}$ Total numbers of survey participants overall and in each strata of the population. ^ Reference category. 


\subsection{Discussion}

The inverse trend in smoking prevalence observed in Italy since 1957, particularly favorable between 2001 and 2013, disappeared in the last quinquennium. No acceleration in the decreasing trend was also observed among the young. These findings are in broad agreement with other Italian data from national and international surveillance systems, which observed a declining trend in smoking prevalence until 2012/2013 and a plateau thereafter [34,35]. According to the Eurobarometer, a similar pattern was observed in Spain and Germany but not in other countries that recently enforced strict tobacco control measures, as France and the UK [34]. Our findings empirically confirm our worries of several years ago [18]: in Italy, the availability of novel products (i.e., electronic cigarettes and HTPs) instead of accelerating the process towards a tobacco endgame, provided a detrimental impact on tobacco control. In fact, due to the availability of these novel (tobacco) products, the number of Italians inhaling nicotine (thus using conventional cigarette, electronic cigarettes or HTPs) is increasing for the first time over the last 6 decades. This has also been shown in other studies based on Italian adolescents [36]. One of the reasons why electronic cigarettes and HTPs on tobacco control may have unfavorable effects is that these new products could renormalize nicotine and tobacco product use [1,27-29].

Although we observed that among both electronic cigarette and HTP users the number of subjects decreasing the number of cigarettes smoked per day is higher than the number of subjects increasing their smoking intensity, we also found that those (re)starting smoking after having used the corresponding novel product outnumber those who stop smoking after having used the novel product. Our findings confirm evidences observed in previous Italian studies [19] and emphasize therefore that, from a public health perspective, novel (tobacco) products have an unfavorable net effect.

Whereas the prevalence of electronic cigarette users decreased in 2019, sales of HTPs markedly increased. One possible explanation is that a part of electronic cigarette users might have recently switched to use HTPs. Today HTPs (mainly IQOS of Philip Morris, whereas glo of British American Tobacco has a marginal role in Italy), representing more than $4 \%$ of total tobacco market share, are the third most sold tobacco product after manufactured cigarettes (85\%) and roll your own (RYO) tobacco (7\%) [9].

We also confirm that novel products more frequently attract the young and individuals with higher socio-economic level. In particular, after adjustment for several covariates including age group, the prevalence of cigarette smokers decreased, whereas prevalence of electronic cigarette users increased, with increasing level of education, taken as a proxy of socio-economic status. It is unlikely that these subjects are part of the small subgroup of the population of hardcore smokers who could really benefit from a harm reduction strategy. On 
the contrary, it seems that novel products are attracting a new slice of users, confirming findings observed among Italian adolescents [36].

The present study has some limitations inherent to its cross-sectional design. It will be important to confirm our findings with the conduction of large longitudinal studies allowing researchers to evaluate changes in the smoking habits of electronic cigarette and HTP users. The sample size of each annual survey is relatively limited and may be inadequate to observe annual differences for relatively uncommon habits as current electronic cigarette and HTP use. Strengths of the study include the availability of the same survey tool with the same methodology and standardized questions on tobacco smoking, electronic cigarettes and HTPs, annually used for the last two decades.

\subsubsection{Conclusions}

In conclusion, our findings from Italy show: i) unfavorable trends in adult smoking prevalence concurrently with the spread of novel products, ii) increasing trends of nicotine use for the first time over the last 6 decades, iii) the majority of novel (tobacco) product users are dual users continuing smoking conventional cigarettes; iv) the use of novel products increases - rather than decreases - the likelihood of smoking conventional cigarettes; and v) novel (tobacco) products frequently attract and are used from slices of population who would unlikely benefit of a harm reduction strategy. We therefore confirm what the WHO and most researchers, independent by conflicts of interest, are warning since several years: besides safety issues, electronic cigarettes and HTPs raise public health concerns that let these products be a gateway towards smoking consumption and a threat for tobacco control $[1,18,19,37,38]$. We therefore concur with the WHO to strongly discourage, at least in Italy, the use of electronic cigarettes and HTPs always, also as an alternative to conventional cigarettes [1]. Today, there is no argument to justify the huge fiscal and regulatory benefits these products continue to have, at least in Italy.

\subsection{References}

1. WHO. WHO Report on the Global Tobacco Epidemic 2019: Offer Help to Quit Tobacco Use. Available online: https://www.who.int/teams/healthpromotion/tobacco-control/who-report-on-the-global-tobacco-epidemic2019 (accessed on 31 December 2020).

2. WHO. WHO Framework Convention on Tobacco Control. 2020. Available online: https://www.who.int/fctc/cop/about/en/ (accessed on 31 December 2020). 
3. IARC. Evaluating the Effectiveness of Smoke-free Policies. IARC Handbooks of Cancer Prevention Volume 13. Available online: https://publications.iarc.fr/Book-And-Report-Series/larc-Handbooks-OfCancer-Prevention/Evaluating-The-Effectiveness-Of-Smoke-free-Policies2009 (accessed on 31 December 2020).

4. Gallus, S.; Zuccaro, P.; Colombo, P.; Apolone, G.; Pacifici, R.; Garattini, S.; La Vecchia, C. Effects of new smoking regulations in Italy. Ann. Oncol. 2006, 17, 346-347.

5. Tramacere, I.; Gallus, S.; Fernandez, E.; Zuccaro, P.; Colombo, P.; La Vecchia, C. Medium-term effects of Italian smoke-free legislation: Findings from four annual population-based surveys. J. Epidemiol. Community Health 2009, 63, 559-562.

6. GBD. Global burden of 87 risk factors in 204 countries and territories, 1990 2019: A systematic analysis for the Global Burden of Disease Study 2019. Lancet 2020, 396, 1223-1249.

7. Gallus, S.; Lugo, A.; Colombo, P.; Pacifici, R.; La Vecchia, C. Smoking prevalence in Italy 2011 and 2012, with a focus on hand-rolled cigarettes. Prev. Med. 2013, 56, 314-318.

8. Lugo, A.; Zuccaro, P.; Pacifici, R.; Gorini, G.; Colombo, P.; La Vecchia, C.; Gallus, S. Smoking in Italy in 2015-2016: Prevalence, trends, roll-your-own cigarettes, and attitudes towards incoming regulations. Tumori 2017, 103, 353-359.

9. Liu, X.; Lugo, A.; Spizzichino, L.; Tabuchi, T.; Gorini, G.; Gallus, S. HeatNot-Burn Tobacco Products Are Getting Hot in Italy. J. Epidemiol. 2018, 28, 274-275.

10. WHO. Electronic nicotine and non-nicotine delivery systems. A brief. Available online:

https://www.euro.who.int/_data/assets/pdf_file/0009/443673/Electronicnicotine-and-non-nicotine-delivery-systems-brief-eng.pdf (accessed on 9 February 2021).

11. Eurobarometer. Attitudes of Europeans towards tobacco and electronic cigarettes. Special Eurobarometer 506, 2021. Available online: https://ec.europa.eu/commfrontoffice/publicopinion/index.cfm/ResultDoc/do wnload/DocumentKy/91136 (accessed on 15 February 2021).

12. Stoklosa, M.; Cahn, Z.; Liber, A.; Nargis, N.; Drope, J. Effect of IQOS introduction on cigarette sales: Evidence of decline and replacement. Tob. Control. 2019, doi:10.1136/tobaccocontrol-2019-054998.

13. WHO FCTC. Conference of the Parties to the WHO Framework Convention on Tobacco Control. FCTC/COP8(22). Novel and emerging tobacco products. Available online: https://www.who.int/fctc/cop/sessions/cop8/decisions/en/ (accessed on 9 February 2021). 
14. Amalia, B.; Fu, M.; Feliu, A.; Tigova, O.; Fayokun, R.; Mauer-Stender, K.; Fernandez, E. Regulation of electronic cigarette use in public and private areas in 48 countries within the WHO European Region: A survey to incountry informants. J. Epidemiol. 2020, 10.2188/jea.JE20200332.

15. Bhalerao, A.; Sivandzade, F.; Archie, S.R.; Cucullo, L. Public Health Policies on E-Cigarettes. Curr. Cardiol. Rep. 2019, 21, 111.

16. Pepper, J.K.; Ribisl, K.M.; Brewer, N.T. Adolescents' interest in trying flavoured e-cigarettes. Tob. Control. 2016, 25, ii62-ii66.

17. Villanti, A.C.; Johnson, A.L.; Ambrose, B.K.; Cummings, K.M.; Stanton, C.A.; Rose, S.W.; Feirman, S.P.; Tworek, C.; Glasser, A.M.; Pearson, J.L.; et al. Flavored Tobacco Product Use in Youth and Adults: Findings From the First Wave of the PATH Study (2013-2014). Am. J. Prev. Med. 2017, 53, 139151.

18. Gallus, S.; Lugo, A.; Pacifici, R.; Pichini, S.; Colombo, P.; Garattini, S.; La Vecchia, C. E-cigarette awareness, use, and harm perceptions in Italy: A national representative survey. Nicotine Tob. Res. 2014, 16, 1541-1548.

19. Liu, X.; Lugo, A.; Davoli, E.; Gorini, G.; Pacifici, R.; Fernandez, E.; Gallus, S. Electronic cigarettes in Italy: A tool for harm reduction or a gateway to smoking tobacco? Tob. Control. 2020, 29, 148-152.

20. Ho, L.L.K.; Li, W.H.C.; Cheung, A.T.; Xia, W.; Lam, T.H. Awareness and Use of Heated Tobacco Products among Youth Smokers in Hong Kong: A CrossSectional Study. Int. J. Environ. Res. Public Health 2020, 17. doi: 10.3390/ijerph17228575.

21. Liu, X.; Lugo, A.; Spizzichino, L.; Tabuchi, T.; Pacifici, R.; Gallus, S. Heatnot-burn tobacco products: Concerns from the Italian experience. Tob. Control. 2019, 28, 113-114.

22. Berry, K.M.; Fetterman, J.L.; Benjamin, E.J.; Bhatnagar, A.; BarringtonTrimis, J.L.; Leventhal, A.M.; Stokes, A. Association of Electronic Cigarette Use With Subsequent Initiation of Tobacco Cigarettes in US Youths. JAMA Netw. Open 2019, 2, e187794.

23. Chaffee, B.W.; Watkins, S.L.; Glantz, S.A. Electronic Cigarette Use and Progression From Experimentation to Established Smoking. Pediatrics 2018, 141., page number, doi: 10.1542/peds.2017-3594.

24. Barnett, T.E.; Soule, E.K.; Forrest, J.R.; Porter, L.; Tomar, S.L. Adolescent Electronic Cigarette Use: Associations With Conventional Cigarette and Hookah Smoking. Am. J. Prev. Med. 2015, 49, 199-206.

25. Soneji, S.; Sargent, J.; Tanski, S. Multiple tobacco product use among US adolescents and young adults. Tob. Control 2016, 25, 174-180.

26. Gallus, S.; Borroni, E.; Liu, X.; Carrozzi, L.; Dalla Pietra, G.; Eslami Varzaneh, S.; Harari, S.; Inciso, G.; Martucci, P.; Papale, M.; et al. Electronic cigarette use among Italian smokers: Patterns, settings, and adverse events. Tumori 2020, doi:10.1177/0300891620915784. 
27. Cataldo, J.K.; Petersen, A.B.; Hunter, M.; Wang, J.; Sheon, N. E-cigarette marketing and older smokers: Road to renormalization. Am. J. Health Behav. 2015, 39, 361-371.

28. Singh, S.; Windle, S.B.; Filion, K.B.; Thombs, B.D.; O'Loughlin, J.L.; Grad, R.; Eisenberg, M.J. E-cigarettes and youth: Patterns of use, potential harms, and recommendations. Prev. Med. 2020, 133, 106009.

29. Walley, S.C.; Jenssen, B.P. Electronic Nicotine Delivery Systems. Pediatrics 2015, 136, 1018-1026.

30. Gallus, S.; Lugo, A.; Liu, X.; Borroni, E.; Clancy, L.; Gorini, G.; Lopez, M.J.; Odone, A.; Przewozniak, K.; Tigova, O.; et al. Use and awareness of heated tobacco products in Europe. J. Epidemiol. 2020, (in press).

31. Ferkol, T.W.; Farber, H.J.; La Grutta, S.; Leone, F.T.; Marshall, H.M.; Neptune, E.; Pisinger, C.; Vanker, A.; Wisotzky, M.; Zabert, G.E.; et al. Electronic cigarette use in youths: A position statement of the Forum of International Respiratory Societies. Eur. Respir J. 2018, 51, page number, doi: 10.1183/13993003.00278-2018.

32. Ford, E.W.; Chan, K.S.; Parikh, M.; Lowe, K.B.; Huerta, T.R. E-cigarette and hookah adoption patterns: Is the harm reduction theory just so much smoke? Addict. Behav. Rep. 2020, 11, 100246.

33. National Cancer Institute. Joinpoint Regression Program, Version 4.8. Available online: https://surveillance.cancer.gov/joinpoint/ (accessed on 12 Junuary 2021).

34. Eurobarometer. Attitudes of Europeans towards tobacco and electronic cigarettes. Special Eurobarometer 458, 2017. Available online: https://ec.europa.eu/commfrontoffice/publicopinion/index.cfm/ResultDoc/do wnload/DocumentKy/79003 (accessed on 15 February 2021)

35. TobaccoEndgame. Andamento della frequenza di fumatori. Available online: https://tobaccoendgame.it/dati/andamento-della-frequenza-di-fumatori/ (accessed on 10 Febraury 2021).

36. Cerrai, S.; Potente, R.; Gorini, G.; Gallus, S.; Molinaro, S. What is the face of new nicotine users? 2012-2018 e-cigarettes and tobacco use among young students in Italy. Int. J. Drug Policy 2020, 86, 102941.

37. Chapman, S. Should electronic cigarettes be as freely available as tobacco cigarettes? No. BMJ 2013, 346, f3840.

38. Chapman, S.; Daube, M.; Maziak, W. Should e-cigarette use be permitted in smoke-free public places? No. Tob. Control. 2017, 26, e3-e4. 


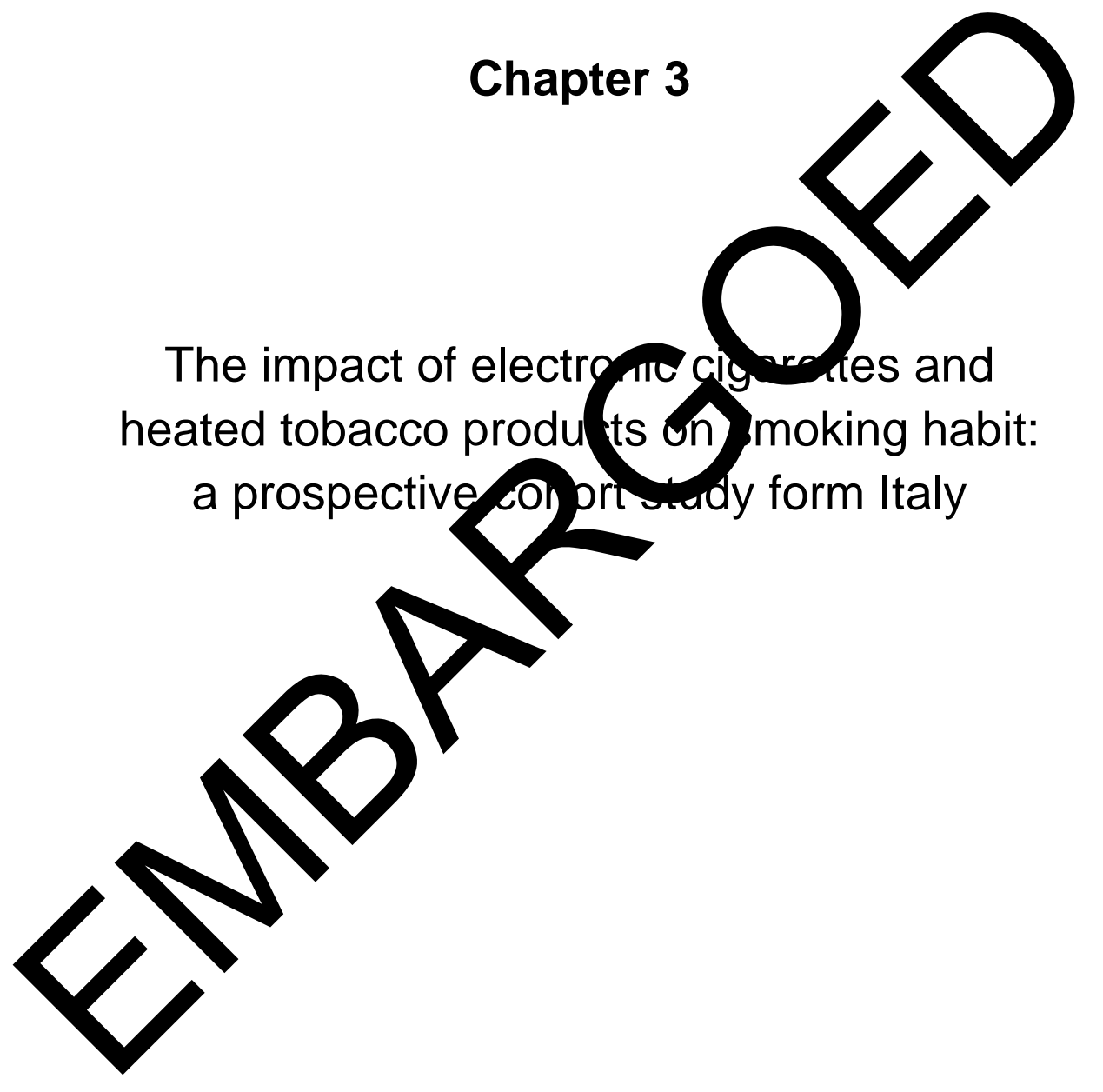




\section{Chapter 4}

Use of electronic cigarettes and heated tobacco products during the Covid-19 pandemic 


\subsection{Abstract}

Only a few studies investigated changes in electronic cigarette (e-cigarette) and heated tobacco product (HTP) use during pandemic restrictions. We conducted a web-based cross-sectional study of a representative sample of 6,003 Italian adults during the strictest phase of the Covid-19 lockdown (April-May 2020). Participants were asked to report changes in e-cigarette and HTP use compared to before the pandemic. E-cigarette users increased from $8.1 \%$ to $9.1 \%$ and HTP users from $4.0 \%$ to $4.5 \%$. Among e-cigarette non-users before lockdown, $1.8 \%$ started using e-cigarettes during lockdown. New users were more frequently younger ( $p$ for trend 0.001 ), men (odds ratio, OR 1.56; 95\% confidence interval, $\mathrm{Cl}: 1.03-2.34$ ), cannabis users (OR 2.35; 95\% Cl: 1.33-4.13), gamblers (OR 3.34; 95\% Cl: 2.18-5.11) and individuals with anxiety symptoms (OR $1.58 ; 95 \% \mathrm{Cl}$ : 1.00-2.52). $1.0 \%$ of HTP non-users started using it during lockdown. New users were less frequently current than never cigarette smokers (OR $0.19 ; 95 \% \mathrm{Cl}$ : 0.06-0.61) and more frequently gamblers (OR 2.23; $95 \% \mathrm{Cl}: 1.22-4.07$ ). Ecigarettes and HTPs played little role as smoking cessation tools for hardcore smokers but rather provided opportunities for young never smokers to engage in socially acceptable activities, perhaps reflecting the obstacles they faced in obtaining other addictive substances during confinement.

Keywords: novel tobacco products; electronic cigarette; heated tobacco product; heat-not-burn tobacco; IQOS; Covid-19; coronavirus; lockdown 


\subsection{Introduction}

Italy was the first European country to experience the full force of the pandemic. On 9 March 2020 its government imposed a nationwide "lockdown" to interrupt transmission of the coronavirus [1]: most workplaces and public places, including shops, bars and restaurants, closed and people were forbidden to leave their homes except to obtain basic necessities and healthcare [2]. In the three weeks prior to 4 May 2020, the regime intensified, suddenly changing the lives of millions of Italians [2]. Yet many shops selling tobacco and electronic cigarettes (ecigarette) were exempt from these restrictions, following normal working hours even during the strictest phase of the lockdown. We now know that Covid-19 had a huge impact on several addictive behaviours among Italian adults. Smoking intensity increased substantially [3]. with commentators invoking the impact of confinement on mental health $[4,5]$.

Few studies have investigated the impact of the Covid-19 lockdown on the use of e-cigarettes and even fewer on the use of heated tobacco products (HTP). These studies - mainly small online surveys based on convenience samples found a major impact on e-cigarette use, with $50-60 \%$ of vapers reporting changes in their use (either starting or quitting or increasing or decreasing consumption) [6-10]. To our knowledge, only two studies addressed the change in HTP use associated with the lockdown [11, 12].

In Italy e-cigarette use has grown since 2010, and HTPs since 2016. The prevalence of regular e-cigarette use rose from $0.4 \%$ in $2014-2015$ to $1.8 \%$ in 2016-2017 but fell back to 1.3\% in 2018 [13]. The market share of HTP among all legal tobacco products increased from $0.01 \%$ in 2015 to $0.67 \%$ in 2017 and to 4.33\% in 2019 [14]. An Italian web-based survey conducted in April 2020 (i.e., during the lockdown) on a convenience sample of 1825 subjects, found that both exclusive e-cigarette users and exclusive HTP users slightly increased their consumption during the lockdown [11].

To our knowledge, no study has investigated the effect of the Covid-19 lockdown on novel (tobacco) product use in adults using representative samples of the general population. To investigate this issue in Italy, we analysed data from a large representative cross-sectional study conducted within the LOckdown and lifeSTyles IN ITALY project [3, 15]. Importantly, given evidence of the influence of industry links on research on this topic [16], there is no conflict of interest in this study.

\subsection{Methods}

We conducted a web-based cross-sectional study with a large representative sample of Italian adults aged 18-74 years (approximately $73 \%$ of the population). 
The interview was carried out during the strictest phase of the lockdown (between 27 April and 3 May 2020). Details on sampling methods are reported elsewhere.[3, 24, 26] Briefly, the survey was run by Doxa, the Italian branch of the Worldwide Independent Network/Gallup International Association. Subjects were randomly selected among the more than 140,000 Doxa online panel participants. A quota sampling method by age, sex and region (Nomenclature of Territorial Units for Statistics, NUTS, 2) was applied. In all, 6003 people (2962 men and 3041 women) participated.

The ethics committee $(E C)$ of the Fondazione IRCCS Istituto Neurologico Carlo Besta approved the study protocol (File number 71-73, April 2020). All participants provided informed consent to participate. All methods were performed in accordance with the relevant guidelines and regulations of Scientific Reports and of Nature Research journals.

Recruited subjects completed an online self-administered questionnaire, giving information on demographic and socio-economic characteristics, such as level of education, selected addictive behaviours, including smoking conventional cigarettes,[3] cannabis use, alcohol use disorder according to the AUDIT-C scale [29], and gambling [26]. Selected mental health indicators were obtained using validated scales, including anxiety levels (Generalized Anxiety Disorder scale, GAD-2) [30], and depression (Patient Health Questionnaire, PHQ-2) [31]. Addictive behaviours and mental health indicators were reported before and during the lockdown.

All participants were asked to report their use of e-cigarettes and HTPs both before the Covid pandemic (reference time: early February 2020) and at the time of interview.[24] E-cigarette use was assessed by asking subjects if they had ever tried, used in the past, occasionally used or regularly (i.e. daily) used electronic cigarettes. HTP use was determined by asking whether they knew about HTPs, if they had ever tried, used in the past, used occasionally or regularly (i.e. daily) HTPs, such as IQOS by Philip Morris or Glo by British American Tobacco.

We used official legal sales figures for HTPs and other tobacco products sold in Italy in 2020 to compute the contemporary market share of HTP tobacco. These data were obtained from the Italian Ministry of Finance [14, 32]. Official sales data do not include electronic cigarettes since in Italy they are not classified as tobacco products.

\subsubsection{Statistical analysis}

The odds ratios $(\mathrm{OR})$ and corresponding 95\% confidence intervals $(\mathrm{Cl})$ for subjects starting vs. those who did not start using e-cigarettes [or HTPs] during lockdown among e-cigarette [or HTP] non-users before lockdown were estimated using multiple logistic regression models after adjustment for sex, age group, level of education, and geographic area. The independent variables (potential 
determinants of starting novel product use), including addictive behaviours and measures of mental health, referred to the period before lockdown (in early February 2020).

A statistical weight was applied to all the analyses to achieve representativeness of the national sample in terms of sex, age, socio-economic status, and geographic area. All analyses were done using SAS 9.4 (Cary, North Carolina, USA).

\subsection{Results}

Of the sample of 6003 participants, 266 (4.4\%) used e-cigarettes occasionally and 220 (3.7\%) regularly before lockdown (early February 2020). The corresponding estimates during lockdown were 279 (4.7\%) for occasional and $266(4.4 \%)$ for regular use. Therefore, current e-cigarette users increased from $8.1 \%$ before lockdown to $9.1 \%$ during lockdown, making the relative increase $12.1 \%$. Regular users increased by $20.9 \%$. Similarly, $153(2.6 \%)$ used HTPs occasionally and 87 (1.5\%) used it regularly before lockdown and 147 (2.4\%) used these products occasionally and $121(2.0 \%)$ regularly during the lockdown. Current HTP users were $4.0 \%$ before and $4.5 \%$ during lockdown, with an $11.7 \%$ relative increase. Regular HTP users increased by $39.1 \%$.

The apparent increase in HTP use in Italy is supported by official sales figures: compared to 2019, HTP sales in 2020 increased by $65 \%$. In 2020, the market share of HTPs $(7.5 \%)$ exceeded that of roll-your-own tobacco $(7.0 \%)$, thus becoming the second most commonly sold tobacco product after conventional cigarettes (market share $81.5 \%$ ).

Of 5516 e-cigarette non-users before lockdown, 98 (1.8\%) started using ecigarettes during lockdown (Table 1). These were more frequently men but initiation was less likely with increasing age ( $p$ for trend=0.001). New e-cigarette users during lockdown were more frequently those who were cannabis users before the lockdown, gamblers, and those reporting anxiety symptoms. Of 5763 HTP non-users before lockdown, 55 (1.0\%) started using them. The probability of initiation increased with level of education ( $p$ for trend 0.005 ), was less among those who smoked just before lockdown (compared to never smokers) and greater among gamblers. 
Table 1. Distribution of non-users of electronic cigarettes (e-cig) and heated tobacco products (HTP) according to starting their use during the Covid-19 lockdown, by selected demographic and socio-economic features, addictive behaviours and other individual characteristics. Corresponding odds ratios* $(\mathrm{OR})$ and $95 \%$ confidence intervals (Cl). Italy, 2020.

\begin{tabular}{|c|c|c|c|c|c|c|}
\hline \multirow{2}{*}{$\begin{array}{l}\text { Characteristics } \\
\text { (pre-lockdown) }\end{array}$} & \multirow{2}{*}{$\begin{array}{l}\text { E-cig } \\
\text { non- } \\
\text { users }\end{array}$} & \multicolumn{2}{|c|}{$\begin{array}{l}\text { People who start using } \\
\text { e-cig during lockdown }\end{array}$} & \multirow{2}{*}{$\begin{array}{l}\text { HTP } \\
\text { non- } \\
\text { users }\end{array}$} & \multicolumn{2}{|c|}{$\begin{array}{l}\text { People who start using } \\
\text { HTP during lockdown }\end{array}$} \\
\hline & & $\%$ & $\mathrm{OR}(95 \% \mathrm{Cl})$ & & $\%$ & OR $(95 \% \mathrm{Cl})$ \\
\hline Total & 5516 & 1.8 & & 5763 & 1.0 & \\
\hline \multicolumn{7}{|l|}{ Sex } \\
\hline Women & 2797 & 1.4 & $1.00^{\circ}$ & 2925 & 0.9 & $1.00^{\circ}$ \\
\hline Men & 2720 & 2.2 & $1.56(1.03-2.34)$ & 2838 & 1.0 & $1.15(0.67-1.97)$ \\
\hline \multicolumn{7}{|l|}{ Aqe group } \\
\hline $18-34$ & 1451 & 2.8 & $1.00^{\circ}$ & 1493 & 1.3 & $1.00^{\circ}$ \\
\hline $35-54$ & 2230 & 1.7 & $0.64(0.41-1.00)$ & 2342 & 1.0 & $0.77(0.42-1.42)$ \\
\hline $55-74$ & 1836 & 1.1 & $0.39(0.23-0.68)$ & 1928 & 0.6 & $0.49(0.23-1.02)$ \\
\hline$P$ for trend & & & 0.001 & & & 0.056 \\
\hline \multicolumn{7}{|l|}{ Level of education } \\
\hline Low & 850 & 1.4 & $1.00^{\circ}$ & 886 & 0.5 & $1.00^{\circ}$ \\
\hline Intermediate & 2803 & 1.8 & $1.22(0.65-2.30)$ & 2922 & 0.7 & $1.25(0.46-3.45)$ \\
\hline High & 1864 & 1.9 & $1.22(0.63-2.37)$ & 1954 & 1.5 & $2.73(1.03-7.30)$ \\
\hline$P$ for trend & & & 0.628 & & & 0.005 \\
\hline \multicolumn{7}{|l|}{ Smoking status } \\
\hline Never & 3758 & 2.0 & $1.00^{\circ}$ & 3887 & 1.2 & $1.00^{\circ}$ \\
\hline Former & 477 & 2.1 & $1.25(0.64-2.47)$ & 537 & 0.8 & $0.74(0.27-2.07)$ \\
\hline Current & 1281 & 1.1 & $0.59(0.33-1.05)$ & 1338 & 0.2 & $0.19(0.06-0.61)$ \\
\hline \multicolumn{7}{|l|}{ Alcohol (AUDIT-C) } \\
\hline Not at risk & 4087 & 1.6 & $1.00^{\circ}$ & 4257 & 0.8 & $1.00^{\circ}$ \\
\hline At risk & 1430 & 2.3 & $1.49(0.98-2.28)$ & 1506 & 1.2 & $1.45(0.82-2.55)$ \\
\hline \multicolumn{7}{|l|}{ Cannabis use } \\
\hline No & 5162 & 1.6 & $1.00^{\circ}$ & 5376 & 0.9 & $1.00^{\circ}$ \\
\hline Yes & 355 & 4.4 & $2.35(1.33-4.13)$ & 386 & 2.0 & $2.04(0.93-4.50)$ \\
\hline \multicolumn{7}{|l|}{ Gambling } \\
\hline No & 4647 & 1.3 & $1.00^{\circ}$ & 4847 & 0.8 & 1.00 \\
\hline Yes & 870 & 4.6 & $3.34(2.18-5.11)$ & 916 & 1.8 & $2.23(1.22-4.07)$ \\
\hline \multicolumn{7}{|l|}{$\begin{array}{l}\text { Anxiety symptoms } \\
\text { (GAD-2) }\end{array}$} \\
\hline No (score <3) & 4527 & 1.6 & $1.00^{\circ}$ & 4720 & 0.8 & $1.00^{\circ}$ \\
\hline Yes (score $\geq 3$ ) & 990 & 2.6 & $1.58(1.00-2.52)$ & 1043 & 1.5 & $1.78(0.98-3.25)$ \\
\hline \multicolumn{7}{|l|}{$\begin{array}{l}\text { Depressive } \\
\text { symptoms (PHQ-2) }\end{array}$} \\
\hline No (score <3) & 4765 & 1.7 & $1.00^{\circ}$ & 4965 & 0.9 & $1.00^{\circ}$ \\
\hline Yes (score $\geq 3$ ) & 751 & 2.3 & $1.35(0.79-2.28)$ & 798 & 1.1 & $1.16(0.55-2.43)$ \\
\hline
\end{tabular}




\subsection{Discussion}

Our cross-sectional survey, based on a large representative sample of Italian adults, found that the prevalence of regular e-cigarette and HTP users rose following imposition of the first lockdown, by roughly $20 \%$ and $40 \%$, respectively. A non-negligible number of Italian adults started using these novel (tobacco) products during the stay-at-home order. These were more frequently young adults, men, and those with certain addictive behaviours and mental health symptoms before lockdown.

Our findings are in line with another Italian survey among 1825 adults, which showed a slight increase in daily consumption among vapers during the lockdown [11], although it should be borne in mind that the survey, which did not claim to be representative, was presented on the website of an organisation that has long promoted e-cigarettes, while one of the authors has close links to the tobacco industry [17]. Our findings are also consistent with evidence on adults from other countries - mainly from the USA and the UK. In general, the majority of adolescents or young adults reported less e-cigarette use during the stay-athome order $[9,18-20]$ whereas the majority of older adults reported moderate to large increases [8, 10, 21, 22].

New e-cigarette users were not more frequently smokers of conventional cigarettes, and new HTP users were even more often never than current smokers. Once addicted to nicotine, these subjects often switch to conventional cigarette smoking, as shown in the few available longitudinal studies [23-25].

Conversely, new users were more frequently people - mostly young men - with specific addictive behaviours that were inaccessible in Italy during the strictest phases of the lockdown, such as some types of gambling [26], or that were unlikely to be acceptable to family members at home, such as cannabis use. This suggests that young adults, unable to satisfy certain addictions during the lockdown, might have attempted to compensate with these novel (tobacco) products. Our findings also point to the worrying link between cannabis and ecigarette use reported in at least one study on US adolescents [27].

New users were also more likely to report anxiety symptoms, and might have been encouraged to engage in e-cigarette use by stress and tension accentuated by the pandemic and lockdown [4]. In fact, an observational study showed that Twitter users who tweeted about e-cigarettes had more concerns than others about the pandemic [28].

This first representative survey shows that in Italy, novel (tobacco) products rather than acting as smoking cessation tools for hardcore smokers, served more as socially acceptable opportunities for young never smokers, with symptoms of anxiety, who were unable to engage in other addictions during the stay-at-home order. 


\subsection{References}

1. Ministri PdCd. Dpcm 9 March 2020 Avaliable at:http://www.governo.it/it/articolo/firmato-il-dpcm-9-marzo-2020/14276 [Accessed:12/10/2020]. 2020.

2. Paterlini M. On the front lines of coronavirus: the Italian response to covid19. BMJ 2020; 368: $\mathrm{m} 1065$.

3. Carreras G, Lugo A, Stival C et al. Impact of COVID-19 lockdown on smoking consumption in a large representative sample of Italian adults. Tob Control 2021.

4. Amerio A, Lugo A, Stival C et al. COVID-19 lockdown impact on mental health in a large representative sample of Italian adults. J Affect Disord 2021; 292: 398-404.

5. Brooks SK, Webster RK, Smith LE et al. The psychological impact of quarantine and how to reduce it: rapid review of the evidence. Lancet 2020; 395: 912-920.

6. Gaiha SM, Lempert LK, Halpern-Felsher B. Underage Youth and Young Adult e-Cigarette Use and Access Before and During the Coronavirus Disease 2019 Pandemic. JAMA Netw Open 2020; 3: e2027572.

7. Gonzalez M, Epperson AE, Halpern-Felsher B et al. Smokers Are More Likely to Smoke More after the COVID-19 California Lockdown Order. Int J Environ Res Public Health 2021; 18.

8. Klemperer EM, West JC, Peasley-Miklus C, Villanti AC. Change in Tobacco and Electronic Cigarette Use and Motivation to Quit in Response to COVID19. Nicotine Tob Res 2020; 22: 1662-1663.

9. Romm KF, Patterson B, Crawford ND et al. Changes in young adult substance use during COVID-19 as a function of ACEs, depression, prior substance use and resilience. Subst Abus 2021; 1-24.

10. Kale D, Herbec A, Perski $O$ et al. Associations between vaping and Covid19: Cross-sectional findings from the HEBECO study. Drug Alcohol Depend 2021; 221: 108590.

11. Caponnetto $P$, Inguscio L, Saitta $C$ et al. Smoking behavior and psychological dynamics during COVID-19 social distancing and stay-athome policies: A survey. Health Psychol Res 2020; 8: 9124.

12. Koyama $S$, Tabuchi T, Okawa $S$ et al. Changes in Smoking Behavior Since the Declaration of the COVID-19 State of Emergency in Japan: A Crosssectional Study From the Osaka Health App. J Epidemiol 2021; 31: 378-386.

13. Liu X, Lugo A, Davoli $E$ et al. Electronic cigarettes in Italy: a tool for harm reduction or a gateway to smoking tobacco? Tob Control 2020; 29: 148-152.

14. Gallus S, Borroni E, Odone A et al. The Role of Novel (Tobacco) Products on Tobacco Control in Italy. Int J Environ Res Public Health 2021; 18. 
15. Odone A, Lugo A, Amerio $A$ et al. COVID-19 lockdown impact on lifestyle habits of Italian adults. Acta Biomed 2020; 91: 87-89.

16. Pisinger C, Godtfredsen N, Bender AM. A conflict of interest is strongly associated with tobacco industry-favourable results, indicating no harm of ecigarettes. Prev Med 2019; 119: 124-131.

17. Tobacco Tactics. Ricardo Polosa. In. 2021.

18. Thorisdottir IE, Asgeirsdottir BB, Kristjansson AL et al. Depressive symptoms, mental wellbeing, and substance use among adolescents before and during the COVID-19 pandemic in Iceland: a longitudinal, populationbased study. Lancet Psychiatry 2021.

19. Kreslake JM, Simard BJ, O'Connor KM et al. E-Cigarette Use Among Youths and Young Adults During the COVID-19 Pandemic: United States, 2020. Am J Public Health 2021; 111: 1132-1140.

20. Hopkins DB, Al-Hamdani M. Young Canadian e-Cigarette Users and the COVID-19 Pandemic: Examining Vaping Behaviors by Pandemic Onset and Gender. Front Public Health 2020; 8: 620748.

21. BinDhim NF, Althumiri NA, Basyouni MH et al. Exploring the Impact of COVID-19 Response on Population Health in Saudi Arabia: Results from the "Sharik" Health Indicators Surveillance System during 2020. Int J Environ Res Public Health 2021; 18.

22. Yach D. Tobacco Use Patterns in Five Countries During the COVID-19 Lockdown. Nicotine Tob Res 2020; 22: 1671-1672.

23. Tabuchi T, Gallus S, Shinozaki T et al. Heat-not-burn tobacco product use in Japan: its prevalence, predictors and perceived symptoms from exposure to secondhand heat-not-burn tobacco aerosol. Tob Control 2018; 27: e25e33.

24. Gallus S, Stival C, Carreras G et al. The impact of electronic cigarette and heated tobacco product on smoking habit: a prospective cohort study form Italy [submitted]. Tobacco Control 2021.

25. McMillen R, Klein JD, Wilson $\mathrm{K}$ et al. E-Cigarette Use and Future Cigarette Initiation Among Never Smokers and Relapse Among Former Smokers in the PATH Study. Public Health Rep 2019; 134: 528-536.

26. Lugo A, Stival C, Paroni L et al. The impact of COVID-19 lockdown on gambling habit: a representative cross-sectional study from Italy [in press]. Journal of Behavioural Addiction 2021.

27. Tai H, Swartz MD, Marsden D, Perry CL. The Future of Substance Abuse Now: Relationships among Adolescent Use of Vaping Devices, Marijuana, and Synthetic Cannabinoids. Subst Use Misuse 2021; 56: 192-204.

28. Gao Y, Xie Z, Li D. Electronic Cigarette Users' Perspective on the COVID19 Pandemic: Observational Study Using Twitter Data. JMIR Public Health Surveill 2021; 7 : e24859. 
29. Saunders JB, Aasland OG, Babor TF et al. Development of the Alcohol Use Disorders Identification Test (AUDIT): WHO Collaborative Project on Early Detection of Persons with Harmful Alcohol Consumption--II. Addiction 1993; 88: 791-804.

30. Spitzer RL, Kroenke K, Williams JB. Validation and utility of a self-report version of PRIME-MD: the PHQ primary care study. Primary Care Evaluation of Mental Disorders. Patient Health Questionnaire. JAMA 1999; 282: 17371744.

31. Kroenke K, Spitzer RL, Williams JB. The Patient Health Questionnaire-2: validity of a two-item depression screener. Med Care 2003; 41: 1284-1292.

32. Liu X, Lugo A, Spizzichino L et al. Heat-Not-Burn Tobacco Products Are Getting Hot in Italy. J Epidemiol 2018; 28: 274-275. 


\section{Chapter 5}

Electronic cigarette use among Italian smokers: patterns, settings and adverse events 


\subsection{Abstract}

Objective: Information is scanty on the patterns and settings of electronic cigarette use and on its possible adverse events. To fill knowledge gap on these issues, we conducted a survey among ever smokers attending smoking cessation services (SCS) in Italy.

Methods: In 2016-2018 we enrolled 395 ever smokers aged $\geq 18$ years who were current or former electronic cigarette users, in 12 SCSs from northern, central and southern Italy.

Results: In all, $12.4 \%$ of ever smokers were regular, $9.4 \%$ occasional, and $78.2 \%$ past users of electronic cigarettes. Of all users, 93.8\% consumed electronic cigarettes with nicotine, $95.9 \%$ used refillable devices, $76.6 \%$ purchased electronic cigarette device or liquid in vape shops. The mean duration of use was 3.7 months and the mean number of puffs per day was 86 . Among users, $71.5 \%$ used electronic cigarettes in at least one smoke-free indoor environment, $53.7 \%$ in workplaces, $49.5 \%$ in restaurants and bars, $33.5 \%$ in train/metro stations or airports, and $18.4 \%$ in public transport. The use of electronic cigarettes in smokefree environments significantly decreased with age and increased with duration of use and nicotine dependence. In our sample, $47.1 \%$ reported at least one adverse event attributable to electronic cigarette use, 19.5\% dry cough, $12.0 \%$ dry mouth, $7.6 \%$ throat or mouth irritation, and $6.8 \%$ sore throat.

Conclusions: In Italy, most conventional cigarette smokers use electronic cigarettes where smoking conventional cigarettes is prohibited. About half of users reported one or more symptoms attributable to electronic cigarettes, despite the relatively short duration of use.

Keywords: e-cigarettes; adverse events; patterns of use; survey; Italy 


\section{$5.2 \quad$ Introduction}

Electronic cigarettes are electronic devices containing a liquid heated to generate an inhalable vapor, which may contain nicotine [1, 2]. In most high-income countries, electronic cigarettes were introduced into the market around 2010, and since then they have gained popularity worldwide [1, 3, 4]. In Europe, after an initial rapid spread of electronic cigarette [5], its use increased only slightly, with the proportion of adult regular users rising from 1.5\% in 2014 to $1.8 \%$ in 2017 [6]. In Italy, the prevalence of adults who had ever tried electronic cigarettes remained stable around $5 \%$ in 2013-2018 [1, 4], and the number of current regular users is still limited (1.3\% in 2018) [1].

In line with several scientific societies [7, 8], the World Health Organization (WHO) recently warned against the use of electronic cigarette not only for nonsmokers, but also as a smoking cessation strategy at a population level, stating that: i) it is "undoubtedly harmful", ii) there is insufficient evidence to support effectiveness in assisting smokers attempting to quit, and iii) the majority of electronic cigarette users are dual users (i.e., concurrently using electronic cigarettes and conventional cigarettes) [9].

In 2013, the WHO already recommended regulating electronic cigarette use, at least banning them in indoor places where smoking conventional cigarettes is prohibited [10]. Despite this, however, and the fact that the general population strongly supports the recommendation [11, 12], to date (2018), only 14 of the 28 European Union (EU) Member States (MS) have partially regulated its use in smoke-free environments and only 4 EU MSs have banned their use in all places where smoking is not allowed [13].

To our knowledge, only few studies have examined the patterns of use of electronic cigarette in smoke-free environments. These studies concluded that the use of electronic cigarette, particularly by young people, is common in places where smoking is banned [14,15]. Thus dual users do not simply replace some conventional cigarettes with less harmful products, but they presumably add the nicotine intake from electronic cigarettes to that from conventional cigarettes. No studies are available so far from Italy, where electronic cigarette use is prohibited only in schools [13], and no national legislation covers their use in indoor workplaces and other public places such as restaurants and bars, where bans can be set by the owner.

As recently noted by the WHO [9], current scientific evidence suggests that electronic cigarette use is not risk-free, and its harm should not be underestimated [16-18]. Given that the majority of electronic cigarette users are dual users [19-22] - also in Italy - [1] the combined use of these products may increase the dose of nicotine [23] and other harmful and potentially harmful substances, and consequently, their related symptoms [24]. Some studies - although mostly based on small or convenience samples [16] - have reported adverse events 
attributable to electronic cigarette use, including cough, wheeze, dry or irritated oral cavity, and increased heart rate [25-27]. Very recently, the US Centers for Disease Control and Prevention (CDC) is investigating whether 200 cases of severe lung illness, including some deaths, are related to electronic cigarette use [28-30]. Furthermore, explosions and burns caused by electronic cigarette use have been reported recently [31,32].

We conducted an observational study to obtain new data about patterns of use and adverse events in ever smokers and electronic cigarette users.

\subsection{Methods}

\subsubsection{Study population}

Data come from e cross-sectional study conducted from June 2016 to July 2018 on Italian adults ( $\geq 18$ years) attending smoking cessation services (SCS). The survey was coordinated by the Italian Association of Hospital Pulmonologists (AIPO) in collaboration with Mario Negri Institute for Pharmacological Research (IRFMN). Participants were enrolled in 12 SCSs from northern, central and southern Italy: AORNA Cardarelli Hospital (Naples); Hospital of Sassari (Sassari); S. Camillo-Forlanini Hospital (Rome); Ospedali Riuniti of Livorno (Livorno); San Camillo de Lellis Hospital (Rieti); IRCCS-INRCA Hospital (Ancona); Regina Elena Institute IRCCS (Rome); Santa Maria della Misericordia Hospital (Rovigo); ASST Vimercate (Vimercate, Monza Brianza); SS. Antonio and Biagio Hospital (Alessandria); ASL Na 3 (Sanitary District 59; Meta di Sorrento, Naples); University Hospital of Pisa (Pisa).

We obtained approval for the study protocol from the Ethics Committee of the coordinating center (Fondazione IRCCS Istituto Neurologico "Carlo Besta") and from the Ethics Committees of each of the 12 SCSs. Details of the survey were provided to all participants by SCS professionals through a structured information sheet, and all participants signed a consent form.

The present study is based on two different samples of subjects (Supplementary Table 1):

i) a sample of 481 current smokers, consecutively attending the SCS for the first time to obtain support for smoking cessation. This sample included 282 electronic cigarette ever users, 2 heated tobacco products (HTP) users, and 197 electronic cigarette never users;

ii) a convenience sample of 152 ever (i.e. current or former) smokers attending the SCS for other reasons, mostly for a control visit. This sample included 113 electronic cigarette ever users, 10 heated tobacco product users, and 29 electronic cigarette never users. 
Overall, 633 subjects were enrolled in the study. For the present analysis, we excluded HTP users and electronic cigarette never users. We considered therefore 395 current and ex-smokers who had ever used electronic cigarettes. All participants answered the same ad hoc designed questionnaire administered by a SCS professional. A first draft of the survey questionnaire in Italian was developed by researchers from the Mario Negri Insitute, mostly based on previous electronic cigarette use questionnaires [4, 33, 34]. A specific commission of five Italian experts among study partners (SG, AL, SH, PM and AS) was set up to review the questionnaire and produce a second version. This version was used for a pilot study based on five electronic cigarette users to evaluate its comprehensiveness. This pilot study resulted in the final version of the questionnaire. Each SCS could choose among three different survey modes: paper questionnaire, electronic online (through SurveyMonkey) or electronic offline (in Excel). Four SCSs used the paper, five the electronic online and three the electronic offline questionnaire.

\subsubsection{Measures}

Participants provided information on socio-demographic characteristics, including sex, age, level of education, and cigarette smoking habits. Ever smokers were participants who smoked at the time of the survey or had smoked in the past. Current smokers were smokers who smoked at the time of the survey, while former smokers were those who had successfully quit. They were asked to specify their age at starting smoking, the number of cigarettes smoked per day and smoking duration. Current smokers attending the SCS to obtain support for smoking cessation were asked about the level of nicotine dependence rated by using the Fagerström Test for Nicotine Dependence (FTND) [35, 36]. We also asked all participants the following question: "Do you use electronic cigarette, even only occasionally?" The answer options were: "Yes, occasionally (less than five days in the last 30 days)" (these subjects were then defined as occasional users); "Yes, usually (five or more days in the last 30 days)" (regular users); "I used it in the past (not in the last 30 days)" (past users); "No" (never users). Electronic cigarette ever users were defined as participants who used electronic cigarettes at the time of the survey (either occasionally or regularly) or in the past. They were then asked about the duration of use of electronic cigarette, number of puffs per day, place of purchase, type of electronic cigarette (refillable, box mod or disposable), and type of liquid (with or without nicotine) and number of different liquids used at the same time, and how the electronic cigarette was used: short sessions described as similar to conventional smoking (i.e. approximately ten puffs in five minutes), while a long session involved one or two puffs approximately every five minutes for one hour. Subjects were divided into three 
groups of nicotine dependence: low-intermediate (FTND $<6$ ), high (6-7) and very high dependence ( $\geq 8)$ [35].

To investigate adverse events (i.e., acute or irritative symptoms) related to electronic cigarette use, we asked participants if they had ever had any of the following symptoms during or after the use of the electronic cigarette: dry cough, dry mouth, throat or mouth irritation, sore throat, shortness of breath, nausea or vomiting, headache or migraine, burn or shock to the lips, bad breath, dizziness or lightheadedness, mouth ulcer. Participants could also report other symptoms that were not included in the list.

We then asked ever users whether they had used electronic cigarettes during the last six months in the following indoor places: home, workplace, relatives' or friends' house, private vehicle, restaurants or bars, train/metro stations, airport, public transport (bus, tram, metro, train, plane), nightclubs, libraries or public offices, cinema/theatre, art/sport/music courses, and hospitals. Answers to these questions were: Yes; No; I did not attend this place over the last six months. Participants who had not visited these places in the last six months were excluded from the corresponding analyses.

\subsubsection{Statistical analyses}

We considered absolute and relative frequencies for categorical variables, and used Pearson's chi-square test of independence to compare the proportions among groups. We calculated means and standard deviations (SD) for continuous variables and used the ANOVA F-test to compare the means. Unconditional multiple logic regression models were used to compute the odds ratios (OR) and corresponding 95\% confidence intervals (Cl) for electronic cigarette users vaping in indoor places and users having at least one adverse event related to electronic cigarette use. All the models were adjusted for age, sex, level of education, electronic cigarette use status and duration of electronic cigarette use. The level of statistical significance was set to a two-sided p-value $<0.05$. All the analyses were done using SAS 9.4 software (SAS Institute, Cary, North Carolina).

\section{$5.4 \quad$ Results}

In our sample of 395 ever electronic cigarette users and ever smokers, 282 (71.4\%) were consecutive smokers visiting a SCS for the first time for smoking cessation and $113(28.6 \%, 90$ current smokers and 22 former smokers) were enrolled among electronic cigarette ever users. Overall, 49 (12.4\%) were regular electronic cigarette users, $37(9.4 \%)$ were occasional users and $309(78.2 \%)$ were past users; 368 (93.4\%) were current smokers and 26 (6.6\%) were former 
smokers. The sample included 211 (53.6\%) men and 183 (46.4\%) women, with a mean age of 51.3 years (SD: 13.0 ; Table 1 ).

Table 1: Distribution of 395 electronic cigarette ever users enrolled in 12 Italian smoking cessation services (SCS) according to selected demographic and socioeconomic characteristics, and electronic cigarette and cigarette smoking features, overall and by electronic cigarette use status. Italy, 2016-2018.

\begin{tabular}{|c|c|c|c|c|c|}
\hline & \multirow{2}{*}{$\begin{array}{l}\text { All ever } \\
\text { users }\end{array}$} & \multicolumn{4}{|c|}{ Electronic cigarette use status, $\mathrm{N}(\%)$} \\
\hline & & Past users & $\begin{array}{l}\text { Occasional } \\
\text { users }\end{array}$ & $\begin{array}{c}\text { Regular } \\
\text { users }\end{array}$ & p-value* \\
\hline TOTAL & $395(100.0)$ & $309(100.0)$ & $37(100.0)$ & $49(100.0)$ & \\
\hline \multicolumn{6}{|l|}{ Reason for attending the $\operatorname{SCS}^{\wedge}$} \\
\hline Smoking cessation & $282(71.4)$ & $240(77.7)$ & $27(73.0)$ & $15(30.6)$ & \multirow{2}{*}{$<0.001$} \\
\hline Other & $113(28.6)$ & $69(22.3)$ & $10(27.0)$ & $34(69.4)$ & \\
\hline \multicolumn{6}{|c|}{ SOCIO-DEMOGRAPHIC CHARACTERISTICS } \\
\hline Age, mean $\pm S D$ & $51.3 \pm 13.0$ & $51.5 \pm 13.2$ & $51.9 \pm 13.2$ & $49.4 \pm 11.5$ & 0.545 \\
\hline \multicolumn{6}{|l|}{$\operatorname{Sex}^{\wedge}$} \\
\hline Women & $183(46.4)$ & $142(46.1)$ & $17(46.0)$ & $24(49.0)$ & \multirow{2}{*}{0.930} \\
\hline Men & $211(53.6)$ & $166(53.9)$ & $20(54.0)$ & $25(51.0)$ & \\
\hline \multicolumn{6}{|l|}{ Education^^} \\
\hline Primary or less & $134(34.1)$ & $105(34.2)$ & $11(29.7)$ & $18(36.7)$ & \multirow{3}{*}{0.661} \\
\hline Secondary & $193(49.1)$ & $147(47.9)$ & $22(59.5)$ & $24(49.0)$ & \\
\hline University & $66(16.8)$ & $55(17.9)$ & $4(10.8)$ & $7(14.3)$ & \\
\hline \multicolumn{6}{|l|}{ ELECTRONIC CIGARETTE USE } \\
\hline \multicolumn{6}{|l|}{ Duration of use ${ }^{\wedge}$} \\
\hline$<1$ month & $135(35.0)$ & $117(38.7)$ & $13(37.1)$ & $5(10.2)$ & \multirow{3}{*}{0.001} \\
\hline 1-2 months & $122(31.6)$ & $94(31.1)$ & $11(31.4)$ & $17(34.7)$ & \\
\hline$\geq 3$ months & $129(33.4)$ & $91(30.1)$ & $11(31.4)$ & $27(55.1)$ & \\
\hline Number of puffs/day, mean $\pm S D$ & $86.4 \pm 203$ & $82.9 \pm 222$ & $55.1 \pm 67.4$ & $121.6 \pm 147$ & 0.357 \\
\hline \multicolumn{6}{|l|}{ Place of purchase ${ }^{\wedge}$} \\
\hline Vape shops & $294(76.6)$ & $234(78.0)$ & $26(74.3)$ & $34(69.4)$ & \multirow{2}{*}{0.396} \\
\hline Other & $90(23.4)$ & $66(22.0)$ & $9(25.7)$ & $15(30.6)$ & \\
\hline \multicolumn{6}{|l|}{ Type of liquid^ } \\
\hline With nicotine & $333(93.8)$ & $258(92.8)$ & $30(96.8)$ & $45(97.8)$ & \multirow{2}{*}{0.328} \\
\hline Without nicotine & $22(6.2)$ & $20(7.2)$ & $1(3.2)$ & $1(2.2)$ & \\
\hline \multicolumn{6}{|l|}{ Number of liquids used^^} \\
\hline 1 & $231(77.0)$ & $198(79.8)$ & $18(69.2)$ & $15(57.7)$ & \multirow{3}{*}{0.092} \\
\hline 2 & $45(15.0)$ & $32(12.9)$ & $6(23.1)$ & $7(26.9)$ & \\
\hline 3 or plus & $24(8.0)$ & $18(7.3)$ & $2(7.7)$ & $4(15.4)$ & \\
\hline \multicolumn{6}{|l|}{ Type of electronic cigarette ${ }^{\wedge}$} \\
\hline Refillable & $281(95.9)$ & $236(97.9)$ & $22(84.6)$ & $23(88.5)$ & \multirow{2}{*}{$<0.001$} \\
\hline Others & $12(4.1)$ & $5(2.1)$ & $4(15.4)$ & $3(11.5)$ & \\
\hline \multicolumn{6}{|l|}{ Type of consumption^ ${ }^{\wedge}$} \\
\hline Short sessions & $247(68.8)$ & $187(67.5)$ & $23(69.7)$ & $37(75.5)$ & \multirow{2}{*}{0.534} \\
\hline Long sessions & $112(31.2)$ & $90(32.5)$ & $10(30.3)$ & $12(24.5)$ & \\
\hline \multicolumn{6}{|l|}{ CIGARETTE SMOKING HABITS } \\
\hline $\begin{array}{l}\text { Smoking intensity } \\
\text { (cigarettes/day), mean } \pm S D\end{array}$ & $22.0 \pm 10.1$ & $22.4 \pm 9.7$ & $22.7 \pm 12.5$ & $19.3 \pm 9.9$ & 0.149 \\
\hline $\begin{array}{l}\text { Smoking duration (years), mean } \\
\pm S D\end{array}$ & $34.4 \pm 13.3$ & $34.7 \pm 13.4$ & $34.4 \pm 14.1$ & $32.6 \pm 11.9$ & 0.623 \\
\hline $\begin{array}{l}\text { Fagerström Test for Nicotine } \\
\text { Dependence, mean } \pm S D\end{array}$ & $5.7 \pm 1.9$ & $5.7 \pm 1.9$ & $6.0 \pm 2.0$ & $5.4 \pm 2.3$ & 0.353 \\
\hline
\end{tabular}


The mean number of traditional cigarettes smoked per day was 22.0 (SD 10.1), mean smoking duration was 34.4 years (SD 13.3) and mean FTND was 5.7 (SD 1.9). Nicotine dependence was low-intermediate (i.e., FTND <6) for $41.0 \%$ of ever smokers, high (i.e., $6-7$ ) for $41.5 \%$ and very high ( $\geq 8$ ) for $18.4 \%$. In all, $95.9 \%$ of electronic cigarette ever users used a refillable device and $93.8 \%$ consumed liquids with nicotine. Mean duration of electronic cigarette use was 3.7 months (SD 6.3), $66.6 \%$ of ever users and $44.9 \%$ of regular users had used electronic cigarette for less than 3 months. Mean number of puffs per day was 86.4 (SD 203.4) for ever and 121.6 (SD 146.6) for regular electronic cigarette users. The majority of users purchased electronic cigarette in vape shops $(76.6 \%)$, consumed one single liquid $(77.0 \%)$, and used electronic cigarette in short sessions $(68.8 \%)$.

Figure 1 shows the proportion of electronic cigarette use in smoke-free public places and in private settings. Among electronic cigarette ever users, $71.5 \%$ used it in at least one smoke-free environment: $53.7 \%$ at workplace, $49.5 \%$ in restaurants or bars, and $33.5 \%$ in train/metro stations or at the airports. Considering private indoor places, $88.9 \%$ has used electronic cigarette at home, $70.8 \%$ at friends' or relatives' house, and $58.6 \%$ in private cars. Among those who used electronic cigarettes in private vehicles (58.6\%), 5.9\% used them in the presence of children.

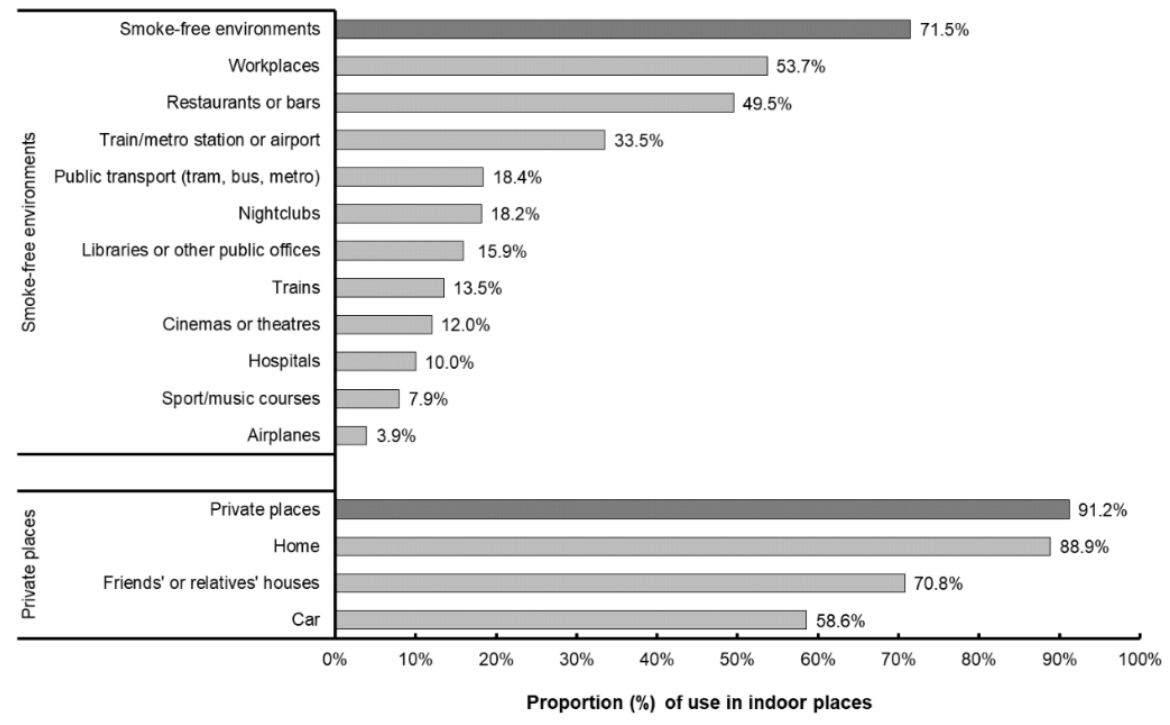

Figure 1: Percent prevalence of ever users using electronic cigarette in selected public and private indoor places. Italy, 2016-2018. 
Use of electronic cigarette in at least one smoke-free indoor environment was significantly less frequent among individuals aged 60 years or more (compared to $18-49$ years, OR=0.32; $95 \% \mathrm{Cl}$ : 0.16-0.64; Table 2).

It was more frequent in those having used electronic cigarette for 1-2 months (OR=2.82; 95\% Cl: $1.49-5.34$ ) or 3 months or more (OR=3.22; 95\% Cl: $1.69-6.15)$ compared to $<1$ month of use, and in users with a high level of nicotine dependence (compared to a FTND <6, OR=3.37, 95\% Cl: 1.70-6.69 for 6-7, and $\mathrm{OR}=3.10,95 \% \mathrm{Cl}: 1.36-7.07$ for a score $\geq 8$ ). No significant relationship was observed between use of electronic cigarette in smoke-free indoor places and sex, education, electronic cigarette use, intensity and way of use, cigarette smoking, intensity and duration. With reference to the use of electronic cigarette in at least one private indoor place, consumption was higher among individuals with an intermediate (6-7) than low (1-5) FTND (OR=4.02; 95\% Cl: 1.19-13.6). None of the other socio-demographic, electronic cigarette and conventional cigarette characteristics were significantly related to the use of electronic cigarettes in private places. 
Table 2: Odds ratios (OR), and corresponding 95\% confidence intervals (Cl) for electronic cigarette use in some public and private places, according to selected demographic and socioeconomic characteristics, and electronic cigarette and tobacco smoking features. Italy, 2016-2018.

\begin{tabular}{|c|c|c|c|c|c|c|c|c|c|}
\hline & \multicolumn{5}{|c|}{$\begin{array}{c}\text { Smoke-free environments, } \mathrm{OR}^{\wedge} \\
(95 \% \mathrm{Cl})\end{array}$} & \multicolumn{4}{|c|}{$\begin{array}{c}\text { Private places, OR } \\
(95 \% \mathrm{Cl})\end{array}$} \\
\hline \multicolumn{10}{|c|}{ SOCIO-DEMOGRAPHIC CHARACTERISTICS } \\
\hline \multicolumn{10}{|c|}{ Age (years) } \\
\hline $18-49$ & $1.00 \dagger$ & $1.00 \dagger$ & $1.00 \dagger$ & $1.00 \dagger$ & $1.00 \dagger$ & $1.00 \dagger$ & $1.00 \dagger$ & $1.00 \dagger$ & $1.00 \dagger$ \\
\hline$\geq 60$ & $\begin{array}{c}0.32 \\
(0.16-0.64)\end{array}$ & $\begin{array}{c}0.28 \\
(0.14-0.59)\end{array}$ & $\begin{array}{c}0.62 \\
(0.33-1.19)\end{array}$ & $\begin{array}{c}0.71 \\
(0.33-1.54)\end{array}$ & $\begin{array}{c}0.84 \\
(0.40-1.76)\end{array}$ & $\begin{array}{c}0.45 \\
(0.14-1.51)\end{array}$ & $\begin{array}{c}1.25 \\
(0.41-3.85)\end{array}$ & $\begin{array}{c}0.57 \\
(0.25-1.29)\end{array}$ & $\begin{array}{c}0.60 \\
(0.31-1.19)\end{array}$ \\
\hline \multicolumn{10}{|l|}{ Sex } \\
\hline Female & $1.00 \dagger$ & $1.00 \dagger$ & $1.00 \dagger$ & $1.00 \dagger$ & $1.00 \dagger$ & $1.00 \dagger$ & $1.00 \dagger$ & $1.00 \dagger$ & $1.00 \dagger$ \\
\hline Male & $\begin{array}{c}1.46 \\
(0.87-2.47)\end{array}$ & $\begin{array}{c}1.96 \\
(1.16-3.31)\end{array}$ & $\begin{array}{c}0.96 \\
(0.59-1.56)\end{array}$ & $\begin{array}{c}1.80 \\
(1.01-3.20)\end{array}$ & $\begin{array}{c}1.22 \\
(0.69-2.16)\end{array}$ & $\begin{array}{c}0.71 \\
(0.28-1.77)\end{array}$ & $\begin{array}{c}0.43 \\
(0.19-1.01)\end{array}$ & $\begin{array}{c}0.97 \\
(0.54-1.74)\end{array}$ & $\begin{array}{c}1.70 \\
(1.03-2.81)\end{array}$ \\
\hline \multicolumn{10}{|l|}{ Education } \\
\hline University & $\begin{array}{c}1.00 \\
(0.45-2.22)\end{array}$ & $\begin{array}{c}0.76 \\
(0.34-1.72)\end{array}$ & $\begin{array}{c}0.84 \\
(0.41-1.72)\end{array}$ & $\begin{array}{c}1.01 \\
(0.42-2.44)\end{array}$ & $\begin{array}{c}0.66 \\
(0.28-1.58)\end{array}$ & $\begin{array}{c}1.08 \\
(0.27-4.28)\end{array}$ & $\begin{array}{c}1.30 \\
(0.38-4.41)\end{array}$ & $\begin{array}{c}1.04 \\
(0.42-2.58)\end{array}$ & $\begin{array}{c}0.65 \\
(0.31-1.38)\end{array}$ \\
\hline \multicolumn{10}{|c|}{ ELECTRONIC CIGARETTE USE } \\
\hline \multicolumn{10}{|c|}{ Status } \\
\hline Past User & $1.00 \dagger$ & $1.00 \dagger$ & $1.00 \dagger$ & $1.00 \dagger$ & $1.00 \dagger$ & $1.00 \dagger$ & $1.00 \dagger$ & $1.00 \dagger$ & $1.00 \dagger$ \\
\hline $\begin{array}{l}\text { Occasiona } \\
\text { I users }\end{array}$ & $\begin{array}{c}1.11 \\
(0.44-2.79)\end{array}$ & $\begin{array}{c}0.28 \\
(0.11-0.69)\end{array}$ & $\begin{array}{c}1.44 \\
(0.62-3.34)\end{array}$ & $\begin{array}{c}0.96 \\
(0.36-2.56)\end{array}$ & $\begin{array}{c}1.90 \\
(0.74-4.90)\end{array}$ & $\begin{array}{c}1.34 \\
(0.23-7.66)\end{array}$ & $\begin{array}{c}0.56 \\
(0.18-1.78)\end{array}$ & $\begin{array}{c}1.14 \\
(0.38-3.42)\end{array}$ & $\begin{array}{c}1.28 \\
(0.51-3.18)\end{array}$ \\
\hline $\begin{array}{l}\text { Regular } \\
\text { users }\end{array}$ & $\begin{array}{c}1.07 \\
(0.43-2.61)\end{array}$ & $\begin{array}{c}0.57 \\
(0.26-1.27)\end{array}$ & $\begin{array}{c}1.12 \\
(0.55-2.27)\end{array}$ & $\begin{array}{c}2.25 \\
(1.00-5.05)\end{array}$ & $\begin{array}{c}1.72 \\
(0.78-3.82)\end{array}$ & --- & $\begin{array}{c}2.18 \\
(0.45-10.5)\end{array}$ & $\begin{array}{c}1.46 \\
(0.61-3.50)\end{array}$ & $\begin{array}{c}1.15 \\
(0.53-2.51)\end{array}$ \\
\hline \multicolumn{10}{|l|}{$\begin{array}{l}\text { Duration of } \\
\text { use }\end{array}$} \\
\hline$<1$ month & $1.00 \dagger$ & $1.00 \dagger$ & $1.00 \dagger$ & $1.00 \dagger$ & $1.00 \dagger$ & $1.00 \dagger$ & $1.00 \dagger$ & $1.00 \dagger$ & $1.00 \dagger$ \\
\hline $\begin{array}{l}1-2 \\
\text { months }\end{array}$ & $\begin{array}{c}2.82 \\
(1.49-5.34)\end{array}$ & $\begin{array}{c}2.59 \\
(1.34-5.01)\end{array}$ & $\begin{array}{c}1.64 \\
(0.90-2.98)\end{array}$ & $\begin{array}{c}2.30 \\
(1.07-4.94)\end{array}$ & $\begin{array}{c}1.22 \\
(0.59-2.50)\end{array}$ & $\begin{array}{c}2.28 \\
(0.74-7.01)\end{array}$ & $\begin{array}{c}1.65 \\
(0.62-4.38)\end{array}$ & $\begin{array}{c}1.57 \\
(0.78-3.14)\end{array}$ & $\begin{array}{c}2.47 \\
(1.32-4.62)\end{array}$ \\
\hline \multicolumn{10}{|l|}{$\begin{array}{l}\text { Number of } \\
\text { puffs/day }\end{array}$} \\
\hline \multicolumn{10}{|l|}{ Way used } \\
\hline $\begin{array}{l}\text { Short } \\
\text { sessions }\end{array}$ & $1.00 \dagger$ & $1.00 \dagger$ & $1.00 \dagger$ & $1.00 \dagger$ & $1.00 \dagger$ & $1.00 \dagger$ & $1.00 \dagger$ & $1.00 \dagger$ & $1.00 \dagger$ \\
\hline $\begin{array}{l}\text { Long } \\
\text { sessions }\end{array}$ & $\begin{array}{c}0.96 \\
(0.52-1.79)\end{array}$ & $\begin{array}{c}0.89 \\
(0.46-1.71)\end{array}$ & $\begin{array}{c}0.72 \\
(0.39-1.30)\end{array}$ & $\begin{array}{c}0.61 \\
(0.30-1.26)\end{array}$ & $\begin{array}{c}1.25 \\
(0.64-2.44)\end{array}$ & $\begin{array}{c}1.01 \\
(0.37-2.76)\end{array}$ & $\begin{array}{c}1.79 \\
(0.63-5.04)\end{array}$ & $\begin{array}{c}0.75 \\
(0.37-1.50)\end{array}$ & $\begin{array}{c}1.15 \\
(0.62-2.11)\end{array}$ \\
\hline \multicolumn{10}{|c|}{ CIGARETTE SMOKING HABITS } \\
\hline \multicolumn{10}{|c|}{$\begin{array}{l}\text { Smoking } \\
\text { status }\end{array}$} \\
\hline Current & $1.00 \dagger$ & $1.00 \dagger$ & $1.00 \dagger$ & $1.00 \dagger$ & $1.00 \dagger$ & $1.00 \dagger$ & $1.00 \dagger$ & $1.00 \dagger$ & $1.00 \dagger$ \\
\hline Former & $\begin{array}{c}0.77 \\
(0.24-2.47)\end{array}$ & $\begin{array}{c}0.66 \\
(0.23-1.85)\end{array}$ & $\begin{array}{c}0.69 \\
(0.25-1.95)\end{array}$ & $\begin{array}{c}0.79 \\
(0.27-2.33)\end{array}$ & $\begin{array}{c}0.40 \\
(0.10-1.62)\end{array}$ & $\begin{array}{c}0.25 \\
(0.03-1.84)\end{array}$ & $\begin{array}{c}0.42 \\
(0.07-2.54)\end{array}$ & $\begin{array}{c}0.90 \\
(0.28-2.87)\end{array}$ & $\begin{array}{c}2.94 \\
(0.75-11.5)\end{array}$ \\
\hline \multicolumn{10}{|l|}{$\begin{array}{l}\text { Smoking } \\
\text { intensity§ }\end{array}$} \\
\hline $1-19$ & $1.00 \dagger$ & $1.00 \dagger$ & $1.00 \dagger$ & $1.00 \dagger$ & $1.00 \dagger$ & $1.00 \dagger$ & $1.00 \dagger$ & $1.00 \dagger$ & $1.00 \dagger$ \\
\hline $20-24$ & $\begin{array}{c}1.24 \\
(0.62-2.50)\end{array}$ & $\begin{array}{c}1.04 \\
(0.51-2.12)\end{array}$ & $\begin{array}{c}1.11 \\
(0.58-2.13)\end{array}$ & $\begin{array}{c}1.00 \\
(0.44-2.26)\end{array}$ & $\begin{array}{c}1.20 \\
(0.57-2.55)\end{array}$ & $\begin{array}{c}0.95 \\
(0.26-3.47)\end{array}$ & $\begin{array}{c}1.53 \\
(0.49-4.76)\end{array}$ & $\begin{array}{c}0.50 \\
(0.22-1.15)\end{array}$ & $\begin{array}{c}2.04 \\
(1.02-4.05)\end{array}$ \\
\hline $25 \geq$ & $\begin{array}{c}1.13 \\
(0.56-2.30)\end{array}$ & $\begin{array}{c}1.02 \\
(0.50-2.10)\end{array}$ & $\begin{array}{c}0.62 \\
(0.32-1.22)\end{array}$ & $\begin{array}{c}1.22 \\
(0.54-2.74)\end{array}$ & $\begin{array}{c}1.01 \\
(0.47-2.19)\end{array}$ & $\begin{array}{c}0.61 \\
(0.16-2.29)\end{array}$ & $\begin{array}{c}1.05 \\
(0.35-3.13)\end{array}$ & $\begin{array}{c}0.60 \\
(0.26-1.41)\end{array}$ & $\begin{array}{c}1.29 \\
(0.65-2.57)\end{array}$ \\
\hline \multicolumn{10}{|l|}{$\begin{array}{l}\text { Smoking } \\
\text { duration§ }\end{array}$} \\
\hline $1-30$ & $1.00 \dagger$ & $1.00 \dagger$ & $1.00 \dagger$ & $1.00 \dagger$ & $1.00 \dagger$ & $1.00 \dagger$ & $1.00 \dagger$ & $1.00 \dagger$ & $1.00 \dagger$ \\
\hline $31-44$ & $\begin{array}{c}2.88 \\
(0.59-14.1)\end{array}$ & $\begin{array}{c}1.38 \\
(0.33-5.78)\end{array}$ & $\begin{array}{c}0.78 \\
(0.25-2.44)\end{array}$ & $\begin{array}{c}0.38 \\
(0.10-1.47)\end{array}$ & $\begin{array}{c}0.27 \\
(0.06-1.31)\end{array}$ & $\begin{array}{c}2.71 \\
(0.24-30.9)\end{array}$ & $\begin{array}{c}1.50 \\
(0.15-15.2)\end{array}$ & $\begin{array}{c}1.02 \\
(0.27-3.86)\end{array}$ & $\begin{array}{c}2.80 \\
(0.68-11.6)\end{array}$ \\
\hline $45 \geq$ & $\begin{array}{c}2.85 \\
(0.45-18.2)\end{array}$ & $\begin{array}{c}1.51 \\
(0.26-8.84)\end{array}$ & $\begin{array}{c}0.90 \\
(0.21-3.87)\end{array}$ & $\begin{array}{c}0.24 \\
(0.04-1.50)\end{array}$ & $\begin{array}{c}0.34 \\
(0.05-2.30)\end{array}$ & $\begin{array}{c}3.98 \\
(0.15-105)\end{array}$ & $\begin{array}{c}1.08 \\
(0.06-21.0)\end{array}$ & $\begin{array}{c}2.02 \\
(0.35-11.6)\end{array}$ & $\begin{array}{c}1.15 \\
(0.20-6.69)\end{array}$ \\
\hline
\end{tabular}




\begin{tabular}{|c|c|c|c|c|c|c|c|c|c|}
\hline & $\begin{array}{c}\text { At least } \\
\text { one } \\
\text { smoke- } \\
\text { free env, }\end{array}$ & $\begin{array}{c}\text { Workplace } \\
\text { s }\end{array}$ & $\begin{array}{c}\text { Restaurant } \\
\mathrm{s} \text { or bars }\end{array}$ & $\begin{array}{c}\text { Public } \\
\text { transport } \\
\text { or stations } \\
\text { or airports }\end{array}$ & $\begin{array}{c}\text { Other } \\
\text { smoke- } \\
\text { free env* }\end{array}$ & $\begin{array}{c}\text { At least } \\
\text { one } \\
\text { private } \\
\text { place }\end{array}$ & Home & $\begin{array}{l}\text { Relatives' } \\
\text { or friends' } \\
\text { house }\end{array}$ & Car \\
\hline \multicolumn{10}{|c|}{ FTND§ } \\
\hline $1-5$ & $1.00 \dagger$ & $1.00 \dagger$ & $1.00 \dagger$ & $1.00 \dagger$ & $1.00 \dagger$ & $1.00 \dagger$ & $1.00 \dagger$ & $1.00 \dagger$ & $1.00 \dagger$ \\
\hline$\geq 8$ & $\begin{array}{c}3.10 \\
(1.36-7.07)\end{array}$ & $\begin{array}{c}2.75 \\
(1.14-6.66)\end{array}$ & $\begin{array}{c}1.01 \\
(0.47-2.15)\end{array}$ & $\begin{array}{c}2.12 \\
(0.85-5.28)\end{array}$ & $\begin{array}{c}1.84 \\
(0.78-4.32)\end{array}$ & $\begin{array}{c}1.48 \\
(0.40-5.40)\end{array}$ & $\begin{array}{c}6.29 \\
(1.16-34.2)\end{array}$ & $\begin{array}{c}0.85 \\
(0.33-2.21)\end{array}$ & $\begin{array}{c}1.64 \\
(0.75-3.61)\end{array}$ \\
\hline
\end{tabular}

${ }^{\wedge}$ Estimated by multiple unconditional logistic regression models after adjustment for age, sex, education, electronic cigarette status, electronic cigarette duration; * Other places include nightclubs, libraries, public offices, cinemas, theatres, art/sport/music courses and hospitals; $\dagger$ Reference category; § Analyses conducted on current smokers only; Fagerström test for nicotine dependence.

Estimates in bold type are statistically significant at 0.05 level.

Almost half $(47.1 \%)$ reported at least one symptom attributable to the use of electronic cigarette (Figure 2). Among these subjects, the most reported adverse events were dry cough $(41.4 \%)$, dry mouth $(25.4 \%)$, throat or mouth irritation $(16.0 \%)$, and sore throat (14.4\%).

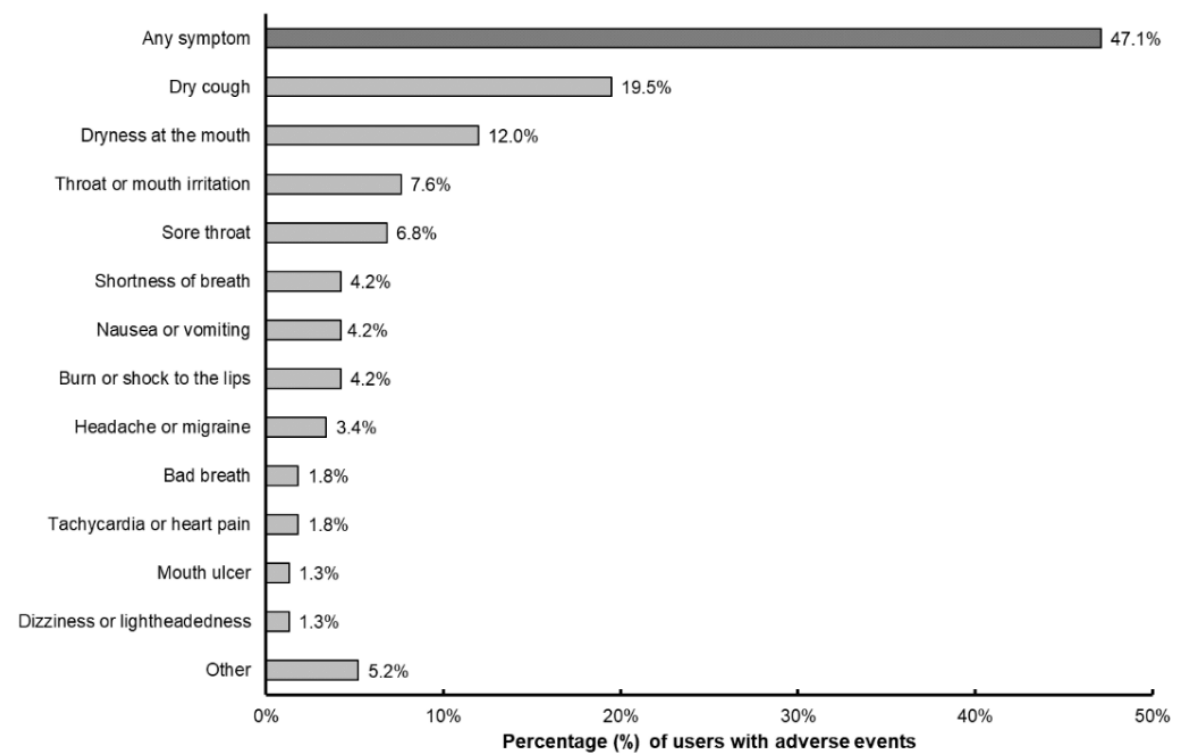

Figure 2: Distribution of main adverse events of electronic cigarette use among 384 electronic cigarette ever users. Italy, 2016-2018.

Table 3 shows the ORs for symptoms related to the use of electronic cigarettes in relation to selected socio-demographic variables and electronic cigarette use and cigarette smoking. Highly nicotine dependent individuals more frequently reported having dry mouth (OR=3.67; $95 \% \mathrm{Cl}: 1.34-10.0$ for FTND $\geq 8$ vs. $<6$ ). 
Table 3: Distribution and odds ratios (OR), and corresponding 95\% confidence intervals $(\mathrm{Cl})$, for any and main symptoms related to electronic cigarette use, according to selected demographic and socioeconomic characteristics, electronic cigarette and tobacco smoking features. Italy, 2016-2018.

\begin{tabular}{|c|c|c|c|c|c|c|c|c|c|c|c|}
\hline & & \multicolumn{2}{|c|}{ Any symptom } & \multicolumn{2}{|c|}{ Dry cough } & \multicolumn{2}{|c|}{ Dry mouth } & \multicolumn{2}{|c|}{$\begin{array}{c}\begin{array}{c}\text { Throat or mouth } \\
\text { irritation }\end{array} \\
\end{array}$} & \multicolumn{2}{|c|}{ Sore throat } \\
\hline & $\begin{array}{c}\text { Tota } \\
1^{\circ}\end{array}$ & $\%$ & $\begin{array}{c}\mathrm{OR}^{\wedge} \\
(95 \% \mathrm{Cl})\end{array}$ & $\%$ & $\begin{array}{c}\mathrm{OR}^{\wedge} \\
(95 \% \mathrm{Cl})\end{array}$ & $\%$ & $\begin{array}{c}\mathrm{OR}^{\wedge} \\
(95 \% \mathrm{Cl})\end{array}$ & $\%$ & $\begin{array}{c}\mathrm{OR}^{\wedge} \\
(95 \% \mathrm{Cl})\end{array}$ & $\%$ & $\begin{array}{c}\mathrm{OR}^{\wedge} \\
(95 \% \mathrm{Cl})\end{array}$ \\
\hline Total & 384 & 47.1 & & 19.5 & & 12.0 & & 7.6 & & 6.8 & \\
\hline \multicolumn{12}{|c|}{$\begin{array}{l}\text { SOCIO-DEMOGRAPHIC CHARACTERISTICS } \\
\text { Age (years)* }\end{array}$} \\
\hline $18-49$ & 151 & 45.0 & $1.00 \dagger$ & 15.9 & $1.00 \dagger$ & 13.9 & $1.00 \dagger$ & 6.0 & $1.00 \dagger$ & 6.6 & $1.00 \dagger$ \\
\hline $50-59$ & 130 & 46.9 & $\begin{array}{c}1.08 \\
(0.64-1.83)\end{array}$ & 23.9 & $\begin{array}{c}1.60 \\
(0.84-3.07)\end{array}$ & 11.5 & $\begin{array}{c}0.87 \\
(0.39-1.92)\end{array}$ & 6.9 & $\begin{array}{c}0.97 \\
(0.35-2.71)\end{array}$ & 6.2 & $\begin{array}{c}0.87 \\
(0.30-2.58)\end{array}$ \\
\hline$\geq 60$ & 99 & 50.5 & $\begin{array}{c}1.11 \\
(0.63-1.98)\end{array}$ & 20.2 & $\begin{array}{c}1.14 \\
(0.55-2.34)\end{array}$ & 8.1 & $\begin{array}{c}0.52 \\
(0.20-1.33)\end{array}$ & 11.1 & $\begin{array}{c}1.19 \\
(0.43-3.29)\end{array}$ & 7.1 & $\begin{array}{c}1.22 \\
(0.40-3.76)\end{array}$ \\
\hline \multicolumn{12}{|l|}{ Sex* } \\
\hline Female & 176 & 49.4 & $1.00 \dagger$ & 23.3 & $1.00 \dagger$ & 11.4 & $1.00 \dagger$ & 9.7 & $1.00 \dagger$ & 8.5 & $1.00 \dagger$ \\
\hline Male & 207 & 44.9 & $\begin{array}{c}0.87 \\
(0.56-1.35)\end{array}$ & 16.4 & $\begin{array}{c}0.69 \\
(0.40-1.19)\end{array}$ & 12.1 & $\begin{array}{c}1.04 \\
(0.52-2.08)\end{array}$ & 5.8 & $\begin{array}{c}0.59 \\
(0.26-1.33)\end{array}$ & 4.8 & $\begin{array}{c}0.61 \\
(0.25-1.49)\end{array}$ \\
\hline \multicolumn{12}{|l|}{ Education* } \\
\hline Primary or less & 130 & 42.3 & $1.00 \dagger$ & 20.0 & $1.00 \dagger$ & 10.8 & $1.00 \dagger$ & 6.2 & $1.00 \dagger$ & 5.4 & $1.00 \dagger$ \\
\hline Secondary & 187 & 49.7 & $\begin{array}{c}1.10 \\
(0.67-1.80)\end{array}$ & 19.3 & $\begin{array}{c}0.86 \\
(0.47-1.60)\end{array}$ & 11.8 & $\begin{array}{c}0.87 \\
(0.40-1.89)\end{array}$ & 7.5 & $\begin{array}{c}1.10 \\
(0.42-2.90)\end{array}$ & 6.4 & $\begin{array}{c}1.33 \\
(0.46-3.81)\end{array}$ \\
\hline University & 65 & 50.8 & $\begin{array}{c}1.29 \\
(0.67-2.48)\end{array}$ & 20.0 & $\begin{array}{c}0.98 \\
(0.44-2.20)\end{array}$ & 15.4 & $\begin{array}{c}1.45 \\
(0.55-3.82)\end{array}$ & 10.8 & $\begin{array}{c}1.68 \\
(0.54-5.19)\end{array}$ & 10.8 & $\begin{array}{c}1.95 \\
(0.56-6.75)\end{array}$ \\
\hline \multicolumn{12}{|c|}{$\begin{array}{l}\text { ELECTRONIC CIGARETTE USE } \\
\text { Status }^{*}\end{array}$} \\
\hline Past User & 300 & 47.7 & $1.00 \dagger$ & 18.3 & $1.00 \dagger$ & 11.0 & $1.00 \dagger$ & 7.7 & $1.00 \dagger$ & 7.3 & $1.00 \dagger$ \\
\hline $\begin{array}{l}\text { Occasional } \\
\text { users }\end{array}$ & 35 & 40.0 & $\begin{array}{c}0.89 \\
(0.42-1.91)\end{array}$ & 25.7 & $\begin{array}{c}1.94 \\
(0.81-4.66)\end{array}$ & 8.6 & $\begin{array}{c}0.93 \\
(0.25-3.48)\end{array}$ & 8.6 & $\begin{array}{c}1.02 \\
(0.27-3.87)\end{array}$ & 2.9 & $\begin{array}{c}0.44 \\
(0.06-3.55)\end{array}$ \\
\hline Regular users & 49 & 49.0 & $\begin{array}{c}1.10 \\
(0.56-2.18)\end{array}$ & 22.5 & $\begin{array}{c}1.53 \\
(0.67-3.49)\end{array}$ & 20.4 & $\begin{array}{c}1.68 \\
(0.68-4.12)\end{array}$ & 6.1 & $\begin{array}{c}0.81 \\
(0.21-3.13)\end{array}$ & 6.1 & $\begin{array}{c}0.71 \\
(0.15-3.52)\end{array}$ \\
\hline \multicolumn{12}{|l|}{ Duration of use ${ }^{*}$} \\
\hline$<1$ month & 134 & 44.8 & $1.00 \dagger$ & 18.7 & $1.00 \dagger$ & 9.0 & $1.00 \dagger$ & 6.7 & $1.00 \dagger$ & 3.0 & $1.00 \dagger$ \\
\hline $1-2$ months & 122 & 43.4 & $\begin{array}{c}0.94 \\
(0.55-1.60)\end{array}$ & 16.4 & $\begin{array}{c}0.83 \\
(0.42-1.66)\end{array}$ & 13.9 & $\begin{array}{c}1.57 \\
(0.67-3.69)\end{array}$ & 5.7 & $\begin{array}{c}1.01 \\
(0.34-2.95)\end{array}$ & 11.5 & $\begin{array}{c}6.08 \\
(1.62-22.8)\end{array}$ \\
\hline$\geq 3$ months & 127 & 52.8 & $\begin{array}{c}1.48 \\
(0.86-2.53)\end{array}$ & 23.6 & $\begin{array}{c}1.40 \\
(0.74-2.68)\end{array}$ & 13.4 & $\begin{array}{c}1.67 \\
(0.70-4.00)\end{array}$ & 10.2 & $\begin{array}{c}1.96 \\
(0.76-5.06)\end{array}$ & 6.3 & $\begin{array}{c}3.00 \\
(0.75-12.0)\end{array}$ \\
\hline \multicolumn{12}{|l|}{ Number of puffs/day } \\
\hline $1-20$ & 111 & 42.3 & $1.00 \dagger$ & 18.9 & $1.00 \dagger$ & 5.4 & $1.00 \dagger$ & 6.3 & $1.00 \dagger$ & 8.1 & $1.00 \dagger$ \\
\hline $21-60$ & 105 & 48.6 & $\begin{array}{c}1.16 \\
(0.58-2.32)\end{array}$ & 20.0 & $\begin{array}{c}1.04 \\
(0.43-2.51)\end{array}$ & 17.1 & $\begin{array}{c}2.47 \\
(0.75-8.13)\end{array}$ & 7.6 & $\begin{array}{c}1.59 \\
(0.41-6.11)\end{array}$ & 7.6 & $\begin{array}{c}1.66 \\
(0.45-6.07)\end{array}$ \\
\hline$\geq 61$ & 86 & 48.8 & $\begin{array}{c}1.36 \\
(0.60-3.12)\end{array}$ & 18.6 & $\begin{array}{c}0.99 \\
(0.34-2.86)\end{array}$ & 10.5 & $\begin{array}{c}1.08 \\
(0.25-4.65)\end{array}$ & 9.3 & $\begin{array}{c}2.66 \\
(0.53-13.3)\end{array}$ & 5.8 & $\begin{array}{c}0.87 \\
(0.16-4.67)\end{array}$ \\
\hline \multicolumn{12}{|c|}{ CIGARETTE SMOKING HABITS } \\
\hline Current & 358 & 47.5 & $1.00 \dagger$ & 19.8 & $1.00 \dagger$ & 12.0 & $1.00 \dagger$ & 7.3 & $1.00 \dagger$ & 7.0 & $1.00 \dagger$ \\
\hline Former & 25 & 40.0 & $\begin{array}{c}0.87 \\
(0.34-2.24)\end{array}$ & 16.0 & $\begin{array}{c}0.82 \\
(0.23-2.89)\end{array}$ & 12.0 & $\begin{array}{c}0.67 \\
(0.16-2.79)\end{array}$ & 12.0 & $\begin{array}{c}4.54 \\
(0.86-23.9)\end{array}$ & 4.0 & $\begin{array}{c}0.74 \\
(0.07-7.46)\end{array}$ \\
\hline \multicolumn{12}{|l|}{ Smoking intensity ${ }^{*} \S$} \\
\hline $1-19$ & 106 & 46.2 & $1.00 \dagger$ & 17.0 & $1.00 \dagger$ & 9.4 & $1.00 \dagger$ & 9.4 & $1.00 \dagger$ & 7.6 & $1.00 \dagger$ \\
\hline $20-24$ & 122 & 49.2 & $\begin{array}{c}0.90 \\
(0.50-1.62)\end{array}$ & 21.3 & $\begin{array}{c}1.23 \\
(0.59-2.56)\end{array}$ & 13.9 & $\begin{array}{c}1.22 \\
(0.47-3.18)\end{array}$ & 5.7 & $\begin{array}{c}0.47 \\
(0.16-1.41)\end{array}$ & 9.8 & $\begin{array}{c}1.41 \\
(0.48-4.09)\end{array}$ \\
\hline $25 \geq$ & 122 & 48.4 & $\begin{array}{c}0.99 \\
(0.55-1.80)\end{array}$ & 21.3 & $\begin{array}{c}1.40 \\
(0.67-2.93)\end{array}$ & 12.3 & $\begin{array}{c}1.39 \\
(0.52-3.69)\end{array}$ & 7.4 & $\begin{array}{c}0.82 \\
(0.28-2.40)\end{array}$ & 4.1 & $\begin{array}{c}0.51 \\
(0.13-1.99)\end{array}$ \\
\hline \multicolumn{12}{|l|}{ Smoking duration*§ } \\
\hline $1-30$ & 123 & 43.9 & $1.00 \dagger$ & 16.3 & $1.00 \dagger$ & 13.0 & $1.00 \dagger$ & 5.7 & $1.00 \dagger$ & 6.5 & $1.00 \dagger$ \\
\hline $31-44$ & 145 & 50.3 & $\begin{array}{c}1.25 \\
(0.46-3.42)\end{array}$ & 24.1 & $\begin{array}{c}1.52 \\
(0.47-4.99)\end{array}$ & 12.4 & $\begin{array}{c}1.54 \\
(0.43-5.53)\end{array}$ & 6.9 & $\begin{array}{c}1.00 \\
(0.17-5.94)\end{array}$ & 6.9 & $\begin{array}{c}1.69 \\
(0.21-13.3)\end{array}$ \\
\hline $45 \geq$ & 82 & 47.6 & $\begin{array}{c}0.70 \\
(0.19-2.68)\end{array}$ & 18.3 & $\begin{array}{c}0.91 \\
(0.20-4.22)\end{array}$ & 8.5 & $\begin{array}{c}2.05 \\
(0.26-15.9)\end{array}$ & 11.0 & $\begin{array}{c}1.09 \\
(0.12-9.77)\end{array}$ & 7.3 & $\begin{array}{c}3.25 \\
(0.22-49.2)\end{array}$ \\
\hline \multicolumn{12}{|l|}{ FTND*§ } \\
\hline $1-5$ & 141 & 45.4 & $1.00 \dagger$ & 17.7 & $1.00 \dagger$ & 9.2 & $1.00 \dagger$ & 5.0 & $1.00 \dagger$ & 7.1 & $1.00 \dagger$ \\
\hline $6-7$ & 144 & 49.3 & $\begin{array}{c}1.04 \\
(0.59-1.84)\end{array}$ & 19.4 & $\begin{array}{c}1.24 \\
(0.62-2.46)\end{array}$ & 12.5 & $\begin{array}{c}1.13 \\
(0.42-3.00)\end{array}$ & 6.9 & $\begin{array}{c}1.03 \\
(0.28-3.82)\end{array}$ & 7.6 & $\begin{array}{c}1.10 \\
(0.37-3.22)\end{array}$ \\
\hline$\geq 8$ & 59 & 50.9 & $\begin{array}{c}1.44 \\
(0.72-2.90)\end{array}$ & 25.4 & $\begin{array}{c}1.45 \\
(0.65-3.25)\end{array}$ & 20.3 & $\begin{array}{c}3.67 \\
(1.34-10.0)\end{array}$ & 11.9 & $\begin{array}{c}2.98 \\
(0.80-11.2)\end{array}$ & 6.8 & $\begin{array}{c}1.10 \\
(0.30-4.07)\end{array}$ \\
\hline
\end{tabular}

- Number of electronic cigarette users with information on related symptoms; ^ Estimated by unconditional multiple logistic regression models after adjustment for age, sex, education, electronic cigarette status, electronic cigarette duration; * The sum does not add up to the total because of some missing values; † Reference category; § Analyses conducted on current smokers only; Fagerström test for nicotine dependence.

Estimates in bold type are statistically significant at 0.05 level. 
Using electronic cigarettes for 1-2 months compared with less than 1 month was directly related with higher odds of sore throat (OR=6.08; 95\% Cl: 1.62-22.8). Long sessions of electronic cigarette use gave higher odds of throat or mouth irritation ( $\mathrm{OR}=2.78,95 \% \mathrm{Cl}$ : 1.13-6.84; data not shown in Table). No other significant relations were observed for dry mouth, throat or mouth irritation and sore throat. For any symptom and dry cough we did not find any significant differences among the characteristics considered.

\subsection{Discussion}

Our study shows that among Italian smokers almost all electronic cigarette ever users consume liquids with nicotine, most of them use the device in smoke-free environments, and about half have experienced at least one acute/irritative symptom caused by the electronic cigarette, despite the relatively limited duration of use for the majority of users.

The most used devices were refillable tanks and the most common places of purchase were vape shops. These results are in agreement with findings from other European countries, showing that $85 \%$ of e-cigarettes used are rechargeable [37], and that specialist vape shops are the most popular places of purchase [38]. Almost all ever users consumed liquid with nicotine, supporting findings from previous studies, particularly in Europe [37, 39].

Almost three out of four electronic cigarette users have used the device in at least one smoke-free environment. Most common smoke-free places of use were workplaces, restaurants or bars and train/metro stations or airports. Among the few previous studies evaluating electronic cigarette use in smoke-free environments, a US study conducted in 2014 showed that $60 \%$ of 952 current users vaped in at least one smoke-free environment [14]. Another study in 2015 in Japan on 1,243 ever users showed that $29 \%$ had used electronic cigarettes in smoke-free restaurants and $26 \%$ in smoke-free workplaces [40]. A study from Australia in 2016 showed that among 66 electronic cigarette current users, 15\% vaped in restaurants and bars and $28 \%$ in workplaces [2]. Finally, in a Spanish study based on 600 electronic cigarette users, 33\% had used electronic cigarettes in workplaces, $69 \%$ in restaurants or bars, $3 \%$ on public transport and $55 \%$ in nightclubs [15]. Compared to the above studies, in general, we found higher prevalence rates of use in smoke-free indoor environments, probably because our sample included mainly relatively heavy smokers looking for smoking cessation support. There is evidence that dual users vape more than exclusively electronic cigarette users in smoke-free environments in order to satisfy their nicotine addiction [14, 23]. Similarly, the total number of puffs per day and nicotine dependence were directly related to the use of electronic cigarette 
in smoke-free environments. The proportion of users in restaurants or bars and nightclubs in Italy was lower than in Spain [15], possibly because our sample was based on older participants, who spent less time in such venues. Differences in geographic areas may also be related to different climates in various countries. Among our ever smokers, the duration of electronic cigarette use was short (i.e., lower than 3 months) for 2 out of 3 users, and for almost half the regular users. Notwithstanding, about half reported at least one symptom attributable to the use of electronic cigarette. Most common adverse events were dry cough, dry mouth, throat or mouth irritation and sore throat. The proportion of electronic cigarette users experiencing an adverse event is lower than in a study in the USA, where $58 \%$ of 1,624 electronic cigarette ever users reported at least one symptom, $40 \%$ cough, and $31 \%$ dry or irritated mouth or throat [27]. These differences can be explained by the fact that our sample comprised relatively heavy smokers who may already have symptoms like cough or dry mouth [41], making it difficult to distinguish adverse events attributable to conventional cigarette from those attributable to electronic cigarettes. This may lead to under-reporting of electronic cigarette adverse events [27]. Indeed, in our population current smokers reported higher proportions of adverse events compared to former smokers [42].

Among other symptoms, 7 cases ( $1.8 \%$ of the total sample) reported tachycardia or heart pain, in line with previous evidence that short-term use of electronic cigarettes rises the heart rate [25]. One case $(0.3 \%)$ reported that the device exploded and burned his/her face. This is not an isolated case as it has been reported that burn and explosion injuries caused by electronic cigarettes are rare but not negligible [31, 32, 38].

This study has some limitations, mainly inherent to the design based on selfreported information, so recall bias cannot be ruled out and conclusions cannot be drawn on causal inference. Moreover, only a few electronic cigarette users were enrolled in northern Italy, thus generalization of findings to the whole country might be debatable. Finally, as we included mainly current smokers seeking support for smoking cessation in SCSs, we cannot generalize the results to all cigarette smokers. Among the study strengths, although the sample is not large enough to evaluate frequencies in sub-groups, this is one of the biggest studies conducted in Europe recording adverse events attributable to electronic cigarettes [16] and to provide data on electronic cigarette use in smoke-free environments [15]. Moreover, although we do not have the response rate in each SCS, the number of smokers who refute to enter the study was null or very limited.

\subsubsection{Conclusions}

In Italy smokers use electronic cigarettes with nicotine where conventional cigarette smoking is banned. Consequently, to avoid dual use of electronic and conventional cigarettes, we support the recent WHO claim to ban electronic 
cigarettes at least in public places and workplaces where smoking is prohibited [9]. Despite the relatively short duration of use in our sample, the risk of adverse events, including dry mouth, irritation in the mouth or throat, and dry cough, was frequent, even for brief duration of consumption. The symptoms attributable to electronic cigarette use should not be underestimated.

\section{$5.6 \quad$ References}

1. Liu X, Lugo A, Davoli $E$ et al. Electronic cigarettes in Italy: a tool for harm reduction or a gateway to smoking tobacco? Tob Control 2019.

2. Twyman L, Watts C, Chapman K, Walsberger SC. Electronic cigarette use in New South Wales, Australia: reasons for use, place of purchase and use in enclosed and outdoor places. Aust N Z J Public Health 2018; 42: 491-496.

3. Dawkins L, Turner J, Roberts A, Soar K. 'Vaping' profiles and preferences: an online survey of electronic cigarette users. Addiction 2013; 108: 11151125.

4. Gallus S, Lugo A, Pacifici R et al. E-cigarette awareness, use, and harm perceptions in Italy: a national representative survey. Nicotine Tob Res 2014; 16: 1541-1548.

5. Filippidis FT, Laverty AA, Gerovasili V, Vardavas Cl. Two-year trends and predictors of e-cigarette use in 27 European Union member states. Tob Control 2017; 26: 98-104.

6. Laverty AA, Filippidis FT, Vardavas $\mathrm{Cl}$. Patterns, trends and determinants of e-cigarette use in 28 European Union Member States 2014-2017. Prev Med 2018; 116: 13-18.

7. Bals R, Boyd J, Esposito $S$ et al. Electronic cigarettes: a task force report from the European Respiratory Society. Eur Respir J 2019; 53.

8. De Marco C, Invernizzi G, Bosi S et al. The electronic cigarette: potential health benefit or mere business? Tumori 2013; 99: 299e-301e.

9. World Health Organization. WHO report on the global tobacco epidemic, 2019. Offer help to quit tobacco use. Available at: https://www.who.int/tobacco/global_report/en/. 2019.

10. Grana R, Benowitz N, Stanton AS. Background Paper on E-cigarettes (Electronic Nicotine Delivery Systems). 2013.

11. Martinez-Sanchez JM, Ballbe M, Fu M et al. Attitudes towards electronic cigarettes regulation in indoor workplaces and selected public and private places: a population-based cross-sectional study. PLoS One 2014; 9: e114256. 
12. Majeed $\mathrm{BA}$, Dube $\mathrm{SR}$, Sterling $\mathrm{K}$ et al. Opinions about electronic cigarette use in smoke-free areas among U.S. Adults, 2012. Nicotine Tob Res 2015; 17: 675-681.

13. Institute for Global Tobacco Control. Country Laws Regulating E-cigarettes: A Policy Scan. Baltimore, MD: Johns Hopkins Bloomberg School of Public Health. https://www.globaltobaccocontrol.org/e-cigarette_policyscan [Last Updated November 2, 2018]. 2018.

14. Shi Y, Cummins SE, Zhu SH. Use of electronic cigarettes in smoke-free environments. Tob Control 2017; 26: e19-e22.

15. Matilla-Santander N, Fu M, Ballbe M et al. Use of electronic cigarettes in public and private settings in Barcelona (Spain). Environ Res 2017; 158: 685-690.

16. Pisinger $C$, Dossing M. A systematic review of health effects of electronic cigarettes. Prev Med 2014; 69: 248-260.

17. Zhang G, Wang Z, Zhang $K$ et al. Safety Assessment of Electronic Cigarettes and Their Relationship with Cardiovascular Disease. Int J Environ Res Public Health 2018; 15.

18. Skotsimara G, Antonopoulos AS, Oikonomou $E$ et al. Cardiovascular effects of electronic cigarettes: A systematic review and meta-analysis. Eur J Prev Cardiol 2019; 26: 1219-1228.

19. King BA, Patel R, Nguyen KH, Dube SR. Trends in awareness and use of electronic cigarettes among US adults, 2010-2013. Nicotine Tob Res 2015; 17: 219-227.

20. Regan AK, Promoff G, Dube SR, Arrazola R. Electronic nicotine delivery systems: adult use and awareness of the 'e-cigarette' in the USA. Tob Control 2013; 22: 19-23.

21. Schoenborn CA, Gindi RM. Electronic Cigarette Use Among Adults: United States, 2014. NCHS Data Brief 2015; 1-8.

22. Delnevo CD, Giovenco DP, Steinberg MB et al. Patterns of Electronic Cigarette Use Among Adults in the United States. Nicotine Tob Res 2016; 18: 715-719.

23. Goldberg RL, Cataldo JK. Using an e-Cigarette is Like Eating Tofu When You Really Want Meat. Am J Health Behav 2018; 42: 54-64.

24. Soule EK, Nasim A, Rosas S. Adverse Effects of Electronic Cigarette Use: A Concept Mapping Approach. Nicotine Tob Res 2016; 18: 678-685.

25. Anonymous. In Eaton DL, Kwan LY, Stratton K (eds): Public Health Consequences of E-Cigarettes. Washington (DC): 2018.

26. St Helen G, Eaton DL. Public Health Consequences of e-Cigarette Use. JAMA Intern Med 2018; 178: 984-986. 
27. King JL, Reboussin BA, Wiseman KD et al. Adverse symptoms users attribute to e-cigarettes: Results from a national survey of US adults. Drug Alcohol Depend 2019; 196: 9-13.

28. Layden JE, Ghinai I, Pray I et al. Pulmonary Illness Related to E-Cigarette Use in Illinois and Wisconsin - Preliminary Report. N Engl J Med 2019.

29. Rimmer A, lacobucci G. Vaping: CDC investigation continues after patient dies from severe lung injuries. BMJ 2019; 366: 15320.

30. Hopkins Tanne J. Vaping: CDC investigates severe lung injuries. BMJ 2019; 366: 15228.

31. Katz MG, Russell KW. Injury from E-Cigarette Explosion. N Engl J Med 2019; 380: 2460.

32. Rossheim ME, Livingston MD, Soule EK et al. Electronic cigarette explosion and burn injuries, US Emergency Departments 2015-2017. Tob Control 2019; 28: 472-474.

33. Amato MS, Boyle RG, Levy D. How to define e-cigarette prevalence? Finding clues in the use frequency distribution. Tob Control 2016; 25: e2429.

34. Lugo A, Asciutto R, Pacifici $R$ et al. Smoking in Italy 2013-2014, with a focus on the young. Tumori 2015; 101: 529-534.

35. Gallus S, Pacifici R, Colombo P et al. Tobacco dependence in the general population in Italy. Ann Oncol 2005; 16: 703-706.

36. Fagerstrom KO, Kunze M, Schoberberger $R$ et al. Nicotine dependence versus smoking prevalence: comparisons among countries and categories of smokers. Tob Control 1996; 5: 52-56.

37. Kyriakos CN, Filippidis FT, Hitchman S et al. Characteristics and correlates of electronic cigarette productattributes and undesirable events during ecigarette use in sixcountries of the EUREST-PLUS ITC Europe Surveys. Tobacco Induced Diseases 2018; 16(Suppl 2): 1-13.

38. McNeill A, Brose LS, Calder $R$ et al. Evidence review of e-cigarettes and heated tobacco products 2018. Available online at: https://www.gov.uk/government/publications/e-cigarettes-and-heatedtobacco-products-evidence-review/evidence-review-of-e-cigarettes-andheated-tobacco-products-2018-executive-summary\#use-of-e-cigarettesin-adults (last access: 30 July 2019). 2018.

39. Zare S, Nemati M, Zheng Y. A systematic review of consumer preference for e-cigarette attributes: Flavor, nicotine strength, and type. PLoS One 2018; 13: e0194145.

40. Kiyohara K, Tabuchi T. Electronic cigarette use in restaurants and workplaces where combustible tobacco smoking is not allowed: an Internet survey in Japan. Tob Control 2018; 27: 254-257. 
41. Chung KF, Pavord ID. Prevalence, pathogenesis, and causes of chronic cough. Lancet 2008; 371: 1364-1374.

42. Hedman L, Backman $\mathrm{H}$, Stridsman $\mathrm{C}$ et al. Association of Electronic Cigarette Use With Smoking Habits, Demographic Factors, and Respiratory Symptoms. JAMA Netw Open 2018; 1: e180789. 
Supplementary Table 1: Distribution of the study population by Smoking Cessation Service (SCS) according to the reason for attending the SCS and electronic cigarette use^ ${ }^{\wedge}$. Italy, 2016-2018.

\begin{tabular}{|c|c|c|c|c|c|c|}
\hline \multirow{2}{*}{$\begin{array}{l}\text { ID Center } \\
\text { (geographic } \\
\text { area) }\end{array}$} & \multirow{2}{*}{$\begin{array}{l}\text { Date of } \\
\text { enrolment }\end{array}$} & \multirow{2}{*}{$\begin{array}{c}\text { Total } \\
\mathrm{N}\end{array}$} & \multicolumn{2}{|c|}{$\begin{array}{l}\text { Sample of current } \\
\text { smokers attending the } \\
\text { SCS for the first time } \\
\text { for smoking cessation }\end{array}$} & \multicolumn{2}{|c|}{$\begin{array}{l}\text { Sample of current or } \\
\text { former smokers } \\
\text { attending the SCS for } \\
\text { other reasons }\end{array}$} \\
\hline & & & $\begin{array}{l}\text { E-cig ever } \\
\text { users } \\
N(\%)\end{array}$ & $\begin{array}{c}\text { E-cig } \\
\text { never } \\
\text { users } \\
\mathrm{N}(\%) \\
\end{array}$ & $\begin{array}{l}\text { E-cig ever } \\
\text { users } \\
\mathrm{N}(\%)\end{array}$ & $\begin{array}{c}\text { E-cig } \\
\text { never } \\
\text { users } \\
\mathrm{N}(\%) \\
\end{array}$ \\
\hline $\begin{array}{l}\text { A (Southern } \\
\text { Italy) }\end{array}$ & $\begin{array}{c}15 / 09 / 2016- \\
24 / 10 / 2017\end{array}$ & 119 & $45(37.8)$ & $54(45.4)$ & $4(3.4)$ & $16(13.5)$ \\
\hline $\begin{array}{l}\text { B (Southern } \\
\text { Italy) }\end{array}$ & $\begin{array}{c}17 / 10 / 2016- \\
14 / 02 / 2018\end{array}$ & 102 & $63(61.8)$ & $26(25.5)$ & $9(8.8)$ & $4(3.9)$ \\
\hline $\begin{array}{l}\text { C (Southern } \\
\text { Italy) }\end{array}$ & $\begin{array}{c}29 / 09 / 2016- \\
30 / 07 / 2018\end{array}$ & 87 & $0(0.0)$ & $0(0.0)$ & $87(100)$ & $0(0.0)$ \\
\hline $\begin{array}{l}\mathrm{D} \text { (Central } \\
\text { Italy) }\end{array}$ & $\begin{array}{c}13 / 09 / 2016- \\
28 / 07 / 2018\end{array}$ & 80 & $42(52.5)$ & $24(30.0)$ & $10(12.5)$ & $4(5.0)$ \\
\hline $\begin{array}{l}\text { E (Central } \\
\text { Italy) }\end{array}$ & $\begin{array}{c}25 / 07 / 2016- \\
31 / 07 / 2017\end{array}$ & 78 & $50(64.1)$ & $28(35.9)$ & $0(0.0)$ & $0(0.0)$ \\
\hline $\begin{array}{l}\mathrm{F} \text { (Central } \\
\text { Italy) }\end{array}$ & $\begin{array}{c}06 / 06 / 2016- \\
06 / 11 / 2017\end{array}$ & 59 & $30(50.8)$ & $29(49.2)$ & $0(0.0)$ & $0(0.0)$ \\
\hline $\begin{array}{l}\text { G (Central } \\
\text { Italy) }\end{array}$ & $\begin{array}{c}21 / 01 / 2016- \\
15 / 12 / 2016\end{array}$ & 36 & $15(41.7)$ & $13(36.1)$ & 7 (19.4) & $1(2.8)$ \\
\hline $\begin{array}{l}\mathrm{H} \text { (Central } \\
\text { Italy) }\end{array}$ & $\begin{array}{c}10 / 02 / 2017- \\
31 / 01 / 2018\end{array}$ & 34 & $23(67.7)$ & $6(17.7)$ & $4(11.8)$ & $1(2.9)$ \\
\hline $\begin{array}{l}\text { I (Central } \\
\text { Italy) }\end{array}$ & $\begin{array}{c}\text { 05/09/2016 - } \\
26 / 09 / 2017\end{array}$ & 24 & $8(33.3)$ & $11(45.8)$ & $2(8.3)$ & $3(12.5)$ \\
\hline $\begin{array}{l}\mathrm{L} \text { (Northern } \\
\text { Italy) }\end{array}$ & $\begin{array}{c}13 / 07 / 2016- \\
26 / 07 / 2017\end{array}$ & 9 & $4(44.4)$ & $5(55.6)$ & $0(0.0)$ & $0(0.0)$ \\
\hline $\begin{array}{l}\text { M (Northern } \\
\text { Italy) }\end{array}$ & $\begin{array}{c}05 / 09 / 2016- \\
21 / 09 / 2016\end{array}$ & 4 & $3(75.0)$ & $1(25.0)$ & $0(0.0)$ & $0(0.0)$ \\
\hline $\begin{array}{l}\mathrm{N} \text { (Northern } \\
\text { Italy) }\end{array}$ & $\begin{array}{c}12 / 09 / 2016- \\
12 / 09 / 2016\end{array}$ & 1 & $1(100.0)$ & $0(0.0)$ & $0(0.0)$ & $0(0.0)$ \\
\hline Total & $\begin{array}{c}06 / 06 / 2016- \\
30 / 07 / 2018\end{array}$ & 633 & $284(44.9)$ & $197(31.1)$ & $123(19.4)$ & $29(4.6)$ \\
\hline
\end{tabular}





\section{Chapter 6}

Electronic cigarette use in 12 European countries. Results from the TackSHS survey 


\subsection{Abstract}

Background: Limited data on electronic cigarette prevalence, patterns and settings of use are available from several European countries.

Methods: Within the TackSHS project, a face-to-face survey was conducted in 2017-2018 in 12 European countries (Bulgaria, England, France, Germany, Greece, Ireland, Italy, Latvia, Poland, Portugal, Romania and Spain). Overall, 11,876 participants, representative of the population aged $\geq 15$ years in each country, provided information on electronic cigarette.

Results: $2.4 \%$ (95\% C.I. $2.2-2.7)$ of the subjects (2.5\% among men and $2.4 \%$ among women; $0.4 \%$ among never, $4.4 \%$ among current- and $6.5 \%$ among exsmokers) reported current use of electronic cigarette, ranging from $0.6 \%$ in Spain to $7.2 \%$ in England. Of the 272 electronic cigarette users, $52.6 \%$ were dual users (i.e., users of both electronic and conventional cigarettes) and $58.8 \%$ used liquids with nicotine. In all, $65.1 \%$ reported using electronic cigarette in at least one indoor setting where smoking is forbidden, in particular in workplaces (34.9\%), and bars and restaurants (41.5\%). Multivariable logistic regression analysis showed that electronic cigarette use was lower among older individuals ( $p$ for trend $<0.001$ ) and higher among individuals with high level of education ( $p$ for trend 0.040). Participants from countries with higher tobacco cigarette prices more frequently reported electronic cigarette use (odds ratio $3.62 ; 95 \%$ confidence interval 1.80-7.30).

Conclusions: Extrapolated to the whole adult population of these 12 European countries, more than 8.3 million people use electronic cigarettes. The majority of users also smoked conventional cigarettes, used electronic cigarettes with nicotine and consumed electronic cigarettes in smoke-free indoor areas.

Keywords: electronic cigarettes; ENDS; nicotine; cross-sectional study; Europe 


\subsection{Introduction}

Electronic cigarettes are electronic devices that heat a liquid to generate an inhalable vapour, which may contain nicotine.[1, 2] In Europe, after an initial rapid spread since 2010, [3] the proportion of adult regular electronic cigarette users rose from $1.5 \%$ in 2014 to $1.8 \%$ in 2017 , with large differences among countries, depending on the fiscal and regulatory 'interventions' or 'climate' these products are subjected to across Europe [4]. An Eurobarometer survey conducted in summer 2020 showed that more than 1 in 10 subject has at least tried e-cigarette, $9 \%$ having tried this product only once or twice, $3 \%$ having used it in the past and $2 \%$ using it currently [5].

Public health experts hold different opinions on the role of electronic cigarettes on tobacco control. Public Health England and electronic cigarette advocates promote the substitution of electronic cigarettes for combustible cigarettes among all smokers, hinting at a possible harm reduction [6]. On the other hand, international organizations including the World Health Organization (WHO) and the European Commission raised some concerns on the use of electronic cigarettes $[7,8]$. The WHO recently warned against electronic cigarette use as a smoking cessation tool, stating that it is "undoubtedly harmful" and that the majority of electronic cigarette users are dual users (who concurrently use conventional and electronic cigarettes) [7]. Several studies have shown that electronic cigarettes have harmful health effects $[9,10]$. Moreover, few studies reported that electronic cigarettes are commonly used in indoor sites where smoking is forbidden [11-13], suggesting that smokers might decide to use electronic cigarettes in smoke-free areas to circumvent smoking bans and be able to maintain their daily intake of nicotine [11]. At least two systematic reviews showed that electronic cigarettes help smokers to quit in clinical and/or controlled settings [14, 15]. This is not true in the real-world use or without further support $[7,15]$. Moreover, ex-smokers having quit through electronic cigarettes could become long-term electronic cigarette users, which may have adverse implications from a public health perspective $[7,16,17]$.

Furthermore, there are even more concerns for non-smokers. Electronic cigarettes are promoted also to never smokers, particularly young people [18], and former smokers who quit. There is increasing evidence that electronic cigarettes constitutes a gateway towards nicotine addiction (or even smoking combustible cigarettes) rather than an effective tool for harm reduction $[1,18,19]$. In addition, some studies on adults found that among electronic cigarette users, non-smokers starting (or ex-smokers re-starting) smoking after using electronic cigarettes outnumbered current smokers who stop smoking after using electronic cigarettes [1, 20].

Given the rapid change in the use of tobacco and related products in European countries [21], it is important to provide updated data on the prevalence and 
characteristics of electronic cigarette users and the patterns of use, particularly in Europe. Comparisons among countries are however difficult, since data are mostly based on national surveys and are collected differently across countries $[1,22-24]$. Even the comparability of previous Eurobarometer data with the most recent ones is difficult due to changes in the methodology [25]. Thus, updated information on electronic cigarette use in different countries is needed, with a standardized assessment tool. In Europe, the prevalence of electronic cigarette use differed across countries: the United Kingdom (UK) had the highest prevalence in 2014 and 2017 (3.6\% and 4.7), and Malta had the lowest (0.0\%) in 2014 with Italy and Bulgaria (0.2\%) in 2017 [4]. However, the landscape for electronic cigarettes is changing constantly, particularly in Europe [3], meaning that the prevalence and patterns of use of electronic cigarettes need to be monitored. Using data from the TackSHS survey, we illustrate the patterns of use of electronic cigarettes with country comparisons in 12 European countries [2628].

\subsection{Methods}

Within the TackSHS project (Tackling second-hand tobacco smoke and electronic cigarette emissions: exposure assessment, novel interventions, impact on lung diseases and economic burden in diverse European populations) [29], in 2017-2018 a survey was conducted in 12 strategically selected European countries (Bulgaria, England, France, Germany, Greece, Ireland, Italy, Latvia, Poland, Portugal, Romania, and Spain), representing geographical, legislative and cultural variations across the European Union (EU) and covering about $80 \%$ of the whole EU-28 population (at the time of the survey). The fieldwork was conducted by Doxa, the Italian branch of the Worldwide Independent Network/Gallup International Association, and its European partners [28].

In each country we surveyed a sample of around 1000 individuals aged 15 years and older (in England $\geq 16$ years and in Ireland $\geq 18$ years), representative of the general population in terms of age, sex, area of residence and - in most countries - socioeconomic characteristics. The survey comprised 11,902 subjects, representative of 342 million inhabitants aged 15 years or older of the 12 selected countries. Sampling methods differed by country: in Bulgaria, Greece, Italy, Latvia and Romania, a multi-stage sampling was used with participants randomly selected to be representative of their population in terms of sex, age, and geographic area (in Italy, also by socio-economic status); in Germany, Ireland, Poland, Portugal and Spain, stratified random sampling was used, combining also quotas on sex and age (in Ireland also social class); in England, cluster sampling was used with quotas on age, sex, socio-economic status (SES), 
region, urban/rural dwelling; in France, quotas on age, sex, region, and city size were used [28].

Ad hoc trained interviewers conducted the survey with computer-assisted personal interviewing in all 12 countries. The testing fieldwork was conducted by DOXA on 1059 participants in November 2016 in Italy. The fieldwork in the other 11 countries was conducted between June 2017 (in Romania) and October 2018 (in Latvia).

Approval for the study was obtained from a local Ethics Committee in each of the 12 countries. The interviewers informed all participants about details of the survey and all participants provided their consent. The study protocol is registered at ClinicalTrials.gov (ID: NCT02928536).

Besides information on demographic (e.g., sex and age) and socio-economic characteristics (e.g., level of education and self-assessed household economic status relative to the country-specific population), a specific section of the questionnaire focused on electronic cigarettes. Participants were asked if they: i) had tried electronic cigarettes once or twice in their life; ii) had used them in the past but not over the last 30 days (past users); iii) used them occasionally ( 5 days or less in the previous 30 days); or iv) used them regularly (more than 5 days in the previous 30 days). Current electronic cigarette users were those reporting electronic cigarette use either occasionally or regularly. Past and current electronic cigarette users provided information on their approximate number of puffs per day, the type of electronic cigarette used (with or without nicotine), and the type of device used (rechargeable, disposable, or mods and variable voltage devices).

Users also provided information on electronic cigarette consumption (i.e., number of puffs per day; separately for working and non-working days) in each of selected indoor areas, including at home, at work, in public transport, in private cars, and in all other indoor places (including restaurants and bars).

Electronic cigarette users were also asked if they had visited specific sites (indoors, indoor transport and outdoors) in the previous six months and if they had used electronic cigarettes during their last visit to each site. Indoor sites (excluding smoking areas) included: i) a friend's or relative's home, ii) drinking establishments (such as bars), iii) eating establishments (restaurants), iv) disco/club/concerts in indoor arenas, v) cinema/theatres, vi) courses or classes in hobbies/sports, vii) public libraries/government offices, viii) indoor train stations or subway stops, ix) airports, x) healthcare centers (e.g., hospitals). Indoor transports included: i) cars/private vehicles together with at least one minor (aged $<18$ years), ii) cars/private vehicles without minors, iii) public transport (tram/bus/subway), iv) trains, v) airplanes. Outdoor sites included: i) patios of restaurants or bars, ii) trams/bus/subway stops, iii) outdoor areas of hospitals, iv) outdoor areas of schools, v) parks, vi) children's playgrounds, vi) stadiums/outdoor arenas, vii) beaches, viii) motorbikes/scooters, ix) bicycles. 
The questionnaire also included a section on smoking habits. Never smokers were defined as participants who had never smoked or had smoked less than 100 cigarettes in their lifetime. Ever smokers were the participants who reported to have smoked at least 100 cigarettes (including hand-rolled cigarettes) during their lifetime. Current smokers were the subjects who reported to be currently smoking at the time of the interview, while ex-smokers were those who had stopped smoking by the time they participated in the study.

The 12 countries were classified according to their gross domestic product (GDP) per capita [30]: $<€ 25,000$ (Latvia, Romania, Poland, Portugal, Greece, Bulgaria) and $\geq € 25,000$ (England, France, Germany, Ireland, Italy, Spain); according to the score of 2016 version of the Tobacco Control Scale (TCS; the score attributed to each country increases with the strength of tobacco control policies up to a maximum of 100 points, indicating full implementation) [31]: $\leq 50$ (Bulgaria, Germany, Greece, Latvia, Poland, Portugal), and $>50$ (Spain, France, Ireland, Italy, Romania, England); and according to the component with the greatest weight in the 2016 version of the TCS, i.e., the component referring to the average price standardized by GDP per capita of cigarettes in the country (with a maximum score equal to 30 , indicating the highest standardized cigarette price), as a proxy of the affordability of tobacco in each country: $<16$ (Germany, Italy, Latvia, Poland, Spain) and $\geq 16$ (England, France, Ireland, Romania, Portugal, Greece, Bulgaria) [32].

\subsubsection{Statistical analysis}

In each country, statistical weights were computed and applied to assure the same age, sex and geographic area specific distribution of each country, using as a standard the data from the corresponding National Institute of Statistics. Estimates for the entire sample were made using "country weights", combining individual weights with an additional weighting factor, each country contributing in proportion to its population aged 15 years or over, according to Eurostat 2018 [33].

To take into account the heterogeneity between the 12 countries, odds ratios $(\mathrm{OR})$ and their $95 \%$ confidence intervals $(\mathrm{Cl})$ for current vs. non-use of electronic cigarettes were calculated with multilevel logistic random-effects models. The study country effects were considered as random intercepts, whereas sex, age, level of education and smoking status were considered as adjusting variables. Country weights were used in all logistic regression models. All the analyses were done with SAS 9.4 (SAS Institute; Cary, North Carolina, USA). 


\subsection{Results}

Of the 11,902 participants, 26 did not provide information on electronic cigarette use. All the analyses are based on the remaining 11,876 (99.8\%) participants. Among all participants, the prevalence of current electronic cigarette users was $2.4 \%$, with the highest estimates in England (7.2\%), France (4.3\%) and Greece $(4.1 \%)$ and the lowest in Spain $(0.6 \%)$, Poland $(0.7 \%)$ and Portugal $(0.9 \%$; Figure 1 and Table 1). The prevalence of electronic cigarette use was $2.5 \%$ in men and $2.4 \%$ in women. Overall, the prevalence of electronic cigarette use was $0.4 \%$ in never smokers, $4.4 \%$ in current and $6.5 \%$ in ex-smokers.

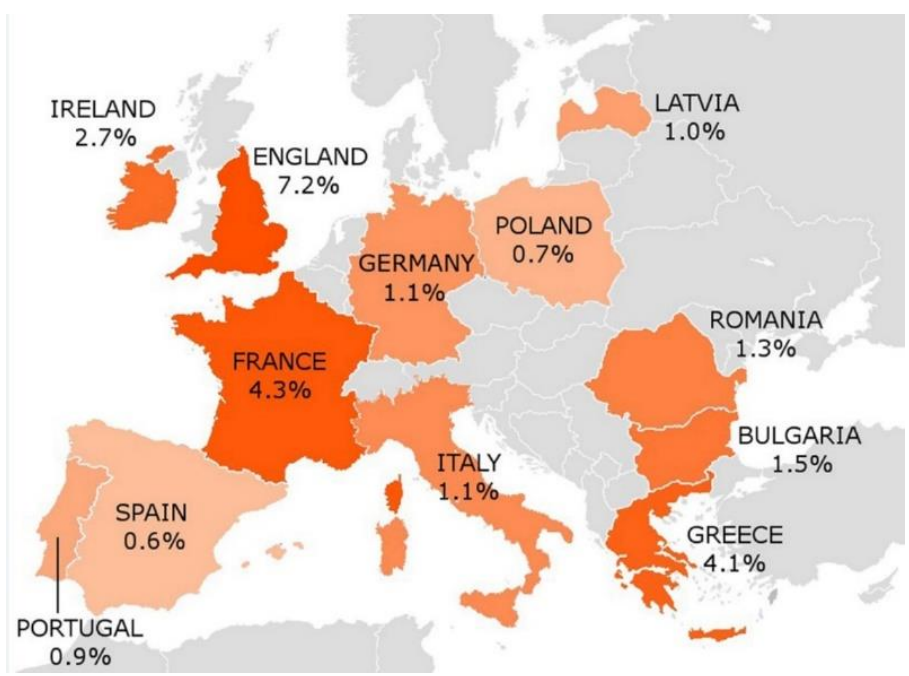

Figure 1: Country-specific prevalence (\%) of electronic cigarette use among subjects aged $\geq 15$ years in 12 selected European countries. TackSHS, 20172018.

${ }^{a}$ Country weights were applied, which combined individual weights with an additional weighting factor, each country contributing in proportion to its population aged 15 years or over (from Eurostat).[33] 
Table 1: Country-specific prevalence (\%) estimates of electronic cigarette use in 12 European countries among adult population aged $\geq 15$ years. TackSHS, 2017-2018.

\begin{tabular}{|c|c|c|c|c|c|c|c|c|c|c|c|}
\hline \multirow{2}{*}{ Country (n) } & \multirow{2}{*}{$\begin{array}{c}\text { Never } \\
\text { users } \\
(\%)\end{array}$} & \multirow{2}{*}{$\begin{array}{l}\text { Tried 1- } \\
2 \text { times } \\
(\%)\end{array}$} & \multirow{2}{*}{$\begin{array}{l}\text { Past } \\
\text { users } \\
(\%)\end{array}$} & \multirow{2}{*}{$\begin{array}{c}\text { Occasi } \\
\text { onal } \\
\text { users } \\
(\%)\end{array}$} & \multirow{2}{*}{$\begin{array}{c}\text { Regular } \\
\text { users } \\
(\%)\end{array}$} & \multicolumn{6}{|c|}{$\begin{array}{c}\begin{array}{c}\text { Current users } \\
(\%)\end{array} \\
\end{array}$} \\
\hline & & & & & & Total & Men & Women & Never & Current & Former \\
\hline Bulgaria (1050) & 81.9 & 13.3 & 3.4 & 0.7 & 0.8 & 1.5 & 2.0 & 1.0 & 0.4 & 3.0 & 1.1 \\
\hline England (1013) & 79.6 & 9.6 & 3.7 & 1.5 & 5.7 & 7.2 & 6.4 & 7.9 & 0.3 & 13.9 & 21.0 \\
\hline France (1018) & 79.7 & 11.4 & 4.6 & 1.2 & 3.1 & 4.3 & 3.9 & 4.7 & 0.8 & 7.6 & 7.8 \\
\hline Germany (1013) & 94.0 & 4.7 & 0.2 & 0.2 & 0.8 & 1.1 & 1.7 & 0.5 & 0.6 & 1.2 & 3.1 \\
\hline Greece (1000) & 74.2 & 14.2 & 7.5 & 1.3 & 2.8 & 4.1 & 4.4 & 3.8 & 0.0 & 8.6 & 4.7 \\
\hline Ireland (941) & 86.8 & 9.1 & 1.4 & 0.7 & 2.1 & 2.7 & 2.7 & 2.7 & 0.6 & 5.6 & 8.1 \\
\hline Italy (1059) & 90.1 & 6.6 & 2.2 & 0.7 & 0.4 & 1.1 & 1.8 & 0.5 & 0.3 & 2.4 & 3.9 \\
\hline Latvia (1022) & 81.0 & 15.3 & 2.8 & 0.6 & 0.5 & 1.0 & 1.7 & 0.4 & 0.4 & 2.0 & 1.5 \\
\hline Poland (724) & 90.2 & 6.6 & 2.6 & 0.1 & 0.6 & 0.7 & 1.1 & 0.3 & 0.3 & 1.3 & 1.4 \\
\hline Portugal (1000) & 89.3 & 9.7 & 0.1 & 0.3 & 0.6 & 0.9 & 1.3 & 0.6 & 0.0 & 1.4 & 2.7 \\
\hline Romania (1010) & 84.6 & 12.6 & 1.6 & 0.9 & 0.3 & 1.3 & 1.2 & 1.3 & 0.0 & 3.2 & 0.8 \\
\hline Spain (1026) & 91.1 & 6.5 & 1.7 & 0.3 & 0.3 & 0.6 & 0.7 & 0.5 & 0.0 & 1.5 & 0.6 \\
\hline
\end{tabular}

${ }^{\mathrm{a} C}$ Country weights were applied, which combined individual weights with an additional weighting factor, each country contributing in proportion to its population aged 15 years or over (from Eurostat).[33]

Table 2 shows patterns of use for all 272 current electronic cigarette users. The median number of puffs per day was 50 and the proportion of dual users was $52.6 \%$ (95\% Cl: $46.6 \%-58.5 \%)$. Overall, $58.8 \%$ (95\% Cl: $53.0 \%-64.7 \%)$ of electronic cigarette users used liquids with nicotine. This proportion increased to $66.4 \%$ (95\% Cl: $58.7 \%-74.2 \%$ ) among dual users. The most commonly used type of device was rechargeable (82.4\%; $95 \% \mathrm{Cl}: 77.8 \%-86.9 \%)$, followed by mods and variable voltage devices (12.9\%; $95 \% \mathrm{Cl}: 8.9 \%-16.9 \%)$ and disposable devices (4.8\%; $95 \% \mathrm{Cl}$ : $2.2 \%-7.3 \%$ ). In all, $80.2 \%$ (95\% Cl: $75.4 \%-85.9 \%)$ of the electronic cigarette users reported using electronic cigarettes daily in indoor settings. The home was the place with the highest proportion of electronic cigarette use (73.5\%; 95\% Cl: 68.3\%-78.8\%). 
Table 2: Patterns ${ }^{a}$ of current (occasional and regular) electronic cigarette use among 272 users in 12 European countries among adults aged $\geq 15$ years. TackSHS, 2017-2018.

\begin{tabular}{|c|c|c|c|c|c|c|c|c|c|c|c|c|}
\hline \multirow{2}{*}{$\begin{array}{l}\text { Country } \\
\text { (No of } \\
\text { current e- } \\
\text { cig users) }\end{array}$} & \multirow{2}{*}{$\begin{array}{c}\text { Median } \\
\text { No of } \\
\text { puffs } \\
\text { per day }\end{array}$} & \multirow{2}{*}{$\begin{array}{l}\text { Dual } \\
\text { use } \\
(\%)\end{array}$} & \multirow{2}{*}{$\begin{array}{c}\text { E-cig } \\
\text { with } \\
\text { nicotine } \\
(\%)\end{array}$} & \multicolumn{3}{|c|}{$\begin{array}{c}\text { Type of electronic cigarette } \\
\text { device }(\%)\end{array}$} & \multicolumn{6}{|c|}{ Daily use in various indoor settings (\%) } \\
\hline & & & & $\begin{array}{l}\text { Rechar } \\
\text { geable }\end{array}$ & $\begin{array}{l}\text { Dispos } \\
\text { able }\end{array}$ & Mods & Home & $\begin{array}{c}\text { Wor } \\
\mathrm{k}\end{array}$ & $\begin{array}{c}\text { Public } \\
\text { transpo } \\
\text { rts }\end{array}$ & $\begin{array}{c}\text { Private } \\
\text { cars }\end{array}$ & $\begin{array}{c}\text { Other } \\
\text { indoor } \\
\text { settings }\end{array}$ & $\begin{array}{c}\text { Any } \\
\text { indoor } \\
\text { settings }\end{array}$ \\
\hline $\begin{array}{l}\text { Total } \\
(272)\end{array}$ & 50 & 52.6 & 58.8 & 82.4 & 4.8 & 12.9 & 73.5 & 34.9 & 8.8 & 27.2 & 34.6 & 80.2 \\
\hline $\begin{array}{l}\text { Bulgaria } \\
\text { (15) }\end{array}$ & 350 & 73.3 & 73.3 & 53.3 & 13.3 & 33.3 & 93.3 & 66.7 & 20.0 & 20.0 & 73.3 & 100.0 \\
\hline $\begin{array}{l}\text { England } \\
(73)\end{array}$ & 80 & 38.4 & 56.2 & 89.0 & 5.5 & 5.5 & 86.3 & 52.1 & 11.0 & 27.4 & 30.1 & 93.2 \\
\hline $\begin{array}{l}\text { France } \\
(44)\end{array}$ & 40 & 54.6 & 68.2 & 84.1 & 2.3 & 13.6 & 70.5 & 20.5 & 18.2 & 27.3 & 38.6 & 75.0 \\
\hline $\begin{array}{l}\text { Germany } \\
\text { (13) }\end{array}$ & 600 & 23.1 & 61.5 & 53.9 & 15.4 & 30.8 & 53.9 & 15.4 & 0.0 & 23.1 & 23.1 & 53.9 \\
\hline $\begin{array}{l}\text { Greece } \\
\text { (41) }\end{array}$ & 200 & 70.7 & 61.0 & 70.7 & 0.0 & 29.3 & 58.5 & 26.8 & 0.0 & 34.2 & 41.5 & 65.9 \\
\hline $\begin{array}{l}\text { Ireland } \\
\text { (25) }\end{array}$ & 40 & 40.0 & 44.0 & 88.0 & 8.0 & 4.0 & 76.0 & 20.0 & 8.0 & 28.0 & 12.0 & 84.0 \\
\hline $\begin{array}{l}\text { Italy } \\
(14)\end{array}$ & 35 & 50.0 & 64.3 & 92.9 & 0.0 & 7.1 & 78.6 & 42.9 & 7.1 & 28.6 & 35.7 & 78.6 \\
\hline $\begin{array}{l}\text { Latvia } \\
\text { (13) }\end{array}$ & 23 & 53.9 & 46.2 & 84.6 & 7.7 & 7.7 & 30.8 & 0.0 & 0.0 & 0.0 & 15.4 & 46.2 \\
\hline $\begin{array}{l}\text { Poland } \\
\text { (6) }\end{array}$ & 15 & 33.3 & 66.7 & 100.0 & 0.0 & 0.0 & 100.0 & 50.0 & 0.0 & 0.0 & 33.3 & 100.0 \\
\hline $\begin{array}{l}\text { Portugal } \\
\text { (9) }\end{array}$ & 99 & 55.6 & 55.6 & 88.9 & 0.0 & 11.1 & 77.8 & 44.4 & 0.0 & 44.4 & 33.3 & 88.9 \\
\hline $\begin{array}{l}\text { Romania } \\
\text { (11) }\end{array}$ & 20 & 90.9 & 54.6 & 90.9 & 9.1 & 0.0 & 81.8 & 45.5 & 9.1 & 27.3 & 45.5 & 90.9 \\
\hline $\begin{array}{l}\text { Spain } \\
\text { (8) }\end{array}$ & 25 & 87.5 & 50.0 & 100.0 & 0.0 & 0.0 & 62.5 & 25.0 & 12.5 & 50.0 & 50.0 & 75.0 \\
\hline
\end{tabular}

${ }^{a}$ All the estimates are unweighted

Figure 2 and Supplementary Table 1 show the proportion of electronic cigarette use in selected indoor and outdoor sites the last time users visited each specific site (in the previous six months). Among electronic cigarette users having visited friends' or relatives' homes in the last six months, $65.8 \%$ reported to have used electronic cigarettes on the last occasion, $49.5 \%$ in bars, $31.3 \%$ in restaurants. In the other indoor sites, electronic cigarette use ranged from $5.1 \%$ in hospitals to $35.8 \%$ in disco or clubs. Use in (indoor) transport ranged between $3.8 \%$ in airplanes and $48.6 \%$ in private cars without minors, with $23.6 \%$ using electronic cigarettes in private vehicles with minors present. For electronic cigarette users visiting outdoor settings over the last six months, those consuming electronic cigarettes ranged from $39.7 \%$ in children's playgrounds to $73.8 \%$ on terraces of hospitality venues. Respectively, $16.0 \%$ and $10.0 \%$ of users consumed electronic cigarettes on motorbikes/scooters or bicycles. 


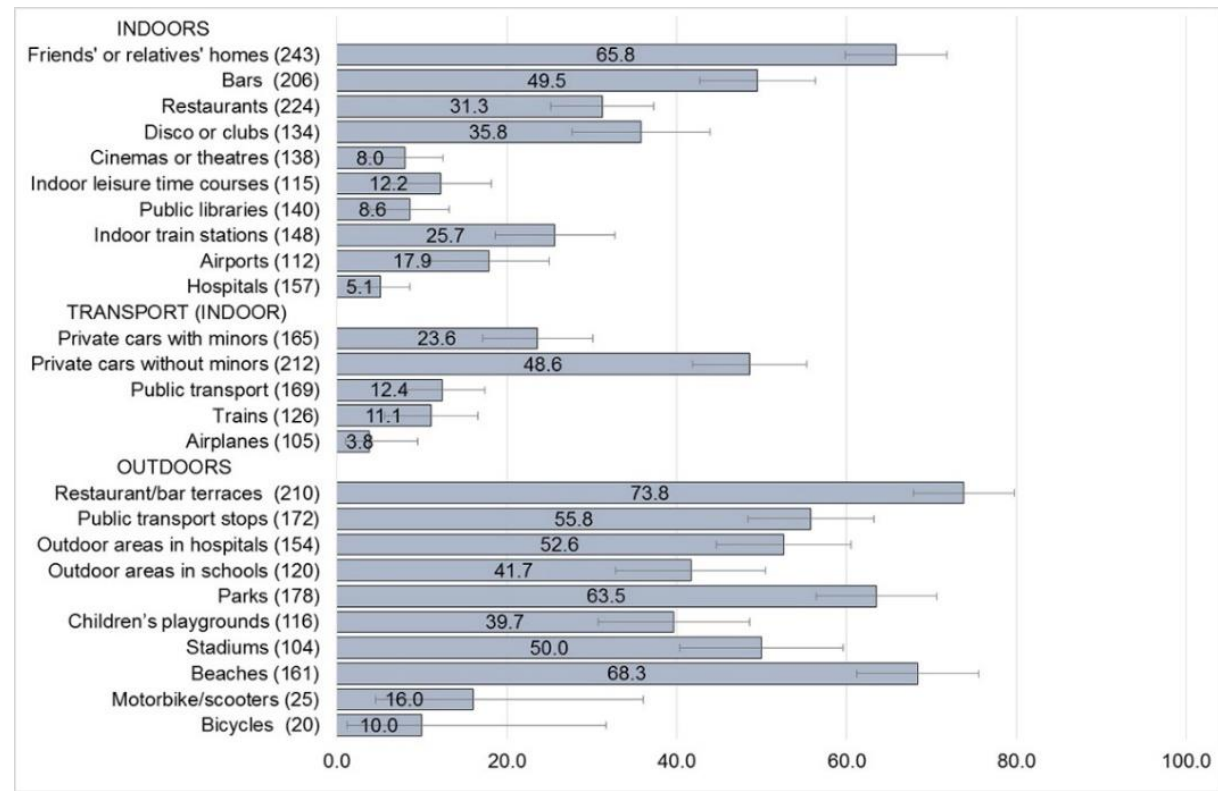

Figure 2: Use of electronic cigarettes in selected indoor and outdoor areas, among 272 users who visited the corresponding setting in the last six months in 12 European countries. Proportions (\%) and corresponding 95\% confidence intervals (Cl). TackSHS survey 2017-2018.

$\mathrm{Cl}$ : Confidence Interval

For each setting, numbers in round brackets are number of the participants who visited the corresponding setting in the last six months and the percentages of participants who visited the setting in the last six months.

Table 3 shows the proportion of users consuming electronic cigarettes in selected indoor sites where smoking is forbidden. In all, $65.1 \%$ (95\% Cl: 59.4\%-70.7\%) reported using electronic cigarettes in one indoor setting, in particular workplaces (34.9\%; 95\% Cl: $29.3 \%-40.6 \%)$ and bars and restaurants $(41.5 \%$; $95 \% \mathrm{Cl}$ : $35.7 \%-47.4 \%)$. The proportion of users consuming electronic cigarettes in places where smoking is forbidden ranged between $23.1 \%$ in Latvia and $93.3 \%$ in Bulgaria. 
Table 3: Distribution a of 272 European current electronic cigarette users aged $\geq 15$ years who used electronic cigarettes in workplaces and selected indoor public places where smoking is forbidden ${ }^{b}$. TackSHS, 2017-2018.

\begin{tabular}{|c|c|c|c|c|c|c|c|}
\hline \multirow{2}{*}{$\begin{array}{l}\text { Country } \\
\text { (No of current e-cig } \\
\text { users) }\end{array}$} & \multirow{2}{*}{$\begin{array}{l}\text { Workplace } \\
\text { (daily use) }\end{array}$} & \multicolumn{5}{|c|}{ Indoor public places where smoking is forbidden ${ }^{\mathrm{b}}(\%)$} & \multirow{2}{*}{$\begin{array}{l}\text { Workplace } \\
\text { and any public } \\
\text { places where } \\
\text { smoking is } \\
\text { forbidden }\end{array}$} \\
\hline & & $\begin{array}{c}\text { Bars \& } \\
\text { Restaurants }\end{array}$ & $\begin{array}{l}\text { Disco, } \\
\text { cinemas, } \\
\text { libraries }^{c}\end{array}$ & $\begin{array}{l}\text { Hospit } \\
\text { als }\end{array}$ & $\begin{array}{l}\text { Transport } \\
\text { stations }^{d}\end{array}$ & $\begin{array}{c}\text { Public } \\
\text { transport }^{\mathrm{e}}\end{array}$ & \\
\hline Total (272) & 34.9 & 41.5 & 22.1 & 2.9 & 15.8 & 9.9 & 65.1 \\
\hline England (73) & 52.1 & 27.4 & 12.3 & 4.1 & 9.6 & 4.1 & 69.9 \\
\hline France (44) & 20.5 & 52.3 & 27.3 & 4.6 & 22.7 & 22.7 & 65.9 \\
\hline Germany (13) & 15.4 & 7.7 & 15.4 & 0.0 & 15.4 & 7.7 & 38.5 \\
\hline Greece (41) & 26.8 & 68.3 & 48.8 & 0.0 & 22.0 & 4.9 & 82.9 \\
\hline Poland (6) & 50.0 & 33.3 & 0.0 & 0.0 & 0.0 & 33.3 & 66.7 \\
\hline Portugal (9) & 44.4 & 22.2 & 11.1 & 0.0 & 11.1 & 0.0 & 55.6 \\
\hline Romania (11) & 45.5 & 54.6 & 0.0 & 0.0 & 9.1 & 0.0 & 72.7 \\
\hline Spain (8) & 25.0 & 37.5 & 0.0 & 0.0 & 25.0 & 12.5 & 50.0 \\
\hline
\end{tabular}

\footnotetext{
${ }^{a}$ All the estimates are unweighted

${ }^{b}$ Use of electronic cigarettes the last visit in each place is the last six months

${ }^{c}$ This category includes disco or clubs, cinemas or theatres, indoor leisure time courses and public libraries

${ }^{d}$ This category includes indoor train stations, subway stops and airports

e This category includes public transport, trains and airplanes
}

Table 4 shows the ORs for current electronic cigarette users according to selected individual and country-specific characteristics. 
Table 4: Odds ratios $(\mathrm{OR})$ for current electronic cigarette user vs. non-users (never and former users combined) and corresponding 95\% confidence intervals $(\mathrm{Cl})$ in the European population aged $\geq 15$ years according to selected individual and country-specific characteristics ${ }^{\mathrm{a}}$. TackSHS, 2017-2018.

\begin{tabular}{|c|c|c|c|c|}
\hline Characteristics & No. $^{b}$ & No. Users ${ }^{b}$ & $\%$ & OR $(95 \% \mathrm{Cl})^{\mathrm{c}}$ \\
\hline Total & 11876 & 272 & 2.4 & \\
\hline \multicolumn{5}{|l|}{ Sex } \\
\hline Female & 6253 & 131 & 2.4 & $1^{d}$ \\
\hline Male & 5623 & 141 & 2.5 & $0.91(0.71-1.17)$ \\
\hline \multicolumn{5}{|l|}{ Age group (years) } \\
\hline$<25$ & 1441 & 40 & 2.3 & $1^{d}$ \\
\hline $25-44$ & 4075 & 120 & 3.2 & $0.90(0.61-1.35)$ \\
\hline $45-64$ & 4318 & 100 & 2.7 & $0.69(0.46-1.03)$ \\
\hline$\geq 65$ & 2042 & 12 & 0.6 & $0.22(0.12-0.43)$ \\
\hline $\mathrm{P}$ for trend & & & & $<0.001$ \\
\hline \multicolumn{5}{|l|}{ Level of education ${ }^{\mathrm{e}}$} \\
\hline Low & 4474 & 93 & 2.1 & $1^{d}$ \\
\hline Intermediate & 4162 & 98 & 2.2 & $0.93(0.69-1.26)$ \\
\hline High & 3237 & 81 & 3.2 & $1.40(1.03-1.89)$ \\
\hline $\mathrm{P}$ for trend & & & & 0.040 \\
\hline \multicolumn{5}{|l|}{ Household economic status ${ }^{\dagger}$} \\
\hline Lower than average & 2905 & 72 & 3.4 & $1^{d}$ \\
\hline Average & 6261 & 132 & 2.4 & $0.74(0.54-1.00)$ \\
\hline Higher than average & 1587 & 54 & 3.3 & $1.03(0.69-1.52)$ \\
\hline $\mathrm{P}$ for trend & & & & 0.777 \\
\hline \multicolumn{5}{|l|}{ Smoking status } \\
\hline Never & 6502 & 24 & 0.4 & $1^{d}$ \\
\hline Current & 3326 & 143 & 4.4 & $12.67(8.29-19.35)$ \\
\hline Former & 2048 & 105 & 6.5 & $18.83(12.24-28.96)$ \\
\hline \multicolumn{5}{|l|}{ GDP per capita ${ }^{g}$} \\
\hline$\leq 25,000 €$ & 5806 & 95 & 1.3 & $1^{d}$ \\
\hline$>25,000 €$ & 6070 & 177 & 2.8 & $2.25(0.75-6.79)$ \\
\hline \multicolumn{5}{|l|}{ TCS $^{h}$} \\
\hline$\leq 50$ & 5809 & 97 & 1.2 & $1^{d}$ \\
\hline$>50$ & 6067 & 175 & 3.2 & $2.10(0.82-5.41)$ \\
\hline \multicolumn{5}{|l|}{ TCS price component } \\
\hline$<16$ & 4844 & 54 & 0.9 & $1^{d}$ \\
\hline$\geq 16$ & 7032 & 218 & 4.5 & $3.62(1.80-7.30)$ \\
\hline
\end{tabular}

Cl: Confidence Interval; GDP: Gross domestic product; OR: Odds Ratio; TCS: Tobacco Control Scale; a Country weights combined individual weights with an additional weighting factor, with each country contributing in proportion to its population aged 15 years or over (from Eurostat)[33]. Unweighted numbers; ${ }^{\mathrm{c}}$ ORs and their $95 \% \mathrm{Cls}$ were calculated using multilevel logistic randomeffects models, to take into account the heterogeneity among the 12 European countries. The country effects were considered as random intercepts, and sex, age, level of education and smoking status as adjusting variables. Figures in bold type are significant at 0.05 ; ${ }^{\mathrm{d}}$ Reference category; ${ }^{e}$ The sum does not add up to the total because of a few missing values; ${ }^{\dagger}$ Selfassessment of household (family) economic status relative to the country-specific population. This variable is missing for all Germans, 79 Latvians and, 35 Romanians; ${ }^{9}$ GDP per capita $\leq 25,000 €$ : BG, GR, LV, PO, PT, RO; >25,000€: ES, FR, GE, IE, IT, UK; ${ }^{\mathrm{h}}$ TCS $\leq 50$ : BG, DE, GR, LV, PL, PT; TCS >50: ES, FR, IE, IT, RO, UK; ' ${ }^{T C S}$ price component<16: DE, IT, LV, PL, ES; $\geq 16$ : BG, FR, GR, IE, PT, RO, UK. 
No statistically significant relationship was observed between sex and electronic cigarette use. Electronic cigarette use was lower in older individuals ( $p$ for trend $<0.001$ ) and higher in individuals with high level of education ( $p$ for trend $=0.040$ ). There was no significant association between household economic status and electronic cigarette use. Compared to never smokers, the OR for current electronic cigarette use was 12.7 (95\% Cl: 8.3-19.4) for current smokers and 18.8 (95\% Cl: 12.2-29.0) for ex-smokers. There was also no significant relationship between GDP per capita or TCS score and electronic cigarette use, but participants from countries with higher cigarette prices more frequently reported electronic cigarette use compared to those from countries with lower prices (OR=3.62; 95\% Cl: 1.80-7.30).

Supplementary Table 2 shows the ORs for dual use among current electronic cigarette users according to selected characteristics. Dual users were less frequently males $(\mathrm{OR}=0.60 ; 95 \% \mathrm{Cl}: 0.36-1.00)$, older ( $p$ for trend $<0.001)$ and with higher income ( $p$ for trend $=0.032$ ).

\subsection{Discussion}

This face-to-face survey, based on a sample representing $80 \%$ of the whole EU28 population in $2017-2018$, shows that $2.4 \%$ of participants aged 15 years or more consumed electronic cigarettes in 12 European countries.

Electronic cigarette use still appears relatively limited in Europe, considering that $30 \%$ of current users are only occasional users, i.e. using the product on 5 days or less in the previous month. However, compared to Eurobarometer data collected in 2014-2017 [4], the prevalence of electronic cigarette use has increased in all countries, except for Germany and Poland where it fell slightly.

The prevalence of electronic cigarette users differed substantially by country, from less than $1 \%$ in Spain, Poland and Portugal to more than $7 \%$ in England. The wide spread of electronic cigarettes in the UK has been reported in several other studies [4,34] and is probably explained by the early endorsement of electronic cigarettes by Public Health England followed by other UK institutions. This governmental agency has included electronic cigarettes among smoking cessation tools, recommending to improve access to these products for smokers in disadvantaged groups [6]. However, in England almost $40 \%$ of current electronic cigarette users are dual users (i.e. also smoking conventional cigarettes). Considering all the 12 European countries combined, the proportion of dual electronic cigarette users exceeds $50 \%$. This result, confirmed by most studies $[4,35,36]$, once again highlights the lack of independent evidence on the effectiveness of these products as a population-level intervention to quit conventional tobacco use [7].

One potential reason why people are dual users is to circumvent smoking bans. In agreement with other studies in Europe [11-13, 37], we found that 
approximately two out of three users consumed electronic cigarettes in indoor smoke-free settings, particularly in workplaces, restaurants and bars, where regulation on this novel products is still limited in Europe [38]. It is increasingly evident that tobacco companies have been using electronic cigarettes and other novel tobacco products as a means to divert attention from effective tobacco control measures, thus possibly attenuating the effects of European smoking bans.

We confirm findings from other studies showing that the majority of European electronic cigarette users use rechargeable devices [11, 39]. We found no indication of high use of disposable devices, although things might change rapidly as it has been recently shown among US youth [40].

Moreover, most users - particularly current smokers - consume electronic cigarettes with nicotine $[39,41]$. Half of non-smokers too use electronic cigarettes with nicotine, thus increasing the risk of starting tobacco smoking or relapsing [1, 42, 43].

Current literature suggests that electronic cigarette use is equally prevalent among men and women [36]. Accordingly, we did not find any significant difference in electronic cigarette use according to sex and in England current electronic cigarette users were even more frequently females. In agreement with current evidence from Europe, younger generations and people with a higher level of education are more likely to use electronic cigarette [44]. In our study income did not appear to be a determinant of electronic cigarette use.

Besides England (7\%), the prevalence of electronic cigarette users among adults was appreciable also in France (4\%), Greece (4\%) and Ireland (3\%), all European countries where the price of cigarettes - standardized by per capita GDP - is relatively high [32]. Thus, whereas we did not find any significant relationship between selected country-specific characteristics, including GDP per-capita and TCS, there was an inverse relationship between affordability of conventional cigarettes and electronic cigarette use. This suggests that, besides other factors, including public-health view of electronic cigarettes, culture and dynamics of tobacco market in countries where tobacco products are expensive, smokers are more likely to seek electronic cigarettes as (cheaper) alternatives.

The limitations of the present study include those inherent to cross-sectional studies with self-reported information, such as the impossibility to derive any causal inference from the results. We also note some differences in sampling methods in various study countries [28]. The age ranges of the participants were also slightly different in some countries [28]. However differences were relatively minor and consequently estimates remain reasonably comparable. We moreover considered only EU countries. Another important aspect to take into account is that the small proportion of electronic cigarette users detected in the overall sample may affect the robustness of the estimates. Our findings should therefore be interpreted with caution. In addition, our study provides a picture of electronic 
cigarette use at the investigated time (2017-2018). However, given the rapid evolution of the market of novel products, it is important to continue the monitoring of electronic cigarette use. The strengths of our survey include the representativeness of the adult population of 12 strategically selected European countries, the European Survey Tool (questionnaire) [28] agreed by a core of tobacco control experts and administered in the 12 countries sampled, the standardized definition of electronic cigarette use and the face-to-face interviews. Finally, the large sample size enabled us to analyse endpoints with relatively low frequency, like the prevalence and patterns of electronic cigarette users. Generalized to the overall adult population, our data indicate that, in the 12 European countries included, 8.3 million people might be currently using electronic cigarettes. In most of the countries, current prevalence estimates have risen with the highest prevalence in England. Most users are dual users, receiving nicotine from both electronic and conventional cigarettes. A large proportion of non-smokers use liquids with nicotine. Most users consume electronic cigarettes indoors, in places where smoking is forbidden. To discourage dual use, it is extremely important to regulate electronic cigarette use, banning this product at least in settings where smoking is already forbidden.

\subsection{References}

1. Liu X, Lugo A, Davoli $E$ et al. Electronic cigarettes in Italy: a tool for harm reduction or a gateway to smoking tobacco? Tob Control 2020; 29: 148-152.

2. World Health Organization. WHO Statement on ENDS/ENNDS. https://www.who.int/tobacco/communications/statements/eletroniccigarettes-january-2017/en/. In. 2019.

3. Filippidis FT, Laverty AA, Gerovasili V, Vardavas Cl. Two-year trends and predictors of e-cigarette use in 27 European Union member states. Tob Control 2017; 26: 98-104.

4. Laverty AA, Filippidis FT, Vardavas $\mathrm{Cl}$. Patterns, trends and determinants of e-cigarette use in 28 European Union Member States 2014-2017. Prev Med 2018; 116: 13-18.

5. Eurobarometer. Special Eurobarometer 506. Attitudes of Europeans towards tobacco and electronic cigarettes. Wave EB93.2 - Kantar. https://ec.europa.eu/commfrontoffice/publicopinion/index.cfm/ResultDoc/do wnload/DocumentKy/91136. 2021.

6. McNeill A, Brose LS, Calder R et al. Evidence review of e-cigarettes and heated tobacco products 2018. https://www.gov.uk/government/publications/e-cigarettes-and-heatedtobacco-products-evidence-review/evidence-review-of-e-cigarettes-and- 
heated-tobacco-products-2018-executive-summary\#use-of-e-cigarettes-inadults. In. England: Public Health England 2018.

7. World Health Organization. WHO Report on the Global Tobacco Epidemic, 2019. Offer help to quit tobacco use. https://www.who.int/tobacco/global_report/en/. In. 2019.

8. SCHEER. SHEER, Preliminary Opinion on electronic cigarettes. European Commission.

https://ec.europa.eu/health/sites/health/files/scientific_committees/scheer/d ocs/scheer_o_017.pdf. In. 2020.

9. Bhatta DN, Glantz SA. Association of E-Cigarette Use With Respiratory Disease Among Adults: A Longitudinal Analysis. Am J Prev Med 2020; 58: 182-190.

10. Wills TA, Soneji SS, Choi K et al. E-cigarette use and respiratory disorders: an integrative review of converging evidence from epidemiological and laboratory studies. Eur Respir J 2021; 57.

11. Gallus S, Borroni E, Liu X et al. Electronic cigarette use among Italian smokers: patterns, settings, and adverse events. Tumori 2020; 300891620915784.

12. Shi Y, Cummins SE, Zhu SH. Use of electronic cigarettes in smoke-free environments. Tob Control 2017; 26: e19-e22.

13. Matilla-Santander N, Fu M, Ballbe M et al. Use of electronic cigarettes in public and private settings in Barcelona (Spain). Environ Res 2017; 158: 685-690.

14. Hartmann-Boyce $\mathrm{J}$, McRobbie $\mathrm{H}$, Lindson $\mathrm{N}$ et al. Electronic cigarettes for smoking cessation. Cochrane Database Syst Rev 2020; 10: CD010216.

15. Wang RJ, Bhadriraju S, Glantz SA. E-Cigarette Use and Adult Cigarette Smoking Cessation: A Meta-Analysis. Am J Public Health 2021; 111: 230246.

16. Pisinger $\mathrm{C}$, Vestbo J. A new Cochrane review on electronic cigarettes for smoking cessation: should we change our practice? Eur Respir J 2020; 56.

17. Borrelli B, O'Connor GT. E-Cigarettes to Assist with Smoking Cessation. N Engl J Med 2019; 380: 678-679.

18. Conner M, Grogan S, Simms-Ellis R et al. Do electronic cigarettes increase cigarette smoking in UK adolescents? Evidence from a 12-month prospective study. Tob Control 2017.

19. Gallus S, Lugo A, Pacifici R et al. E-cigarette awareness, use, and harm perceptions in Italy: a national representative survey. Nicotine Tob Res 2014; 16: 1541-1548.

20. Coleman B, Rostron B, Johnson SE et al. Transitions in electronic cigarette use among adults in the Population Assessment of Tobacco and Health (PATH) Study, Waves 1 and 2 (2013-2015). Tob Control 2019; 28: 50-59. 
21. Gallus S, Borroni E, Odone A et al. The Role of Novel (Tobacco) Products on Tobacco Control in Italy. Int J Environ Res Public Health 2021; 18.

22. Eichler M, Blettner M, Singer S. The Use of E-Cigarettes. Dtsch Arztebl Int 2016; 113: 847-854.

23. Hedman L, Backman $\mathrm{H}$, Stridsman $\mathrm{C}$ et al. Association of Electronic Cigarette Use With Smoking Habits, Demographic Factors, and Respiratory Symptoms. JAMA Netw Open 2018; 1: e180789.

24. Lidon-Moyano C, Martinez-Sanchez JM, Fu M et al. [Prevalence and user profile of electronic cigarettes in Spain (2014)]. Gac Sanit 2016; 30: 432437.

25. Eurobarometer. Special Eurobarometer 458. Attitudes of Europeans towards tobacco and electronic cigarettes. Wave EB87.1-TNS opinion\& social. https://op.europa.eu/en/publication-detail/-/publication/2f01a3d10af2-11e8-966a-01aa75ed71a1. In. 2017.

26. Gallus S, Lugo A, Liu X et al. Use and Awareness of Heated Tobacco Products in Europe. J Epidemiol 2021.

27. Amalia B, Liu X, Lugo A et al. Exposure to secondhand aerosol of electronic cigarettes in indoor settings in 12 European countries: data from the TackSHS survey. Tob Control 2021; 30: 49-56.

28. Gallus S, Lugo A, Liu X et al. Who Smokes in Europe? Data From 12 European Countries in the TackSHS Survey (2017-2018). J Epidemiol 2021; 31: 145-151.

29. Fernandez E, Lopez MJ, Gallus S et al. Tackling second-hand exposure to tobacco smoke and aerosols of electronic cigarettes: the TackSHS project protocol. Gac Sanit 2020; 34: 77-82.

30. World Bank. GDP per capita (current US\$), World Bank national accounts data and OECD National Accounts data files. https://data. worldbank.org/indicator/NY.GDP.PCAP.CD?locations=EU. In. 2018.

31. Feliu A, Fernandez E, Baena A et al. The Tobacco Control Scale as a research tool to measure country-level tobacco control policy implementation. Tob Induc Dis 2020; 18: 91.

32. Joossens L, Raw M. The Tobacco control scale 2016 in Europe. https://www.tobaccocontrolscale.org/TCS2016.pdf. In. Association of European Cancer leagues. Brussels, Belgium 2017.

33. European Commission. Eurostat https://ec.europa.eu/eurostat/data/database. .

34. Beard E, West R, Michie S, Brown J. Association of prevalence of electronic cigarette use with smoking cessation and cigarette consumption in England: a time-series analysis between 2006 and 2017. Addiction 2020; 115: 961 974. 
35. Vardavas CI, Filippidis FT, Agaku IT. Determinants and prevalence of ecigarette use throughout the European Union: a secondary analysis of 26 566 youth and adults from 27 Countries. Tob Control 2015; 24: 442-448.

36. Levy DT, Yuan Z, Li Y. The Prevalence and Characteristics of E-Cigarette Users in the U.S. Int J Environ Res Public Health 2017; 14.

37. Kiyohara K, Tabuchi T. Electronic cigarette use in restaurants and workplaces where combustible tobacco smoking is not allowed: an Internet survey in Japan. Tob Control 2018; 27: 254-257.

38. Amalia B, Fu M, Feliu A et al. Regulation of electronic cigarette use in public and private areas in 48 countries within the WHO European Region: a survey to in-country informants. J Epidemiol 2020.

39. Kyriakos CN, Filippidis FT, Hitchman S et al. Characteristics and correlates of electronic cigarette product attributes and undesirable events during ecigarette use in six countries of the EUREST-PLUS ITC Europe Surveys. Tob Induc Dis 2018; 16: A1.

40. Wang TW, Gentzke AS, Neff LJ et al. Disposable E-Cigarette Use among U.S. Youth - An Emerging Public Health Challenge. N Engl J Med 2021; 384: 1573-1576.

41. Farsalinos KE, Poulas K, Voudris V, Le Houezec J. Electronic cigarette use in the European Union: analysis of a representative sample of 27460 Europeans from 28 countries. Addiction 2016; 111: 2032-2040.

42. Soneji S, Barrington-Trimis JL, Wills TA et al. Association Between Initial Use of e-Cigarettes and Subsequent Cigarette Smoking Among Adolescents and Young Adults: A Systematic Review and Meta-analysis. JAMA Pediatr 2017; 171: 788-797.

43. Zhong J, Cao S, Gong W et al. Electronic Cigarettes Use and Intention to Cigarette Smoking among Never-Smoking Adolescents and Young Adults: A Meta-Analysis. Int J Environ Res Public Health 2016; 13.

44. Ooms GI, Bosdriesz JR, Portrait FR, Kunst AE. Sociodemographic Differences in the Use of Electronic Nicotine Delivery Systems in the European Union. Nicotine Tob Res 2016; 18: 724-729. 
Supplementary Table 1: Prevalence (\%) and 95\% confidence intervals (Cl) of electronic cigarette use among 272 users in selected indoor and outdoor sites in the last six months in 12 European countries. TackSHS survey 2017-2018.

\begin{tabular}{lccc}
\hline & \multirow{2}{*}{$\begin{array}{c}\text { Not visited in the } \\
\text { last six months } \\
\text { Indoor and outdoor sites }\end{array}$} & $\begin{array}{c}\text { No electronic } \\
\text { cigarette use } \\
\text { (\%; 95\% Cl) }\end{array}$ & $\begin{array}{c}\text { Electronic } \\
\text { cigarette use } \\
(\% ; 95 \% \mathrm{Cl})\end{array}$ \\
\hline INDOORS (excluding smoking areas) & & & \\
$\quad$ Friends' or relatives' homes & $6.5(3.5-9.5)$ & $31.9(26.3-37.6)$ & $61.5(55.6-67.5)$ \\
Bars & $22.9(17.8-27.9)$ & $39.0(33.1-44.8)$ & $38.2(32.4-44.0)$ \\
Restaurants & $16.4(12.0-20.9)$ & $57.5(51.5-63.4)$ & $26.1(20.9-31.4)$ \\
Disco or clubs & $50.4(44.4-56.3)$ & $31.9(26.3-37.4)$ & $17.8(13.2-22.3)$ \\
Cinemas or theatres & $49.1(43.1-55.0)$ & $46.9(40.9-52.8)$ & $4.1(1.7-6.4)$ \\
Indoor leisure time courses & $57.1(51.2-63.0)$ & $37.7(31.9-43.5)$ & $5.2(2.6-7.9)$ \\
Public libraries & $47.8(41.8-53.7)$ & $47.8(41.8-53.7)$ & $4.5(2.0-7.0)$ \\
Indoor train stations & $44.6(38.6-50.5)$ & $41.2(35.3-47.1)$ & $14.2(10.0-18.4)$ \\
Airports & $58.4(52.5-64.3)$ & $34.2(28.5-39.9)$ & $7.4(4.3-10.6)$ \\
Hospitals & $41.6(35.7-47.5)$ & $55.4(49.5-61.3)$ & $3.0(0.9-5.0)$ \\
TRANSPORT (INDOOR) & & & \\
Private cars with minors & $38.4(32.6-44.3)$ & $47.0(41.0-53.0)$ & $14.6(10.3-18.8)$ \\
Private cars without minors & $20.9(16.0-25.8)$ & $40.7(34.8-46.6)$ & $38.4(32.6-44.3)$ \\
Public transport & $37.4(31.6-43.2)$ & $54.8(48.9-60.8)$ & $7.8(4.6-11.0)$ \\
Trains & $53.3(47.4-59.3)$ & $41.5(35.6-47.4)$ & $5.2(2.5-7.8)$ \\
Airplanes & $61.1(55.3-66.9)$ & $37.4(31.6-43.2)$ & $1.5(0.4-3.8)$ \\
\hline OUTDOORS & & & \\
Restaurant/bar terraces & $21.6(16.7-26.6)$ & $20.5(15.7-25.4)$ & $57.8(51.9-63.8)$ \\
Public transport stops & $36.1(30.3-41.8)$ & $28.3(22.9-33.6)$ & $35.7(30.0-41.4)$ \\
Outdoor areas in hospitals & $42.8(36.8-48.7)$ & $27.1(21.8-32.5)$ & $30.1(24.6-35.6)$ \\
Outdoor areas in schools & $55.6(49.6-61.5)$ & $25.9(20.7-31.2)$ & $18.5(13.9-23.2)$ \\
Parks & $33.8(28.2-39.5)$ & $24.2(19.1-29.3)$ & $42.0(36.1-47.9)$ \\
Children's playgrounds & $56.7(50.8-62.7)$ & $26.1(20.9-31.4)$ & $17.2(12.7-21.7)$ \\
Stadiums & $61.5(55.7-67.3)$ & $19.3(14.6-24.0)$ & $19.3(14.6-24.0)$ \\
Beaches & $40.2(34.3-46.0)$ & $19.0(14.3-23.6)$ & $40.9(35.0-46.8)$ \\
Motorbike/scooters & $78.6(71.2-86.1)$ & $18.0(11.0-24.9)$ & $3.4(0.9-8.5)$ \\
Bicycles & $83.6(77.0-90.2)$ & $14.8(8.5-21.1)$ & $1.6(0.2-5.8)$ \\
\hline
\end{tabular}


Supplementary Table 2: Odds ratios (OR) for dual users (current electronic cigarette, e-cig, user and conventional cigarette smokers) vs. exclusive electronic cigarette users and corresponding 95\% confidence intervals $(\mathrm{Cl})$ among 272 current European electronic cigarette users, according to selected characteristics ${ }^{a}$. TackSHS, 2017-2018.

\begin{tabular}{|c|c|c|c|}
\hline Characteristics & $\begin{array}{l}\text { No. of current } \\
\text { e-cig users }\end{array}$ & $\begin{array}{c}\text { Dual } \\
\text { users (\%) }\end{array}$ & OR $(95 \% \mathrm{CI})^{\mathrm{c}}$ \\
\hline Total & 272 & 52.6 & \\
\hline \multicolumn{4}{|l|}{ Sex } \\
\hline Female & 131 & 56.5 & $1^{d}$ \\
\hline Male & 141 & 48.9 & $0.60(0.36-1.00)$ \\
\hline \multicolumn{4}{|l|}{ Age group (years) } \\
\hline$<25$ & 40 & 77.5 & $1^{d}$ \\
\hline $25-44$ & 120 & 51.7 & $0.28(0.12-0.64)$ \\
\hline $45-64$ & 100 & 46.0 & $0.20(0.08-0.47)$ \\
\hline$\geq 65$ & 12 & 33.3 & $0.13(0.03-0.56)$ \\
\hline$P$ for trend & & & $<0.001$ \\
\hline \multicolumn{4}{|l|}{ Level of education ${ }^{e}$} \\
\hline Low & 93 & 53.8 & $1^{d}$ \\
\hline Intermediate & 98 & 50.0 & $0.82(0.45-1.48)$ \\
\hline High & 81 & 54.3 & $1.05(0.56-1.95)$ \\
\hline$P$ for trend & & & 0.911 \\
\hline \multicolumn{4}{|l|}{ Household economic status ${ }^{\dagger}$} \\
\hline Lower than average & 72 & 65.3 & $1^{d}$ \\
\hline Average & 132 & 49.2 & $0.46(0.24-0.85)$ \\
\hline Higher than average & 54 & 50.0 & $0.45(0.20-0.98)$ \\
\hline $\mathrm{P}$ for trend & & & 0.032 \\
\hline
\end{tabular}

Cl: Confidence Intervals

OR: Odds Ratios

${ }^{a}$ Country weights combined individual weights with an additional weighting factor, with each country contributing in proportion to its population aged 15 years or over (from Eurostat) [33].

${ }^{\text {b }}$ Raw sample size

c ORs and their 95\% Cls were calculated using multiple logistic regression models after adjustment for sex, age group and level of education. Estimates in bold are statistically significant at 0.05 level.

${ }^{\mathrm{d}}$ Reference category

e The sum does not add up to the total because of a few missing values.

${ }^{f}$ Self-assessment of household (family) economic status relative to the country-specific population. The sum does not add up to the total because of a few missing values. 


\title{
Chapter 7
}

\author{
Use and awareness of \\ heated tobacco products in Europe
}




\subsection{Abstract}

Background Heated tobacco products (HTP) are new forms of tobacco consumption with limited information available on their use among the general population. Our objective was to analyze the prevalence and associations of use of HTP across 11 countries in Europe.

Methods Within the TackSHS Project, in 2017-2018 we conducted a crosssectional study with information on HTP use in the following countries: Bulgaria, England, France, Germany, Greece, Italy, Latvia, Poland, Portugal, Romania and Spain. In each country, face-to-face interviews were performed on a representative sample of around 1,000 subjects aged $\geq 15$ years, for a total of 10,839 subjects.

Results Overall, $27.8 \%$ of study participants were aware of HTPs, $1.8 \%$ were ever HTP users (ranging from $0.6 \%$ in Spain to $8.3 \%$ in Greece), and $0.1 \%$ were current users. Men were more frequently HTP ever users than women (adjusted odds ratio [aOR] 1.47; 95\% confidence interval [Cl], 1.11-1.95). Ever HTP use was inversely related to age ( $p$ for trend $<0.001$ ) and more frequent in ex-smokers (compared with never smokers, aOR 4.32; 95\% Cl, 2.69-6.95) and current smokers (aOR 8.35; 95\% Cl, 5.67-12.28), and in electronic cigarette past users (compared with never users, aOR 5.48; 95\% Cl, 3.46-8.68) and current users (aOR 5.92; 95\% Cl, 3.73-9.40).

Conclusions In 2017-2018, HTP use was still limited in Europe among the general population; however, the dual use of these products, their high use among younger generations, and the interest of non-smokers in these products are worrying and indicate the need for close monitoring in terms of prevalence and the characteristics of users.

Keywords: heated tobacco products; heat-not-burn tobacco products; IQOS; survey; Europe 


\subsection{Introduction}

Heated tobacco products (HTP) are electronic devices heating a tobacco stick to generate an inhalable aerosol containing nicotine (and other toxicants) [1]. In December 2014, Phillip Morris International (PMI) launched in Italy and Japan its first HTP, named IQOS [2-4]. This product is now in commerce in most highincome countries, including the majority of European Union (EU) Member States (MS). Meanwhile, HTPs from other tobacco companies (e.g., glo by the British American Tobacco and Ploom TECH by Japan Tobacco International) are also available in some EU MSs.

These products raise concerns about their safety [3, 5-7]. In fact, although HTPs produce lower levels of some carcinogens and toxic chemicals compared to conventional cigarettes, they are not risk-free $[5,8,9]$. Moreover, they produce new substances not generated by conventional cigarettes [7], having uncertain impact on health [10]. In addition, long-term effects of HTPs are still unknown [8]. Besides safety problems, HTPs raise serious public health concerns, similar to those of electronic cigarettes. These include the dual use with other traditional tobacco products and electronic cigarettes of the majority of HTP users, the lack of evidence on the effectiveness of HTPs in assisting smokers to quit, and the possible "gateway effect" due to the use of these products also by non-smokers and young adults who are the target of the tobacco industry and can become addicted to nicotine through HTPs [11-17].

Only a few independent studies, mostly from Japan where HTPs are substantially prevalent $[4,8,18]$ and the United States [19], have investigated the diffusion and/or the public health consequences of HTPs. To our knowledge, data from Europe are limited to three representative national-based surveys from Italy and United Kingdom showing a limited but increasing prevalence of use [2, 3, 20], and the interest in use by non-smokers [3] and adolescents [21]. One recent study based on smokers only has identified factors related to product use from six European countries [22].

The objective of this study was to evaluate HTP spread in Europe, providing the first measure of prevalence and associated factors related to awareness and use of HTPs in 11 European countries.

\subsection{Methods}

Within the Horizon2020 - TackSHS project [23], we conducted a cross-sectional study, based on a face-to-face survey, in 12 strategically selected European countries: Bulgaria (fieldwork time: October 2017), England (January-February 2017), France (November-December 2017), Germany (June 2018), Greece (June-July 2018), Ireland (November 2017), Italy (November 2016), Latvia 
(October 2018), Poland (September 2018), Portugal (November-December 2017), Romania (June-July 2017), and Spain (October 2017), representing about $80 \%$ of the whole EU population. The detailed methods of the TackSHS survey, including the questionnaire development, have been explained elsewhere [2325]. Briefly, in each country we sampled around 1,000 subjects, representative of the general population aged 15 years or older in terms of age, sex, geographic area, and socioeconomic characteristics. Subjects were selected mainly through a multi-stage or a stratified random sampling. We obtained the approval of the protocol of the TackSHS survey from a local ethics committee in each of the 12 countries, and the protocol was registered inClinicalTrials.gov (ID: NCT02928536).

After providing their consent to participate, all subjects were interviewed by ad hoc trained interviewers using computer-assisted personal interviewing (CAPI). The survey used a standardized questionnaire including information on demographic and socioeconomic characteristics, cigarette smoking and electronic cigarette use [23, 24]. The questionnaire was first developed in English and subsequently translated in country-specific languages by bilingual (i.e., local language and English language) tobacco control experts. Thus, questions were asked in participants' primary languages.

Level of education was categorized as country-specific tertiles of schooling years. Self-assessment of household family economic status relative to the countryspecific population was classified into three levels (higher than average, average, and lower than average). All subjects were asked to answer the following question: "Have you ever heard about IQOS (the heat-not-burn tobacco cigarette by Philip Morris International); do you use or did you use it?" (in England, where both IQOS and glo were in the market: "Have you ever heard about heat-not-burn tobacco products; do you use or did you use it?"). Possible answers were: 1) "I have never heard about it"; 2) "I heard about it but I never used it"; 3) "I have just tried it a couple of times"; 4) "I used it in the past (not over the last 30 days)"; 5) "I use it occasionally ( 5 days or less in the last 30 days)"; 6 ) "I use it regularly (more than 5 days in the last 30 days)". Subjects answering options 3-6 were classified as "ever HTP users", those answering options 5-6 as "current HTP users".

Supplementary Table 1 shows selected country-specific information regarding the commercialization of HTPs (e.g., month of debut in the local market). In five countries the survey was conducted less than 12 months after HTP introduction (Bulgaria, England, France, Italy, and Spain) while in six countries it was conducted at least 12 months after HTP introduction in local markets (Germany, Greece, Latvia, Poland, Portugal, and Romania). Moreover, by the time of the survey, no HTP was marketed in Ireland, thus the question on HTPs was not asked in Ireland. Excluding Ireland, the survey included a sample of 10,961 subjects from 11 European countries. 
Adjusted odds ratios (aORs) and their corresponding 95\% confidence intervals (Cls) for ever HTP use were estimated using unconditional multiple logistic regression models after adjusting for sex, age, level of education, and country. To compute prevalence estimates and aORs we applied a statistical weight to guarantee the representativeness of the general adult population in each country; for pooled estimates we further applied a statistical weight with each country contributing in proportion to its population aged 15 years or over [26]. Statistical analyses were performed using SAS 9.4 (SAS Institute; Cary, NC, USA).

\subsection{Results}

Of 10,961 subjects from 11 European countries, 10,839 (98.9\%) provided valid responses on HTP awareness and use, and were included in this analysis. Overall, $72.2 \%$ had never heard about HTPs (from $53.0 \%$ in Greece to $84.6 \%$ in Spain), $26.0 \%$ had heard about these products but never used them (from 13.4\% in Romania to $38.7 \%$ in Greece), $1.5 \%$ had tried them once or twice, $0.1 \%$ were past users and $0.1 \%$ were current users (Table 1). Overall, $1.8 \%$ of respondents described themselves as ever HTP users (from $0.6 \%$ in Spain to $8.3 \%$ in Greece). Men were more frequently HTP ever users than women (aOR $1.47 ; 95 \% \mathrm{Cl}$, 1.11-1.95). Ever use was inversely related to age (compared with $<25$ years, aOR $0.84 ; 95 \% \mathrm{Cl}, 0.57-1.22$ for $25-44$ years; aOR $0.63 ; 95 \% \mathrm{Cl}, 0.43-0.94$ for $45-64$ years; and aOR $0.14 ; 95 \% \mathrm{Cl}, 0.06-0.32$ for $\geq 65$ years of age; $p$ for trend<0.001). Ever HTP use was more frequent in ex-smokers (compared with never smokers, aOR 4.32; 95\% Cl, 2.69-6.95) and current smokers (aOR 8.35; $95 \% \mathrm{Cl}, 5.67-12.28$ ), and in electronic cigarette past users (compared with never users, aOR 5.48; 95\% Cl, 3.46-8.68) and current users (aOR 5.92; 95\% Cl, 3.739.40). No statistically significant relationship was observed between HTP use and socio-economic characteristics, including level of education and household economic status. 
Table 1. Odds ratios ${ }^{a}(\mathrm{OR})$ for heated tobacco product (HTP) ever vs. never use and corresponding $95 \%$ confidence intervals $(\mathrm{Cl})$ in the European population aged $\geq 15$ years, according to selected individual-level characteristics. TackSHS, 2017-2018

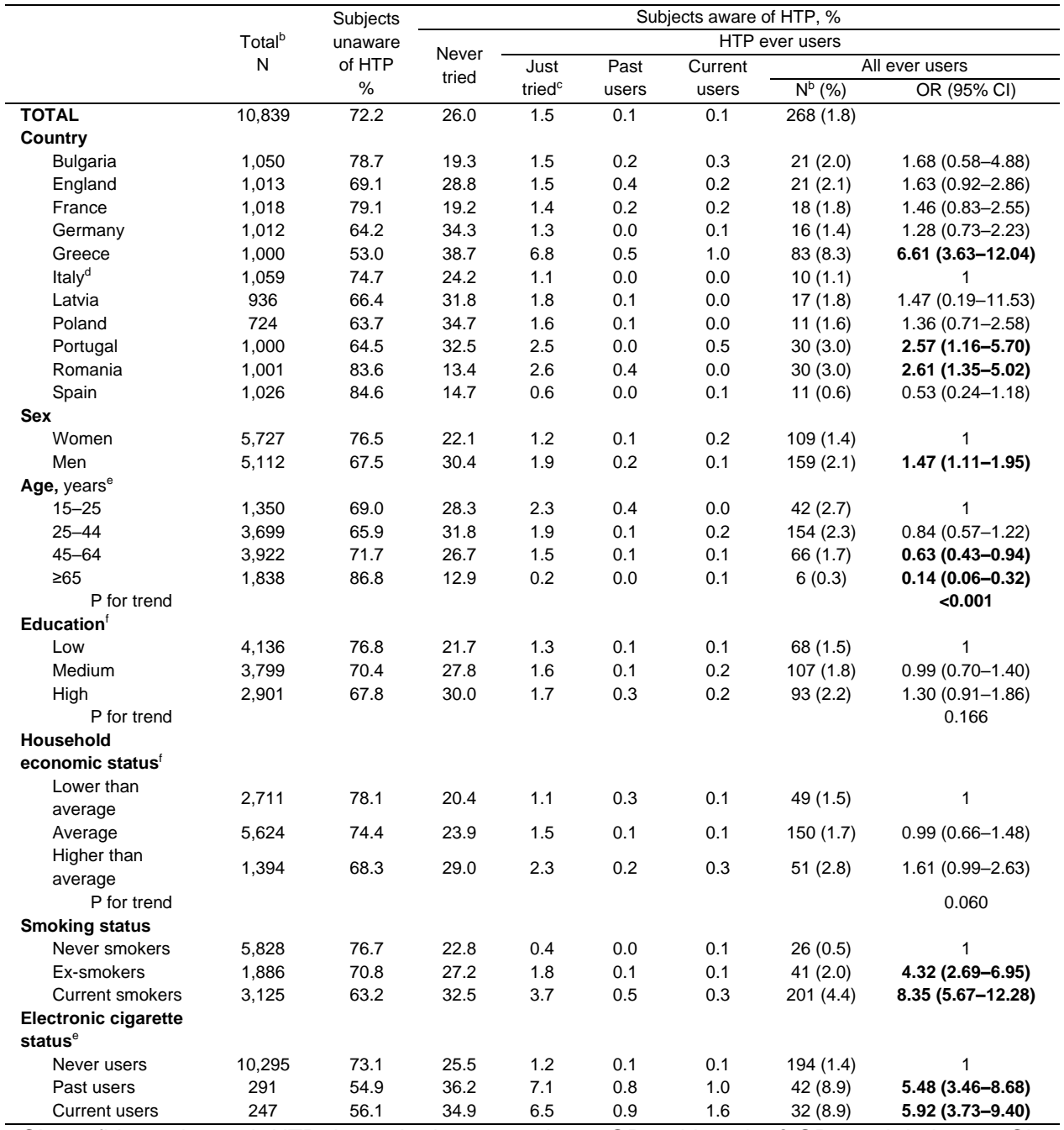

$\mathrm{Cl}$, confidence interval; HTP, heated tobacco products; OR, odds ratio; ${ }^{a}$ ORs and their $95 \% \mathrm{Cls}$ were estimated using unconditional multiple logistic regression models adjusting for sex, age, level of education, and country. Estimates in bold are statistically significant at 0.05 level; b Unweighted number of subjects with available information on HTP use $(\mathrm{N}=10,839)$ or unweighted number of ever users of HTPs ( $\mathrm{N}=268)$; ' Subjects reporting to have tried HTP a couple of times; ${ }^{\mathrm{d}}$ Italy was used as the pilot country, thus, its fieldwork was anticipated to November 2016. Italy has been chosen as the reference category because it is the first European country where IQOS was launched; ' $P$ articipants' age was $\geq 15$ years in all countries, except England $(\geq 16)$, Ireland ( $\geq 18)$, Greece (15-64), and Latvia (15-74); ${ }^{\dagger}$ The sum does not add up to the total because of few missing values. In particular, the household economic status was missing in Germany. 
In countries where HTPs were introduced less than 12 months before the survey conduction, the prevalence of HTP awareness was $23.3 \%$ and that of HTP ever users was $1.4 \%$. Corresponding estimates in countries where HTPs were introduced more than 12 months before the survey conduction were $34.3 \%$ and $2.2 \%$ ( $p<0.001$ and $p=0.001$ for awareness and use, respectively).

Among 41 HTP ever users and ex- cigarette smokers at the time of the survey, $20(49 \%)$ quit smoking before HTPs were introduced in the local market of each country.

\subsection{Discussion}

This study provides the prevalence and factors related to the HTP use among the general population in multiple European countries. We found that the prevalence of ever HTP use (and the frequency of use) was still low. Overall, almost $2 \%$ of European adults already tried (or used) HTPs, with a wide variation between countries. Young people, men, ever smokers, and electronic cigarette users were more likely to be attracted to these new products, in line with previous researches $[21,27]$. The large variation in HTP awareness (ranging between $15 \%$ and $47 \%$ ) and use (ranging between $1 \%$ and $8 \%$ ) also reflects differences in the commercialization of these products. In fact, countries with a shorter experience of HTPs (i.e., with time since HTPs introduction in the local market lower than 12 months at the time of the survey) were those with a lower awareness and use of these tobacco products.

Subjects aged 15-24 years have more frequently tried HTPs, in agreement with previous findings $[15,20]$. This suggests that the youngest generations could be the key target subpopulation of HTP marketing promotions. However, the number of current HTP users among the young is null, likely due to the relatively expensive device - as compared to electronic cigarette - that discourages initiation for a regular use [17].

Although no statistically significant relationship has been observed between the use of HTP and socioeconomic characteristics, wealthier subjects systematically reported the highest levels of HTP awareness and use, in line with previous studies [3, 20].

The majority of HTP ever users were dual users (i.e. also smokers of conventional cigarettes). This raises concerns that, similar to what has been observed for electronic cigarettes [28-30], HTPs could also be used in places where combustible cigarettes are not permitted while HTPs are not covered by the national legislation. These findings are in line with a recent research conducted among 6,027 smokers from 6 EU MSs according to which ever use of HTPs was significantly higher among those who had tried to quit smoking in the last 12 
months, had tried electronic cigarettes during their lifetime and among those that perceived HTPs as less dangerous than combustible cigarettes [22]. A qualitative study conducted in the United Kingdom in 2018 found that IQOS users mostly experimented with IQOS to reduce or to stop smoking combustible cigarettes due to health risks, perceiving IQOS as an (healthier) alternative way to continue smoking [17]. Moreover, only a few had completely stopped smoking both IQOS and combustible cigarettes, as people mainly used IQOS in place of (or alongside) traditional cigarettes [17].

In line with the current evidence [3], our study found that a limited but not negligible proportion of HTP users (i.e., $10 \%$ of all HTP ever users) were never smokers, suggesting that these products are attracting towards nicotine dependence new segments of population, with potentially different characteristics from those known to be associated with exclusive tobacco consumption. Moreover, almost half of ex-smokers who used HTPs quit smoking before HTPs were launched in the local markets. This supports the fact that a large proportion of ex-smokers using HTPs are not people switching to HTPs to reduce their harm, but people who relapse nicotine addiction, being attracted by this new alleged safe product. How HTPs are attracting non-smokers to nicotine addiction is a matter of concern that requires further research.

This study has some weaknesses, mainly related to its cross-sectional design. Although the overall sample size is large, our study is based on a small sample of European HTP users. In many countries the survey was conducted only a few months after HTP introduction into the market, and the fieldwork was conducted in different time periods (ranging between November 2016 and October 2018), making the comparisons of HTP use among countries difficult. Furthermore, some differences in terms of sampling methodology used [24] add complexity to the interpretation of the results. Moreover, no pictures of heated tobacco products were shown to participants during the interviews. This, together with some possible differences in the wording of questions asked in various countries, may have resulted in a response bias. The strengths of our survey include the representativeness of the adult population of the included European countries in terms of age, sex and habitat, and the use of face-to-face interview. More importantly, this is the first European study evaluating the spread of HTP among the general population, using the same standardized questionnaire in different countries. Therefore, our estimates may serve as key baseline measures for future studies.

Our study shows that only $0.1 \%$ of Europeans currently use HTPs. Once generalized to the $28 \mathrm{EU}$ MSs, our estimate is compatible with more than half million adults currently using this product. Our data show that HTPs are: i) mainly used in combination with other products, ii) mainly used by the youngest generations, and iii) also used by (and likely promoted to) never smokers. These 
findings are worrying and indicate the need for close monitoring of prevalence, trends and determinants of HTP use. Our study could be useful to support the planning, implementation and monitoring of targeted prevention intervention, as well as inform decision making at the normative and public health level in Europe.

\subsection{References}

1. Auer R, Concha-Lozano N, Jacot-Sadowski I et al. Heat-Not-Burn Tobacco Cigarettes: Smoke by Any Other Name. JAMA Intern Med 2017; 177: 10501052.

2. Liu X, Lugo A, Spizzichino L et al. Heat-Not-Burn Tobacco Products Are Getting Hot in Italy. J Epidemiol 2018; 28: 274-275.

3. Liu X, Lugo A, Spizzichino L et al. Heat-not-burn tobacco products: concerns from the Italian experience. Tob Control 2019; 28: 113-114.

4. Tabuchi T, Gallus S, Shinozaki T et al. Heat-not-burn tobacco product use in Japan: its prevalence, predictors and perceived symptoms from exposure to secondhand heat-not-burn tobacco aerosol. Tob Control 2018; 27: e25e33.

5. WHO. Heated tobacco products (HTPs) market monitoring information sheet. Available at: https://apps.who.int/iris/bitstream/handle/10665/273459/WHO-NMHPND-18.7-eng.pdf?ua=1. 2018.

6. Stephens WE. Comparing the cancer potencies of emissions from vapourised nicotine products including e-cigarettes with those of tobacco smoke. Tob Control 2017.

7. St Helen G, Jacob lii P, Nardone N, Benowitz NL. IQOS: examination of Philip Morris International's claim of reduced exposure. Tob Control 2018; 27: s30-s36.

8. Jankowski M, Brozek GM, Lawson J et al. New ideas, old problems? Heated tobacco products - a systematic review. Int J Occup Med Environ Health 2019; 32: 595-634.

9. Glantz SA. Heated tobacco products: the example of IQOS. Tob Control 2018; 27: s1-s6.

10. Chun L, Moazed F, Matthay M et al. Possible hepatotoxicity of IQOS. Tob Control 2018; 27: s39-s40.

11. Liu X, Lugo A, Davoli $E$ et al. Electronic cigarettes in Italy: a tool for harm reduction or a gateway to smoking tobacco? Tob Control 2019.

12. World Health Organization. WHO Report on the Global Tobacco Epidemic, 2019. Offer help to quit tobacco use. Available at: https://www.who.int/tobacco/global_report/en/. 2019. 
13. World Health Organization. WHO Statement on ENDS/ENNDS. Available at: https://www.who.int/tobacco/communications/statements/eletroniccigarettes-january-2017/en/. 2019.

14. Filippidis FT, Laverty AA, Gerovasili V, Vardavas Cl. Two-year trends and predictors of e-cigarette use in 27 European Union member states. Tob Control 2017; 26: 98-104.

15. Marynak KL, Wang TW, King BA et al. Awareness and Ever Use of "HeatNot-Burn" Tobacco Products Among U.S. Adults, 2017. Am J Prev Med 2018; 55: 551-554.

16. McKelvey K, Popova L, Kim M et al. Heated tobacco products likely appeal to adolescents and young adults. Tob Control 2018; 27: s41-s47.

17. Tompkins CNE, Burnley A, McNeill A, Hitchman SC. Factors that influence smokers' and ex-smokers' use of IQOS: a qualitative study of IQOS users and ex-users in the UK. Tob Control 2020.

18. Tabuchi T, Kiyohara K, Hoshino $T$ et al. Awareness and use of electronic cigarettes and heat-not-burn tobacco products in Japan. Addiction 2016; 111: 706-713.

19. Nyman AL, Weaver SR, Popova $L$ et al. Awareness and use of heated tobacco products among US adults, 2016-2017. Tob Control 2018; 27: s55s61.

20. Brose LSS, E.; Cheeseman, H. . Awareness and Use of 'Heat-not-burn' Tobacco Products in Great Britain. Tob Regul Sci 2018; 4: 44-50.

21. Czoli CD, White CM, Reid JL et al. Awareness and interest in IQOS heated tobacco products among youth in Canada, England and the USA. Tob Control 2020; 29: 89-95.

22. Lotrean. Awareness and use of heated tobacco products among adult smokers in six European countries: Findings from the EUREST-PLUS ITC Europe Surveys. In press. Eur J Pub Health. 2020.

23. Fernandez E, Lopez MJ, Gallus $S$ et al. Tackling second-hand exposure to tobacco smoke and aerosols of electronic cigarettes: the TackSHS project protocol. Gac Sanit 2020; 34: 77-82.

24. Gallus S, Lugo A, Liu X et al. Who smokes in Europe? Data from 12 European countries in the TackSHS survey (2017-2018). In press. J Epidemiol 2020.

25. Amalia B, Liu X, Lugo A et al. Exposure to secondhand aerosol of electronic cigarettes in indoor settings in 12 European countries: data from the TackSHS survey. In press. Tob Control 2020.

26. Eurostat. Population on 1 January by age and sex. Available online at https://ec.europa.eu/eurostat/data/database. 2017.

27. Hwang JH, Ryu DH, Park SW. Heated tobacco products: Cigarette complements, not substitutes. Drug Alcohol Depend 2019; 204: 107576. 
28. Gallus S, Borroni E, Liu X et al. Electronic cigarette use among Italian smokers: patterns, settings and adverse events. In press. Tumori J 2020.

29. Goldberg RL, Cataldo JK. Using an e-Cigarette is Like Eating Tofu When You Really Want Meat. Am J Health Behav 2018; 42: 54-64.

30. Shi Y, Cummins SE, Zhu SH. Use of electronic cigarettes in smoke-free environments. Tob Control 2017; 26: e19-e22. 
Supplementary Table 1: Information on heated tobacco products (HTP) commercialization in 12 European countries

\begin{tabular}{lcccc}
\hline Country & Fieldwork date & $\begin{array}{c}\text { Date of launch } \\
\text { of HTPs }\end{array}$ & $\begin{array}{c}\text { Time since HTPs } \\
\text { introduction in } \\
\text { the local market }^{\mathrm{a}}\end{array}$ & $\begin{array}{c}\text { HTPs available } \\
\text { at the time of } \\
\text { the survey }\end{array}$ \\
\hline Bulgaria & Oct 2017 & Nov 2017 & 1 monthb & IQOS \\
England & Jan-Feb 2017 & Dec 2016 & 2 months & IQOS \\
France & Nov-Dec 2017 & Apr 2017 & 7 months & IQOS, gloc \\
Germany & Jun 2018 & Jun 2016 & 24 months & IQOS \\
Greece & Jun-Jul 2018 & March 2017 & 15 months & IQOS \\
Italy & Nov 2016 & Dec 2015 & 11 months & IQOS \\
Ireland & Nov 2017 & Not in commerce & - & - \\
Latvia & Oct 2018 & Jun 2016 & 28 months & IQOS \\
Poland & Sep 2018 & May 2017 & 16 months & IQOS \\
Portugal & Nov-Dec 2017 & Nov 2015 & 24 months & IQOS \\
Romania & Jun-Jul 2017 & Nov 2015 & 19 months & IQOS \\
Spain & Oct 2017 & Dec 2016 & 10 months & IQOS \\
\hline
\end{tabular}

${ }^{a}$ Difference between the date of launch of HTPs and the date of the conduction of the fieldwork, in each country.

b IQOS was introduced in the Bulgarian market in November 2017, but the introduction of IQOS was discussed in the media at the beginning of October 2017.

${ }^{c}$ glo products have been on the French market between end-2017 and end-2019, and were withdrawn later on.

d In October 2016, IQOS was introduced in Athens. Only in March 2017 the market was extended to the whole Greece.

e In December 2014, IQOS was introduced in Milan. Only in December 2015 the market was extended to the whole Italy. 


\section{Chapter 8}

Exposure to secondhand aerosol of electronic cigarettes in indoor settings in 12 European countries: data from the TackSHS survey 


\subsection{Abstract}

Introduction: Exposure to secondhand aerosol from e-cigarette (SHA) may pose harmful effects to bystanders. This study aims to investigate the prevalence, duration, and determinants of SHA exposure in various indoor settings in 12 European countries.

Methods: In 2017-2018, we conducted a cross-sectional study, the TackSHS survey, on a representative sample of the population aged $\geq 15$ years in 12 European countries (Bulgaria, England, France, Germany, Greece, Ireland, Italy, Latvia, Poland, Portugal, Romania, and Spain). We described the prevalence and duration of exposure to SHA in several indoor settings among 11,604 e-cigarette non-users. Individual- and country-level characteristics associated with SHA exposure were also explored using multi-level logistic regression analyses.

Results: Overall, $16.0 \%$ of e-cigarette non-users were exposed to SHA in any indoor setting at least weekly, ranging from $4.3 \%$ in Spain to $29.6 \%$ in England. The median duration of SHA exposure among those who were exposed was 43 minutes/day. "Other indoor settings" (e.g. bar, restaurant) was reported as the place where most of e-cigarette non-users were exposed (8.3\%), followed by workplace/educational venues $(6.4 \%)$, home $(5.8 \%)$, public transportation (3.5\%), and private transportation (2.7\%). SHA exposure was more likely to occur in certain groups of non-users: men, younger age groups, those with higher level of education, e-cigarette past users, current smokers, those perceiving SHA harmless and living in countries with a higher e-cigarette use prevalence.

Conclusions: We found inequalities of SHA exposure across and within European countries. Governments should consider extending their tobacco smoke-free legislation to e-cigarettes to protect bystanders, particularly vulnerable populations such as young people.

Keywords: electronic nicotine delivery devices; environment; secondhand smoke; surveillance and monitoring. 


\subsection{Introduction}

Electronic cigarette (e-cigarette) use has increased in many parts of the world. In the United States (US), with Juul's extraordinary growth and marketing strategy, e-cigarette use has been declared as an epidemic in youth by the US Surgeon General as it substantially increased by $78 \%$ from 2017 to 2018.[1,2] According to the Eurobarometer surveys, the prevalence of adults who had at least tried ecigarettes in 28 European countries has grown from 12\% in 2014 to $15 \%$ in 2017 [3].

The growing use of e-cigarettes has raised concerns as the product is potentially harmful not only to users, but also to bystanders [4,5]. Whilst some studies showed that e-cigarettes emit lower levels of some toxic chemicals compared to smoke from conventional cigarettes other studies revealed that e-cigarette aerosol contains comparable or higher levels of other harmful constituents, such as nicotine and metals [6-9]. It has been also shown that bystanders absorb nicotine from e-cigarette's aerosol at levels comparable with secondhand tobacco smoke (SHS) [10]. Additionally, e-cigarette's aerosol may expose non-users to toxic chemicals, including particulate matter and carcinogens, such as volatile organic compounds, polycyclic aromatic hydrocarbons, formaldehyde, acetaldehyde and tobacco-specific nitrosamines [11-14]. Secondhand aerosol (SHA) from e-cigarettes has been found to cause acute reduced lung function and associated with higher odds of asthma exacerbations, which might reflect more adverse health effects with longer period of exposure [15,16]. Exposure to SHA from e-cigarette may renormalise tobacco smoking, induce relapse to smoking for those who have quit smoking, and trigger initiation of e-cigarette use among non-smokers, particularly young people [17-21]. The above evidence suggests that appropriate regulations are needed to prevent involuntary exposure to SHA.

The World Health Organization (WHO) recommends to Parties of the Framework Convention on Tobacco Control (FCTC) to consider the prohibition of e-cigarette use in indoor settings or at least those places where smoking is already banned [22]. In Europe, e-cigarette use has been frequently observed in indoor places where smoking is normally banned, such as workplaces, bars, restaurants, and train and metro stations [23-25]. Evading smoke-free regulation has been reported by e-cigarette users as one of the main reasons for the use of $e$ cigarettes [26-28]. To the best of our knowledge, to date there have been 28 European countries regulating the use of e-cigarettes, but mostly in selected public places only [29].

While public debate about the risks and benefits of e-cigarette use continues to arise, evidence on the extent of the population's exposure to the SHA has been documented [30]. According to the 2015 National Youth Tobacco Survey data, exposure to SHA in indoor or outdoor public places was reported by one in four 
middle and high-school students in the US, including 4.4 million who were ecigarette non-users and one million not exposed to SHS [31]. Recent data from six European countries indicated that $37 \%$ of smokers (e-cigarette non-users) were exposed to SHA, ranging from $18 \%$ in Spain to $63 \%$ in Greece [23]. However, there has been no study on exposure to SHA from e-cigarettes among the general population in Europe.

This paper aims to assess the prevalence and duration of exposure to SHA from e-cigarettes in various indoor settings among e-cigarette non-users aged 15 years or older in 12 European countries. We also explored the socio-demographic factors at the individual and country level that were associated with SHA exposure.

\subsection{Methods}

\subsubsection{Data Source}

This is a questionnaire-based cross-sectional study using data from the TackSHS survey, conducted in 12 selected European countries (Bulgaria, England, France, Germany, Greece, Ireland, Italy, Latvia, Poland, Portugal, Romania, and Spain). The detailed methods of the TackSHS survey, including the questionnaire development, have been explained elsewhere $[32,33]$. Sampling methods varied across countries, including multistage sampling (in Bulgaria, Greece, Italy, Latvia, Poland and Romania), cluster sampling with quotas (in England and France), and stratified random sampling (in Germany, Ireland, Portugal and Spain). In each country, we sampled around 1,000 people representative of the general population in terms of age, sex, geographic area, and in most of countries, socioeconomic characteristics. In total, the survey included 11,902 subjects aged 15 years or older from 12 European countries, representing $79.2 \%$ of the whole EU population. A pilot study was conducted in Italy in November 2016 while the fieldwork in other countries was conducted between June 2017 (in Romania) and October 2018 (in Latvia), using the same questionnaire administered with computer-assisted personal interviewing (CAPI) in all 12 countries. The questionnaire included information on socioeconomic and demographic characteristics, cigarette smoking, e-cigarette use, SHS and SHA exposures in various indoor and outdoor settings, and attitudes and perception towards SHS and SHA exposures [33].

For the purpose of this study, only e-cigarette non-users were included. Thus, the total sample size in this study was 11,604 subjects. 


\subsubsection{Ethical issues}

We obtained the approval from a local ethics committee in each of the 12 countries. The study protocol has been registered in ClinicalTrials.gov (ID: NCT02928536). All respondents received detailed information about the survey before they provided their consent to participate.

\subsubsection{Measures}

Respondents who reported that they had never used e-cigarette during their lifetime or had stopped using it at least for 30 days before the time of the survey were considered as e-cigarette non-users (i.e., never and ex-users). From a question "On average, how much time per day do you think you are exposed to e-cigarette aerosol in each of the following sites?", interviewees indicated one or more of the indoor settings where they experienced SHA exposure. Five indoor settings were considered: home, workplace (or educational venues for students), public transportation (e.g. train, tram, bus, subway), private transportation, and "other indoor places" (e.g., cafeterias, bars, restaurants, leisure facilities). For each indoor setting, e-cigarette non-users reported the average exposure time (in minutes/day) during a working and non-working day. An e-cigarette non-user was defined as exposed to SHA in a certain setting, if (s)he was exposed in that setting at least one minute per day in a working and/or non-working day. The prevalence (\%) of exposure (at least weekly) was computed for each setting and overall. Duration of SHA exposure was computed as the weighted daily average minutes of exposure in working and non-working days among subjects exposed to SHA in each setting.

Ever smokers were defined as respondents who reported smoking at least 100 cigarettes (including hand-rolled cigarettes) during their lifetime. Among ever smokers, current smokers were participants who reported current smoking at the time they participated in this survey, while ex-smokers were those who had stopped smoking by the time they participated in this survey [34].

Information on harm perception from SHA exposure was obtained by asking respondents "Do you agree or disagree with the following sentence? Exposure to e-cigarette vapour is harmful to my health, with five possible answer options: 1) Strongly agree; 2) Moderately agree; 3) Moderately disagree; 4) Strongly disagree; 5) Does not know OR does not answer". Options 1 and 2 were categorised as "harmful", whereas options 3 and 4 were categorised as "harmless".

Level of education was constructed by taking country-specific tertiles of schooling years as low, intermediate, and high. The 12 countries were classified by their geographic area into Northern Europe, Western Europe, Southern Europe, and Eastern Europe according to United Nations M49 Standard, [35] by the World Bank gross domestic product (GDP) per capita [36], by their score in the 2016 
Tobacco Control Scale [37], by country's smoking prevalence, and by country's e-cigarette use prevalence. The latter two were estimated from the TackSHS survey data.

\subsubsection{Statistical analysis}

We reported proportion, and median estimates of the SHA exposure among ecigarette non-users across countries and socio-demographic sub-populations. We used the median of the minutes exposed as point of estimates for duration of SHA due to extremely right-skewed distribution of the data.

A multilevel logistic regression model, allowing for clustering of observations at the country level was fitted to examine the relationship between SHA exposure status (as a binary dependent variable) and socio-demographic characteristics at individual and country level (independent variables). Adjusted odds ratios (aOR), and their corresponding 95\% confidence intervals $(\mathrm{Cl})$, were estimated after adjusting for sex, age, level of education, e-cigarette use status, and smoking status.

Statistical weights were used to generate representative estimates of the general population of each country (individual weight). To calculate results for the entire sample, we applied "country weights", which combined individual weights with an additional weighting factor, with each country contributing in proportion to its population aged 15 years or over, obtained by Eurostat [38]. Analyses were performed with STATA 14.0.

\subsection{Results}

The sample sociodemographic characteristics are presented in Supplementary Table 1. Among 11,604 e-cigarette non-users, 16.0\% (95\% Cl: 15.3-16.7\%) were exposed at least weekly to SHA from e-cigarettes in any indoor setting, and ranged from $4.3 \%$ (95\% Cl: $3.2-5.7)$ in Spain to $29.6 \%$ (95\% Cl: $26.7-32.6)$ in England, with significant differences among men and women (17.2\% vs. $15.0 \%$, $\mathrm{p}<0.001$ ) for the 12 countries combined (Table 1). 
Table 1. Country-specific prevalence (\%) of e-cigarette secondhand aerosol (SHA) exposure (at least weekly), overall and by sex in e-cigarette non-users of the European population aged $\geq 15$ years. ${ }^{*}$ TackSHS survey, 2017-2018.

\begin{tabular}{|c|c|c|c|c|}
\hline \multirow{2}{*}{ Country } & \multirow{2}{*}{$\mathbf{N}^{\dagger}$} & \multicolumn{3}{|c|}{$\begin{array}{l}\text { \% exposure to SHA from e-cigarettes } \\
\qquad(95 \% \mathrm{Cl})\end{array}$} \\
\hline & & Total & Men & Women \\
\hline Bulgaria & 1035 & $14.9(12.8-17.2)$ & $14.3(11.4-17.6)$ & $15.4(12.6-18.7)$ \\
\hline England & 940 & $29.6(26.7-32.6)$ & $31.8(27.5-36.3)$ & $27.8(24.1-31.8)$ \\
\hline France & 974 & $26.3(23.6-29.1)$ & $27.5(23.6-31.7)$ & $25.2(21.6-29.2)$ \\
\hline Germany & 1000 & $11.1(9.2-13.2)$ & $12.6(10.0-15.9)$ & $9.5(7.3-12.4)$ \\
\hline Greece & 959 & $28.9(26.1-31.8)$ & $30.3(26.4-34.6)$ & $27.4(23.6-31.6)$ \\
\hline Ireland & 916 & $22.1(19.6-24.9)$ & $24.6(20.8-28.8)$ & $19.8(16.4-23.7)$ \\
\hline Italy & 1045 & $12.8(10.9-15.0)$ & $15.7(12.8-19.2)$ & $10.1(7.9-13.0)$ \\
\hline Latvia & 1009 & $5.6(4.4-7.2)$ & $6.7(4.8-9.3)$ & $4.7(3.2-6.8)$ \\
\hline Poland & 718 & $12.3(10.1-14.9)$ & $13.9(10.5-18.1)$ & $11.0(8.2-14.5)$ \\
\hline Portugal & 991 & $11.4(9.6-13.5)$ & $12.5(9.8-15.8)$ & $10.5(8.1-13.4)$ \\
\hline Romania & 999 & $10.0(8.3-12.0)$ & $10.9(8.5-14.0)$ & $9.2(6.9-12.0)$ \\
\hline Spain & 1018 & $4.3(3.2-5.7)$ & $2.2(1.2-3.9)$ & $6.3(4.5-8.7)$ \\
\hline Total & 11,604 & $16.0(15.3-16.7)$ & $17.2(16.2-18.2)$ & $15.0(14.1-15.9)$ \\
\hline \multicolumn{5}{|c|}{ 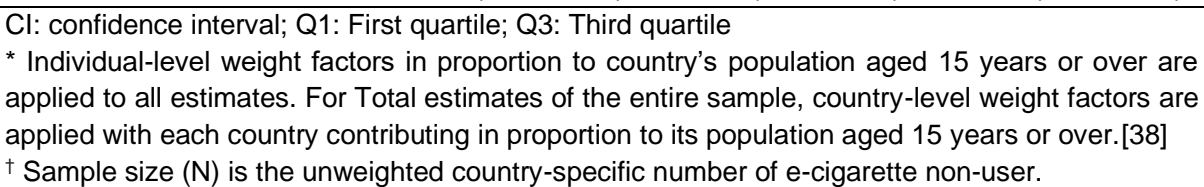 } \\
\hline
\end{tabular}

The highest prevalence of at least weekly SHA exposure was observed in England for both men and women $(31.8 \%$ and $27.8 \%$, respectively). Overall, the median duration of SHA exposure for e-cigarette non-users who had been exposed to SHA was 43 minutes/day (Q1-Q3: 14-130). The duration of SHA exposure ranged from 2 minutes/day (Q1-Q3: 1-7) in Spain to 103 minutes/day (Q1-Q3: 21-240) in Italy (Figure 1). 


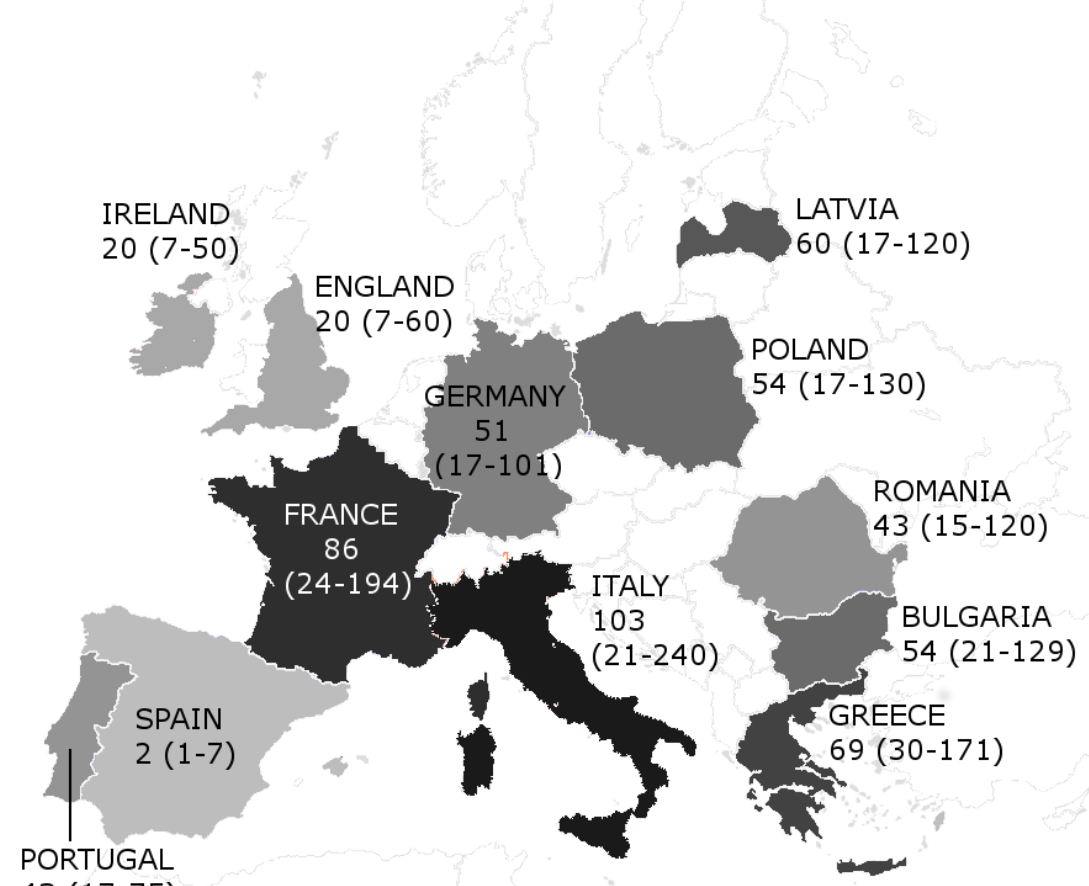

$43(17-75)$

Figure 1. Median (Q1-Q3) intensity of exposure to SHA (minutes/day) from e-cigarettes. TackSHS survey, 2017-2018. Median estimates were calculated among e-cigarette non-users who had been exposed to SHA at any indoor settings.

Table 2 shows the country-specific prevalence and duration of SHA exposure in various indoor settings. SHA exposure among e-cigarette non-users mostly occurred in "other indoor settings" $(8.3 \%)$, followed by workplace/educational venues $(6.4 \%)$, home $(5.8 \%)$, public transportation (3.5\%), and private transportation $(2.7 \%)$. France had the highest prevalence of SHA exposure at home (12.0\%), workplace/educational venues (13.2\%), and private vehicles (5.9\%) compared to other countries, while the highest prevalence of SHA exposure in public transportation was in England (7.9\%) and in "other indoor settings" in Greece (19.0\%). The longest median duration of SHA exposure was 43 minutes/day which was taken place at home and workplace, while the shortest one was in public transportation with a median of 14 minutes/day of exposure. Despite the low prevalence of SHA exposure (1.8\%) among Latvian e-cigarette non-users in "other indoor places", they reported a 2-hour-per-day of SHA exposure in these venues. 
Table 2. Country-specific at least weekly prevalence (\%) and duration (minutes/day) of e-cigarette secondhand aerosol (SHA) exposure in selected indoor settings among e-cigarette non-users of the European population aged $\geq 15$ years. ${ }^{*}$ TackSHS survey, 2017-2018.

\begin{tabular}{|c|c|c|c|c|c|c|c|c|c|c|c|}
\hline \multirow{2}{*}{ Country } & \multirow{2}{*}{$\mathbf{N}^{\dagger}$} & \multicolumn{2}{|c|}{ Home } & \multicolumn{2}{|c|}{$\begin{array}{c}\text { Workplace } \\
\text { / Educational } \\
\text { venues }\end{array}$} & \multicolumn{2}{|c|}{$\begin{array}{c}\text { Public } \\
\text { Transportation }\end{array}$} & \multicolumn{2}{|c|}{$\begin{array}{c}\text { Private } \\
\text { Transportation }\end{array}$} & \multicolumn{2}{|c|}{$\begin{array}{l}\text { Other Indoor } \\
\text { Places }\end{array}$} \\
\hline & & $\%$ & $\begin{array}{l}\text { Median }^{\ddagger} \\
\text { minutes } \\
\text { /day }\end{array}$ & $\%$ & $\begin{array}{l}\text { Median }^{\ddagger} \\
\text { minutes } \\
\text { /day }\end{array}$ & $\%$ & $\begin{array}{l}\text { Median }^{\ddagger} \\
\text { minutes } \\
\text { /day }\end{array}$ & $\%$ & $\begin{array}{l}\text { Median }^{\ddagger} \\
\text { minutes } \\
\text { /day }\end{array}$ & $\%$ & $\begin{array}{c}\text { Median }^{\ddagger} \\
\text { minutes } \\
\text { /day }\end{array}$ \\
\hline Bulgaria & 1035 & 4.6 & 64 & 4.6 & 43 & 2.8 & 17 & 1.3 & 43 & 10.8 & 43 \\
\hline England & 940 & 7.6 & 30 & 10.9 & 14 & 7.9 & 7 & 5.1 & 12 & 14.2 & 17 \\
\hline France & 974 & 12.0 & 34 & 13.2 & 48 & 5.1 & 24 & 5.9 & 17 & 14.2 & 48 \\
\hline Germany & 1000 & 2.3 & 34 & 2.8 & 43 & 2.6 & 30 & 1.4 & 27 & 8.0 & 26 \\
\hline Greece & 959 & 8.1 & 60 & 10.8 & 46 & 3.4 & 43 & 1.6 & 60 & 19.0 & 60.0 \\
\hline Ireland & 916 & 8.8 & 31 & 9.4 & 14 & 3.8 & 7 & 2.3 & 10 & 11.6 & 10 \\
\hline Italy & 1045 & 5.6 & 60 & 6.3 & 43 & 3.3 & 60 & 3.0 & 60 & 5.1 & 60 \\
\hline Latvia & 1009 & 2.1 & 60 & 2.4 & 43 & 0.3 & 21 & 0.3 & 14 & 1.8 & 120 \\
\hline Poland & 718 & 6.6 & 69 & 4.8 & 21 & 2.9 & 14 & 0.9 & 19 & 3.7 & 33 \\
\hline Portugal & 991 & 4.4 & 60 & 4.2 & 21 & 0.3 & 6 & 2.3 & 17 & 6.8 & 18 \\
\hline Romania & 999 & 4.1 & 60 & 4.4 & 43 & 1.4 & 15 & 2.5 & 21 & 3.4 & 24 \\
\hline Spain & 1018 & 1.5 & 10 & 0.5 & 4 & 0.9 & 1 & 0.0 & 0 & 1.9 & 2 \\
\hline Total & 11,604 & 5.8 & 43 & 6.4 & 43 & 3.5 & 14 & 2.7 & 21 & 8.3 & 33 \\
\hline
\end{tabular}

* Individual-level weight factors in proportion to country's population aged 15 years or over are applied to all estimates in each country. For total estimates of the entire sample, country-level weight factors are applied with each country contributing in proportion to its population aged 15 years or over.[38]

${ }^{\dagger}$ Sample size $(\mathrm{N})$ is the unweighted, country-specific number of e-cigarette non-users

${ }^{\ddagger}$ Median estimates were calculated among e-cigarette non-users who had been exposed to SHA at the corresponding indoor setting. 
Table 3 shows the proportion of SHA exposure and the corresponding aOR according to selected individual-level characteristics. At least weekly SHA exposure was more frequent in men (aOR: $1.13 ; 95 \% \mathrm{Cl}: 1.01-1.25)$ than in women and in the young (aOR for $<25$ vs. $\geq 65$ years: $3.13 ; 95 \% \mathrm{Cl}: 2.52-3.94 ; p$ for trend $<0.001$ ). The higher the level of education, the more likely the e-cigarette non-users were exposed to SHA (aORs for intermediate level of education: 1.19; $95 \% \mathrm{Cl}: 1.05-1.35$, and for high-level of education: 1.26 ; $95 \% \mathrm{Cl}: 1.10-1.44$; $p$ for trend $<0.001)$. Higher odds of SHA exposure was related with being an ecigarette past user (compared with never users aOR: 1.49; $95 \% \mathrm{Cl}: 1.14-1.95)$ and being a current smoker (compared with never smokers, aOR: $1.54 ; 95 \% \mathrm{Cl}$ : 1.36-1.74). Those who perceived SHA exposure as harmful were less likely to be exposed to SHA (vs. harmless; aOR: 0.69; 95\% Cl: 0.61-0.78).

Compared to Northern Europe, the SHA exposure was lower among e-cigarette non-users living in Southern (aOR: 0.27; 95\% Cl: 0.11-0.68) and Eastern Europe (aOR: $0.35 ; 95 \% \mathrm{Cl}: 0.13-0.94$ ) (Table 4). E-cigarette non-users living in countries with higher prevalence of e-cigarette use were more likely to be exposed to SHA (vs. < $1 \%$ e-cigarette use prevalence; aOR for $1 \%-4 \%$ group: 1.64, 95\% Cl :1.05-2.56; aOR for $>4 \%$ group: $4.35,95 \% \mathrm{Cl}: 2.72-6.96$; $\mathrm{p}$ for trend $<0.001)$. 
Table 3. Proportion (\%) and Adjusted Odds Ratios (aOR) for at least weekly exposure to e-cigarette secondhand aerosol (SHA) and corresponding 95\% confidence intervals $(\mathrm{Cl})$ according to selected individual-level characteristics among e-cigarette non-users of European population aged $\geq 15$ years. ${ }^{*}$ TackSHS survey, 2017-2018.

\begin{tabular}{|c|c|c|c|}
\hline \multirow[b]{2}{*}{ Individual-level characteristics } & \multirow[t]{2}{*}{$\mathrm{N}^{\dagger}$} & \multicolumn{2}{|c|}{$\begin{array}{l}\text { At least weekly exposed to SHA } \\
\text { from e-cigarettes }\end{array}$} \\
\hline & & $\%$ & $\mathrm{aOR}(95 \% \mathrm{Cl})^{\ddagger}$ \\
\hline \multicolumn{4}{|l|}{ Sex } \\
\hline Women & 6122 & 15.0 & $1 \S$ \\
\hline Men & 5482 & 17.2 & $1.13(1.01-1.25)$ \\
\hline \multicolumn{4}{|l|}{ Age group (years) } \\
\hline$<25$ & 1401 & 20.9 & $3.15(2.52-3.94)$ \\
\hline $25-44$ & 3955 & 19.3 & $2.69(2.20-3.30)$ \\
\hline $45-64$ & 4218 & 16.4 & $2.23(1.83-2.73)$ \\
\hline$\geq 65$ & 2030 & 6.2 & $1 \S$ \\
\hline$P$ for trend & & & $<0.001$ \\
\hline \multicolumn{4}{|l|}{ Level of education } \\
\hline Low & 4381 & 13.4 & $1 \S$ \\
\hline Intermediate & 4064 & 17.5 & $1.19(1.05-1.35)$ \\
\hline High & 3156 & 17.8 & $1.26(1.10-1.44)$ \\
\hline$P$ for trend & & & 0.001 \\
\hline \multicolumn{4}{|l|}{ E-cigarette use status } \\
\hline Never user & 11299 & 15.6 & $1 \S$ \\
\hline Past user & 305 & 32.9 & $1.49(1.14-1.95)$ \\
\hline \multicolumn{4}{|l|}{ Smoking status } \\
\hline Never smoker & 6478 & 14.2 & $1 \S$ \\
\hline Former smoker & 1943 & 15.2 & $1.12(0.96-1.31)$ \\
\hline Current smoker & 3183 & 20.9 & $1.54(1.36-1.74)$ \\
\hline \multicolumn{4}{|c|}{$\begin{array}{l}\text { Perception of SHA exposure } \\
\text { harm }\end{array}$} \\
\hline Harmless & 2104 & 22.8 & $1 \S$ \\
\hline Harmful & 7662 & 14.6 & $0.69(0.61-0.78)$ \\
\hline
\end{tabular}

${ }^{*}$ Country-level weight factors are applied with each country contributing in proportion to its population aged 15 years or over.[38]; 'Sample size $(\mathrm{N})$ is the unweighted number of e-cigarette non-users for each corresponding individual-level characteristic; ${ }^{\ddagger}$ aORs for individual-level characteristics were estimated using multiple logistic regression models, adjusting for sex, age, level of education, e-cigarette use status, and smoking status. A multilevel model was used to include variation among countries. Estimates in bold are statistically significant at 0.05 level.

$\S$ Reference category; ${ }^{\uparrow}$ The sum does not add to the total because of missing values. 
Table 4. Proportion (\%) and Adjusted Odds Ratios (aOR) for at least weekly exposure to e-cigarette secondhand aerosol (SHA) and corresponding 95\% confidence intervals $(\mathrm{Cl})$ according to selected country-level characteristics among e-cigarette non-users of European population aged $\geq 15$ years. ${ }^{*}$ TackSHS survey, 2017-2018.

\begin{tabular}{|c|c|c|c|}
\hline \multirow[b]{2}{*}{ Country-level characteristics } & \multirow[t]{2}{*}{$\mathbf{N}^{\dagger}$} & \multicolumn{2}{|c|}{$\begin{array}{l}\text { At least weekly exposure to SHA } \\
\text { from e-cigarettes }\end{array}$} \\
\hline & & $\%$ & aOR $(95 \% \mathrm{Cl})^{\ddagger}$ \\
\hline \multicolumn{4}{|l|}{ Geographic area } \\
\hline Northern Europe & 2865 & 28.2 & $1 \S$ \\
\hline Western Europe & 1974 & 17.6 & $0.52(0.22-1.27)$ \\
\hline Southern Europe & 4013 & 10.9 & $0.27(0.11-0.68)$ \\
\hline Eastern Europe & 2752 & 11.9 & $0.35(0.13-0.94)$ \\
\hline \multicolumn{4}{|l|}{ Gross Domestic Product per Capita } \\
\hline$\leq 25.000 €$ & 5711 & 13.7 & $1 \S$ \\
\hline$>25.000 €$ & 5893 & 16.7 & $1.22(0.51-2.89)$ \\
\hline \multicolumn{4}{|l|}{ Tobacco Control Scale score } \\
\hline$\leq 50$ & 5712 & 12.8 & $1 \S$ \\
\hline$>50$ & 5892 & 18.0 & $1.31(0.62-2.79)$ \\
\hline $\begin{array}{l}\text { Total population } \\
\text { prevalence }(\%)\end{array}$ & & & \\
\hline$<20$ & 2901 & 20.4 & $1 \S$ \\
\hline $20-30$ & 2727 & 11.4 & $0.52(0.22-1.25)$ \\
\hline$>30$ & 5976 & 16.4 & $0.58(0.25-1.37)$ \\
\hline$P$ for trend & & & $<0.266$ \\
\hline \multicolumn{4}{|l|}{$\begin{array}{l}\text { Total population e-cigarette use } \\
\text { prevalence }(\%)\end{array}$} \\
\hline$<1$ & 2727 & 8.3 & $1 \S$ \\
\hline $1-4$ & 6004 & 11.9 & $1.64(1.05-2.56)$ \\
\hline$>4$ & 2873 & 27.8 & $4.35(2.72-6.96)$ \\
\hline $\mathrm{P}$ for trend & & & $<0.001$ \\
\hline
\end{tabular}

\footnotetext{
* Country-level weight factors are applied with each country contributing in proportion to its population aged 15 years or over.[38]; ${ }^{\dagger}$ Sample size $(\mathrm{N})$ is the unweighted number of e-cigarette non-users for each corresponding country-level characteristic; ${ }^{\ddagger} \mathrm{aOR}$ were estimated using multiple logistic regression models, adjusting for sex, age, level of education, e-cigarette use status, and smoking status. A multilevel model was used to include variation among countries. Estimates in bold are statistically significant at 0.05 level; § Reference category; Geographic area was categorised into Northern Europe (Ireland, Latvia, England), Western Europe (France, Germany), Southern Europe (Italy, Greece, Portugal, Spain), and Eastern Europe (Bulgaria, Poland, Romania) according to United Nations M49 Standard [35], by the World Bank gross domestic product (GDP) per capita into GDP per capita [36] $\leq 25.000 €$ (Bulgaria, Latvia, Romania, Poland, Portugal, Greece) and GDP per capita $>25.000 €$ (England, France, Germany, Ireland, Italy, Spain), by score of Tobacco Control Scale 2016 [37] into Tobacco Control Scale $\leq 50$ (Bulgaria, Poland,
} 
Portugal, Latvia, Greece, Germany) and Tobacco Control Scale >50 (England, Ireland, France, Romania, Italy, Spain), by country's total smoking prevalence into $<20 \%$ (Ireland, Italy, England), 20\%-30\% (Germany, Latvia, Poland), and $>30 \%$ (Bulgaria, France, Greece, Portugal, Romania, Spain) [33] and by country's total population e-cigarette use prevalence into $<1 \%$ (Poland, Portugal, Spain), 1\%-4\% (Bulgaria, Germany, Ireland, Italy, Latvia, Romania), and $>4 \%$ (France, Greece, England). The latter two were estimated from the TackSHS survey data.

\subsection{Discussion}

Sixteen percent of e-cigarette non-users in 12 European countries were exposed to SHA at least weekly in any indoor setting, with this group reporting a median of 43 minutes/day of exposure. Most of their exposure took in "other indoor settings" that includes restaurants and bars, but, importantly, the exposure of longest duration occurred at home and workplace (43 minutes/day). It is also evident that variability in SHA exposure exists across countries and among different socio-demographic groups -- men, the youngest, highly educated, past e-cigarette users, current smokers, those perceiving SHA as harmless, and living in a country with high e-cigarette use prevalence were among individuals who were more likely to be exposed to SHA.

The highest prevalence of SHA exposure (more than 1 in 4 non-users, England) does not correspond to the longest duration of SHA exposure (103 minutes/day, Italy). The discrepancy might be partly due to lower time-sensitisation towards duration of SHA exposure among bystanders in countries where SHA exposure was more common; they perceived shorter duration of SHA exposure because they had already accustomed to it. However, the discrepancy highlights the importance of monitoring both measures, prevalence and duration of SHA exposure, in a population. There has been no evidence on the safety levels of SHA exposure, while for SHS, there has been established evidence showing that there is no risk-free level of SHS.[39-41]. However, it has been shown that 2 hours/day of exposure to exhaled aerosol of e-cigarettes for a week may significantly increase urinary and salivary cotinine among bystanders living in homes with e-cigarette users [10]. Another study also found that after a SHA exposure of one hour, the serum cotinine concentrations increased at similar levels as in subjects exposed to SHS [42]. That indicates bystanders may systematically absorb the nicotine from acute exposure to SHA.

A previous study, conducted among smokers in 6 European countries (Germany, Greece, Hungary, Poland, Romania, Spain) from June to September 2016, also identified differences in SHA exposure prevalence across countries, with Spain having the lowest exposure (18\%) and Greece having the highest one (63\%) [23]. The variation of SHA exposure across countries may reflect a diverse country's e-cigarette use prevalence in the region. Spain, for instance, was within the lowest e-cigarette use prevalence group $(<1 \%)$ and had the lowest SHA exposure 
among others (4.3\%). Indeed, the higher odds of SHA exposure in countries with higher e-cigarette use prevalence was evident from our regression analysis as we would expect, especially, if the use of the device is unregulated. The regression analysis revealed that country's e-cigarette use prevalence was an independent factor of SHA exposure among e-cigarette non-users, suggesting the need for countries to restrict the place of e-cigarette use. The policy for ecigarette use restriction can be included in the country's current tobacco control strategy as, our study has shown, the current score of Tobacco Control Scale was still irrelevant to SHA exposure status. Moreover, a strong association found between SHA exposure and geographic area of the 12 countries might be attributable to the widespread "vape-free" policy from one country to the neighbouring countries, as has been shown in the policy diffusion theory for local and national smoking ban regulations [43,44].

Similar to what has been described with SHS exposure, each country's regulatory environment may also affect the differences in SHA exposure among countries [45-48]. Among the 12 countries included in this study, only Greece had introduced a "vape-free" policy in all indoor settings by the time this study was conducted [29]. Despite the extensive coverage of "vape-free" policy in Greece, non-users in the country were still markedly more exposed to SHA in indoor settings compared to other countries without any national "vape-free" policy, like Bulgaria, Germany, Latvia, and Romania [29]. In workplaces, including school and university, France, a country which already banned e-cigarette use in such settings, had the highest prevalence of SHA exposure [29]. This finding underscores the importance of implementing and enforcing existing policies on e-cigarette use in indoor places. Most of the SHA exposure occurred in "other indoor settings", which include bars and restaurants where smoking, but not ecigarette use is prohibited in all the 12 countries examined [49]. A previous European study indicated a $20 \%$ prevalence of e-cigarette use in indoor places where smoking was banned [23]. The greater opportunity of using e-cigarette compared to smoking conventional cigarettes in enclosed spaces, including pubs, bars, and restaurants, has been mentioned as one of the motivations of using e-cigarettes in such settings $[27,50]$. That opportunity may encourage ecigarette users, most of whom are dual users, to use e-cigarettes as an alternative to smoking in places where smoking is banned, as it is the case in "other indoor settings" $[3,27,50]$. Moreover, the already prevalent social norm of smoking in certain recreational facilities, including bars and restaurants, could also drive e-cigarette use in these settings [51]. Thus, they are important factors to be considered in future public policies.

E-cigarette use in homes and private vehicles is a source of involuntary exposure to SHA for vulnerable populations, especially children. Despite the low prevalence of SHA exposure in homes shown in this study, an intense SHA exposure (43 minutes/day) occurred in such setting. In the UK, less than $10 \%$ of 
e-cigarette users forbid e-cigarette use in their homes, while a study in the US indicates that about one in five e-cigarette users reported banning e-cigarette use inside their homes and cars [52]. We also identified socio-demographic discrepancies in SHA exposure. Men, young, highly educated, current smokers and e-cigarette past users were more likely to be exposed to SHA in indoor settings. These determinants of SHA exposure were also true for smokers as has been shown in a study among 6 European countries [23]. Being in the younger age groups or the higher educational level were also positive determinants for $\mathrm{e}$ cigarette use and awareness about e-cigarettes [53-55]. This peculiarity might be explained by the diffusion of innovation theory which states that early adopters of new behaviours tend to be males and those from higher socioeconomic status [56]. Accordingly, our data also found that SHA exposure was associated with highly educated non-users, as it is likely that users and bystanders are peers and they socialise together.

Exposure to SHA has its impact on social norm and using e-cigarette. Constant SHA exposure among youths may increase their susceptibility to using ecigarettes and tobacco products, as well as decreased their harm perception of e-cigarettes [19,57]. A higher likelihood of SHA exposure among e-cigarette past users (compared to never users) found in this study may pose a risk of relapse for those who have quit using e-cigarette. An experimental study reported that passive exposure to e-cigarette significantly increased desire to use e-cigarette [21]. Additionally, exposure to SHA may put current smokers at a risk of being dual users, as they might start using e-cigarettes $[58,59]$. Thus, more preventive campaigns are needed to avoid initiation, relapse and dual use in such vulnerable populations.

In line with a study among youth in the US [57], our study found that those who perceived SHA as harmful were less likely to report SHA exposure. Generally, people viewed SHA as less harmful than SHS [60]. A parental interview data in the US has shown that, while compared to smoke-free policy at homes and cars, there were fewer parents who enforced "vape-free" homes and cars, suggesting that parents perceived e-cigarette aerosol was safe for their children [61]. Therefore, increasing awareness of the potential harmful effects might decrease SHA exposure.

This study was limited by the inherent nature of the cross-sectional study design and the use of self-reported data by respondents. The accuracy of responses, indeed, relies on participants' perception to sense the passive exposure itself. Moreover, our question did not define the specific sign of SHA exposure (e.g, smell, visibility of the cloud, etc) as it may freely capture all possible indicators of SHA exposure. A similar question has also been used by the ITC 6 European Country survey [23]. Another strength associated to using self-reported exposure is that the respondents assign it to specific setting, which cannot be ascertained when using personal biomarkers of exposure. We reported exposure at home, 
workplace (and educational venues for students), public transportation, private transportation and other indoor places (mainly hospitality venues). The questionnaire gathered information on SHA in working and non-working days in separate, thus preventing potential information bias derived from using longer times of recall but it cannot ascertain daily prevalence. We have computed prevalence of "at least weekly" exposure that in addition to be reliable is useful, given the relatively low exposure to SHA.

There was relatively small sample size in each country (approximately 1,000 subjects), but the total sample size is large enough to draw an overall inference. Lastly, this study had some differences in sampling methods across countries [33]. However, we ensured the representativeness of the sample in proportion to each country's population aged $>15$ years by applying the weight factors into the analyses.

To our knowledge, this is the first study that investigates self-reported exposure to SHA at the population level in European countries using a standardised questionnaire that allows comparison among countries. The duration of SHA exposure described in this study may offer an alternative measure of SHA exposure burden apart from the prevalence. Additionally, countries selected in this study enable us to understand the variation of SHA exposure in different regions and tobacco products, including e-cigarette regulatory environment. In conclusion, we found that there was a substantial proportion and duration of exposure to SHA among non-users of e-cigarettes in indoor settings in European countries, with heterogeneity of exposure across countries and among sociodemographic groups. Thus, governments are strongly recommended to include e-cigarettes in smoke-free laws and tailor such legislation to be specifically targeted to vulnerable groups, particularly young people and former users, to protect them from the harms of SHA exposure and the temptation to (re)fall into nicotine addiction. Enforcement to increase compliance with existing e-cigarette use legislation is needed. Lastly, future work should include repeated crosssectional and/or longitudinal studies on SHA exposure to monitor the change of burden of such exposure in a population.

\subsection{References}

1 Cullen KA, Ambrose BK, Gentzke AS, et al. Notes from the Field: Use of Electronic Cigarettes and Any Tobacco Product Among Middle and High School Students - United States, 2011-2018. MMWR Morb Mortal Wkly Rep 2018;67:1276-7. doi:10.15585/mmwr.mm6745a5

2 Huang J, Duan Z, Kwok J, et al. Vaping versus JUULing: how the extraordinary growth and marketing of JUUL transformed the US retail e- 
cigarette market. Tob Control 2019;28:146-51. doi:10.1136/tobaccocontrol2018-054382

3 European Comission. Special Eurobarometer 458 Report Attitudes of Europeans towards tobacco and electronic cigarettes Fieldwork March 2017 May 2017 Survey requested by the European Commission, Special Eurobarometer 458 Report Attitudes of Europeans towards tobacco and elect. 2017.

4 Hess I, Lachireddy K, Capon A. A systematic review of the health risks from passive exposure to electronic cigarette vapour. Public Heal Res Pract 2016;26:1-9. doi:10.17061/phrp2621617

5 Logue JM, Sleiman M, Montesinos VN, et al. Emissions from electronic cigarettes: assessing vapers' intake of toxic compounds, secondhand exposures, and the associated health impacts. Environ Sci Technol 2017;51:9271-9. doi:10.1021/acs.est.7b00710

6 Ramôa CP, Hiler MM, Spindle TR, et al. Electronic cigarette nicotine delivery can exceed that of combustible cigarettes: a preliminary report. Tob Control 2016;25:e6-9. doi:10.1136/tobaccocontrol-2015-052447

7 Wagener TL, Floyd EL, Stepanov I, et al. Have combustible cigarettes met their match? The nicotine delivery profiles and harmful constituent exposures of second-generation and third-generation electronic cigarette users. Tob Control 2017;26:e23-8. doi:10.1136/tobaccocontrol-2016053041

8 Olmedo P, Goessler W, Tanda S, et al. Metal Concentrations in e-Cigarette Liquid and Aerosol Samples: The Contribution of Metallic Coils. Environ Health Perspect 2018;126:027010. doi:10.1289/EHP2175

9 Williams M, Bozhilov K, Ghai S, et al. Elements including metals in the atomizer and aerosol of disposable electronic cigarettes and electronic hookahs. PLoS One 2017;12:e0175430. doi:10.1371/journal.pone.0175430

10 Ballbè M, Martínez-Sánchez JM, Sureda X, et al. Cigarettes vs. e-cigarettes: Passive exposure at home measured by means of airborne marker and biomarkers. Environ

Res

2014;135:76-80.

doi:10.1016/J.ENVRES.2014.09.005

11 Rachel G, Neal B, A. GS. E-Cigarettes. Circulation 2014;129:1972-86. doi:10.1161/CIRCULATIONAHA.114.007667

12 Goniewicz ML, Knysak J, Gawron M, et al. Levels of selected carcinogens and toxicants in vapour from electronic cigarettes. Tob Control 2014;23:1339. doi:10.1136/tobaccocontrol-2012-050859

13 Fernández E, Ballbè $\mathrm{M}$, Sureda $\mathrm{X}$, et al. Particulate Matter from Electronic Cigarettes and Conventional Cigarettes: a Systematic Review and Observational Study. Curr Environ Heal Reports 2015;2:423-9. doi:10.1007/s40572-015-0072-x

14 Martínez-Sánchez JM, Ballbè M, Pérez-Ortuño R, et al. Secondhand 
exposure to aerosol from electronic cigarettes: pilot study of assessment of tobacco-specific nitrosamine (NNAL) in urine. Gac Sanit Published Online First: 28 October 2018. doi:10.1016/j.gaceta.2018.07.016

15 Tzortzi A, Teloniatis S, Matiampa G, et al. Passive Exposure to E-cigarette Emissions: Immediate Respiratory Effects. Tob Prev Cessat 2018;4:1-8. doi:10.18332/tpc/89977

16 Bayly JE, Bernat D, Porter L, et al. Secondhand Exposure to Aerosols From Electronic Nicotine Delivery Systems and Asthma Exacerbations Among Youth With Asthma. Chest 2019;155:88-93. doi:10.1016/j.chest.2018.10.005

17 King AC, Smith LJ, Fridberg DJ, et al. Exposure to electronic nicotine delivery systems (ENDS) visual imagery increases smoking urge and desire. Psychol Addict Behav 2016;30:106-12. doi:10.1037/adb0000123

18 Faletau J, Glover M, Nosa V, et al. Looks like smoking, is it smoking? Children's perceptions of cigarette-like nicotine delivery systems, smoking and cessation. Harm Reduct J 2013;10:30. doi:10.1186/1477-7517-10-30

19 Agaku IT, Perks SN, Odani S, et al. Associations between public e-cigarette use and tobacco-related social norms among youth. Tob Control 2019;:tobaccocontrol-2018-054728.

doi:http://dx.doi.org/10.1136/tobaccocontrol-2018-054728

20 Mirbolouk M, Charkhchi P, Orimoloye OA, et al. E-Cigarette Use Without a History of Combustible Cigarette Smoking Among U.S. Adults: Behavioral Risk Factor Surveillance System, 2016. Ann Intern Med 2019;170:76. doi:10.7326/M18-1826

21 King AC, Smith LJ, McNamara PJ, et al. Passive exposure to electronic cigarette (e-cigarette) use increases desire for combustible and e-cigarettes in young adult smokers. Tob Control 2015;24:501-4. doi:10.1136/tobaccocontrol-2014-051563

22 WHO FCTC COP 7. WHO Report: Electronic Nicotine Delivery Systems and Electronic Non-Nicotine Delivery Systems ( ENDS / ENNDS ). 2016;:7-12.

23 Tigova O, Beladenta A, Castellano $\mathrm{Y}$, et al. Secondhand exposure to ecigarette aerosols among smokers: A cross-sectional study in six European countries of the EUREST-PLUS ITC Europe Surveys. Tob Induc Dis 2019;16. doi:10.18332/tid/99117

24 Liu X, Lugo A, Gallus S. Passive exposure to electronic cigarette aerosol in Italy: data from the TackSHS pan-European survey. Tob Induc Dis 2018;16. doi:10.18332/tid/84268

25 Matilla-Santander N, Fu M, Ballbè M, et al. Use of electronic cigarettes in public and private settings in Barcelona (Spain). Environ Res 2017;158:68590. doi:10.1016/j.envres.2017.07.019

26 Windsor-shellard B. Adult smoking habits in the UK : 2015. 2017;2016:1-13. doi:10.2105/AJPH.76.11.1337 
27 Patel D, Davis KC, Cox S, et al. Reasons for current E-cigarette use among U.S. adults. Prev Med (Baltim) 2016;93:14-20. doi:10.1016/j.ypmed.2016.09.011

28 Simonavicius $E$, McNeill $A$, Arnott $D$, et al. What factors are associated with current smokers using or stopping e-cigarette use? Drug Alcohol Depend 2017;173:139-43. doi:10.1016/j.drugalcdep.2017.01.002

29 Amalia B, Fu M, Feliu A, et al. Regulation of electronic cigarette use and protection of bystanders in public and private areas: a cross-sectional survey in 48 countries within the WHO European Region. Tob Control[Submitted]

30 Liu X, Lugo A, Davoli E, et al. Electronic cigarettes in Italy: a tool for harm reduction or a gateway to smoking tobacco? Tob Control 2019;:tobaccocontrol-2018-054726. doi:10.1136/TOBACCOCONTROL2018-054726

31 Wang TW, Marynak KL, Agaku IT, et al. Secondhand Exposure to Electronic Cigarette Aerosol Among US Youths. JAMA Pediatr 2017;171:490-2. doi:10.1001/jamapediatrics.2016.4973

32 Fernández E, López MJ, Gallus S, et al. Tackling Secondhand Exposure to Tobacco Smoke and Aerosols of Electronic Cigarettes: the TackSHS Project Protocol. Gac Sanit Published Online First: 2019.In Press

33 Gallus S, Lugo A, Liu X, et al. Cigarette smoking prevalence in 12 European countries in 2017-2018: the TACKSHS survey. J Epidemiol 2019;Submitted.

34 Gallus S, Lugo A, La Vecchia C, et al. Pricing Policies And Control of Tobacco in Europe (PPACTE) project: Cross-national comparison of smoking prevalence in 18 European countries. Eur $\mathrm{J}$ Cancer Prev 2014;23:177-85. doi:10.1097/CEJ.0000000000000009

35 United Nations. UNSD - Methodology. https://unstats.un.org/unsd/methodology/m49/ (accessed 13 Jun 2019).

36 World Bank. GDP per capita (current US\$) | Data. https://data.worldbank.org/indicator/ny.gdp.pcap.cd (accessed 1 Jul 2019).

37 Joossens L, Raw M. The Tobacco Control Scale 2016 in Europe. 2017. www.europeancancerleagues.org (accessed 1 Jul 2019).

38 European Commission. Database - Eurostat. 2017.https://ec.europa.eu/eurostat/data/database (accessed $15 \mathrm{Jul} 2019$ ).

39 Potera C. Smoking and secondhand smoke. Study finds no level of SHS exposure free of effects. Environ Health Perspect 2010;118:A474. doi:10.1289/ehp.118-a474a

40 Strulovici-Barel Y, Omberg L, O'Mahony M, et al. Threshold of Biologic Responses of the Small Airway Epithelium to Low Levels of Tobacco Smoke. Am J Respir Crit Care Med 2010;182:1524-32. doi:10.1164/rccm.201002-02940C

41 Centers for Disease Control and Prevention. The Health Consequences of Smoking - 50 Years of Progress: A Report of the Surgeon General. Atlanta: 
2014. www.cdc.gov/tobacco (accessed 18 Jun 2019).

42 Flouris AD, Chorti MS, Poulianiti KP, et al. Acute impact of active and passive electronic cigarette smoking on serum cotinine and lung function. Inhal Toxicol 2013;25:91-101. doi:10.3109/08958378.2012.758197

43 Shipan CR, Volden C. The Diffusion of Local Antismoking Policies. https://pdfs.semanticscholar.org/55ec/5bfb3e9a4b236fd9e54f997d96bbeca ffae4.pdf (accessed 28 Jun 2019).

44 Candace J Nykiforuk Cl, Eyles FRSC J, Sharon Campbell H, et al. Smokefree spaces over time: a policy diffusion study of bylaw development in Alberta and Ontario, Canada. Heal Soc Care Community 2008;16:64-74. doi:10.1111/j.1365-2524.2007.00727.x

45 Filippidis FT, Agaku IT, Girvalaki C, et al. Relationship of secondhand smoke exposure with sociodemographic factors and smoke-free legislation in the European Union. Eur J Public Health 2016;26:344-9. doi:10.1093/eurpub/ckv204

46 Bauld L, Amos A, Ayres J, et al. The impact of smokefree legislation in England: evidence review. 2011. https://assets.publishing.service.gov.uk/government/uploads/system/uploa ds/attachment_data/file/216319/dh_124959.pdf (accessed 1 Jul 2019).

47 Sureda X, Martínez-Sánchez JM, Fu M, et al. Impact of the Spanish SmokeFree Legislation on Adult, Non-Smoker Exposure to Secondhand Smoke: Cross-Sectional Surveys before (2004) and after (2012) Legislation. PLoS One 2014;9:e89430. doi:10.1371/journal.pone.0089430

48 Martínez-Sánchez JM, Blanch C, Fu M, et al. Do smoke-free policies in work and public places increase smoking in private venues? Tob Control 2014;23:204-207. doi:10.1136/tobaccocontrol-2012-050877

49 Smoke Free Partnership. Smokefree Map. https://smokefreepartnership.eu/our-policy-work/smokefree-map (accessed 1 Jul 2019).

50 Wadsworth E, Neale J, McNeill A, et al. How and Why Do Smokers Start Using E-Cigarettes? Qualitative Study of Vapers in London, UK. Int J Environ Res Public Health 2016;13. doi:10.3390/ijerph13070661

51 Trotter L, Wakefield M, Borland R. Socially cued smoking in bars, nightclubs, and gaming venues: A case for introducing smoke-free policies. Tob Control 2002;11:300-4. doi:10.1136/tc.11.4.300

52 Gentzke AS, Homa DM, Kenemer JB, et al. Rules to prohibit the use of electronic vapor products inside homes and personal vehicles among adults in the U.S., 2017. Prev Med (Baltim) 2018;114:47-53. doi:10.1016/j.ypmed.2018.05.025

53 Gallus S, Lugo A, Pacifici R, et al. E-Cigarette Awareness, Use, and Harm Perceptions in Italy: A National Representative Survey. Nicotine Tob Res 2014;16:1541-8. doi:10.1093/ntr/ntu124 
54 King BA, Patel R, Nguyen $\mathrm{KH}$, et al. Trends in Awareness and Use of Electronic Cigarettes Among US Adults, 2010-2013. Nicotine Tob Res 2015;17:219-27. doi:10.1093/ntr/ntu191

55 Vardavas Cl, Filippidis FT, Agaku IT. Determinants and prevalence of ecigarette use throughout the European Union: a secondary analysis of 26 566 youth and adults from 27 Countries. Tob Control 2015;24:442-8. doi:10.1136/tobaccocontrol-2013-051394

56 Rogers EM. Diffusion of Innovations. 5th ed. New York: : Simon \& Schuster 2003.

57 Bayly JE, Bernat D, Porter L, et al. Prevalence and characteristics of secondhand smoke and secondhand vapour exposure among youth. Tob Control 2019;28:305-10. doi:10.1136/tobaccocontrol-2018-054265

58 Brandon T, Martinez U, Simmons V, et al. Dual use of combustible and electronic cigarettes: patterns and associations between products. Tob Induc Dis 2018;16. doi:10.18332/tid/83791

59 Robertson L, Hoek J, Blank M-L, et al. Dual use of electronic nicotine delivery systems (ENDS) and smoked tobacco: a qualitative analysis. Tob Control 2019;28:13-9. doi:10.1136/tobaccocontrol-2017-054070

60 Tan ASL, Bigman CA, Mello S, et al. Is exposure to e-cigarette communication associated with perceived harms of e-cigarette secondhand vapour? Results from a national survey of US adults. BMJ Open 2015;5:e007134. doi:10.1136/bmjopen-2014-007134

61 Drehmer JE, Nabi-Burza E, Hipple Walters B, et al. Parental Smoking and E-cigarette Use in Homes and Cars. Pediatrics 2019;143:e20183249. doi:10.1542/peds.2018-3249 
Supplementary Table 1: Sociodemographic characteristics of e-cigarette nonusers of European population aged $\geq 15$ years. ${ }^{*}$ TackSHS survey, 2017-2018 (Total: 11,604)

\begin{tabular}{|c|c|c|c|}
\hline & $N^{\wedge}$ & $\%$ & $95 \% \mathrm{Cl}$ \\
\hline \multicolumn{4}{|l|}{ Country } \\
\hline Bulgaria & 1035 & 8.9 & $8.4-9.4$ \\
\hline England & 940 & 8.4 & $7.6-8.6$ \\
\hline France & 974 & 8.6 & $7.9-8.9$ \\
\hline Germany & 1000 & 8.3 & $8.1-9.1$ \\
\hline Greece & 959 & 7.9 & $7.8-8.8$ \\
\hline Ireland & 916 & 9.0 & $7.4-8.4$ \\
\hline Italy & 1045 & 8.7 & $8.5-9.6$ \\
\hline Latvia & 1009 & 6.2 & $8.2-9.2$ \\
\hline Poland & 718 & 8.5 & $5.8-6.6$ \\
\hline Portugal & 991 & 8.6 & $8.0-9.1$ \\
\hline Romania & 999 & 8.8 & $8.1-9.1$ \\
\hline Spain & 1018 & 8.1 & 8.3-9.3 \\
\hline \multicolumn{4}{|l|}{ Sex } \\
\hline Women & 6122 & 52.4 & $51.4-53-3$ \\
\hline Men & 5482 & 47.6 & $46.7-48.5$ \\
\hline \multicolumn{4}{|l|}{ Age group (years) } \\
\hline$<25$ & 1401 & 12.8 & $12.2-13.5$ \\
\hline $25-44$ & 3955 & 33.5 & $32.6-34.3$ \\
\hline $45-64$ & 4218 & 34.6 & $33.8-35.5$ \\
\hline$\geq 65$ & 2030 & 19.0 & 18.3-19.7 \\
\hline \multicolumn{4}{|l|}{ Level of education ${ }^{\circ}$} \\
\hline Low & 4381 & 38.6 & $37.7-39.5$ \\
\hline Intermediate & 4064 & 35.8 & $35.0-36.7$ \\
\hline High & 3156 & 25.5 & $24.7-26.3$ \\
\hline \multicolumn{4}{|l|}{ E-cigarette use status } \\
\hline Never user & 11299 & 97.5 & $97.1-97.8$ \\
\hline Past user & 305 & 2.5 & $2.2-2.8$ \\
\hline \multicolumn{4}{|l|}{ Smoking status } \\
\hline Never smoker & 6478 & 59.0 & $58.1-59.9$ \\
\hline Former smoker & 1943 & 15.8 & $15.2-16.5$ \\
\hline Current smoker & 3183 & 25.2 & $24.4-26.0$ \\
\hline \multicolumn{4}{|c|}{$\begin{array}{l}\text { Perception of SHA exposure } \\
\text { harm }^{\circ}\end{array}$} \\
\hline Harmless & 2104 & 23.6 & $22.7-24.4$ \\
\hline Harmful & 7662 & 76.4 & 75.6-77.3 \\
\hline
\end{tabular}




\begin{tabular}{|c|c|c|c|}
\hline & $\mathbf{N}^{\wedge}$ & $\%$ & $95 \% \mathrm{Cl}$ \\
\hline \multicolumn{4}{|l|}{ Geographic area } \\
\hline Northern Europe & 2865 & 14.3 & $13.7-15.0$ \\
\hline Western Europe & 1974 & 36.5 & $35.6-37.4$ \\
\hline Southern Europe & 4013 & 32.8 & $31.9-33.6$ \\
\hline Eastern Europe & 2752 & 16.4 & 15.7-17.1 \\
\hline \multicolumn{4}{|c|}{ Gross Domestic Product per } \\
\hline \multicolumn{4}{|c|}{ Capita } \\
\hline$\leq 25.000 €$ & 5711 & 22.2 & 21.4-22.9 \\
\hline$>25.000 €$ & 5893 & 77.8 & $77.0-78.6$ \\
\hline \multicolumn{4}{|c|}{ Tobacco Control Scale score } \\
\hline$\leq 50$ & 5712 & 38.0 & $37.1-38.9$ \\
\hline$>50$ & 5892 & 62.0 & $61.1-62.9$ \\
\hline \multicolumn{4}{|c|}{$\begin{array}{l}\text { Total population smoking } \\
\text { prevalence (\%) }\end{array}$} \\
\hline$<20$ & 2901 & 29.5 & $28.6-30.3$ \\
\hline $20-30$ & 2727 & 30.9 & $30.0-31.7$ \\
\hline$>30$ & 5976 & 39.7 & $38.8-40.6$ \\
\hline \multicolumn{4}{|c|}{$\begin{array}{l}\text { Total population e-cigarette use } \\
\text { prevalence (\%) }\end{array}$} \\
\hline$<1$ & 2727 & 24.1 & 23.4-24.9 \\
\hline $1-4$ & 6004 & 44.7 & $43.7-45.6$ \\
\hline$>4$ & 2873 & 31.2 & $30.3-32.0$ \\
\hline
\end{tabular}

Abbreviation: $\mathrm{Cl}$, Confidence Interval

* Country-level weight factors are applied with each country contributing in proportion to its population aged 15 years or over, except for country variable where individual-level weight factors in proportion to country's population aged 15 years or over are applied to all estimates in each country [38].

^ Sample size $(\mathrm{N})$ is the unweighted number of e-cigarette non-users

- The sum does not add to the total because of missing values. 



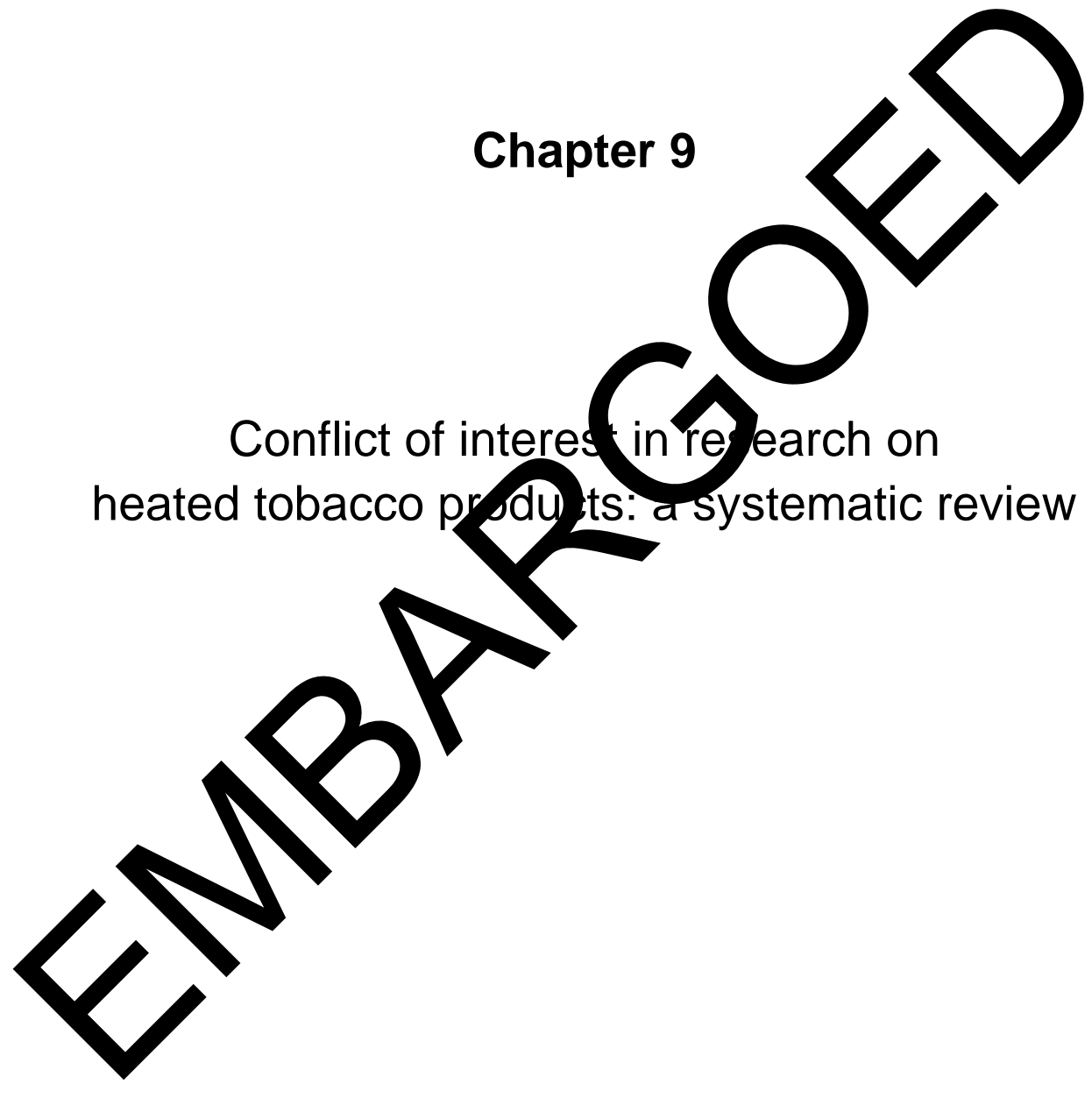


Chapter 10

General discussion 


\subsection{Main findings}

10.1.1 What's new: brief summary of the most relevant findings

Within this $\mathrm{PhD}$ programme, eight manuscripts focusing on electronic cigarette (e-cigarette) and heated tobacco product (HTP) use in Italy and Europe have been written. Their content is reported in Chapter 2-Chapter 9 of the present dissertation.

In particular, through a series of cross-sectional studies conducted annually on a representative sample of Italian adults, we observed that in 2017-2019 the prevalence of current e-cigarette users was $2.1 \%$ and in 2019 the prevalence of current HTP users was $1.1 \%$. Of all e-cigarette users the proportion of those starting or re-starting smoking conventional cigarettes $(23 \%)$ exceeded the number of those quitting smoking $(16 \%)$ as a consequence of e-cigarette use. Similarly, among HTP ever users, those starting or re-starting smoking conventional cigarettes (19\%) outnumbered those quitting smoking $(15 \%$; Chapter 2, [1]). Between April and December 2020 in Italy we conducted one of the few available prospective cohort studies tracking transitions in conventional cigarette smoking in relation to the use of e-cigarettes and HTPs. Our study confirmed findings from the series of cross-sectional studies. In details, it showed that never cigarette smokers who use e-cigarettes or HTPs are much more likely to start conventional tobacco smoking, and ex-smokers to relapse. Moreover, current smokers who quit are fewer among current e-cigarette or HTP users (Chapter 3, [2]).

Taking advantage of a representative cross-sectional study conducted during the strictest phase of the Covid-19 lockdown among Italian adults, we observed an increase by $12 \%$ in the prevalence of both e-cigarette and HTP use. New users were more frequently young adults unable to satisfy certain addictions, as cannabis use and gambling, due to imposed movement limitations. Unexpectedly new HTP users were less frequently current than never conventional cigarette smokers (Chapter 4, [3]).

Using data from a cross-sectional study conducted in 2016-2018 on a sample of adult ever-smokers from 12 Italian smoking cessation services (SCS), we found that among current or former e-cigarette users, $72 \%$ used e-cigarettes in at least one smoke-free indoor environment $(54 \%$ in workplaces and $50 \%$ in bars and restaurants; Chapter 5, [4]). Similar findings have been observed in the TackSHS survey, a study conducted in 2017-2018 in representative samples of 12 European countries: $65 \%$ of users reported using e-cigarette in at least one indoor setting where smoking is forbidden (35\% in workplaces and $42 \%$ in bars and restaurants; Chapter 6 [5]). The same TackSHS dataset has been used to observe a relatively low prevalence of HTP use in 2017-2018 in Europe, but a higher prevalence among young adults. Interestingly, among HTP ever users and 
ex-cigarette smokers at the time of the survey, approximately half had quit smoking before HTPs were introduced in the local market of each country (Chapter 7, [6]). The TackSHS survey also allowed us to observe that $16 \%$ of ecigarette non-users in Europe were exposed to second-hand aerosol from ecigarette (SHA) in any indoor setting at least weekly, ranging from $4 \%$ in Spain to $30 \%$ in England (Chapter 8, [7]).

Finally, a systematic review showed that $58 \%$ of all the 211 papers dealing with HTP in the scientific literature declared a conflict of interest (COI) with tobacco companies, mainly Philip Morris International (PMI). Of all studies with COI with any tobacco company, $89 \%$ supported HTPs, $11 \%$ were neutral and $0 \%$ opposed HTPs. Of all studies not reporting COI with tobacco industry, $20 \%$ supported HTPs, $33 \%$ were neutral and $47 \%$ opposed HTPs as harm reduction strategy (Chapter 9, [8]).

\subsubsection{Methodological considerations of the studies used}

The present PhD programme is built on original investigations based on different study designs, including repeated surveys, multi-country cross-sectional studies, prospective cohort studies and systematic reviews. Such studies, conducted over the last years in Italy and Europe, are described below. For each study, methodological considerations are also discussed.

Doxa surveys on smoking (Italy, 2017-2019; funded by National Health Institute; ISS) were computer-assisted personal interview (CAPI) surveys annually conducted by the market research institute Doxa, in collaboration with ISS and Mario Negri Institute (IRFMN) to monitor trends in tobacco smoking among Italian adults [1]. These cross-sectional studies are based each year on a sample of around three thousand subjects representative of the general Italian adult population. Survey participants are selected through a representative multistage sampling. The Ethics Committee of Istituto Neurologico Carlo Besta, Milan, acknowledged the collection of anonymous data in face-to-face populationbased, observational, cross-sectional studies (File number 37, 2017). Strengths of the studies included the representativeness of the sample and the availability of the same survey tool with the same methodology and standardized questions on tobacco smoking and other lifestyle habits, including use of novel (tobacco) products. The sample size of each annual survey was relatively limited and could be inadequate to observe annual differences for relatively uncommon habits as current e-cigarette and HTP use. More importantly, these studies had limitations inherent to their cross-sectional design, including the fact that it is not possible to derive causal inference. In fact, in these studies the information on a specific outcome and that of its potential determinants referred to the same moment of time. It is therefore impossible to understand the mechanisms by which a specific outcome (e.g., smoking initiation, relapse or cessation) and its potential 
determinants (e.g., use of e-cigarettes or use of HTPs) mutually interact. Results from these studies should be interpreted with caution and confirmed by the conduction of longitudinal data.

For this reason, we were the principal investigators of one of the few prospective cohort studies so far available on the issue (Italy, 2020; funded by ISS, Università S. Raffaele Vita e Salute and University of Pavia; [2, 9]). We took advantage of a web-based cross-sectional study of a representative sample of six thousand adults within the Lost in Italy project [9]. Participants were recruited during the strictest phase of the Covid-19 lockdown (27 April-3 May 2020). Overall, 3,185 individuals accepted to participate in a follow-up interview approximately seven months after baseline interview (between 27 November and 20 December 2020). The ethics committee of the Fondazione IRCCS Istituto Neurologico Carlo Besta approved the study protocol (File number 71-73, April 2020). This study design is ideal for the evaluation of the impact of e-cigarette and HTP use on smoking habits, although the sample size was relatively limited.

We were also the principal investigators of a multi-centre study conducted in collaboration with the Italian Association of Hospital Pneumologists (AIPO). The main aim of this study was to investigate patterns of use of e-cigarettes among smokers attempting to quit, and the role of electronic cigarette use on smoking cessation. Without any financial support, 12 AIPO smoking cessation services (SCS) from southern, central and northern Italy in 2016-2018 collected data on more than 650 current smokers approaching for the first time the SCS to quit smoking (cross-sectional phase, already concluded). We obtained approval for the study protocol from the ethics committee of the coordinating center (Fondazione IRCCS Istituto Neurologico "Carlo Besta") and from the ethics committees of each of the 12 SCS [4].

Within the TackSHS Project (www.tackshs.eu), in 2016-2018 we conducted a cross-sectional, face-to-face survey in 12 strategically selected European countries (Bulgaria, England, France, Germany, Greece, Ireland, Italy, Latvia, Poland, Portugal, Romania, and Spain; 2016-2018, funded by EC within a H2020 project; [5-7]). In each country, a sample of around 1,000 participants was randomly selected to be representative of the general adult population in each country. The survey included a specific section on electronic cigarette use and passive exposure to its aerosol in selected private and public indoor places, plus a single question on awareness and use of HTPs. We obtained approval for the study protocol from the ethics committee of the Italian coordinating center (Fondazione IRCCS Istituto Neurologico "Carlo Besta") and from the ethics committees of each of the other 11 European countries.

Finally, we conducted a systematic review of the scientific literature aimed at quantifying for the first time the proportion of HTP research funded by the tobacco industry and to investigate any influence on results interpretation. The original 
methodology used in this systematic review has been registered in PROSPERO (2020: CRD42020137394) [8].

\subsection{Advance in knowledge}

10.2.1 Frequency of use of novel (tobacco) products in Italy and Europe

The research conducted within the present $\mathrm{PhD}$ programme, added in knowledge on the frequency of use of e-cigarette $[1,3,5]$ and HTP $[1,6]$ in Italy and Europe. E-cigarette use was still relatively limited in Europe in 2017-2018, being current users only less than one out of forty adults and considering that $30 \%$ of current users were occasional users [5]. However, compared to the Eurobarometer data collected in 2014-2017, the prevalence of e-cigarette use has increased in many European countries, including five of the seven most populated countries (namely, France, Italy, Spain, England, Romania), whereas in Germany and Poland it fell slightly [10].

More importantly, the prevalence of e-cigarette users differed substantially by country, ranging from less than $1 \%$ in Spain, Poland and Portugal to more than $4 \%$ in Greece and France, and more than 7\% in England [5]. The wide spread of e-cigarettes in the UK has been reported in several other studies $[10,11]$ and is explained by the formal endorsement towards e-cigarettes by the governmental agency Public Health England in 2015, then followed by other UK institutions [1215]. Public Health England has in fact included e-cigarettes among smoking cessation tools, recommending to improve access to these products for smokers in disadvantaged groups $[12,16]$. This has been done in disagreement with the World Health Organization (WHO) and most of the tobacco control community, who warned about the need to obtain evidence to quantify the long-term risk associated with e-cigarette use or dual use and the risk of initiation among children and adolescents [17-20].

Globally, only a few independent studies assessed the prevalence of HTP use among adults. These studies were mostly conducted in Japan where HTPs are substantially prevalent [21-23] and in the United States [24]. Data from Europe were limited to a few representative national-based surveys from Italy - conducted by our research group - and the UK [25-27]. With the representative crosssectional studies conducted within this $\mathrm{PhD}$ programme, in Italy [1,3] and in Europe [6] we advance in knowledge and update data on HTP spread, confirming a small but increasing prevalence of use in the adult population.

We also found that the youngest (aged 15-24 years) are those more frequently exposed to HTPs, as well as e-cigarette use, in agreement with previous findings [25, 27-29]. In two additional studies conducted outside this PhD, we were able 
to demonstrate that the prevalence of e-cigarette use is extremely high among Italian adolescents [30, 31].

\subsubsection{Trends of electronic cigarette, HTP and nicotine use in Italy}

The research conducted within the present $\mathrm{PhD}$ programme, substantially contributed also to the knowledge on the trends of e-cigarette and HTP use in Italy [1, 4].

Analyzing data from repeated representative surveys, we observed that the inverse trend in smoking prevalence observed in Italy since the late 1950's, stopped since 2013, concurrently with the spread of e-cigarettes [1]. These findings confirm those from other Italian datasets. For example, the Eurobarometer observed a declining trend in smoking prevalence in Italy until 2012/2013 and a plateau thereafter [32]. A similar pattern was observed in some European countries, including Spain and Germany, but not in other countries [32], where tobacco control measures have been recently enforced, as France and the UK [33].

Among Italian young adults, we also did not observe over the last decade an acceleration of the decreasing trend in tobacco smoking [1]. Accordingly, despite a slight decrease in cigarette smoking, the prevalence of Italian adolescents consuming nicotine in their lifetime (either through the use of conventional cigarettes or novel products) has been shown to substantially increase in Italy [30, 31]. An Italian study on adolescents showed some different characteristics of e-cigarette users exclusively using this product, compared to exclusive tobacco smokers and dual users, suggesting that e-cigarettes might attract a novel portion of young people [30]. Adolescents, both smokers and non-smokers, are also highly interested in trying HTPs [34].

Our findings clearly confirm what we warned against several years ago [1,17]: in Italy, the availability of novel products provided a detrimental impact on tobacco control instead of accelerating the process towards a society without tobacco (the tobacco endgame). In fact, due to the availability of these novel products, the number of Italian adults [1] or adolescents [30,31] inhaling nicotine (thus using conventional cigarette, electronic cigarettes or HTP) is increasing for the first time over the last 6 decades.

Due to the growing awareness over the last decades of the health consequences of tobacco smoking or of second-hand smoke (SHS), in many social contexts smoking conventional cigarettes had been "denormalized", for example in indoor public areas or even in homes [20,35]. The use of e-cigarettes and HTPs mimics the hand to mouth action of conventional cigarette smoking. Consequently, the use of novel products might result in a renormalization of smoking behaviour, particularly among younger populations [20, 36-39]. 


\subsection{Contribution of the research to the existing knowledge on e- cigarette and HTP safety}

The present dissertation is not focused on safety, toxicity or health effects of ecigarettes or HTPs. However, we had the possibility to partially contribute also to this issue, having collected information on adverse events related to e-cigarette use in one specific study. In this chapter, we will discuss currently available evidence on i) the exposure and safety of the second-hand aerosol of e-cigarettes (SHA); ii) the health effects of e-cigarettes and HTPs; and iii) the use of these novel products during the COVID-19 pandemic.

10.3.1 Safety issues on second-hand aerosol (SHA) of e-cigarettes and SHA exposure in Europe

E-cigarettes do not emit side-stream smoke but they produce main-stream emissions, which is the aerosol exhaled by the e-cigarette user into the ambient air [40]. The exhaled aerosol, the so called second-hand aerosol from ecigarettes (SHA), is not simply steam as it is perceived by e-cigarette users [41]. Actually, e-cigarette emits toxicants, including nicotine and ultrafine particles [4244] and other potentially harmful substances, including glycerine heating products (formaldehyde, acetaldehyde, acrolein) and metals (lead, chromium and nickel) $[40,45]$, at concentrations that might be similar, or even higher, to those emitted by conventional cigarettes [40, 46, 47].

During 2015-2019 we were involved as partner and work-package leader in one collaborative research project funded by the European Union's Horizon 2020 Research and Innovation Programme. The TackSHS project (www.tackshs.eu) aimed to improve our understanding of second-hand tobacco smoke (SHS) and SHA with the final objective to tackle the health burden caused by exposure to these aerosols [48]. The main findings obtained within the TackSHS project with reference to SHA were that e-cigarette use impairs air quality with particulate matter, nicotine, volatile organic compounds, and heavy metals, among others [49]. Moreover, individuals exposed to SHA showed immediate alterations of their lung functions (respiratory mechanisms and exhaled biomarkers) and experienced symptoms of eye, nose and throat irritation [49]. It is clear therefore that the currently available evidence indicates that SHA is not harmless [40, 41, 49].

Within this project, we conducted a cross-sectional study in 12 European countries. We found that despite the generally low prevalence of electronic cigarette use in Europe, daily exposure to SHA is frequently reported in various indoor settings [7]. In particular, we found that in Europe, 2.4\% of the adult population is current e-cigarette user [5], and $16.0 \%$ of e-cigarette non-users are daily exposed to SHA [7]. This means that each e-cigarette user in Europe daily exposes to SHA a large number of non-users. This is likely due to the 
misperception of European e-cigarette users and non-users that SHA is simply steam [41], or not harmful for human's health.

\subsubsection{Health effects of e-cigarettes and HTPs}

In the IRFMN-AIPO study we collected information on adverse events related to e-cigarette use. Despite the relatively limited duration of use of e-cigarettes (average use less than 4 months) we found that, out of 395 e-cigarette users from 12 Italian Smoking Cessation Services, almost half reported at least one adverse event related to e-cigarette use, including cough and dry or irritated throat or mouth [4]. Thus, we were able to confirm the high proportion of e-cigarette users experiencing an adverse event found by other studies [50]. Results on adverse events related to e-cigarette use add to the evidence on safety, toxicity and health effects of e-cigarette and HTP use. In particular today we know that:

1) E-cigarettes cause respiratory diseases: Tobacco and related industries market and promote e-cigarette as "safer" alternatives to conventional cigarettes. However, as we described in Chapter 1.3.3, a new pulmonary disease associated specifically to e-cigarettes, named e-cigarette or vaping product use associated lung injury (EVALI), already caused more than 2700 hospitalizations and 60 deaths in the USA [40,51]. In addition, studies on the impact of e-cigarette use on respiratory health show measurable effects on organ and cellular health in humans, in animals, and in vitro, and e-cigarette use might be associated with asthma and COPD [52, 53].

2) E-cigarettes cause cardiovascular diseases: E-cigarettes have been shown to have negative acute effects on cardiovascular health, including heart rate and blood pressure [54] and daily e-cigarette use has been shown to be associated with increased risk of myocardial infarction [55].

3) Dual users might be at higher health risk than smokers of conventional cigarettes: Many e-cigarettes users are dual users. Dual use might have a more deleterious effect rather than the use of e-cigarette or conventional cigarettes alone [56-58].

4) Nicotine and other e-cigarette compounds are toxic: Besides being highly addictive, nicotine also poses health risks to children and adolescents, having deleterious impacts on brain development - potentially leading to learning and anxiety disorders $[59,60]$ - and pregnant women $[20,40]$. Some of the common components of e-liquids are known to have harmful health effects. For example, many of the thousands flavours used in e-cigarettes have been shown to increase the toxicity of their aerosols $[20,40]$.

5) The knowledge on e-cigarette safety is complicated by the variation of product types: There is a huge diversity of e-cigarettes available in the market in terms of designs, product types, interchangeable parts. Moreover, there is a wide variety of e-liquids and flavours that e-cigarette users can find in commerce [20, 40]. 
Many e-cigarettes are also customizable by the user. Thus, users might change the battery power, the heating coil and the temperature that the heating component reaches. All these aspects can have a significant impact on the emissions to which users are exposed. In fact, e-cigarette safety and toxicity likely vary according to the composition of the e-cigarette device and liquid [20, 40].

6) HTPs are extremely harmful for human's health: HTPs showed levels of nicotine $(57-84 \%)$ and total particulate $(89-122 \%)$ comparable to those of conventional cigarettes $[61,62]$. Compared to conventional cigarettes, HTPs emit lower but still measurable levels ( 10\%) of carcinogenic substances, such as nitrosamines, acrolein, acetaldehyde and formaldehyde [62-64]. Moreover, invitro studies have shown that HTPs have similar cytotoxicity to traditional cigarettes [65] or slightly lower but greater than e-cigarettes [66]. A possible hepatotoxicity of IQOS has been observed in various animal studies [67]. In mice, endothelial vascular function is impaired by emissions from a single IQOS HeatStick in the same way as a conventional cigarette [68]. The WHO, in its Report on Global Tobacco Epidemic, 2019 [69], explained how HTPs, containing tobacco, are and should be considered tobacco products. In fact, HTPs produce toxic emissions, many of which are similar to toxicants found in cigarette smoke. Moreover, some potentially harmful substances included in HTPs (or generated heating the HTP sticks) are not present when smoking conventional cigarettes [70]. Finally, given that HTPs contain nicotine, also HTPs are linked to health harms, particularly in children and adolescents and pregnant women [69].

7) Long-term health impacts of e-cigarette and HTP use are still unknown. Longterm health effects of the use of these novel products are still unknown: it will not be possible to determine the comparative toxicity of these new products for at least a decade or two, i.e., after the dissemination of results of prospective cohort studies conducted on the issue.

In general, we can conclude that it is still unknown whether e-cigarettes or HTPs are safer or not than conventional cigarettes. However we know that these products are certainly harmful for human health [20,40].

The safety issues of e-cigarettes have major implications on the consideration of these products as smoking cessation tools. As a member of the European Network for Smoking and tobacco Prevention (ENSP), I co-signed a manifesto stating that it is not in the interest "of public health to replace a very harmful product like conventional cigarettes with potentially less, but still harmful and addictive products such as e-cigarettes" $[40,71]$. This is also the viewpoint of the European Respiratory Society (ERS) Tobacco Control Committee (TCC), which published a position paper on tobacco harm reduction in May 2019, stating that tobacco harm reduction strategies using e-cigarette or HTPs are not effective as they are based upon incorrect assumptions and undocumented claims about the safety and effectiveness of e-cigarettes [72]. Also the WHO in its latest report on 
global tobacco epidemic rejected the e-cigarette as a smoking cessation tool [20, 69].

With reference to HTPs, in the same WHO Reports, it is clarified that, according to the Framework Convention on Tobacco Control (WHO-FCTC), switching from tobacco use to HTPs does not constitute cessation of tobacco use, simply because HTPs are and should be considered tobacco products [20,69]. I strongly support the WHO viewpoint, also since most quitters using e-cigarettes as a smoking cessation tool use them for prolonged periods [73, 74] and their continued dependence on nicotine might be expected to increase relapse to use of conventional tobacco [75], as confirmed by our prospective data [2].

\subsubsection{Electronic cigarette and HTP use during the COVID-19 pandemic}

Whilst emerging research on COVID-19 and smoking has started to provide evidence on the increased risk of severe and fatal COVID-19 among conventional cigarette smokers [76, 77], much less attention has been given to the use of other tobacco products, as HTPs and e-cigarettes.

A commentary provided the rationale that coronaviruses can attach the particles suspended in SHA from e-cigarettes exhaled when breathing, coughing or sneezing [78], thus potentially increasing SARS-CoV-2 infection. However, on the basis of the relatively low smoking prevalence of selected case-series, some authors argued that smoking could reduce SARS-CoV-2 infection due to nicotine, which might compete with the SARS-CoV-2 by binding to selected nAChRs [79]. Consequently, some authors claimed that e-cigarettes could be used to increase nicotine consumption to reduce SARS-CoV-2 infection [80].

Only a few studies are available on the role of e-cigarettes on SARS-CoV-2 infection, all showing an apparent increased risk of infection for users of novel (tobacco) products [81-83]. An ecological study, with major limitations in its study design, showed a significant direct association between the proportion of ecigarette users and the COVID-19 prevalence and case fatality [81]. An on-line cross-sectional study conducted in the USA showed a direct association between youth use of e-cigarettes and COVID-19 [82]. Finally, in a study on 499 Italian dental staff subjects, we showed a lack of a favourable role of e-cigarette and HTP use on SARS-CoV-2 infection. The odds ratio (OR) of having a SARS-CoV2 antibody positive test for e-cigarette users vs non-users was 1.44 and the OR for HTP users compared with non-users was 1.57 [83]. Both the OR estimates failed to reach statistical significance.

Two other commentaries warned about the potential acute pulmonary toxicity of e-cigarettes, suggesting that these products could be enhancing progression of COVID-19, including morbidity and mortality [84, 85].

However, to our knowledge no study provided original data to understand the role of e-cigarettes and HTPS on COVID-19 hospitalization, severity and mortality. 
Given the lack of knowledge on the issue, we are finalizing the conduction of a multicentre study (the Covid-19 and SMOking in ITaly, COSMO-IT, study), based on more than 2,000 COVID-19 patients in Italy, aimed at quantifying the determinants of COVID-19 progression. The results of the COSMO-IT study will also contribute to fill the gap on knowledge on the role of e-cigarette and HTP use on COVID-19 severity and mortality [86].

Due to the COVID-19 pandemic most governments worldwide imposed a stayat-home order to interrupt transmission of the coronavirus. Most public places, including shops, bars and restaurants were closed and people were forbidden to leave their homes except to obtain basic necessities and healthcare. A huge occasion has been lost, since only a few country governments worldwide decided to apply the lockdown also to tobacco or e-cigarette shops, including South Africa [87]. Italy was the first European country experiencing the full force of the pandemic and imposed a strict nationwide lockdown in March-May 2020 [3, 88]. Shops selling tobacco and e-cigarettes were exempt from these restrictions. We conducted one of the first independent studies based on a representative sample of Italian adults [3]. The prevalence of regular e-cigarette and HTP users among Italian adults rose by roughly $12 \%$ during the first Covid-19 lockdown [3].

\subsection{Contribution of the research to the understanding of the role of e- cigarette and HTP on tobacco smoking}

\subsubsection{Implications for current smokers}

Tobacco harm reduction advocates claim that e-cigarettes might be useful for tobacco control, the e-cigarettes (and even HTPs for certain tobacco harm reduction advocates) representing a game-changer in quitting smoking [18, 19, 89]. They are convinced that smokers who stop smoking tobacco to switch to ecigarettes (or to HTPs) will reduce their risk. In Chapter 10.3.2 we showed that this is not necessarily true, particularly for HTPs. Also assuming that e-cigarettes are less harmful than conventional cigarettes, e-cigarettes might be useful only under certain conditions, i.e. for current smokers with the following characteristics at once:

1) Smokers who are not able to quit alone or with standard smoking cessation treatments (it is self-evident that quitting smoking using an evidence-based effective treatment - say varenicline - is better than quitting smoking using ecigarettes, for safety reasons and being e-cigarette associated with prolonged nicotine intake);

2) Smokers stopping smoking completely, switching exclusively to e-cigarettes (it is clear that dual users, who continue to smoke conventional cigarettes, will not have any benefits by the use of e-cigarette). 
For all other individuals (those who do not meet one or more of the four conditions) e-cigarette does not provide any benefit and is a serious harm. With our research, we were able to show that the number of people who will really benefit of e-cigarettes are just a small proportion of all e-cigarette users in Italy and Europe. In fact, our research highly contributed to show that most e-cigarette users do not adhere to the four conditions above: C1-C4. In particular:

1) Besides psychological therapy, today a number of pharmacological treatments (e.g., varenicline, bupropion, citisine and nicotine replacement therapies; NRTs) have been approved by a drug registration authority and are available in the market [90]. In theory, e-cigarette should be considered by potential quitters only after having tried to quit using those effective standard treatments. This however does not usually happen in the community. At least two systematic reviews [91, 92] clarified the role of e-cigarette on smoking cessation. E-cigarettes appear to slightly help smokers to quit in clinical and/or controlled settings. However, no randomized controlled trial (RCT), to date, compares e-cigarette with the standard of treatment, varenicline, which has been shown to be superior to all other treatments, including NRT [90], and might be superior also to e-cigarette. Moreover, a beneficial effect is not observed at the community level or without further support [20,92]. With reference to HTPs, I strongly support WHO's stance that "HTPs are tobacco products and therefore, even if a tobacco user converts from the use of conventional cigarettes to HTPs, this would not constitute cessation" [20]. One of our main contribution to the issue is given by the analysis of prospective data, confirming a lack of effectiveness at the community level of both e-cigarettes and HTPs in increasing smoking cessation among current smokers [2].

2) We confirmed that the majority of e-cigarette and HTP users are dual users (also consuming conventional cigarettes). For all these subjects, the availability of novel (tobacco) products is deleterious. In fact, we found in studies conducted in Italy [4] and Europe [5] that the majority of dual users consume e-cigarettes where smoking is forbidden (dual users), suggesting that smokers might decide to use e-cigarettes in smoke-free areas in order to have the possibility to assume their daily amount of nicotine [4].

\subsubsection{Implications for ex-smokers}

It is obvious that the category of ex-smokers having quit without the support of novel (tobacco) products will not have any benefit by the availability in the market of e-cigarettes or HTPs. Moreover, following a representative sample of 3185 Italian adults for 7 months, I showed that among ex-smokers at baseline, 17.2\% relapsed at follow-up. Compared with never users, ex-smokers relapsing were more frequently e-cigarette (OR 7.05) and HTP users (OR 9.78) [2]. Our findings confirm those from two recent meta-analysis of longitudinal studies, showing that, 
among ex-smokers, e-cigarette users had at least twice the risk of relapse compared to e-cigarette never users [75, 93].

Moreover, a survey we conducted in 12 European countries within the present $\mathrm{PhD}$ program showed that a large proportion (approximately half) of ex-smokers using HTPs did not quit smoking switching to HTPs but they first quit and then relapsed to the use of tobacco [6].

The best available RCT comparing the effectiveness of e-cigarette with that of NRTs showed that $80 \%$ of subjects who quit with e-cigarette continue to use ecigarette after one year of treatment (only $9 \%$ continue to use NRTs in the NRT group) [73]. Thus, most of those who quit due to e-cigarettes become long-term e-cigarette users. This has major implications [74] since, as confirmed by our research, ex-smokers using e-cigarettes have a much higher risk of relapsing compared with e-cigarette non-users [2].

\subsubsection{Implications for never smokers}

The whole category of never smokers will not have any benefit by the availability in the market of e-cigarettes or HTPs. More importantly, never smokers who use e-cigarettes may become addicted to conventional tobacco products [20]. Accordingly, using data from the prospective cohort study conducted in Italy, we showed how never cigarette smokers who used e-cigarettes at baseline were much more likely to start smoking (compared with never users, OR 10.98). Also who used HTP at baseline had a higher risk of smoking initiation (OR 6.92) [2] These findings are in broad agreement with a recent meta-analysis showing that all the studies analyzing the effect of e-cigarettes on smoking initiation found increased risk of smoking uptake with e-cigarette exposure. In particular, comparing e-cigarette users versus non-e-cigarette users, among never-smokers at baseline the OR for smoking initiation was 3.25 for e-cigarette users compared with non-users [93].

Given that many e-cigarettes are marketed to be attractive to youth, they have been taken up by adolescents and children in large numbers in some countries [20]. Youngest generations are initially attracted by likeable flavors and nonregulated appealing advertisements, also on social media [94]. Once addicted to nicotine they may switch to conventional cigarette smoking [93, 95].

In conclusion, several studies have observed that electronic cigarette use increases - rather than decreases - tobacco smoking in the general adult population and has been associated with tobacco smoking initiation among adolescents [1, 28]. In this landscape, it is clear that novel (tobacco) products may have an unfavorable public health effect, rather than being harm reduction tools. 


\subsection{The role of the tobacco industry and electronic cigarette industry}

\subsubsection{Tobacco harm reduction}

Harm reduction is a public health strategy aimed at reducing the harm caused by a substance or a behaviour that are otherwise difficult to eliminate [20,96]. The main principle of harm-reduction is that 'if it is not (yet) possible to 'cure' a hard drug user, one should at least try to minimize the harm they cause to themselves and their environment" [97]. A classic example of an harm reduction approach which resulted as an effective strategy since 1970s was the use of methadone for detoxification and maintenance treatment to prevent withdrawal symptoms for heroin patients [40,96, 98]. When administered in adequate dosages, it could relieve the craving for heroin, effectively reducing heroin use, crime, and injectionrelated risk behaviors [96, 98, 99]. Some, including the UK government agency Public Health England $[12,16]$, have endorsed the idea that e-cigarettes could be used as part of a harm-reduction approach [20].

The reason why Public Health England has endorsed e-cigarettes, thus espousing the tobacco harm reduction strategy, is probably due to the difficulties to strengthen effective tobacco control strategies in one of the countries globally - and the country in Europe - with the highest implementation of tobacco control strategies at a government level [33]. Actually, in the UK tobacco smoking is strongly discouraged since several years: in this country a pack of cigarettes costs today more than $€ 10$, smoking bans and advertising bans are among the strictest ones, conventional cigarettes are sold without any branding (plain packaging) and smokers wishing to quit smoking obtain the most effective pharmacological and psychological support to quit free of charge [33]. Thus, in 2015, given the limited room to further implement effective tobacco control policies, Public Health England and other main UK institutions viewed in ecigarettes the new game-changer in quitting smoking, formally endorsing this novel product in an attempt to speed up the process for a tobacco endgame [18, 19, 89].

This endorsement has been promptly criticized by most of the tobacco control community [17-19] for several reasons. First of all, e-cigarettes might be less harmful than conventional cigarettes but not about the highly controversial " $95 \%$ safer" figure cited by Public Health England $[18,19]$ and long-term health effects of e-cigarette use are unknown [20, 40]. Secondly, e-cigarettes are not as effective as expected to quit smoking and the risk of initiation among children and adolescents and relapse among ex-smokers is high [2, 18, 20]. Thirdly, the harm reduction strategy, that has been shown to be useful in certain circumstances [96, 98, 99], is not applicable to tobacco [19].

In my opinion, today e-cigarettes (much less HTPs) are not eligible as tobacco harm reduction strategies for at least the following three reasons: i) other smoking cessation pharmacological (and psychological) therapies are available [90] that 
could be potentially more effective for smoking cessation than e-cigarettes (no alternatives to methadone were available for individuals addicted to heroin); ii) ecigarettes are also proposed to non-smokers (methadone was not proposed to people non addicted to heroin); iii) the marketing of both the addiction (i.e., tobacco) and of the harm reduction tool (i.e., e-cigarettes and/or HTPs) is today controlled by the same entity (i.e., the tobacco industry). In fact, almost all major multinational tobacco companies, such as BAT, PMI and its sister company Altria have purchased shares in e-cigarettes market or developed their own e-cigarette brands [20]. The tobacco industry will therefore have easy game to favour one of the two products, playing on the their differential price.

With growing evidence on the issue, also corroborated by the findings from the present dissertation, we are empirically observing the failure of e-cigarette as a harm reduction strategy or as a smoking cessation tool also in England, where almost $40 \%$ of current e-cigarette users remain dual users (i.e., also smoking conventional cigarettes) [5]. It is also possible that in the UK the endorsement of Public Health England towards e-cigarettes results in public cuts of resources allocated to support traditional strategies for smoking cessation [100]. Considering all these aspects, for this country e-cigarettes will likely delay - rather than speed up - the achievement of a tobacco-free society [17-19]. This is even more true for all other countries with less advanced tobacco control policies. This is the case of Italy, where a stop to the decline in smoking prevalence has been observed concurrently with the spread of e-cigarettes [1].

For these reasons, the last report on the global epidemic by WHO is entirely dedicated to warn against e-cigarettes [20]. It will be sufficient to provide the three key messages of the entire report: 1) "Electronic Nicotine Delivery Systems (ENDS) are addictive and not without harm"; 2) "ENDS should be strictly regulated for maximum protection of public health"; and 3) "Children and adolescents who use ENDS can double their risk of smoking cigarettes" [20].

The issue became more complex since the entrance in commerce of HTPs after 2015. The tobacco industry allocated huge investments to contaminate the scientific literature of studies supporting the tobacco harm reduction strategy in an attempt to make sense out of their novel tobacco products $[18,101]$.

\subsubsection{Action of tobacco industry to raise a voice on tobacco control}

Since several decades, the tobacco industry tried to raise a voice into the scientific debate in an attempt to reassure smokers about the effects of smoking on health to contrast the growing empirical evidence from independent research, strongly opposing tobacco [102, 103]. Having the tobacco industry denied the unfavourable effects of smoking tobacco, it had lost its credibility [104]. Thus, the tobacco industry engaged third parties, in particular scientists, preferably but not 
only prominent, willing to promulgate its messages in exchange for money [101, 102].

Tobacco harm reduction (THR) has always been a very dear argument to the tobacco companies $[105,106]$. Thus, in the past, the tobacco industry invested money to produce research supportive of products as low-tar cigarettes (the so called "light cigarettes") or smokeless tobacco or Swedish snus [105]. However, a couple of decades ago, due to several factors including i) the recommendations of the World Health Organization (WHO) to rely on the evidence from independent research only, iii) the decision of several journals to refuse to publish findings from studies linked to tobacco companies [101, 107] and iii) the growing awareness of the harmful effects of tobacco [108], the tobacco industry had major difficulties to enroll tobacco advocates among researchers, thus having only limited room to contrast the growing overwhelming evidence against tobacco. Until 2010, when e-cigarette entered the market of most high income countries. This gave the opportunity to the tobacco industry to re-raise a voice in the scientific community, espousing the same cause of e-cigarette companies: tobacco harm reduction. Tobacco companies were in fact ready to launch their electronic devices designed allegedly to be relatively safe compared with conventional cigarettes: the HTPs. These products are now proposed by the tobacco companies as electronic products similar to e-cigarettes [20]. PMI has recently allocated almost US\$1bilion for the next 12 years in the Foundation for a Smoke-Free World, an organization whose main aim is to finance research to justify the assertion that IQOS is acceptable from both a safety and a public health perspective [109]. Also other tobacco companies, including BAT and JT, are investing massive amount of money for the same reason. Surprisingly, some tobacco control experts still accept to work with the tobacco industry, forgetting how the industry has used scientists in the past [110]. Therefore, on the issue of tobacco harm reduction, the scientific literature is already highly "contaminated" by potentially biased data, funded and controlled by the e-cigarette industry and, more importantly, by the tobacco industry [111].

In Italy and in a few other countries, the tobacco industry (in particular PMI) and also some e-cigarette companies (e.g., Juul) found the way to raise a voice in the scientific debate also organizing meetings with scientists engaged by the tobacco industry, or funding national congresses of conniving scientific societies where the industry has the possibility to promote tobacco harm reduction and their novel tobacco products, either through third parties or directly. With the support of my Institute and in collaboration with many independent Italian tobacco control experts, I reacted to this situation in Italy drafting a position paper aimed at reaffirming the importance of research independence from the tobacco industry. This document, was signed by most of the main Italian scientific societies and institutions [112]. Signatories commit themselves to: i) avoid accepting any direct or indirect remuneration or financing from the tobacco companies; ii) avoid 
involving the tobacco companies in any way in scientific debate venues; and iii) conduct advocacy activities in the fight against smoking [112]. Unfortunately, not all the societies that have been invited to adhere, accepted to sign the position paper.

10.5.3 Consequences on the scientific literature, already contaminated by misleading conclusions

The massive investments of the tobacco industry to support tobacco harm reduction, in particular that of PMI for its Foundation for a Smoke-Free World, resulted in a large part of the scientific literature on tobacco harm reduction suffering from serious conflict of interest [40, 111]. A few systematic reviews conducted on e-cigarettes or on harm reduction strategies showed how practically all studies without industry links conclude that e-cigarettes are hazardous to health and warn against tobacco harm reduction, whereas only a negligible part of industry-funded studies arrive at the same conclusion [40, 105, $111,113]$. Actually, it has already been shown that authors holding different standpoints might reach opposite conclusions also when interpreting the same scientific results $[114,115]$. Thus, for example, using the same data of the Eurobarometer survey conducted in 2014, harm reduction advocates linked to ecigarette trade organizations and likely to the tobacco industry [Tobacco-tactics] concluded in favour of e-cigarettes: "more than one-third of current e-cigarette users polled reported smoking cessation and reduction" [114]. On the opposite, conflict of interest-free researchers concluded against e-cigarettes ("e-cigarettes are associated with inhibiting rather than assisting in smoking cessation") [115]. For the first time, we conducted a systematic review to investigate tobacco industry influence on support for HTP [8]. We found that scientific knowledge on HTPs is currently based on studies compromised by stated or unstated conflicts of interest. The large majority of COI-free studies oppose HTPs. We confirm that, despite the statements of tobacco harm reduction advocates [116], research sponsored by tobacco companies, putting economic interests over public health interests, can seriously bias our knowledge and understanding of the unfavourable health effect of novel tobacco products, and may be itself a threat to public health [8].

\subsubsection{Fiscal and regulatory benefits of novel products}

The large amount of money the Italian political parties received from the lobbying activities of the tobacco industry over the last few years, is likely to have had major consequences on HTP (and e-cigarette) regulation in Italy. This was evident already in 2014, when Italy was chosen by PMI as the pilot country for the European market for the launch of Iqos [26]. The then Prime Minister, Matteo 
Renzi, participated as the guest of honor to the inauguration of a large HTP plant of PMI in Bologna, after putting the first stone of the plant in 2014 [117].

Without any independent scientific evidence, in Italy policymakers became convinced that HTPs were less harmful than combustible tobacco and effective in reducing the consumption of traditional cigarettes and the number of smokers. Because of their alleged consideration of products with a lower health risk, in Italy the enforcement of various tobacco control regulations is only minimally adopted for HTPs, although they actually are tobacco products. First of all, health warnings are required to cover only $30 \%$ of the HTP packaging (instead of $65 \%$ for conventional cigarettes), without pictorial images. Second, comprehensive smoke-free regulations prohibiting smoking in all public places and workplaces do not apply to HTPs. Finally, advertising and promotions are not banned for these new products [26]. In Italy HTPs enjoy regulatory and fiscal benefits similar to those enjoyed by e-cigarettes. The excise taxes of HTPs are one fourth those of conventional cigarettes and this benefit has been recognized to novel (tobacco) products.

In January 2019, PMI made a formal request to the Italian authorities to evaluate the relative harmfulness of their novel tobacco product. The Italian Ministry of Health and the National Health Institute (Istituto Superore di Sanità; ISS) declared that it was impossible to acknowledge both the reduction of HTP's toxic substances and the potential risk reduction of HTPs compared to combusted products, under the same conditions of use. There was a more than one year delay - orchestrated by PMI - in the publication of the report on HTPs by ISS. Through an investigation broadcast on the national TV programme "Report", I contributed to ensure that this report were made publicly available. This notwithstanding, the proposed amendment to the decree $18 / 2020$ to substantially increase the taxation of novel tobacco products did not pass and current legislation foresees a negligible increase in taxation for HTPs and e-cigarettes by $5 \%$ each year.

All European countries allow the sale of e-cigarettes, and most of the regulations are only partial for e-cigarettes and HTPs $[20,26,40]$. It is worth noting that Australia will become soon the first country in the world to ban the purchase or import of e-cigarettes by consumers unless they have a valid doctor's prescription to do so for smoking cessation [20]. A survey among experts was conducted in 2018 to understand the legislation regulating e-cigarette use in public and private places from all countries of the WHO European Region. Authors concluded that although the majority of countries had introduced e-cigarette use legislation at the national level, only a few protect bystanders in indoor settings [118]. 


\subsection{Conclusions, implications and key considerations}

\subsubsection{Key messages emerged from the research in this dissertation}

After a drop in smoking prevalence over the last decades, in Italy we recently observed an increase of Italians inhaling nicotine (either smoking conventional cigarettes or using e-cigarettes or HTPs), along with the spread of novel (tobacco) products [1]. In Italy, both e-cigarette and HTP use predict starting smoking and relapse and do not increase - and may reduce - smoking cessation among current smokers [2]. More in general, the use of novel products increases the likelihood of smoking conventional cigarettes [1,2].

During the Covid-19 pandemic, e-cigarettes and HTPs played a minor role as smoking cessation tools for heavy smokers in Italy, but rather provided opportunities for young never smokers to engage in socially acceptable activities, in some cases perhaps reflecting the obstacles they faced during the stay-athome order in obtaining other addictive substances, such as cannabis [3].

In Italy and Europe, most users of products with liquids containing nicotine, are dual users and use e-cigarettes where smoking conventional cigarette tobacco is prohibited [4, 5]. The majority of HTP users are also dual users, HTP is used mostly by younger generations and attracts non-smokers too. Moreover, a large proportion of ex-smokers using HTPs are not people moving from conventional tobacco smoking to HTP use in an attempt to reduce their harm, but people who relapse nicotine addiction, being attracted by this new alleged safe (or safer) product [6]. In Europe, despite the relatively low prevalence of e-cigarette users, there is a notable proportion of e-cigarette non-users who are daily exposed to SHA in indoor settings [7].

Current scientific knowledge on HTPs is based on studies mostly conducted or supported by the tobacco industry, which provide biased findings. The large majority of COI-free studies do not support HTPs [8].

10.6.2 Research gaps and recommendations for the scientific and public health community

The introduction of e-cigarettes and HTPs has led to a debate about their impact on health and tobacco control. It is desirable that the scientific community continues to fuel this debate on the relative importance of harm reduction compared to nicotine reduction [119]. What is not acceptable, however, is that tobacco companies have an active voice (directly or through third parties) in this debate [120]. For the first time, though a meta-analysis on HTPs we showed that most of the knowledge on these novel tobacco products comes from studies supported by the tobacco industry, and that all these studies are biased and misleading in their conclusions [8]. Our systematic review found for HTPs findings similar to those already observed for e-cigarettes and tobacco harm reduction 
$[105,111,113]$. Given the need for independent data, the most important recommendation to the tobacco control and public health experts and, more in general, to the scientific community is to avoid collaborations with the tobacco industry [20]. This in fact would represent a point of no return, since after the engagement with the tobacco industry it is impossible to keep an unbiased viewpoint [8]. This notwithstanding, many scientists, including prominent public health experts, accept to collaborate with the tobacco industry, seemingly unaware of the malfeasance of the tobacco industry, as recognized in the WHOFCTC, which explicitly advises against engagement with the industry [18]. Thus, as we already recommend to Italian scientific societies, we strongly suggest to public health and scientific researchers to: i) avoid accepting any direct or indirect remuneration or financing from the tobacco companies; ii) avoid involving the tobacco companies in any way in scientific debate venues; and iii) conduct advocacy activities in the fight against tobacco smoking [112].

Besides not always free of conflicts of interest, knowledge about e-cigarettes and HTPs remains currently fragmented and small-scale. Also our studies, including the prospective cohort, suffer from some limitations, including the relatively limited sample size. Thus, our findings should be confirmed by larger longitudinal studies.

The main independent projects that are urgently needed to fill the knowledge gap on the role of novel (tobacco) products on tobacco control are, in my opinion, the following:

1) Establish robust cohort studies in adult and adolescent populations to determine short-, medium-, and long-term effects of e-cigarette use on smoking behaviour. Following the approach used in our prospective cohort study [2], it will be possible to observe if e-cigarette and HTP use increases or decreases the risk of starting, relapsing, and continuing smoking by comparing the trajectories of smoking habits between e-cigarette or HTP users and non-users.

2) Establish new cohort studies to evaluate long-term health consequences, in terms of incidence of chronic diseases and mortality, of e-cigarette or HTP use. We know that long-term effects will be available only after the conduction of large cohort studies focused on e-cigarettes and HTPs and having as the main endpoint the risk of total and cause-specific morbidity and mortality. To date, no such study has already been planned. The most effective and efficient study design is a robust prospective study obtained through record-linkage. In particular, large cross-sectional studies should be conducted on samples possibly representative of the general population obtained from areas that have administrative healthcare databases available for record-linkage. Participants will provide detailed information on smoking and novel product use history and information required for their identification in the healthcare databases. These databases will provide data about incidence and mortality of cancer and other 
smoking-related conditions (e.g., respiratory and cardiovascular diseases), besides healthcare expenditures and other healthcare data.

Alternatively, it would be possible to conduct a pooled-analysis with already available datasets of existing international cohorts (e.g., UK Longitudinal Household Survey, UK BioBank, and Healthy Ireland), providing information on e-cigarette use and risk of morbidity and/or mortality outcomes and associated healthcare costs, that are captured in routine data sources.

3) Knowledge on the role of e-cigarette on smoking cessation is still incomplete. Indeed, existing RCTs are frequently underpowered. Moreover, they compare ecigarette with nicotine replacement therapy (NRT), which is not the standard of care of smoking cessation in clinical settings [90]. To make an objective and accurate evaluation of e-cigarette as a tool for smoking cessation, this product should be compared with the most effective currently available pharmacological support (i.e., varenicline) in a large RCT.

With reference to future studies on the safety of e-cigarettes and HTPs, more than being interested to know whether they are more or less harmful than conventional cigarettes, we need to know if those products are harmful to health. The toxicity of conventional cigarettes is tremendous, thus, the fact that something is "less toxic" than conventional cigarettes does not in any way mean that it is not harmful to health [40]. Consequently, in future toxicological, in vitro or in vivo studies of novel products I recommend to compare the use of ecigarettes and HTPs with "no use" instead of conventional cigarettes. These studies should be followed by a formal risk assessment.

\subsubsection{Recommendations for policy makers}

Also policy makers might be among the victims of lobbying actions by the tobacco industry. Thus, policy makers of every country worldwide should refute partnerships and agreements with the tobacco industry. This is required to comply with the WHO FCTC, signed by the large majority of countries globally, and to respect the spirit of its Article 5.3. This specific article legally obligates Parties to the treaty "to protect their public health policies related to tobacco control from commercial and other vested interests of the tobacco industry" [121]. It is important that policy makers rely exclusively on conflict of interest-free research, being evident that studies linked to the tobacco and e-cigarette industry have biased and misleading conclusions [8, 105, 111, 113].

The findings of our research confirm that the balance between benefits and risks associated to e-cigarettes and HTPs is negative [1-7]. Probably the most important result of my dissertation is that users of these novel products more frequently start smoking conventional cigarettes if they are never smokers, relapse if they are former smokers and continue smoking if they are current 
smokers [1, 2, 6]. Based on these findings, I see no argument to justify the huge fiscal and regulatory benefits these products continue to have, at least in Italy [1]. I concur with respected health organizations [40, 71, 72, 122], and in particular the WHO, that all these novel products should be strictly regulated for maximum protection of public health [20]. HTPs (being tobacco products) but also ecigarettes should be legally equated with conventional tobacco cigarettes in terms of use, sale and purchase, labelling, emission-free spaces, advertising, promotion, sponsorship and taxation [20, 40, 71].

Today, at least in Italy, misleading marketing messages supporting HTPs or in favour of tobacco harm reduction are spread, without any scientific validation, to many different populations. In particular: i) policy makers and healthcare providers are bombarded with e-mails, newsletters or articles published in conniving magazines reporting comments of so-called "experts" who fail to disclose their conflicts of interest with the tobacco industry; ii) adolescents and young people, who are the target population of hidden advertising, usually spread by influencers in many different online social networks; iii) smokers receive marketing information from more and more intrepid advertisements in practically all the media. A strong reaction from policy makers and governmental body is needed not only to ban e-cigarette and HTP advertisements, but also to regulate and contrast all the tactics used by the tobacco industry to promote their products. Policy makers should support the planning, implementation, monitoring and evaluation of the efficacy of evidence-based health education and communication interventions in the field of novel tobacco products which is directly and indirectly independent from the tobacco industry.

Particular importance should be given to the implementation of health education programs on novel tobacco products based on the scientific evidence, targeting particularly young people, which represents the most vulnerable population. These education programs could be implemented in schools to reach adolescents, highly attracted by novel (tobacco) products and the main target population of the industry.

\subsection{Recommendations to healthcare providers}

Many different types of healthcare providers are at the forefront in the fight against tobacco. Besides those - usually pneumologists or psychologists working in smoking cessation services (SCS), many physicians specialized in smoking-related diseases, including oncologists and cardiologists, general practitioners (GPs), but also dentists, pharmacists and others offer to their patients smoking cessation interventions, usually providing a minimal advice. These healthcare providers are often bombarded by misleading messages pretending that tobacco harm reduction is a consolidated tobacco control strategy. For example, in Italy, the Foundation for a Smoke Free World (FSFW) 
frequently sends to a mailing list of almost 200,000 healthcare providers its online magazine Popular Science, with articles promoting HTPs. The reached healthcare providers include almost 25,000 pharmacists, 45,000 nurses, 30,000 dentists, 15,000 cardiologists and 35,000 GPs.

These healthcare providers should rely on independent research only and follow the recommendations of namely all the serious and independent international health organizations, including the WHO [20], the ENSP [71], the European Respiratory Society [72], the American College of Cardiology, the American Heart Association, the European Society of Cardiology and the World Heart Federation [122] and others [40], suggesting that tobacco harm reduction as a populationbased strategy is not acceptable and discouraging use of e-cigarettes and HTPs for any reason.

Healthcare providers should be aware that e-cigarettes and HTPs might serve as a gateway to conventional smoking among young people or the renormalization of smoking in the society $[1,2,20]$. When reading scientific papers on the issue, healthcare providers should also pay attention to the potential conflicts of interests of Authors, and beware of Authors supporting HTPs or tobacco harm reduction [8].

The campaigns organized by the tobacco industry encourage smokers to "change to a better alternative" undermining tobacco cessation initiatives by presenting a tempting and easy "alternative" (i.e., the HTPs) to breaking a nicotine addiction. This undermines successful tobacco control initiatives (which have denormalized smoking in many countries) by portraying this form of tobacco use as socially acceptable [20]

Actually, tobacco control efforts should avoid distractions created by tobacco industries and be focused on reducing tobacco smoking [20]. Instead of proposing risky alternatives as e-cigarettes, healthcare providers should therefore recommend smoking cessation to all smokers, being aware that there are effective pharmacological (or psychological) treatments in support of smoking cessation [72, 90]. These therapies have obtained approval for commerce by national or international regulatory agencies having demonstrated to be unequivocally effective and safe. This was never demonstrated for e-cigarettes and HTPs.

Besides being often smokers [123], healthcare providers are relatively frequently novel (tobacco) product users, at least in Italy [83]. Before acting as key reference point in the fight against smoking, healthcare providers should set a good example: those who smoke or use e-cigarettes or HTPs should urgently quit or at least refrain from smoking or vaping during working hours [123]. 
10.6.5 Evidence-based messages for the general public

The majority of smokers want to quit [72]. E-cigarettes and in particular HTPs are often promoted by the industry as smoking cessation aids. However, there is no reliable evidence independent of the tobacco or e-cigarette industry on the impact of these products on conventional smoking cessation [20]. Therefore, it is important to recommend primary prevention interventions in order to spread the message to the general population that the main goal should be to quit smoking, instead of trusting the industry and give in to temptation of an alleged safer alternative to conventional cigarettes. This temptation, often promoted by misleading advertising in various media including online social networks, at the end will continue to keep people slave of nicotine with higher risk of relapse [2]. Worldwide, millions of smokers have quit and most have stopped by will-power only [72]. Today we have several medications effective as smoking cessation tools, which highly support smokers who want to quit [90]. Smokers should be also aware that quitting smoking completely instead of switching to alternative products will result not only in a gain in health, but also in a substantial money saving. The control of novel tobacco products should be added to the control of tobacco in those prevention programs approaching smokers in workplaces.

Parents of adolescents should be aware that young people starting using ecigarettes or HTPs will become addicted to nicotine and will have a higher risk to start smoking conventional cigarettes [2]. Evidence-based prevention programs addressing e-cigarettes and HTPs should target adolescents in schools to contrast the misleading marketing messages coming from online social networks. Last but not least, people should be aware that the SHS of HTPs but also the aerosol exhaled by e-cigarette users into the ambient air (i.e., the SHA) is not simply steam [41] but it is toxic, including potentially harmful substances that might harm the health of non-user bystanders $[40,45]$.

\subsection{References}

1. Gallus S, Borroni E, Odone A et al. The Role of Novel (Tobacco) Products on Tobacco Control in Italy. Int J Environ Res Public Health 2021; 18: 1895.

2. Gallus S, Stival C, McKee M et al. The impact of electronic cigarette and heated tobacco product on smoking habit: a prospective cohort study form Italy. Tob Control 2021; Submitted.

3. Gallus S, Stival C, Carreras G et al. Use of electronic cigarettes and heated tobacco products during the Covid-19 pandemic. Sci Rep 2022; In press.

4. Gallus S, Borroni E, Liu X et al. Electronic cigarette use among Italian smokers: patterns, settings, and adverse events. Tumori 2020; 300891620915784. 
5. Gallus S, Lugo A, Stival C et al. Electronic cigarette use in 12 European countries. Results from the TackSHS survey. J Epidemiol 2021; In press.

6. Gallus S, Lugo A, Liu X et al. Use and Awareness of Heated Tobacco Products in Europe. J Epidemiol 2021; In press.

7. Amalia B, Liu X, Lugo A et al. Exposure to secondhand aerosol of electronic cigarettes in indoor settings in 12 European countries: data from the TackSHS survey. Tob Control 2021; 30: 49-56.

8. Gallus S, Odone A, van den Brandt PA et al. Conflict of interest research in heated tobacco products: a systematic review. BMJ 2022; Under review.

9. Odone A, Lugo A, Amerio A et al. COVID-19 lockdown impact on lifestyle habits of Italian adults. Acta Biomed 2020; 91: 87-89.

10. Laverty AA, Filippidis FT, Vardavas $\mathrm{Cl}$. Patterns, trends and determinants of e-cigarette use in 28 European Union Member States 2014-2017. Prev Med 2018; 116: 13-18.

11. Beard E, West R, Michie S, Brown J. Association of prevalence of electronic cigarette use with smoking cessation and cigarette consumption in England: a time-series analysis between 2006 and 2017. Addiction 2020; 115: 961-974.

12. Torjesen I. Stop smoking services must become "e-cigarette" friendly, says Public Health England. BMJ 2015; 351: h4518.

13. Britton J. E-cigarettes, Public Health England, and common sense. Lancet 2015; 386: 1238-1239.

14. E-cigarettes: Public Health England's evidence-based confusion. Lancet 2015; 386: 829.

15. O'Dowd A. Leading journal questions Public Health England's stance on ecigarettes. BMJ 2015; 351: h4684.

16. McNeill A, Brose LS, Calder $R$ et al. Evidence review of e-cigarettes and heated tobacco products 2018. Available online at: https://www.gov.uk/government/publications/e-cigarettes-and-heatedtobacco-products-evidence-review/evidence-review-of-e-cigarettes-andheated-tobacco-products-2018-executive-summary\#use-of-e-cigarettesin-adults (last access: 30 July 2019). 2018.

17. Gallus S, Lugo A, Pacifici R et al. E-cigarette awareness, use, and harm perceptions in Italy: a national representative survey. Nicotine Tob Res 2014; 16: 1541-1548.

18. McKee M, Daube M, Chapman S. E-cigarettes should be regulated. Med J Aust 2016; 204: 331.

19. Moore M, McKee M, Daube M. Harm reduction and e-cigarettes: Distorting the approach. J Public Health Policy 2016; 37: 403-410.

20. World Health Organization. WHO Report on the Global Tobacco Epidemic, 2021. Addressing new and emerging products. Available online at: 
https://www.who.int/teams/health-promotion/tobacco-control/globaltobacco-report-2021. 2021.

21. Tabuchi T, Gallus S, Shinozaki T et al. Heat-not-burn tobacco product use in Japan: its prevalence, predictors and perceived symptoms from exposure to secondhand heat-not-burn tobacco aerosol. Tob Control 2018; 27: e25-e33.

22. Tabuchi T, Kiyohara K, Hoshino $\mathrm{T}$ et al. Awareness and use of electronic cigarettes and heat-not-burn tobacco products in Japan. Addiction 2016; 111: 706-713.

23. Jankowski M, Brozek GM, Lawson $\mathrm{J}$ et al. New ideas, old problems? Heated tobacco products - a systematic review. Int J Occup Med Environ Health 2019; 32: 595-634.

24. Nyman AL, Weaver SR, Popova L et al. Awareness and use of heated tobacco products among US adults, 2016-2017. Tob Control 2018; 27: s55-s61.

25. Brose L, Simonavicius E, Cheeseman H. Awareness and use of 'heat-notburn' tobacco products in Great Britain. Tob Regul Sci 2018; 4:: 44-50.

26. Liu X, Lugo A, Spizzichino L et al. Heat-Not-Burn Tobacco Products Are Getting Hot in Italy. J Epidemiol 2018; 28: 274-275.

27. Liu X, Lugo A, Spizzichino L et al. Heat-not-burn tobacco products: concerns from the Italian experience. Tob Control 2019; 28: 113-114.

28. Liu X, Lugo A, Davoli $E$ et al. Electronic cigarettes in Italy: a tool for harm reduction or a gateway to smoking tobacco? Tob Control 2020; 29: 148152.

29. Marynak KL, Wang TW, King BA et al. Awareness and Ever Use of "HeatNot-Burn" Tobacco Products Among U.S. Adults, 2017. Am J Prev Med 2018; 55: 551-554.

30. Cerrai S, Potente R, Gorini G et al. What is the face of new nicotine users? 2012-2018 e-cigarettes and tobacco use among young students in Italy. Int J Drug Policy 2020; 86: 102941.

31. Gorini G, Gallus S, Carreras G et al. Prevalence of tobacco smoking and electronic cigarette use among adolescents in Italy: Global Youth Tobacco Surveys (GYTS), 2010, 2014, 2018. Prev Med 2020; 131: 105903.

32. Eurobarometer. Attitudes of Europeans Towards Tobacco and Electronic Cigarettes. Special Eurobarometer 458. Available online at: https://europa.eu/eurobarometer/surveys/detail/2146. 2017.

33. Joossens L, Feliu A, Fernandez E. The Tobacco Control Scale 2019 in Europe. Brussels: Association of European Cancer Leagues, Catalan Institute of Oncology; 2020. Available online at: http://www.tobaccocontrolscale.org/TCS2019.pdf. 2020. 
34. Czoli CD, White CM, Reid JL et al. Awareness and interest in IQOS heated tobacco products among youth in Canada, England and the USA. Tob Control 2020; 29: 89-95.

35. Gallus S, Lugo A, Gorini G et al. Voluntary home smoking ban: prevalence, trend and determinants in Italy. Eur J Public Health 2016; 26: 841-844.

36. Cataldo JK, Petersen AB, Hunter $\mathrm{M}$ et al. E-cigarette marketing and older smokers: road to renormalization. Am J Health Behav 2015; 39: 361-371.

37. Singh S, Windle SB, Filion KB et al. E-cigarettes and youth: Patterns of use, potential harms, and recommendations. Prev Med 2020; 133: 106009.

38. Fairchild AL, Bayer R, Colgrove J. The renormalization of smoking? Ecigarettes and the tobacco "endgame". N Engl J Med 2014; 370: 293-295.

39. Saebo G, Scheffels J. Assessing notions of denormalization and renormalization of smoking in light of e-cigarette regulation. Int J Drug Policy 2017; 49: 58-64.

40. Baena García A, Córdoba García R, Regina Dalmau González-Galarza $\mathrm{RD}$ et al. CNPT Consensus Document On Nicotine Delivery Devices. Comité Nacional para la Prevención del Tabaquismo. Madrid, Spain. 2020.

41. Haggart K, Robertson L, Blank ML et al. It's Just Steam: a qualitative analysis of New Zealand ENDS users' perceptions of secondhand aerosol. Tob Control 2021; 30: 30-35.

42. Fernandez E, Ballbe M, Sureda X et al. Particulate Matter from Electronic Cigarettes and Conventional Cigarettes: a Systematic Review and Observational Study. Curr Environ Health Rep 2015; 2: 423-429.

43. Ruprecht AA, De Marco C, Pozzi P et al. Comparison between particulate matter and ultrafine particle emission by electronic and normal cigarettes in real-life conditions. Tumori 2014; 100: e24-27.

44. Soule EK, Maloney SF, Spindle TR et al. Electronic cigarette use and indoor air quality in a natural setting. Tob Control 2017; 26: 109-112.

45. O'Connell G, Colard S, Cahours X, Pritchard JD. An Assessment of Indoor Air Quality before, during and after Unrestricted Use of E-Cigarettes in a Small Room. Int J Environ Res Public Health 2015; 12: 4889-4907.

46. Ballbe M, Martinez-Sanchez JM, Sureda $X$ et al. Cigarettes vs. ecigarettes: Passive exposure at home measured by means of airborne marker and biomarkers. Environ Res 2014; 135: 76-80.

47. Czogala J, Goniewicz ML, Fidelus B et al. Secondhand exposure to vapors from electronic cigarettes. Nicotine Tob Res 2014; 16: 655-662.

48. Fernandez E, Lopez MJ, Gallus S et al. Tackling second-hand exposure to tobacco smoke and aerosols of electronic cigarettes: the TackSHS project protocol. Gac Sanit 2020; 34: 77-82.

49. TackSHS Project Investigators. TackSHS leaflet: Key Messages and Recommendations. Available online at: http://tackshs.eu/news/tackshsleaflet-key-messages-and-recommendations/. 2019. 
50. King JL, Reboussin BA, Wiseman KD et al. Adverse symptoms users attribute to e-cigarettes: Results from a national survey of US adults. Drug Alcohol Depend 2019; 196: 9-13.

51. Aldy K, Cao DJ, Weaver MM et al. E-cigarette or vaping product useassociated lung injury (EVALI) features and recognition in the emergency department. J Am Coll Emerg Physicians Open 2020; 1: 1090-1096.

52. Wills TA, Soneji SS, Choi K et al. E-cigarette use and respiratory disorders: an integrative review of converging evidence from epidemiological and laboratory studies. Eur Respir J 2021; 57.

53. Gotts JE, Jordt SE, McConnell R, Tarran R. What are the respiratory effects of e-cigarettes? BMJ 2019; 366: 15275.

54. Kennedy CD, van Schalkwyk MCl, McKee M, Pisinger C. The cardiovascular effects of electronic cigarettes: A systematic review of experimental studies. Prev Med 2019; 127: 105770.

55. Tsai M, Byun MK, Shin J, Crotty Alexander LE. Effects of e-cigarettes and vaping devices on cardiac and pulmonary physiology. J Physiol 2020; 598: 5039-5062.

56. Reddy KP, Schwamm E, Kalkhoran $S$ et al. Respiratory Symptom Incidence among People Using Electronic Cigarettes, Combustible Tobacco, or Both. Am J Respir Crit Care Med 2021; 204: 231-234.

57. Kim CY, Paek YJ, Seo HG et al. Dual use of electronic and conventional cigarettes is associated with higher cardiovascular risk factors in Korean men. Sci Rep 2020; 10: 5612.

58. Wang JB, Olgin JE, Nah G et al. Cigarette and e-cigarette dual use and risk of cardiopulmonary symptoms in the Health eHeart Study. PLoS One 2018; 13: e0198681.

59. Hall FS, Der-Avakian A, Gould TJ et al. Negative affective states and cognitive impairments in nicotine dependence. Neurosci Biobehav Rev 2015; 58: 168-185.

60. Yuan M, Cross SJ, Loughlin SE, Leslie FM. Nicotine and the adolescent brain. J Physiol 2015; 593: 3397-3412.

61. Auer R, Concha-Lozano N, Jacot-Sadowski I et al. Heat-Not-Burn Tobacco Cigarettes: Smoke by Any Other Name. JAMA Intern Med 2017; 177: 1050-1052.

62. Simonavicius E, McNeill A, Shahab L, Brose LS. Heat-not-burn tobacco products: a systematic literature review. Tob Control 2019; 28: 582-594.

63. De Marco C, Borgini A, Ruprecht AA et al. [Formaldehyde in electronic cigarettes and in heat-not-burn products: let's make the point]. Epidemiol Prev 2018; 42: 351-355.

64. Leigh NJ, Palumbo MN, Marino AM et al. Tobacco-specific nitrosamines (TSNA) in heated tobacco product IQOS. Tob Control 2018; 27: s37-s38. 
65. Sohal SS, Eapen MS, Naidu VGM, Sharma P. IQOS exposure impairs human airway cell homeostasis: direct comparison with traditional cigarette and e-cigarette. ERJ Open Res 2019; 5.

66. Leigh NJ, Tran PL, O'Connor RJ, Goniewicz ML. Cytotoxic effects of heated tobacco products (HTP) on human bronchial epithelial cells. Tob Control 2018; 27: s26-s29.

67. Chun L, Moazed F, Matthay M et al. Possible hepatotoxicity of IQOS. Tob Control 2018; 27: s39-s40.

68. Nabavizadeh P, Liu J, Havel CM et al. Vascular endothelial function is impaired by aerosol from a single IQOS HeatStick to the same extent as by cigarette smoke. Tob Control 2018; 27: s13-s19.

69. World Health Organization. WHO Report on the Global Tobacco Epidemic, 2019. Offer help to quit tobacco use. Available at: https://www.who.int/tobacco/global_report/en/. 2019.

70. St Helen G, Jacob lii P, Nardone N, Benowitz NL. IQOS: examination of Philip Morris International's claim of reduced exposure. Tob Control 2018; 27: s30-s36.

71. European Network of Smoking and Tobacco Prevention (ENSP). ENSP Calls for European Response to Electronic Cigarettes Rising Epidemic. Available online at: https://ensp.network/ensp-calls-for-europeanresponse-to-electronic-cigarettes-rising-epidemic/.

72. European Respiratory Society (ERS) Tobacco Control Committee. ERS Position Paper on Tobacco Harm Reduction. Available online at: https://ers.app.box.com/v/ERSTCC-Harm-Reduction-Position. 2019.

73. Hajek P, Phillips-Waller A, Przulj D et al. A Randomized Trial of ECigarettes versus Nicotine-Replacement Therapy. N Engl J Med 2019; 380: 629-637.

74. Borrelli B, O'Connor GT. E-Cigarettes to Assist with Smoking Cessation. N Engl J Med 2019; 380: 678-679.

75. Barufaldi LA, Guerra RL, de Albuquerque RCR et al. Risk of smoking relapse with the use of electronic cigarettes: A systematic review with meta-analysis of longitudinal studies. Tob Prev Cessat 2021; 29: 29.

76. Gallus S, Lugo A, Gorini G. No double-edged sword and no doubt about the relation between smoking and COVID-19 severity. Eur J Intern Med 2020; 77: 33-35.

77. Simons D, Shahab L, Brown J, Perski O. The association of smoking status with SARS-CoV-2 infection, hospitalization and mortality from COVID-19: a living rapid evidence review with Bayesian meta-analyses (version 7). Addiction 2021; 116: 1319-1368.

78. Mahabee-Gittens EM, Merianos AL, Matt GE. Letter to the Editor Regarding: "An Imperative Need for Research on the Role of Environmental Factors in Transmission of Novel Coronavirus (COVID-19)" 
-Secondhand and Thirdhand Smoke As Potential Sources of COVID-19. Environ Sci Technol 2020; 54: 5309-5310.

79. Changeux JA, Z.; Rey, F. A.; Miyara, M. A nicotinic hypothesis for Covid19 with preventiveand therapeutic implications. Comptes Rendus Biologies 2020.

80. Soule EK, Kheradmand F, Eissenberg T. Health practitioners should caution about misinformation and association of adverse effects of electronic cigarette use and COVID-19. Prev Med Rep 2020; 20: 101255.

81. Li D, Croft DP, Ossip DJ, Xie Z. Are Vapers More Susceptible to COVID19 Infection? medRxiv 2020.

82. Gaiha SM, Cheng J, Halpern-Felsher B. Association Between Youth Smoking, Electronic Cigarette Use, and COVID-19. J Adolesc Health 2020; 67: 519-523.

83. Gallus S, Paroni L, Re D et al. SARS-CoV-2 Infection among the Dental Staff from Lombardy Region, Italy. Int J Environ Res Public Health 2021; 18.

84. Singh AG, Chaturvedi P. Tobacco use and vaping in the COVID-19 era. Head Neck 2020.

85. Javelle E. Electronic cigarette and vaping should be discouraged during the new coronavirus SARS-CoV-2 pandemic. Arch Toxicol 2020; 1-2.

86. Cattaruzza MS, Gorini G, Bosetti $\mathrm{C}$ et al. Covid-19 and the role of smoking: the protocol of the multicentric prospective study COSMO-IT (COvid19 and SMOking in ITaly). Acta Biomed 2020; 91: e2020062.

87. Saloojee Y, Mathee A. COVID-19 and a temporary ban on tobacco sales in South Africa: impact on smoking cessation. Tob Control 2021.

88. Carreras G, Lugo A, Stival C et al. Impact of COVID-19 lockdown on smoking consumption in a large representative sample of Italian adults. Tob Control 2021.

89. Branston JR, Sweanor D. Big tobacco, E-cigarettes, and a road to the smoking endgame. Int J Drug Policy 2016; 29: 14-18.

90. European Network of Smoking and Tobacco Prevention (ENSP). Guidelines for treating tobacco dependence. Available online at: http://ensp.network/ensp-tdt-guidelines/. 2020.

91. Hartmann-Boyce J, McRobbie H, Lindson $\mathrm{N}$ et al. Electronic cigarettes for smoking cessation. Cochrane Database Syst Rev 2020; 10: CD010216.

92. Wang RJ, Bhadriraju S, Glantz SA. E-Cigarette Use and Adult Cigarette Smoking Cessation: A Meta-Analysis. Am J Public Health 2021; 111: 230 246.

93. Baenziger ON, Ford L, Yazidjoglou A et al. E-cigarette use and combustible tobacco cigarette smoking uptake among non-smokers, including relapse in former smokers: umbrella review, systematic review and meta-analysis. BMJ Open 2021; 11: e045603. 
94. Villanti AC, Johnson AL, Ambrose BK et al. Flavored Tobacco Product Use in Youth and Adults: Findings From the First Wave of the PATH Study (2013-2014). Am J Prev Med 2017; 53: 139-151.

95. Berry KM, Fetterman JL, Benjamin EJ et al. Association of Electronic Cigarette Use With Subsequent Initiation of Tobacco Cigarettes in US Youths. JAMA Netw Open 2019; 2: e187794.

96. Langendam MW, van Brussel GH, Coutinho RA, van Ameijden EJ. The impact of harm-reduction-based methadone treatment on mortality among heroin users. Am J Public Health 2001; 91: 774-780.

97. Buning EC, Van Brussel GH, Van Santen G. The 'methadone by bus' project in Amsterdam. Br J Addict 1990; 85: 1247-1250.

98. Cushman P, Dole VP. Detoxification of rehabilitated methadonemaintained patients. JAMA 1973; 226: 747-752.

99. Gronbladh L, Ohlund LS, Gunne LM. Mortality in heroin addiction: impact of methadone treatment. Acta Psychiatr Scand 1990; 82: 223-227.

100. Watson MC, Lloyd J. Why the rules should not be relaxed for e-cigarettes to encourage people to stop smoking. BMJ 2019; 364: 1555.

101. Legg $T$, Legendre $M$, Gilmore $A B$. Paying lip service to publication ethics: scientific publishing practices and the Foundation for a Smoke-Free World. Tob Control 2021.

102. Fields N, Chapman S. Chasing Ernst L Wynder: 40 years of Philip Morris' efforts to influence a leading scientist. J Epidemiol Community Health 2003; 57: 571-578.

103. Francey N, Chapman S. "Operation Berkshire": the international tobacco companies' conspiracy. BMJ 2000; 321: 371-374.

104. Glantz SA. The truth about big tobacco in its own words. BMJ 2000; 321 : 313-314.

105. Hendlin YH, Vora M, Elias J, Ling PM. Financial Conflicts of Interest and Stance on Tobacco Harm Reduction: A Systematic Review. Am J Public Health 2019; 109: e1-e8.

106. Shields PG. Tobacco smoking, harm reduction, and biomarkers. J Natl Cancer Inst 2002; 94: 1435-1444.

107. Shaw DM, Etter JF, Elger BS. Should academic journals publish ecigarette research linked to tobacco companies? Addiction 2016; 111: 1328-1332.

108. IARC. IARC Monograph on the Evaluation of Carcinogenic Risks to Humans. Volume 100E. A review of human carcinogens - Personal habits and indoor combustions. Lyon, France,2012.

109. van der Eijk Y, Bero LA, Malone RE. Philip Morris International-funded 'Foundation for a Smoke-Free World': analysing its claims of independence. Tob Control 2019; 28: 712-718. 
110. McKee M. The Tobacco Industry: The Pioneer of Fake News. J Public Health Res 2017; 6: 878.

111. Pisinger C, Godtfredsen N, Bender AM. A conflict of interest is strongly associated with tobacco industry-favourable results, indicating no harm of e-cigarettes. Prev Med 2019; 119: 124-131.

112. Gallus S, Lugo A, Garattini S. Independence of the Italian scientific societies from the tobacco industry. Tabaccologia 2018; 3: 10-13.

113. Martinez C, Fu M, Galan I et al. Conflicts of interest in research on electronic cigarettes. Tob Induc Dis 2018; 16: 28.

114. Farsalinos KE, Poulas K, Voudris V, Le Houezec J. Electronic cigarette use in the European Union: analysis of a representative sample of 27460 Europeans from 28 countries. Addiction 2016; 111: 2032-2040.

115. Kulik MC, Lisha NE, Glantz SA. E-cigarettes Associated With Depressed Smoking Cessation: A Cross-sectional Study of 28 European Union Countries. Am J Prev Med 2018; 54: 603-609.

116. Anonymous. Progress in Tobacco Control Demands Open Science and Respectful Debate-Not Boycotts and Bans. Foundation for a Smoke-Free World. Available online at: https://www.smokefreeworld.org/openletters/progress-in-tobacco-control-demands-open-science-andrespectful-debate-not-boycotts-and-bans/. 2021.

117. Gallus S, Cattaruzza MS, Gorini G et al. Vatican beats Italy 1-0 in the tobacco endgame. Tob Control 2018.

118. Amalia B, Fu M, Feliu A et al. Regulation of electronic cigarette use in public and private areas in 48 countries within the WHO European Region: a survey to in-country informants. J Epidemiol 2020.

119. Newton JN, Dockrell M, Marczylo T. Making sense of the latest evidence on electronic cigarettes. Lancet 2018; 391: 639-642.

120. Bialous SA, Glantz SA. Heated tobacco products: another tobacco industry global strategy to slow progress in tobacco control. Tob Control 2018.

121. World Health Organization. World Health Organization Framework Convention on Tobacco Control (WHO FCTC). Available online: http://www.who.int/fctc/en/. In. Geneva: World Health Organization 2003.

122. Willett J, Achenbach S, Pinto FJ et al. The Tobacco Endgame-Eradicating a Worsening Epidemic: A Joint Opinion From the American Heart Association, World Heart Federation, American College of Cardiology, and the European Society of Cardiology. Circulation 2021; 144: e1-e5.

123. Gallus S, Lugo A, Garattini S et al. General Practitioners and Dentists: A Call for Action Against Tobacco. Nicotine Tob Res 2016; 18: 2202-2208. 
Summary 
The introduction of electronic cigarettes (e-cigarettes) and heated tobacco products (HTP) has led to a debate about their impact on human health and tobacco control. These products are most likely safer than conventional cigarettes, yet they are far from being safe. They in fact generate toxic compounds and potential carcinogens which are inhaled, potentially compromising the health of users and bystanders. Besides safety issues, the debate around the risk-benefit balance of these products should be guided by their effectiveness in reducing smoking conventional cigarettes. Relying on a few controlled trials showing for e-cigarettes a certain favourable effect on smoking cessation in clinical settings, some researchers claimed e-cigarettes to have the potential to lessen the harm of smokers of conventional cigarettes. Since Philip Morris International (PMI) has invested almost 1 billion US $\$$ to support research on their HTPs, the number of tobacco harm reduction advocates has grown substantially, and HTPs are increasingly added to e-cigarettes as potentially effective tools. However, the majority of independent studies have already shown that e-cigarettes and HTPs fail to boost smoking cessation in real-world settings. More importantly, non-smokers are also eager to attempt these novel nicotinecontaining products. Consequently, many independent researchers warn that ecigarettes and HTPs might represent more a gateway to smoking tobacco rather than an effective tobacco harm reduction strategy. In any case, knowledge about these new products remains fragmented, small-scale and not always free of conflicts of interest.

\section{Aims and Data}

Within this PhD program, we aimed to provide comprehensive evidence on the benefits and risks of e-cigarette and HTP use for current smokers, ex-smokers and never smokers. To accomplish this aim, we took advantage of several investigations with different study designs. These studies included multiple Italian cross-sectional studies representative of the general adult population, one multicentre cross-sectional study conducted on a sample of Italian current smokers, one Italian prospective cohort study (the Lost in Italy study), and one large multinational survey on a representative sample of adults from 12 European countries (the TackSHS study). Furthermore, a systematic review of the scientific literature was conducted to understand the role of the interference of the tobacco industry on the current scientific evidence on HTPs. All these studies were undertaken independently of the tobacco, e-cigarette or even pharmaceutical industries.

\section{Effectiveness of e-cigarettes and HTPs as harm reduction tools}

In Chapter 2, analysing data from repeated representative surveys in Italy, we showed that the decreasing trend in smoking prevalence observed in Italy since the late 1950's, stopped since 2013, coinciding with the spread of e-cigarettes and HTPs. Official legal sales data confirmed these unfavourable trends. 
Moreover, among e-cigarette or HTP users the proportion of those starting or restarting smoking conventional cigarettes outnumbered those quitting smoking as a consequence of e-cigarette or HTP use. Accordingly, in Chapter 3, using data from one of the few available longitudinal studies, we showed that never cigarette smokers who use e-cigarettes or HTPs are much more likely to start conventional tobacco smoking, and ex-smokers to relapse. Furthermore, current smokers who quit are fewer among current e-cigarette or HTP users. Using three different approaches, namely ecological analyses on smoking prevalence and tobacco sales, analysis of cross-sectional data, and - for the first time in Europe - a prospective cohort study, we were able to confirm that, at least in ltaly, the use of novel products increases the likelihood of smoking conventional cigarettes.

\section{E-cigarettes and HTPs patterns of use in Italy and Europe}

In Italy, we observed an increase by $12 \%$ in the prevalence of both e-cigarette and HTP use during the Covid-19 pandemic home confinement (Chapter 4). New users were more frequently young adults unable to satisfy certain addictions, as cannabis use and gambling, due to imposed movement limitations. New users were less frequently current than never conventional cigarette smokers. In Chapter 5 analyzing data from a sample of Italian ever smokers, we were able to confirm the high proportion of e-cigarette users experiencing an adverse event reported by other studies. Our data confirmed that e-cigarettes and HTPs are often used by young people. Moreover, most novel (tobacco) product users are dual users (also consuming conventional cigarettes). In Italy and Europe the large majority of dual users consume these novel products in smoke-free indoor environments, including workplaces, bars and restaurants (Chapter 6). Moreover, Chapter 7 showed that among European HTP ever users who quit conventional cigarette smoking, approximately half had quit smoking before HTPs were introduced in the local market of each country, suggesting that a large proportion of ex-smokers relapsed into nicotine intake and tobacco consumption due to HTP availability in the market. In Chapter 8 we showed that in Europe, despite a relatively limited prevalence of e-cigarette use, the proportion of non-users daily exposed to secondhand aerosol of e-cigarettes is relatively large. This is likely due to the misperception that the secondhand aerosol of e-cigarettes is merely steam, or not detrimental to human health. Our multiple cross-sectional studies from Italy and Europe, allowed us to observe unfavourable and worrying patterns of use of e-cigarettes and HTPs.

\section{The role of the tobacco industry on scientific evidence}

In Chapter 9, we showed findings from a comprehensive systematic review of all the studies dealing with HTPs. We found 211 eligible papers published before February 2020. The majority of these papers declared a conflict of interest (COI) with tobacco companies, primarily PMI. Among studies with a COI with any 
tobacco company, $89 \%$ supported HTPs, $11 \%$ were neutral and none opposed HTPs as an harm reduction strategy. Of all studies not reporting $\mathrm{COI}$ with tobacco industry, $20 \%$ supported HTPs, $33 \%$ were neutral and $47 \%$ opposed HTPs. Our findings suggest that: i) scientific knowledge on HTPs is currently based on studies compromised by stated or unstated COls; ii) the large majority of COIfree studies oppose HTPs lii) tobacco industry-sponsored studies can seriously bias our knowledge and understanding of the unfavourable health effect of novel tobacco products, with potential detrimental effects on population health

\section{Conclusions}

Within this $\mathrm{PhD}$ programme, we clearly confirm that the balance between benefits and risks associated with e-cigarettes and HTPs is negative. Users of these novel products more frequently start smoking conventional cigarettes if they are never smokers, relapse if they are former smokers and continue smoking if they are current smokers. Based on these findings, there is no argument to justify the massive fiscal and regulatory benefits these products continue to have, at least in Italy and in many European countries. Therefore, it is urgently needed to legally equate novel (tobacco) products with conventional tobacco cigarettes. A relevant recommendation to the scientific community and policy makers is to avoid collaborations with the tobacco industry. It is also crucial that policy makers rely exclusively on COI-free research, as studies linked to the tobacco and e-cigarette industry have biased and misleading conclusions. There are still significant knowledge gaps on the role of novel (tobacco) products on tobacco control. In particular, the establishment of robust cohort studies is required to prospectively confirm our findings and to evaluate long-term health consequences of $\mathrm{e}$ cigarette or HTP use, in terms of incidence of chronic diseases and mortality. Consequently, policy makers should guarantee financial support for research independent from COls with the tobacco and the e-cigarette industry. Finally, rather than proposing risky alternatives such as e-cigarettes or HTPs, healthcare providers should recommend smoking cessation to all smokers, being aware that there are effective pharmacological (or psychological) treatments in support of smoking cessation. 
Riassunto 
L'introduzione sul mercato delle sigarette elettroniche e dei prodotti a tabacco riscaldato (in inglese, heated tobacco products, HTP) ha acceso un dibattito circa il loro impatto sulla salute e sul controllo del tabagismo. Questi prodotti sono probabilmente più sicuri delle sigarette tradizionali, ma sono tutt'altro che sicuri. Generano infatti composti tossici e sostanze potenzialmente cancerogene che mettono in pericolo la salute di coloro che li utilizzano o di coloro che sono esposti passivamente ai loro vapori. Oltre alle questioni di sicurezza, il dibattito sul rapporto rischi-benefici di questi prodotti dovrebbe essere guidato dalla loro efficacia nel ridurre il fumo di sigarette tradizionali. Mossi dai risultati di alcuni clinical trial controllati che mostrano per le sigarette elettroniche un certo effetto favorevole sulla cessazione dal fumo in ambito clinico, alcuni ricercatori affermano che questi prodotti hanno il potenziale per ridurre i danni dei fumatori. Da quando Philip Morris International (PMI) ha investito quasi 1 miliardo di dollari USA per sostenere la ricerca sugli HTP, il numero di ricercatori che sostengono la strategia di riduzione del danno per il tabacco è cresciuto notevolmente e gli HTP vengono sempre più frequentemente aggiunti alle sigarette elettroniche come possibili strumenti di controllo del tabagismo. Tuttavia, la maggior parte degli studi indipendenti ha già dimostrato che le sigarette elettroniche e gli HTP non riescono a promuovere la cessazione del fumo in contesti reali. Ancora più importante, anche i non fumatori sono desiderosi di provare questi nuovi prodotti contenenti nicotina. Di conseguenza, molti ricercatori indipendenti avvertono che le sigarette elettroniche e gli HTP potrebbero rappresentare più una via d'accesso al fumo di tabacco tradizionale che un'efficace strategia di riduzione del danno da tabacco. In ogni caso, le conoscenze su questi nuovi prodotti rimangano poche, frammentarie e non sempre prive di conflitti di interesse.

\section{Obiettivi e dati}

All'interno di questo programma di dottorato, abbiamo mirato a fornire prove complete sui benefici e rischi dell'uso di sigarette elettroniche e HTP per fumatori, ex fumatori e coloro che non hanno mai fumato. Per raggiungere questo obiettivo, abbiamo condotto svariate indagini utilizzando differenti disegni di studio. Gli studi presi in esame includevano molti studi trasversali rappresentativi della popolazione adulta Italiana, uno studio trasversale multicentrico condotto su un campione di fumatori italiani, uno studio di coorte italiano (studio Lost in Italy) e un'ampia indagine su un campione rappresentativo di adulti di 12 paesi europei (studio TackSHS). Inoltre, è stata condotta una revisione sistematica della letteratura scientifica per comprendere il ruolo dell'interferenza dell'industria del tabacco sulle evidenze scientifiche sugli http ad oggi disponibili. Tutti questi studi sono stati condotti senza alcun supporto da parte dell'industria del tabacco, delle sigarette elettroniche e neppure da parte delle industrie farmaceutiche. 
Efficacia delle sigarette elettroniche e degli HTP come strumenti di riduzione del danno

Nel Capitolo 2, analizzando i dati di ripetute indagini rappresentative della popolazione italiana, abbiamo mostrato che il trend decrescente della prevalenza del fumo osservato in Italia dalla fine degli anni '50, si è interrotto dal 2013, in corrispondenza della diffusione delle sigarette elettroniche e degli HTP. I dati ufficiali sulle vendite legali hanno confermato queste tendenze sfavorevoli. Inoltre, tra gli utilizzatori di sigarette elettroniche o HTP, la proporzione di coloro che iniziano o ricominciano a fumare sigarette convenzionali supera quella di coloro che hanno smesso di fumare grazie all'uso di sigarette elettroniche o HTP. Inoltre, nel Capitolo 3, utilizzando i dati di uno dei pochi studi longitudinali disponibili, abbiamo dimostrato come tra i non fumatori (coloro che non hanno mai fumato sigarette tradizionali) gli utilizzatori di sigarette elettroniche o HTP hanno molte più probabilità di iniziare a fumare, e tra gli ex-fumatori di ricadere. Inoltre, tra i fumatori coloro che smettono sono meno numerosi tra gli utilizzatori di sigarette elettroniche o HTP. Utilizzando tre diversi approcci, ovvero analisi ecologiche sulla prevalenza del fumo e sulle vendite di tabacco, analisi di dati trasversali e, per la prima volta in Europa, uno studio prospettico di coorte, abbiamo potuto confermare che, almeno in Italia, I'uso sigaretta elettronica e HTP aumenta la probabilità di fumare sigarette tradizionali.

Modalità di consumo di sigarette elettroniche e HTP in Italia e in Europa In Italia, abbiamo osservato un aumento del $12 \%$ nella prevalenza dell'uso sia di sigaretta elettronica che di HTP durante il confinamento domiciliare della pandemia da Covid-19 (Capitolo 4). I nuovi utilizzatori erano più frequentemente giovani adulti che non potevano soddisfare altre dipendenze, come l'uso di cannabis e il gioco d'azzardo, a causa delle limitazioni di movimento imposte. I nuovi utilizzatori erano meno frequentemente fumatori di sigarette tradizionali. Nel Capitolo 5, analizzando i dati di un campione di fumatori o ex-fumatori italiani, siamo stati in grado di confermare l'elevata percentuale di utenti di sigarette elettroniche che hanno riscontrato un evento avverso. I nostri dati hanno confermato che le sigarette elettroniche e gli HTP sono spesso utilizzati dai giovani. Inoltre, la maggior parte degli utilizzatori dei nuovi prodotti (del tabacco) ne fanno un uso duale (consumano cioè anche sigarette tradizionali). In Italia e in Europa la grande maggioranza degli utilizzatori duali consuma questi prodotti in ambienti al chiuso dove è vietato fumare, compresi luoghi di lavoro, bar e ristoranti (Capitolo 6 della presente tesi). Inoltre, nel Capitolo 7 mostriamo che in Europa circa la metà degli utilizzatori di HTP che hanno smesso di fumare sigarette tradizionali aveva smesso di fumare prima che gli HTP fossero introdotti nel mercato locale del proprio paese. Questo suggerisce che una grande proporzione di ex-fumatori ha avuto una ricaduta nell'assunzione di nicotina e nel consumo di tabacco a causa della disponibilità di HTP nel mercato. Nel Capitolo 
8 abbiamo mostrato come in Europa, nonostante ci sia una bassa prevalenza dell'uso di sigarette elettroniche, la proporzione di non-utilizzatori esposti quotidianamente ai vapori passivi delle sigarette elettroniche è relativamente ampia. Ciò è probabilmente dovuto all'errata percezione che i vapori passivi delle sigarette elettroniche non siano dannosi per la salute umana. I nostri molteplici studi trasversali condotti in Italia e in Europa, ci hanno permesso di osservare modalità di consumo di sigarette elettroniche e HTP sfavorevoli e preoccupanti.

\section{Il ruolo dell'industria del tabacco sull'evidenza scientifica}

Nel Capitolo 9, abbiamo mostrato i risultati di una revisione sistematica completa di tutti gli studi che si occupano di HTP. Abbiamo trovato 211 articoli pubblicati prima di febbraio 2020. La maggior parte di questi articoli dichiarava un conflitto di interessi (in inglese, conflict of interest, $\mathrm{COI}$ ) con le aziende produttrici di tabacco, principalmente PMI. Tra gli studi che dichiaravano un COI con una qualsiasi azienda del tabacco, I' $89 \%$ sosteneva gli HTP, I'11\% era neutrale e nessuno si opponeva agli HTP come strategia di riduzione del danno. Di tutti gli studi che non riportavano $\mathrm{COI}$ con l'industria del tabacco, il $20 \%$ sosteneva gli HTP, il $33 \%$ era neutrale e il $47 \%$ si opponeva a questi prodotti. I nostri risultati suggeriscono che: i) la conoscenza scientifica sugli HTP è attualmente compromessa da studi con $\mathrm{COI}$; ii) la grande maggioranza degli studi privi di $\mathrm{COI}$ si oppone agli HTP lii) gli studi sponsorizzati dall'industria del tabacco possono influenzare seriamente la nostra conoscenza e comprensione degli effetti negativi sulla salute dei nuovi prodotti del tabacco, con potenziali effetti dannosi sulla salute della popolazione.

\section{Conclusioni}

All'interno di questo percorso di $\mathrm{PhD}$, confermiamo chiaramente che il rapporto tra benefici e rischi associati alle sigarette elettroniche e agli HTP è negativo. Rispetto a chi non utilizza questi nuovi prodotti, gli utilizzatori iniziano più frequentemente a fumare sigarette tradizionali se non fumano, ricadono se sono ex-fumatori e continuano a fumare se sono fumatori. Sulla base di questi risultati, non ci sono argomenti per giustificare gli enormi benefici fiscali e normativi che questi prodotti continuano ad avere, almeno in Italia e in molti paesi europei. Pertanto, è urgente un'equiparazione normativa delle sigarette elettroniche e HTP con le sigarette di tabacco tradizionali. Raccomandiamo fortemente alla comunità scientifica e ai policy maker di evitare collaborazioni con l'industria del tabacco. È anche fondamentale che i policy maker si affidino esclusivamente alla ricerca esente da $\mathrm{COI}$, poiché gli studi collegati all'industria presentano conclusioni distorte e fuorvianti. È ancora necessario studiare il ruolo di questi nuovi prodotti nel controllo del tabacco. In particolare, è necessaria la creazione di solidi studi di coorte per confermare in modo prospettico i nostri risultati e per valutare le conseguenze a lungo termine sulla salute dell'uso di sigarette 
elettroniche o HTP, in termini di incidenza di malattie croniche e mortalità. I policy maker dovrebbero garantire un sostegno finanziario per la ricerca indipendente dall'l'industria del tabacco. Infine, piuttosto che proporre alternative rischiose come le sigarette elettroniche o gli HTP, gli operatori sanitari dovrebbero raccomandare di smettere di fumare a tutti i fumatori, consapevoli che esistono trattamenti farmacologici (o psicologici) efficaci a sostegno della cessazione dal fumo. 

Impact Statement 
In this chapter I detail how the main results of this thesis have been disseminated during the PhD trajectory and discuss their impact from a public health perspective. Moreover, I will discuss how our findings might have an impact on the planning, implementation and evaluation of future research and public health practice.

\section{The dissemination of results during the $\mathrm{PhD}$ trajectory}

During my $\mathrm{PhD}$ trajectory, the dissemination of study results have been disseminated to a broad audience, including researchers, policy makers, journalists, students and the general public, through the following means:

\section{Peer-reviewed publications}

Study findings from five out of eight manuscripts written within the present thesis have already been published in various peer-reviewed journals [1-5]. These findings, combined with those from researches conducted by other independent tobacco control experts, build up robust scientific evidence pointing out the negative benefit-risk balance for novel (tobacco) products. Electronic cigarettes (e-cigarette) and, particularly, heated tobacco products (HTP) represent more a strategy of the tobacco industry to spread nicotine and to find new customers among future generations, rather than a mean to reduce tobacco harm.

\section{Other publications}

Our findings have been spread also in local Italian journals or websites to reach a broader audience of Italian experts in the field of tobacco control. Since January 2020, I am the editor-in-chief of Tabaccologia - the Journal of Tobacco Sciences, which is the quarterly journal of the Italian Society of Tobaccology (SITAB). Since my first editorial, I shared my viewpoint on the role of e-cigarettes and HTP on tobacco control, supported by findings of my research within the present dissertation [6]. The last editorial dealt with the unjustified fiscal and regulatory benefits of e-cigarettes and HTPs in Italy. Within this editorial, we reacted to the open letter signed by a group of 100 specialists claiming to be independent of commercial conflicts of interest with the tobacco industry [7]. In this letter, addressed to the delegates of the Framework Convention on Tobacco Control (FCTC), who met in November 2021 for the Conference of Parties (COP-9), the 100 specialists recommended the use not only of e-cigarettes but also of HTPs for harm reduction purpose, even in the absence of a clinical anti-smoking context. After preliminary investigations, it turned out that most of those specialists was not expert in tobacco control and, more importantly, some of them had links with the e-cigarette or tobacco industry, including for example four members of the scientific board of the Lega Italiana Anti Fumo (LIAF), an organization that, according to TobaccoTactics, received grants from the 
Foundation for a Smoke-Free Word (FSFW; the foundation of Philip Morris International, PMI) and is a partner of COEHAR and ECLAT, having received millions of US\$ from FSFW [8]. In an attempt to raise the voice of the Italian truly independent experts on tobacco control, in support of WHO, we promptly posted the editorial also on tobaccoendgame.it, a website held by a group of independent experts on tobacco control in Italy, often followed by Italian policy makers. Finally, it is worth to mention the publication on the website of the Union for International Cancer Control (UICC), to tell the story of HTPs in Italy, the country chosen by PMI as the pilot country for the launch of lqos, the first HTP [9].

\section{Oral speech}

Oral presentations were used to disseminate study results to a broad audience, including researchers, policy makers, journalists, students and the general public. Researchers: our scientific findings were presented at various national and international conferences and symposia for audiences with a heterogeneous background. At a national level, every year we were invited at the Italian Health Institute (Istituto Superiore di Sanità, ISS) in occasion of the World No Tobacco Day and at the congress of the Italian Society on Tobacco (Società Italiana di Tabaccologia, SITAB) for an oral speech, often on my research on the effects of e-cigarettes and HTPs on tobacco control in Italy. The same topic has been considered also at an international level, in some webinars organized by the European Network for Smoking and Tobacco Prevention (ENSP) and the 2020 European Conference on Tobacco or Health (ECToH) in Berlin. Moreover, we were invited as speakers at the final conference of the TackSHS project at the European Parliament, to present data of the TackSHS survey - conducted in 12 European countries - analyzed within the present PhD trajectory [3-5]. Furthermore, I have been included in the Expert Group of the WHO on Articles 9 and 10 of the FCTC and I participated in the corresponding 2-day meeting in Bilthoven (NL) in 2019. Finally, in 2020 I was invited as an international expert to critically comment on a monograph on e-cigarettes prepared by the Spanish National Committee of Tobacco Prevention (CNPT).

Policy makers and journalists: We were invited by the ENSP to the Lithuanian Parliament in Vilnius and the Spanish Ministry of Health in Madrid to inform selected politicians, policy makers and journalists about the concerns on HTP spread in Italy. Moreover, we were and are still in contact with officers of selected ministries or governmental agencies from Italy and a few other countries. We regularly meet to inform about our research on novel (tobacco) products.

Students: During the PhD trajectory, we had the opportunity to teach during the Public Health course in the Faculty of Medicine at the University Vita-Salute San Raffaele, invited by the co-promoter of the PhD, Prof Anna Odone, and at Master courses of Mario Negri Institute and the Business School Sole24Ore, presenting lessons on HTPs and more in general on tobacco control. Following the IG-Nobel prize on medicine obtained in September 2019 for some early studies on the 
association between pizza consumption and cancer risk [10], I was invited to give speeches in a few Universities, including an on-site seminar at Sant'Anna School of Advanced Studies, Pisa, Italy and an online lunch lecture for the science faculty of the Radboud University in Nijmegen, The Netherlands. In those occasions, I also presented findings on novel (tobacco) products in Italy and Europe.

General population: Extremely important was the dissemination of our findings to the general population. For example, in 2019 I was invited as speakers in Milan at a meeting of the event "Tempo della Salute" organized by Corriere della Sera - one of the main Italian newspapers - to provide a speech on my research about e-cigarettes.

\section{Lay press}

Findings from this dissertation were widely disseminated in the lay press through several interviews in national and international newspapers. At a national level, in the last interview dated 22 October 2021 we informed the Italian audience about our viewpoint on tobacco harm reduction [11]. More importantly, we have posted several articles in tobaccoendgame.it, a website of a group of independent tobacco control experts with the aim of carrying on selected advocacy actions or to support increases in taxation of e-cigarettes or HTPs in Italy. At an international level, it is worth mentioning our contribution to the Organized Crime and Corruption Reporting Project (OCCRP), which has conducted a series of investigations $[12,13]$ on HTPs, to unmask the hidden tactics of the tobacco industry to prevent, reduce, or stymie efforts to control tobacco.

\section{Television}

In January 2019, PMI made a formal request to the Italian authorities to evaluate the relative harmfulness of their novel tobacco products. The Italian Ministry of Health and the Italian Health Institute declared that it was impossible to acknowledge both the reduction of HTP's toxic substances and the potential risk reduction of HTPs compared to combusted products, under the same conditions of use. The results of this evaluation were sealed for more than one year, but we contributed to ensuring that they were made publicly known through an investigation broadcast on the national TV program "Report" [14]. Moreover, I was recently interviewed for an investigation on HTPs in Italy that will be broadcasted soon in a Greek TV channel.

\section{Impact of the dissemination of findings during the PhD trajectory}

It is not easy to evaluate the exact impact that this thesis had on a social and public health perspective and which of our numerous actions or dissemination methods were more effective. However, this impact appears to be substantial, if we assume it is proportional to the reactions of the industry. More and more often, 
in fact, the publication of our findings or our interviews in the lay press is promptly criticized by people linked to the tobacco industry or e-cigarette producers [15, 16].

In Italy, our research on HTPs has been likely relevant in the decision of the National Health Institute to reject the claims by PMI alleging that lqos devices are less harmful than conventional cigarettes $[1,17,18]$.

Moreover, the TV Program "Report" enabled our research to reach a broad audience beyond the scientific community. Besides revealing to Italians the hidden tobacco tactics of PMI in promoting their HTPs [14], "Report" allowed us to inform millions of Italians about our research on HTPs, claiming that, based on our findings, there is no argument to justify the huge fiscal and regulatory benefits these products continue to have in Italy.

The research conducted within this dissertation has been used for advocacy actions by the Italian independent scientific community. For example, we have supported some politicians committed to increasing excise taxation from $20 \%$ up to $80 \%$ of that of conventional tobacco cigarettes through amendments to government decrees [19]. However, that proposed amendment was not approved and current legislation foresees a negligible increase in taxation for HTPs and ecigarettes by $5 \%$ each year. Thus, today the excise tax of HTPs and e-cigarettes in Italy is $25 \%$ compared with that of conventional tobacco cigarette. This disappointing result is likely due to the lobbying actions of the tobacco industry, clearly more effective than our advocacy actions. This appears to be the direct consequence of the relatively low efforts by the Italian government to counter the tobacco industry interference. We contributed to the 2021 Global Tobacco Industry Interference Index providing scores for Italy. This index showed that Italy, together with Romania, is the EU Member State with the worst tobacco industry interference index [20]. It is not by coincidence that PMI launched lqos in Italy and that the main tobacco industries, including PMI and British American Tobacco (BAT), are investing their money in Italy to create research institutes and tobacco production plants.

At an international level, thanks to our reputation as highly trusted independent tobacco control experts, we believe to have contributed to creating the scientific evidence, embraced by WHO [21], rejecting harm reduction as an effective strategy for tobacco. At least, we are confident that the research conducted within this dissertation helped in the drafting of the position paper by ENSP on ecigarettes, supporting the $\mathrm{WHO}$ in recommending for e-cigarettes strict regulations, bans, and increased taxation [22]. Paradoxically, our research was used less in Italy rather than in other countries. In fact, officers from governmental agencies or ministries of selected countries acknowledged the contribution provided by us, which helped politicians to deny or delay the marketing of HTPs in their countries. 


\section{Future impact of the generated knowledge}

The findings presented in this dissertation are expected to have great scientific and social implications in the (nearby) future. In particular, the most important investigations of the present dissertation are still unpublished, and they are currently under review in high impact journals $[17,18,23]$. These papers will likely have a major impact in Italy and worldwide. A large representative survey showed for the first time the trend of e-cigarette and HTP use during the COVID-19 lockdown in Italy [17].

More importantly, we conducted one of the few available prospective cohort studies tracking transitions in conventional cigarette smoking in relation to the use of e-cigarettes and HTPs. Our study confirmed previous findings from crosssectional investigations, showing that in Italy e-cigarettes and HTPs increase the risk of initiation of conventional cigarette smoking among those who have never smoked, increase the risk of relapse among ex-smokers and reduce the risk to quit for current smokers [18]. These findings, from one of the few cohort studies on the issue, have been presented at a national conference, obtaining wide attention from the media. These results represent the main rationale provided by ISS to reject harm reduction as an effective tobacco control strategy. The publication of these data in a peer-reviewed journal, followed by a press release, will likely have major implications on a public health perspective, not only in Italy, but also globally.

Probably the paper potentially with the highest impact on a public health perspective is the systematic review of the scientific literature about HTPs [23]. It shows for the first time that the scientific knowledge on these novel tobacco products is largely based on studies conducted or supported by the tobacco industry that appear to reach biased conclusions. This review shows that the tobacco companies, through their massive investment, have succeeded in creating a situation in which the scientific community is divided, when there is overwhelming evidence from independent research consistently opposing HTPs. Moreover, we confirm that it is not uncommon that the tobacco industry scientific affiliates (i.e., researchers who are paid directly or indirectly from the tobacco industry, fail to disclose their conflicts of interest [24]. This seems to be a growing tactic that is not limited to scientific research. Thus, a recent investigation by Le Monde (FR) and The Investigative Desk (NL) revealed the lobbying actions towards tobacco harm reduction by selected consumer organizations, including World Vapers' Alliance or the Consumer Choice Center, pretending to be independent, which were in fact disguised entities financially supported by the tobacco industry [25]. Today, endorsing HTPs as a tobacco harm reduction tool appears to be the best predictor of having a conflict of interest with the tobacco industry. Consequently, the hoped and expected implications of this work are that authorities and policy makers of various governments, for decisions on how to 
regulate novel tobacco products, rely exclusively on the scientific evidence from truly independent research, and that policy makers understand that there is an urgent need to fund and sustain independent research on novel tobacco products. In addition, after having disseminated our findings, we expect the few tobacco harm reduction advocates, who are truly independent of conflicts of interest with the industry, to make a clear distinction between e-cigarettes and HTPs (the latter, being tobacco, to be rejected always and without any conditions).

In case the several recommendations provided within this thesis, which will be spread through different means, are followed by various stakeholders, including policy makers, healthcare providers and public health researchers, the work conducted could guide the planning, implementation, monitoring and evaluation of i) public health interventions (e.g., information campaigns and health promotion in different settings as schools or workplaces), primary prevention interventions targeting selected subgroups (e.g., students, young generations) and advocacy communication; ii) regulations/normative action at the regional, national and international level; and iii) future research and collaborations (e.g., cohort studies or pooled analyses and intervention studies).

\section{References}

1. Gallus S, Borroni E, Odone A et al. The Role of Novel (Tobacco) Products on Tobacco Control in Italy. Int J Environ Res Public Health 2021; 18: 1895.

2. Gallus S, Borroni E, Liu X et al. Electronic cigarette use among Italian smokers: patterns, settings, and adverse events. Tumori 2020; 300891620915784.

3. Gallus S, Lugo A, Stival $C$ et al. Electronic cigarette use in 12 European countries. Results from the TackSHS survey. J Epidemiol 2021; https://doi.org/10.2188/jea.JE20210329.

4. Amalia B, Liu X, Lugo A et al. Exposure to secondhand aerosol of electronic cigarettes in indoor settings in 12 European countries: data from the TackSHS survey. Tob Control 2021; 30: 49-56.

5. Gallus S, Lugo A, Liu X et al. Use and Awareness of Heated Tobacco Products in Europe. J Epidemiol 2021; doi: 10.2188/jea.JE20200248.

6. Gallus S. ... right full rudder and full speed ahead! Tabaccologia 2020; 1: 58.

7. Abad ML, Abrams D, Ahluwalia JS et al. Letter from one hundred specialists in nicotine science, policy, and practice. 18 October 2021. Available online at: https://clivebates.com/documents/WHOCOP9LetterOct2021-EN.pdf. 
8. Tobacco Tactics. Centre of Excellence for the Acceleration of Harm Reduction (CoEHAR). Tobacco Tactics, University of Bath. 13 July 2021. Available online at: https:/tobaccotactics.org/wiki/coehar/.

9. Gallus S, Lugo A. The curious case of Heated Tobacco Products. Union for International Cancer Control (UICC), 3 November 2020. https://www.uicc.org/blog/curious-case-heated-tobacco-products.

10. Gallus S, Bosetti C, Negri E et al. Does pizza protect against cancer? Int J Cancer 2003; 107: 283-284.

11. Ditta A. Le sigarette elettroniche aiutano davvero a smettere di fumare? The Post Internazionale 22 October 2021. Available online at: https://www.tpi.it/cronaca/sigarette-elettroniche-aiutano-davvero-smetterefumare-20211026836935/. 2021.

12. OCCRP. Unsmoking for Health. OCCRP 25 May 2020. Available online at: https://www.occrp.org/en/loosetobacco/blowing-unsmoke/unsmoking-forhealth. 2020.

13. Cerantola A. Tobaccopoli: The Secret Battle to Control Italy's Cigarette Market. OCCRP 11 March 2020. Available online at: https://www.occrp.org/en/loosetobacco/without-a-trace/tobaccopoli-thesecret-battle-to-control-italys-cigarette-market 2020.

14. Moskowitz E. OCCRP - Italy Releases Confidential Study on Philip Morris' IQOS. Available online at: https://www.occrp.org/en/daily/12452-italyreleases-secret-study-on-philip-morris-iqos. 2020.

15. Caliciuri S. "La riduzione del danno ha funzionato con i tossicodipendenti, non serve ai fumatori". Sigmagazine, 26 October 2021. Available online at: https://www.sigmagazine.it/2021/10/metadone-riduzione-del-danno/. 2021.

16. Redazione TPI. "Uno spunto in più sulle sigarette elettroniche": la lettera di Luigi Godi (Philip Morris Italia). The Post Internazionale 15 November 2021. Available online at: https://www.tpi.it/scienza/sigarette-elettroniche-letteraluigi-godi-philip-morris-italia-20211115842317/. 2021.

17. Gallus S, Stival C, Carreras $\mathrm{G}$ et al. Use of electronic cigarettes and heated tobacco products during the Covid-19 pandemic. Sci Rep 2021; In press.

18. Gallus S, Stival $\mathrm{C}$, McKee $\mathrm{M}$ et al. The impact of electronic cigarette and heated tobacco product on smoking habit: a prospective cohort study form Italy. Tob Control 2021; Submitted.

19. Anonymous. Emergenza Coronavirus: in Senato due emendamenti a favore di un aumento della tassazione sui tabacchi. Tobacco Endgame, 4 April 2020. Available online at: https://www.tabaccoendgame.it/news/emergenzacoronavirus-in-senato-due-emendamenti-a-favore-di-un-aumento-dellatassazione-sui-tabacchi/.

20. Anonymous. GLOBAL TOBACCO INDUSTRY INTERFERENCE INDEX 2021. Global Tobacco Index, 2021. Available online at: https://globaltobaccoindex.org/. 
21. World Health Organization. WHO Report on the Global Tobacco Epidemic, 2021. Addressing new and emerging products. Available online at: https://www.who.int/teams/health-promotion/tobacco-control/globaltobacco-report-2021. 2021.

22. European Network of Smoking and Tobacco Prevention (ENSP). ENSP Calls for European Response to Electronic Cigarettes Rising Epidemic. Available online at: https://ensp.network/ensp-calls-for-european-responseto-electronic-cigarettes-rising-epidemic/.

23. Gallus S, Odone A, van den Brandt PA et al. Conflict of interest research in heated tobacco products: a systematic review. BMJ 2022; Under review.

24. Legg $T$, Legendre $M$, Gilmore $A B$. Paying lip service to publication ethics: scientific publishing practices and the Foundation for a Smoke-Free World. Tob Control 2021.

25. Horel S. Vaping: The real dollars behind fake consumer organisations. Le Monde, 3 November 2021. Available online at: https://www.lemonde.fr/societe/article/2021/11/03/vaping-the-real-dollarsbehind-fake-consumer-organisations_6100848_3224.html. 2021. 



\section{Acknowledgements}


I would like to thank all the colleagues and friends who participated directly or indirectly to my $\mathrm{PhD}$ work and have offered their help and support in the preparation of this dissertation.

In particular many thanks to:

My supervisors, Piet van den Brandt and Anna Odone, who gave me the great opportunity to do a PhD at the Maastricht University, supervised all my work, revised my articles critically, and provided me with precious suggestions to successfully finalize this dissertation.

My mentors and masters, including my father, Giuseppe Gallus who first drew me closer to math and biostatistics, Carlo La Vecchia who taught me all on epidemiology, and Prof. Silvio Garattini who explained to me the importance of the intellectual honesty of an independent research.

My collaborators and friends Chiara Stival and in particular Alessandra Lugo and Cristina Bosetti, who conducted most of the statistical analyses within the present dissertation and substantially helped me in the finalization of this thesis.

Other Italian colleagues from the Mario Negri Institute who supported my research in the past or participated at various levels in this work, including Eva Negri, Alessandra Tavani, Giovanni Apolone, Marta Rossi, Davide Bazzi, Liliane Chatenoud, Eugenio Santoro, Elisa Borroni, Xiaoqiu (Julia) Liu, and Carlotta Jarach.

The collaborators of the TackSHS Project who gave me helpful comments for the finalization of the manuscripts for publication, including in particular Giuseppe Gorini, Giulia Carreras, Esteve Fernandez, and Luke Clancy.

The collaborators of the Lost in Italy study, including Roberta Pacifici, Andrea Amerio, and Paolo Colombo.

My mum, my sister Angela, and particularly my brother Enrico, the main supporter of my successes.

And, last but not least, my family: my wife Tiziana, our beloved daughter Clementina, and our sausage dog Giotto. They are my strength and my life. Tiziana, many thanks for your support and patience! 
About the Author 
Silvano Gallus was born in Milan, Italy, on November, 20 1970. He holds an MSc in Computer Science from the University of Milan (1999) where he graduated with the thesis: "Implementation of a software to compute analyses of cohort studies". In 2019 he started his PhD project on the role of electronic cigarettes and heated tobacco products on tobacco control at the Care and Public Health Research Institute (CAPHRI) at Maastricht University.

He worked as a research fellow at the Laboratory of General Epidemiology at Mario Negri Institute during 1997-2005 and was head of the Unit of Epidemiology for Clinical Research during 2006-2016. Since 2017, he is head of the Laboratory of Lifestyle Epidemiology of Mario Negri Institute. In 2017-2021 he was Honorary Associate Professor at the University of Nottingham, UK. Silvano Gallus has been a visiting scientist at the Cancer Prevention and Control Unit, Institut Català d'Oncologia, Barcelona, Spain and at the Fields and Intervention Studies, International Agency for Research on Cancer (IARC), Lyon, France.

At the beginning of his career, the main fields of interests of Silvano Gallus focused on the association between selected factors, including tobacco, alcohol, obesity and diet, and the risk of cancer. Among various relationships investigated, he first analyzed the association between pizza consumption and cancer risk, showing surprising findings: in Italy, regular pizza consumers had a significant reduced risk of selected digestive tract cancers. These results received widespread attention in the lay press and the scientific community since the first publication on the issue (2003) up to 2019, when he received the Ig-Nobel prize for medicine for his research on pizza and cancer. The conclusions of these publications are far from being playful: in Italy pizza consumption represents a general indicator of the "Italian diet", which, as other Mediterranean diets, has been shown to have major health benefits, particularly on cancer. Through his research, Silvano Gallus had the opportunity to extensively promote the importance of the Mediterranean diet in cancer prevention in Italy and worldwide. Since 2001, Silvano Gallus is the responsible scientist for tobacco control in his Institute. His studies initially focused on the effects of the Italian smoke-free law, adopted in 2005. With his research he showed how this legislation was effective in reducing exposure to second-hand smoke in Italy, and how it had undisputed success from a public health perspective: it was widely supported and highly respected, restaurant and bar owners did not observe any decline in their business, and tobacco smoking substantially decreased in the short and medium term. Also due to the participation in international collaborative projects, Silvano Gallus focused his research on taxation, the most important strategy to control tobacco use. With his research, he was able to confirm also for Italy that the increase in taxation of tobacco products is an effective and feasible strategy, promotes the health of Italians, favours public finance and is strongly accepted by non-smokers as well as by a substantial proportion of smokers. His commitment within the most important independent scientific boards advocating 
tobacco control, allowed him to frequently raise a voice on the need to increase taxation of various tobacco products, including novel tobacco products in Italy. Since 2016, Silvano Gallus and his collaborators have been conducting a series of systematic reviews on the role of smoking on the risk of cancer. This has been made possible thanks to an original search strategy proposed and described by Gallus and colleagues, allowing them to comprehensively identify the evidence from the literature in an effective and efficient way. So far, meta-analyses have been published on pancreatic, ovarian, kidney, gallbladder and colorectal cancer. Other cancers are in pipeline. Since 2013, Silvano Gallus and his team opened a line of research on the epidemiology of tinnitus. Rather than a disease, tinnitus is a symptom of underlying problems that describes the perception of ringing or other noises in the brain or ears when no corresponding external acoustic stimuli are present. Using a series of analytical epidemiological studies, Silvano Gallus is providing valuable knowledge on the prevalence and potential determinants of this condition.

Silvano Gallus participated as PI or Work-Package Leader or partner in several national or international collaborative research projects, supported by the European Commission (at least 8 projects), the Italian Ministry of Health, the DG Welfare of Lombardy Region and the main Italian charities on cancers, including the Italian Association for Research on Cancer (AIRC) and the Italian League Against Cancer (LILT).

$\mathrm{He}$ is author or co-author of more than 400 articles, including more than 350 papers in peer-reviewed journals (Scopus h-index: 61). 
List of publications 
- Gallus S, Borroni E, Odone A, van den Brandt PA, Gorini G, Spizzichino L, Pacifici R, Lugo A. The Role of Novel (Tobacco) Products on Tobacco Control in Italy. Int J Environ Res Public Health. 2021 Feb 16;18(4):1895. doi: 10.3390/ijerph18041895.

- Gallus S, Stival C, McKee M, Carreras G, Gorini G, Odone A, van den Brandt PA, Pacifici R, Lugo A. The impact of electronic cigarettes and heated tobacco products on smoking habit: a prospective cohort study form Italy. Tob Control 2022; Submitted.

- Gallus S, Stival C, Carreras G, Gorini G, Amerio A, McKee M, Odone A, van den Brandt PA, Spizzichino L, Pacifici R, Lugo A. Use of electronic cigarettes and heated tobacco products during the Covid-19 pandemic. Sci Rep 2022 Jan 13; doi: 10.1038/s41598-021-04438-7.

- Gallus S, Borroni E, Liu X, Carrozzi L, Dalla Pietra G, Eslami Varzaneh S, Harari S, Inciso G, Martucci P, Papale M, Pistelli F, Polla B, Polo MF, Principe R, Pulerà N, Raschi S, Sarzani R, Serafini A, Odone A, van den Brandt $P$, Lugo A. Electronic cigarette use among Italian smokers: patterns, settings, and adverse events. Tumori. 2020 Apr 26:300891620915784. doi: $10.1177 / 0300891620915784$.

- Gallus S, Lugo A, Stival C, Cerrai S, Clancy L, Filippidis FT, Gorini G, Lopez MJ, López-Nicolás Á, Molinaro S, Odone A, Soriano JB, Tigova O, VAN DEN Brandt PA, Vardavas $\mathrm{Cl}$, Fernandez E; TackSHS Project Investigators. Electronic cigarette use in 12 European countries. Results from the TackSHS survey. J Epidemiol. 2021 Nov 13. doi: 10.2188/jea.JE20210329.

- Amalia B, Liu X, Lugo A, Fu M, Odone A, van den Brandt PA, Semple S, Clancy L, Soriano JB, Fernández E, Gallus S; TackSHS Project Investigators. Exposure to secondhand aerosol of electronic cigarettes in indoor settings in 12 European countries: data from the TackSHS survey. Tob Control. 2021 Jan;30(1):49-56. doi: 10.1136/tobaccocontrol-2019-055376.

- Gallus S, Lugo A, Liu X, Borroni E, Clancy L, Gorini G, Lopez MJ, Odone A, Przewozniak K, Tigova O, van den Brandt P, Vardavas C, Fernandez E; TackSHS Project Investigators. Use and Awareness of Heated Tobacco Products in Europe. J Epidemiol 2021; doi: 10.2188/jea.JE20200248.

- Gallus S, Odone A, van den Brandt PA, McKee M, Lugo A. Conflict of interest in research on heated tobacco products: a systematic review. BMJ 2022; Under review. 